\title{
"A good neighbor with bad fences": \\ Liminality and the Construction of Canadian Threat in US Popular Media by
}

\author{
Richard Baker
}

\begin{abstract}
A thesis submitted to the Faculty of Graduate and Postdoctoral Affairs in partial fulfillment of the requirements for the degree of
\end{abstract}

\author{
Doctor of Philosophy \\ in \\ Political Science \\ Carleton University
Ottawa, Ontario
}

(C) Richard Baker, 2010 


$\begin{array}{ll}\begin{array}{l}\text { Library and Archives } \\ \text { Canada }\end{array} & \begin{array}{l}\text { Bibliothèque et } \\ \text { Archives Canada }\end{array} \\ \begin{array}{l}\text { Published Heritage } \\ \text { Branch }\end{array} & \begin{array}{l}\text { Direction du } \\ \text { Patrimoine de l'édition }\end{array} \\ \begin{array}{l}\text { 395 Wellington Street } \\ \text { Ottawa ON K1A ON4 } \\ \text { Canada }\end{array} & \begin{array}{l}395, \text { rue Wellington } \\ \text { Ottawa ON K1A ON4 } \\ \text { Canada }\end{array}\end{array}$

Your file Votre référence

ISBN: 978-0-494-70544-5

Our file Notre réfórence

ISBN: 978-0-494-70544-5

NOTICE:

The author has granted a nonexclusive license allowing Library and Archives Canada to reproduce, publish, archive, preserve, conserve, communicate to the public by telecommunication or on the Internet, loan, distribute and sell theses worldwide, for commercial or noncommercial purposes, in microform, paper, electronic and/or any other formats.

The author retains copyright ownership and moral rights in this thesis. Neither the thesis nor substantial extracts from it may be printed or otherwise reproduced without the author's permission.
AVIS:

L'auteur a accordé une licence non exclusive permettant à la Bibliothèque et Archives Canada de reproduire, publier, archiver, sauvegarder, conserver, transmettre au public par télécommunication ou par l'Internet, prêter, distribuer et vendre des thèses partout dans le monde, à des fins commerciales ou autres, sur support microforme, papier, électronique et/ou autres formats.

L'auteur conserve la propriété du droit d'auteur et des droits moraux qui protège cette thèse. $\mathrm{Ni}$ la thèse ni des extraits substantiels de celle-ci ne doivent être imprimés ou autrement reproduits sans son autorisation.
In compliance with the Canadian Privacy Act some supporting forms may have been removed from this thesis.

While these forms may be included in the document page count, their removal does not represent any loss of content from the thesis.
Conformément à la loi canadienne sur la protection de la vie privée, quelques formulaires secondaires ont été enlevés de cette thèse.

Bien que ces formulaires aient inclus dans la pagination, il n'y aura aucun contenu manquant.

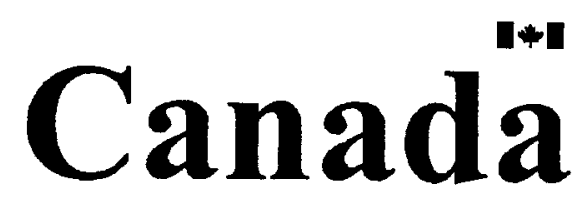




\begin{abstract}
This dissertation explores Canada's capacity to provoke insecurity among Americans. It asks the question, 'How is it possible that Canada becomes understood as a threat to US security?' To answer this, I draw upon Anne Norton's understanding of the role played by the liminar in the creation of identity. Exploring representations of Canada in Hollywood films and US news reports, I contend that Canada occupies a place of liminality in the American imaginary - it is considered to be simultaneously part of and separate from the American experience. When the United States is facing an external threat, Canada's otherness prompts the American self to script Canada as a local manifestation of the threatening Other. However, because Canada also reflects an image of likeness, the threat that it represents takes on an omnipresent quality. By serving as a localized proxy of the Other, Canada prompts the American self to script its identity in increasingly rigid terms. Therefore, in response to my research question, I demonstrate that Canada's capacity to threaten US security can be understood as a subsidiary consequence of the dynamics of identity whereby the American self defines itself in opposition to an Other.
\end{abstract}




\section{Acknowledgments}

I would never have re-started my education, to say nothing of finishing this dissertation, without the support of my family. My family's home was always a place of critical debate, and that atmosphere continues to shape my approach to this day. I owe a very real debt of gratitude to my mother and father, my sister and my brothers.

While studying in Ottawa, my academic and social life was enriched immeasurably by Nadia Verrelli and Anu Pandey. I am so pleased that we found each other and I take great comfort in our continuing friendships.

Laura Macdonald and Simon Dalby were generous with their time under a tight deadline that was not of their making. Their insightful comments and suggestions not only improved this dissertation, but also improved my own understanding of the material.

Kelly Saunders provided me with the encouragement I needed at a crucial moment. I can say, without a hint of embellishment, that this dissertation would never have been completed without her intervention at the time when it was needed the most.

Fiona Robinson has served as a remarkable supervisor. She is a compassionate person and a rigorous and discerning scholar. Her faith in my abilities, her endless supply of patience, and her timely reassurances were fundamental in seeing this process through to completion. Her expert guidance in this project is very much appreciated.

Sandy Smith is my best friend and my partner in all things. It is the most extreme of understatements to say that this project would not have been possible without her. Her unflagging support for me in the completion of this dissertation, and in everything I do, moves me beyond words. Sandy, this really only makes sense because of you. 


\section{Table of Contents}

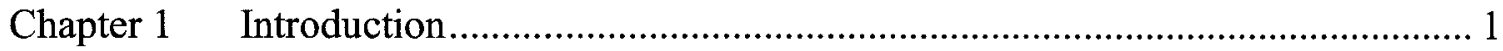

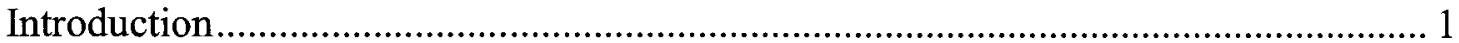

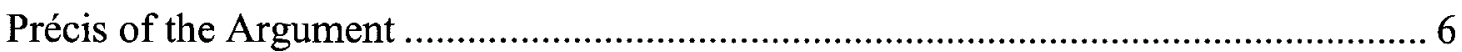

Canada's Place in the American Imaginary ............................................................ 9

Otherness, Liminality and Threat ........................................................................ 19

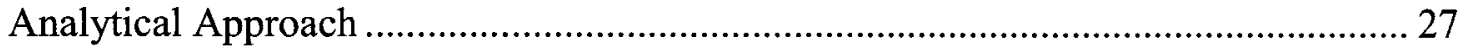

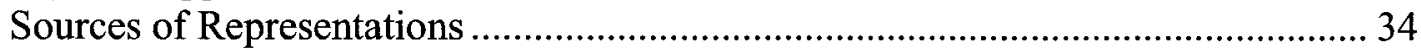

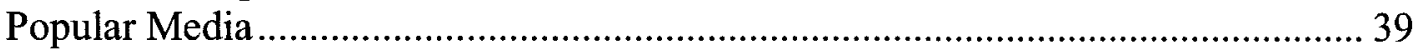

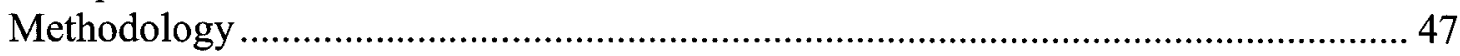

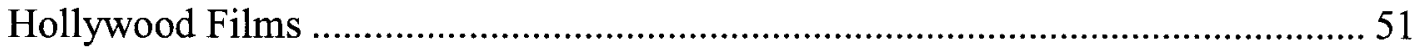

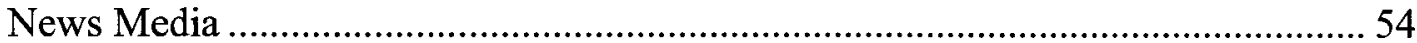

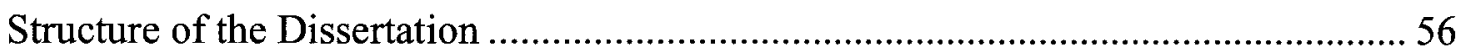

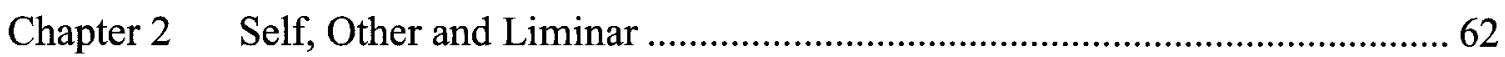

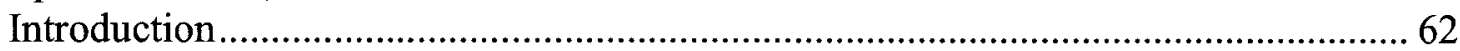

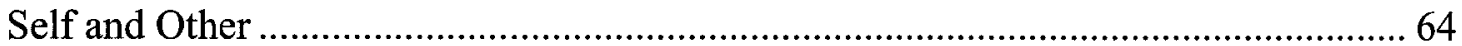

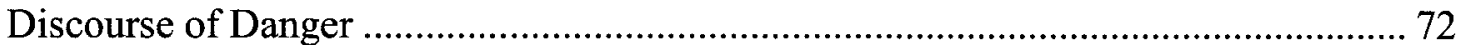

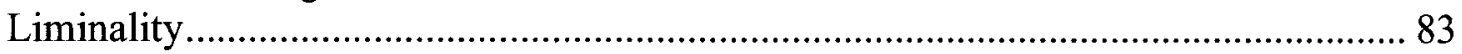

Canadian Foreign Policy ............................................................................... 102

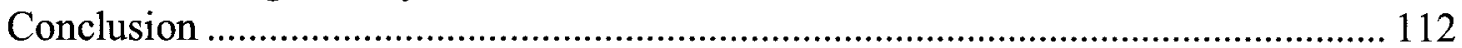

Chapter 3 Hollywood Films and Themes of Canadian Otherness............................ 114

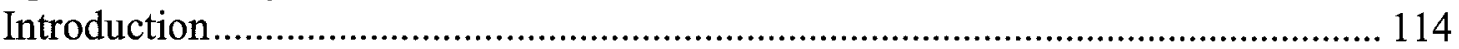

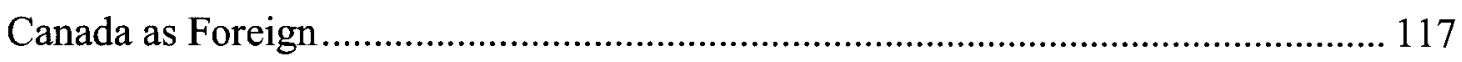

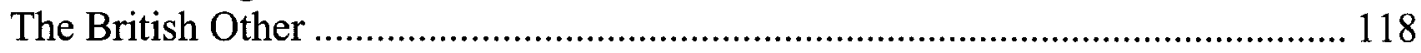

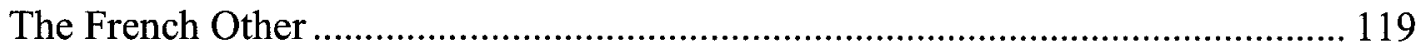

The Métis Other ...................................................................................... 122

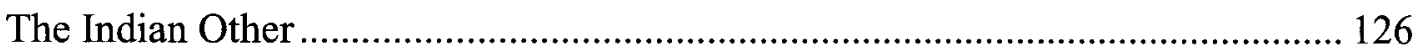

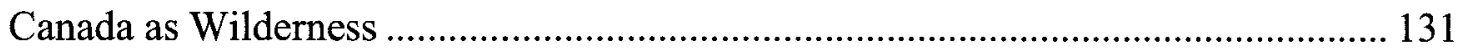

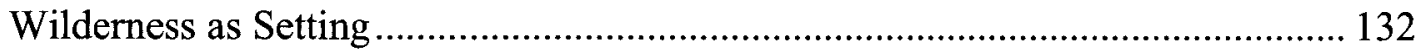

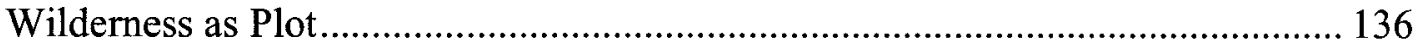

Wilderness as Characterization.................................................................. 138

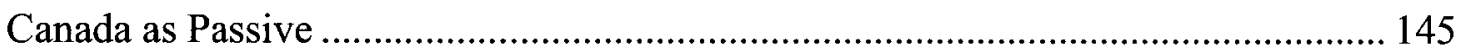

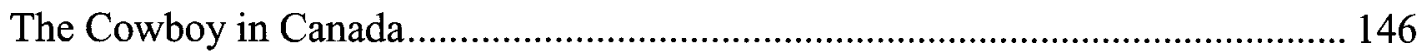

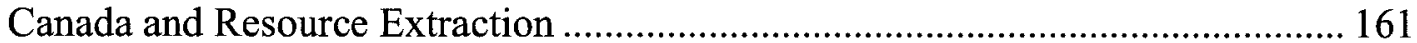

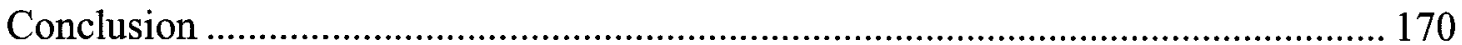

Chapter 4 Hollywood Films and Themes of Canadian Liminality.......................... 172

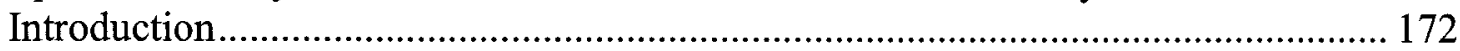

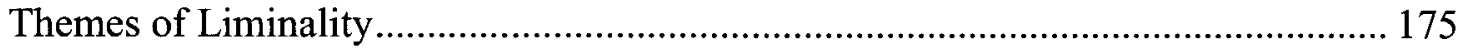

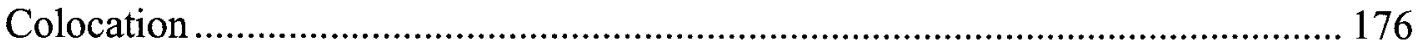

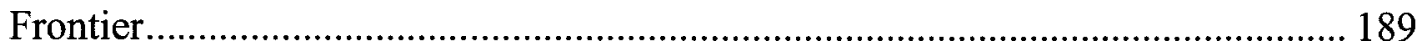

Canada as a Threat ........................................................................................ 200

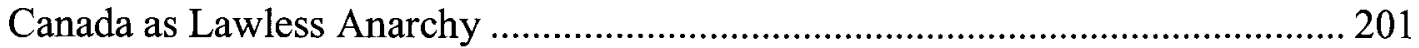

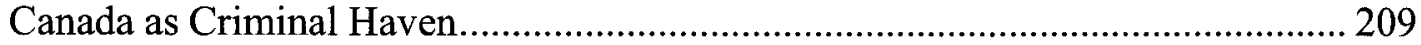

Canada as Vulnerable Ally .......................................................................... 216

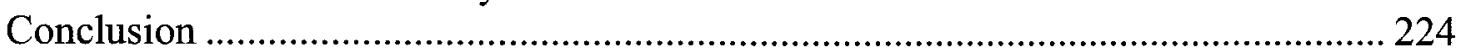


Chapter 5 US News Media and Themes of Canadian Otherness ............................ 227

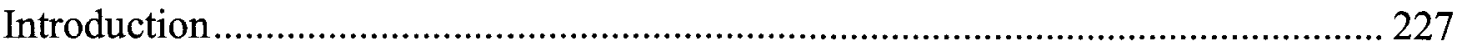

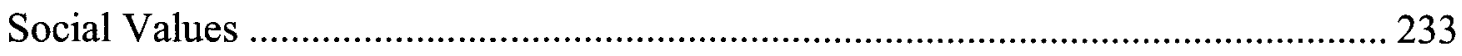

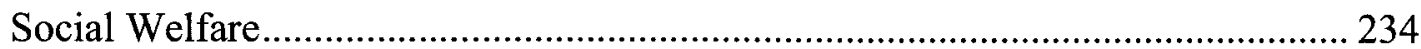

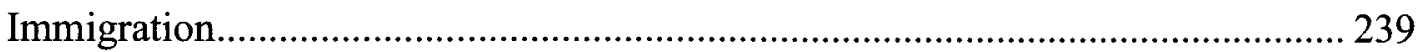

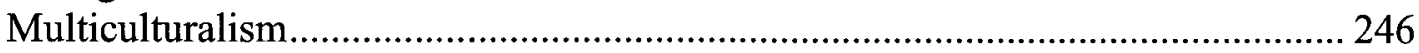

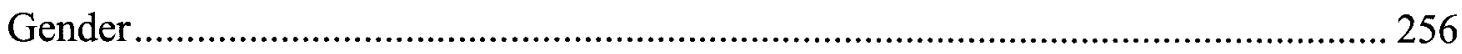

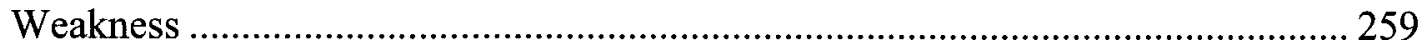

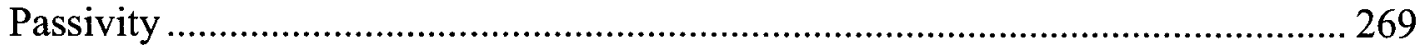

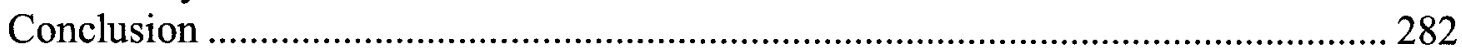

Chapter 6 US News Media and Themes of Canadian Liminality ............................. 284

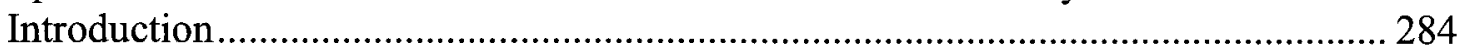

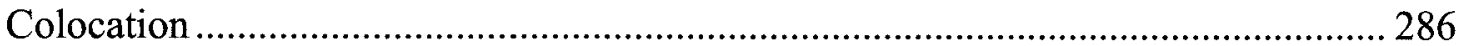

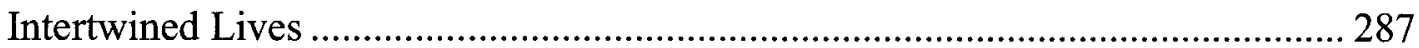

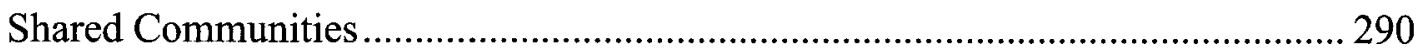

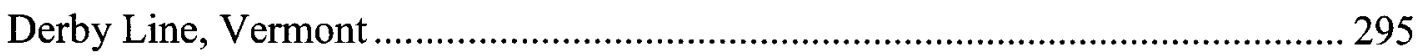

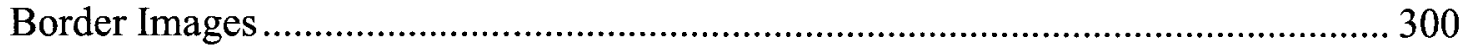

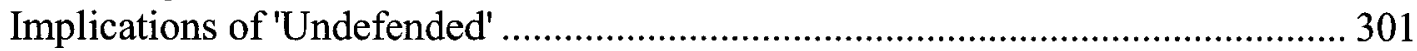

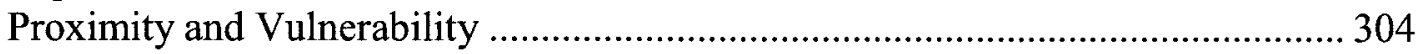

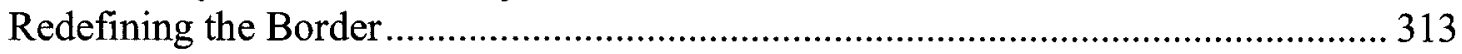

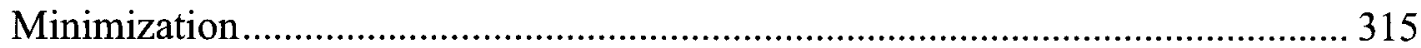

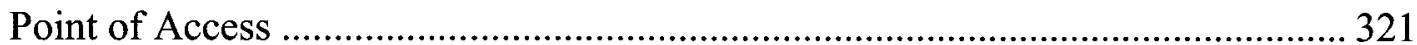

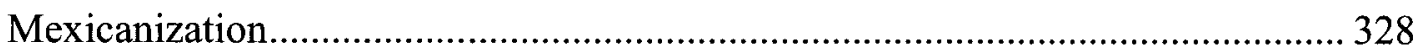

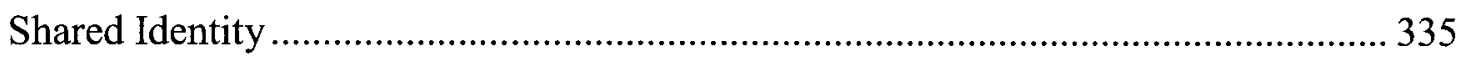

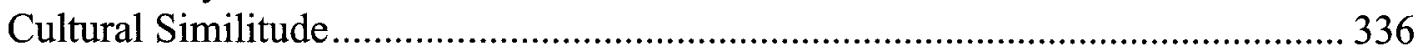

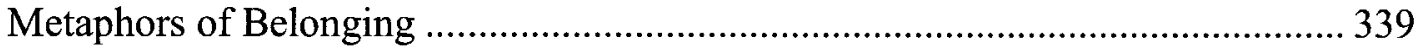

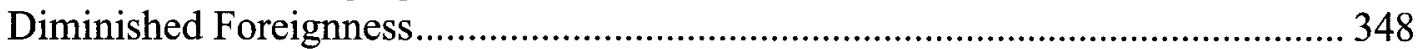

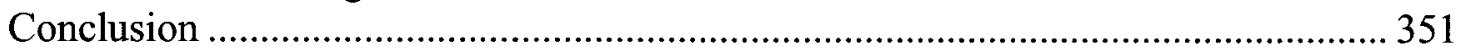

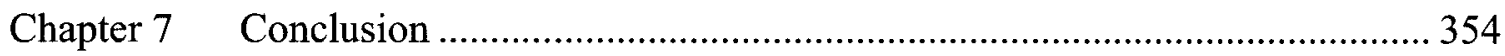

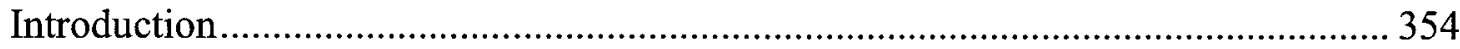

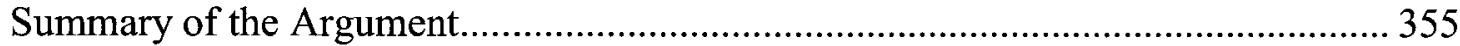

The Liminality of Canadian Space …………………............................................ 357

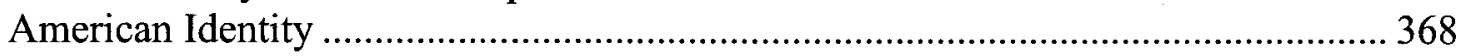

International Relations Scholarship …............................................................... 372

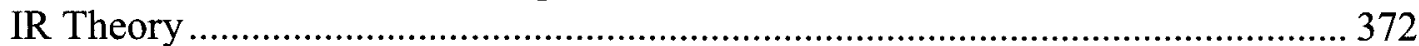

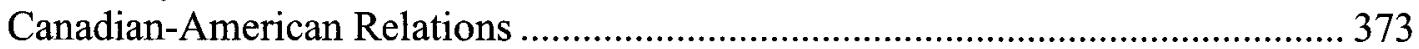

The Practice of Canadian-American Relations.......................................................... 374

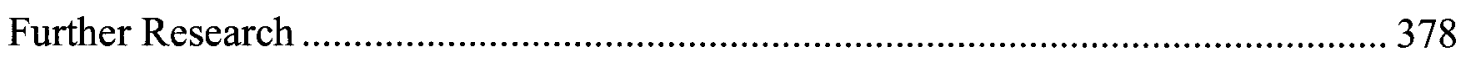

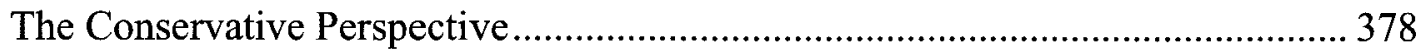

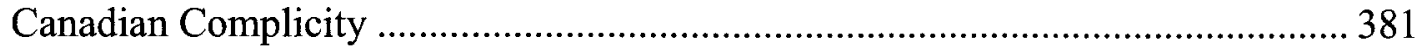

Liminality in Comparative Perspective ........................................................... 384

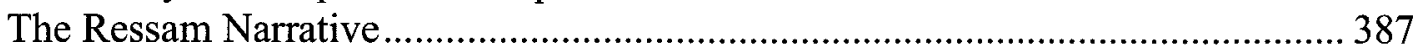

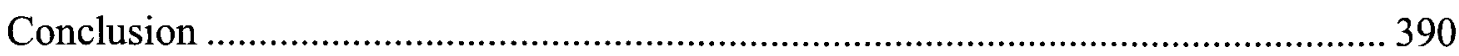

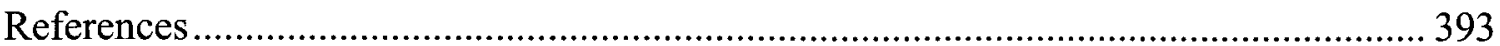




\section{Chapter 1 Introduction*}

\section{Introduction}

In the aftermath of the traumatic events of September 11, 2001, Americans began looking for ways to understand what had happened. Government officials and public intellectuals plumbed the depth of the American imaginary in an attempt to make sense of the events. A number of crucial frames of reference were used to better understand and contextualize the situation. One of the frames revolved around the 1941 Japanese attack on Pearl Harbor, complete with such elements as an unprovoked and surprise attack and a determined response to take the battle to the enemy (Dalby, 2003). ${ }^{1}$ A second prominent frame, drawing from the Cold War, revolved around the notion that American freedoms were under siege and must be defended at all cost. These frames helped Americans to both make sense of the attacks and structure their response. ${ }^{2}$ For the most part, the US response ultimately unfolded in a distressingly predictable manner. But from the perspective of Canadian-American relations, there was one element of the US reaction that was intriguing.

\footnotetext{
${ }^{*}$ The title of this dissertation draws from a section heading found in Strobel et al. (2000): "Canada's Border: A good neighbor with bad fences."

${ }^{1}$ For example, President Bush drew from the analogy of Pearl Harbor as early as the evening of September 11, when he made his journal entry for the day: "The Pearl Harbor of the 21 st century took place today" (Balz and Woodward, 2002).

${ }^{2}$ The temptation to turn to historical analogies as a way to make sense of unfolding events and future actions is certainly not an unusual one (Khong, 1987).
} 
In the days and weeks that followed $9 / 11$, a theory developed that some of the terrorists had entered the United States from Canada. It was initially picked up by a number of US newspapers and eventually began finding expression in statements from ranking politicians, including the junior Senator from New York, Hillary Clinton. ${ }^{3}$ Although no conclusive proof of this connection was ever forthcoming, and the theory itself was actually refuted in relatively short order, the rumour persisted (Whitaker, 2004/05; Gecelovsky, 2007). ${ }^{4}$ Indeed, despite considerable sustained efforts (Struck, 2005 ) to dispel the rumour, it became so entrenched that Canadian officials were still confronting it many years after 9/11. As recently as April 2009, even the US Secretary of Homeland Security suggested that terrorists from the $9 / 11$ attacks entered the United States from Canada (Alberts, 2009a). To compound the matter even further, when Secretary Napolitano's comments were met with a wave of frustrated Canadian objections, former presidential candidate John McCain came to her defence: "Well, some of the 9/11 hijackers did come through Canada, as you know" (Alberts, 2009b). As Whitaker suggests, "it would seem that the Canadian connection has now moved into the realm of entrenched mythology, from whence it has proved difficult to get some people

\footnotetext{
${ }^{3}$ Among the papers that carried the story were the Boston Globe, Boston Herald, Washington Post and the
New York Post (Struck, 2005).

${ }^{4}$ The persistence of the rumour was likely helped to no small degree by an episode of the popular television
series West Wing that aired just three weeks after $9 / 11$. episode is framed around a scenario in the non-existent Ontario-Vermont border).
} 
back to reality" (2004/05: 60$).^{5}$ The rumour's continued obstinacy is puzzling. How is it able to persist in the face of consistent and categorical refutation?

At the same time that Canada's alleged 9/11 connection was circulating, a broader notion also began taking hold in the United States that suggested that Canada and the Canadian border had become threats to US security (Haglund, 2003, 677-680). News reports seemed to be uncovering evidence that implicated Canada as a haven for terrorists. The border itself came under sustained scrutiny for its apparent inability to keep Americans safe, and politicians increasingly called for a militarized response to the border situation. In the years immediately following $9 / 11$, those ideas gained broader and firmer traction in the US news media, though the marked increase in reportage was certainly not supported by a verifiable increase in terrorists coming across the border. How is it, then, that this perception, fed to no small degree by the false $9 / 11$ connection discussed above, was able to find such traction in the United States?

The increasing acceptance of a threatening version of Canada is particularly puzzling because the image has had to contend with the entrenched and powerful tropes that define the Canadian-American relationship in terms of partnership, friendship, family and 'the world's longest undefended border.' As Gecelovsky indicates, even though Americans often view Canada in stereotypical terms, those stereotypes are almost uniformly positive (2007: 519-521). His examination of prevalent images of Canada in American culture and polling data from both before and after $9 / 11$ supports the

\footnotetext{
${ }^{5}$ Taylor notes the phenomenon whereby initial interpretations of events remain resilient in the face of conflicting accounts: "once [a story] has entered the public sphere through the media it also becomes extremely difficult to modify or revise it" (1997: 101).
} 
impression that "Americans have consistently regarded Canada and Canadians in a favorable light" (520). Given the existence of these powerful tropes, why was the rather different notion of Canada as a threat accepted as plausible by so many Americans?

Even in the face of increased bilateral cooperation at the border, the passage of new anti-terrorism laws and persistent efforts to reassure Americans of Canada's vigilance, Canadian officials have been unable to counter the perception of a Canadian threat. Whitaker blames the persistence on a confluence of "reckless media, politicized intelligence, and opportunistic politicians" (2004/05: 54). While it is undeniable that these factors have contributed to the problem, I am not convinced that they are able to explain the alacrity and tenacity with which the idea took hold in US society. There is a sense in which the US public was primed to accept the idea of Canada as a threat. As Eagles suggests, the US reaction to 9/11 "reflected a willingness on the part of Americans to see the Canadian border as a source of vulnerability" (2006: 821).

The possibility that there is a "willingness" among Americans to accept the idea of a Canadian threat is a useful first step in answering some of the questions posed above. Todorov hints at a similar idea that is of value in understanding how the image of Canadian threat is able to find traction, despite the presence of evidence and tropes to the contrary:

When an author is mistaken or lying, his text is no less significant than when he is speaking the truth; the important thing is that the text be 'receivable' by contemporaries, or that it has been regarded as such by its producer. From this point of view, the notion of 'false' is irrelevant here. (1984: 54) 
In other words, the surface plausibility or truth of a statement is not the conclusive factor in determining the degree to which that statement is accepted as true. What is more important is the degree to which that statement is made "receivable" to its audience. In the case of the image of Canadian threat, what matters, therefore, is not the degree to which the image corresponds to reality. Instead, what matters is the degree to which the American consciousness has been primed to accept the image as plausible. This dissertation addresses the important role that plausibility plays in sustaining the perception of a Canadian threat.

The research question that guides this dissertation is a simple one: 'How has Canada become understood as a threat to US security?' This question seems apt considering the combination of factors - historical partnership, contemporary evidence, conventional wisdom - that would otherwise conspire to render its premise nonsensical. To answer the question, I explore the place that Canada occupies in the American imaginary - that is, the mythic version of Canada that Americans draw upon when making judgments about their relations with that country. I show how popular media draw from this collective understanding of Canada to create representational patterns that combine to script Canada as a threat to America. I also explore the meaning and implications of this image of threat, not in terms of its correspondence to a rational specification of objective danger, but in terms of its capacity to play a constitutive role in the definition of American identity. In other words, I explore how the depiction of Canadian threat assists those social dynamics working to entrench American identity. 


\section{Précis of the Argument}

This dissertation examines how Canada comes to be understood as a threat to US security. There are, admittedly, a number of factors that work against the likelihood of such an understanding adhering with any significant degree of plausibility, including a vast power asymmetry between the two nations and widely-shared impressions of amity and partnership. Nonetheless, there is little doubt that Canada is indeed sometimes understood as a threat: representations of Canada during the War on Terror provide a compelling example of this reality. ${ }^{6}$

In order to understand how the notion of threat is able to cling to Canada, it is important to first understand what threat is. Orthodox International Relations (IR) scholarship understands the notion of threat primarily in the context of the anarchical international system. In this context, threats are understood as objective manifestations of the material capabilities of rival states (Waltz, 1979). In the more specific context of Canadian-American relations, however, threat has been understood in a somewhat different manner. From a realist perspective, Canada's vulnerability to overwhelming US power has ensured that the country could never pose an intentional threat to the United States and has long since marked the country for bandwagoning (Walt, 1987). Understood from this perspective, Canada's capacity for threat has instead been understood, since before the Second World War, in terms of its potential inability to stop

\footnotetext{
${ }^{6}$ Consider, for instance, this headline from a 2003 article in the New York Times: "A Nation at War: The
Canadian Border" (Kraus, 2003b).
} 
external enemies from using its territory to threaten the United States (Fortmann and Haglund, 2002).

Along with other critical responses to this orthodox perspective (Campbell, 1992; Weldes, 1999a; Weldes et al., 1999a), I understand threat not as an objective and material reality, but as a social construction. Thus, instead of seeing the specification of threat as part of a wider attempt to safeguard the interests of the state, I argue that it should be understood as part of a sociological process that works to define the very content and boundaries of that state. Representing the space beyond the state's borders as a dangerous and threatening "outside" enables the possibility of the state's very existence. It conditions and domesticates an otherwise recalcitrant and heterogeneous "inside" by offering shelter in the form of the nation's promise of belonging and the state's guarantee of protection (Walker, 1993). Thus, the act of identifying international threats provides an opportunity for the self to construct itself in opposition to enmity and rigidifies the borders that define the nation. Understood in this sense, the representation of Canada as a threat should be appreciated not as a rational act of identifying a self-evident reality, but as one element in the ongoing series of processes that works to define American identity.

Even conceding that threats are the product of social construction, it might still be seen as a stretch to suggest that Canada could play a constitutive role in defining American identity. After all, prevalent representations of Canada clearly lack the gravitas that accompanies more obvious constitutive foils, like the Soviet Union (Ó Tuathail and Agnew, 1992) or terrorism (Sharp, 2000: 144-145). Indeed, I do not argue that Canada functions as a significant Other against which American identity is constructed. Rather, I 
suggest that Canada plays a supporting role in this constitutive process. In order to understand Canada's impact in this area, I draw on the concept of liminality.

A concept explored in depth by Norton (1988), liminality is the ambiguous state of simultaneous belonging and exclusion. Groups that exist on the margins of society, neither entirely accepted, nor entirely rejected, are liminal groups. In this dissertation, I contend that Canada occupies a place of liminality in the American imaginary. In other words, the country is understood and represented as both part of and separate from the American experience. Canada's role as a liminar comes into play in times of crisis or danger, when the American self is being scripted in opposition to a threatening Other. As a liminar, Canada has the capacity to simultaneously embody elements of both the American self and its Other. In terms of the latter, Canada's difference shades into otherness in such a way that it becomes plausible for Americans to see how Canada could play host to dangerous or threatening forces. In effect, Canada is made different enough that it is rendered a dangerous space, the kind of place where threatening forces or actors might be able to find purchase. In terms of the former, however, the impression that Canada is essentially an extension of the United States implies that if danger is already present in Canada, then it is effectively already within the boundaries of America as well. In this sense, Canada's representation as liminal makes the country a local proxy for the more distant and abstract threat of the Other. It renders the country a conduit through which that distant threat is instantiated in North America and conveyed to the American interior. This more immediate appreciation of threat contributes to the sociological processes that confirm American identity. 


\section{Canada's Place in the American Imaginary}

As I suggested above, Americans searched their collective memory in order to make sense of the events of $9 / 11$. This collective memory, what I refer to as the American imaginary, is that broad repository of cultural understandings that helps Americans to situate and define their national identity. My understanding of the American imaginary is similar to Sharp's (1998) use of the term "national culture," which she defines as "a common source of narratives and understandings that provide a sense of belonging." She suggests that these narratives are used "to define and explain new situations and their importance to individuals in the community" (156). Dittmer (2005) advances a similar notion with his discussion on "structures of expectation." For Dittmer, popular culture is one of several sources that communicate a shared understanding of territorial belonging that conditions how people interpret and respond to new situations (627). ${ }^{7}$ These shared understandings enable scripts that attempt "to create order out of the complexity of global events by constructing narratives through which the region's place in the world is understandable and legitimate." Both of these ideas follow closely on a concept Ó Tuathail refers to as "geopolitical culture." This idea posits the contention that a collective imaginary provides people with a framework for understanding their state's place among other states:

\footnotetext{
${ }^{7}$ See Anderson (1991) for a broader discussion on how media generates a sense of shared belonging in terms of an "imagined community."
} 
All states, as recognized territorial institutions within an international system of states, have a geopolitical culture, namely a culture of conceptualizing their state and its unique identity, position and role in the world. Geopolitical culture emerges from a state's encounter with the world. It is conditioned by a series of factors: a state's geographic position, historical formation, and bureaucratic organization, discourses of national identity and traditions of theorizing its relationship to the wider world, and the networks that operate within that state. (Ó Tuathail, 2006: 7)

I contend that the American imaginary contains within it broad and shifting impressions of Canada that structure how Americans respond to the country. These impressions help Americans to make sense of Canada. They provide clues for Americans on how to position their country in relation to Canada. This version of Canada that exists within the American geopolitical culture conditions US expectations and reactions when engaging with the country.

The characteristic that most dominates Canada's place in the American imaginary is one of ambiguity. Although Canada is clearly not a constituent element of American culture in a formal sense, it was, to borrow Acheson's phrase, "present at the creation," and has been a constant fixture on the American frontier ever since. On one hand, in terms of political reality, Canada is obviously a foreign country. However, on the other hand, the certainty of this foreignness is constantly questioned. Norton (1988) refers to this state of ambiguity, in which an identity is understood to be simultaneously part of and separate from the self, as liminality. It is this characteristic, which depicts Canada as simultaneously belonging to and excluded from the American experience, that dominates Canada's place in the US geopolitical culture. It is a prevailing image that is produced and reproduced through an intertextual weave that crosses multiple varying facets of US 
political and social life. Most of the time, Canada's liminal status provides a reassuring image of sameness that contributes to US security and American identity. However, this dissertation argues that during times of crisis, when US security and American identity are scripted in opposition to threatening enemies or dangerous forces, Canada's liminality becomes a source of danger. Representations of the country intertwine traces of otherness with impressions of sameness in such a way that Canada is rendered a proximate instantiation of the danger that menaces America. In this way, it becomes possible for Americans to comprehend and believe that an otherwise model ally could become a threat to US security.

In many ways, Canada appears to occupy a place of irrelevance in the American imaginary. ${ }^{8}$ As historians John Thompson and Stephen Randall suggest, Canada has been of "consuming disinterest to the United States public and to most of its leaders" (2002: 3). One of Canada's former ambassadors to the United States confirms this impression, claiming that "neglect of Canada is a chronic condition in America" (Burney, 2003/2004: 46). Leal points to a similar lack of interest when it comes to US scholars and the study of Canadian politics: "I have noticed that asking scholars to care about Canadian politics is like asking them to get a physical or eat more vegetables. Everyone agrees these are probably good ideas, but there is often a certain reluctance to comply" (2006: 813). This neglect is not, however, borne out of a sense of intentional dismissal. In other words, Canada is not deemed irrelevant as a result of a self-conscious evaluative effort on the

\footnotetext{
${ }^{8}$ Meyer relates a story that captures the essence of this idea nicely: "At a Frankfurt book fair there was once a straw vote for the most boring title; the winner by acclamation was a culinary work, Great Canadian Desserts" (2003, p. 103). The sentiment is similar to that implied by the winner of the New Republic's famous contest for the world's most boring headline: "Worthwhile Canadian Initiative" (Krugman, 2010).
} 
part of Americans. Instead, I argue that Canada fails to merit focused attention because it is not considered entirely exterior to the American experience.

Understood as intertwined within the American conception of the self, Canada is simply not foreign enough to deserve sustained consideration. In other words, the sense of irrelevance that Americans attach to Canada issues from a widespread belief that Canadians are just like Americans. A tongue-in-cheek CNN feature provides an example of how impressions of Canadian irrelevance are fuelled by a prevalent sense of sameness:

Beautiful, yes. Big, very: the second-largest country on Earth. The thing about Canada, though, there's a third $b$-word that does come up...having to do with Canada, allegedly, not being all that interesting. What is it about us down here in our little patch of North America when it comes to Canada? Maybe it's just we're such good friends, the place just doesn't much keep us up nights. Or is it really the place kind of puts us to sleep? (CNN, 2001a)

Indeed, as Burney argues, even though most Americans do not consider Canada at length, many nonetheless "tend to see Canadians benignly as being 'just like Americans"' (2005: 48). Eagles (2006) uses similar language when he discusses the presence of "a benign indifference towards Canada that is characteristic of both citizens and many policymakers" (822). He goes on to suggest that "the very closeness of historic ties makes it relatively easy for Americans to assume that the interests of both countries are complementary, and that Canada is simply an unofficial $51^{\text {st }}$ state to the north" $(823)$. Thus, in this sense, Canada's irrelevance in the eyes of Americans can be understood as deriving from simply being taken for granted.

Impressions of Canadian liminality are common in US popular culture. Berton (1975) makes it clear that Hollywood's portrayal of Canada is, in many ways, simply a 
slightly altered reproduction of an American image. For instance, he claims that US filmmakers "undoubtedly viewed Canadians as simpler, less complicated versions of Americans" (75). Similarly, he contends that Hollywood films "have carried the implicit message that the Canadian image differs from the American image only in the matter of degree" (230). Similarly, Brégent-Heald (2007) identifies a process whereby Hollywood and the US tourism industry were able to create a single understanding of 'the west,' in which Canada's northwest was incorporated into the American west. Considering the crucial importance of the frontier and the idea of 'the west' in the self-definition of America (Slotkin, 1973; Turner, 1966 [1894]), the linkage of Canada with this concept says a great deal about the place Canada occupies within the American imaginary (see Drache, 2004: 37).

When National Geographic runs pictorial features on Canada, the editors are faced with an unusual task. When preparing articles on other regions of the world, particularly "third world societies," the editors attempt to limit the sense of difference communicated by their representations of the subject matter (Beaudreau, 2002: 518). In other words, the editors want to make their material exotic, but not so different that American audiences are unable to relate to the images they are consuming. In the case of Canada, however, the editors encounter the opposite problem: Canada is not foreign enough. As Beaudreau explains,

Canada, for the most part, is a country that Americans don't think about a lot; when they do, they tend to think of it as America's 'back yard' - as a kind of bigger, emptier, more natural and more polite version of the United States...And Canada, a large, North American country whose inhabitants are mainly of European descent, is like the United States in so many ways. (517-518) 
As a consequence, the editors of National Geographic have to find ways to represent Canada such that the country's similarity to the United States is reduced. Americans, it turns out, have to be convinced of Canada's unique identity. In other words, the editors have to demonstrate to their audience that Canada is foreign enough to deserve their attention. As Beaudreau phrases it, when representing Canada to their readers, the editors have to "exoticize' the familiar" (518).

A number of commentators have suggested that the US policy response towards Canada is structured by a similar understanding of the country. For instance, Mahant and Mount discuss a pattern in Canadian-American relations in which US leaders assume Canada will willingly adapt to US policies because Canadians are so similar to Americans (1999: 198-99). As the authors suggest, "in its most extreme form, this policy sees Canada as a place that can be treated just like the United States" (199). ${ }^{9}$ This is an impression shared by one of the most high-profile of Canadian foreign policy practitioners, Lester Pearson: "The American authorities often tend to consider us as not a foreign nation at all, but as one of themselves" (quoted in Stewart, 1992: 184). Other scholars have remarked how for many years the US State Department did not have a specific and established institutional framework for dealing with Canadian issues. As Drache claims, “in Washington's eyes the US-Canada relationship fell into a grey zone, neither totally foreign nor domestic; it belonged somewhere in between" (2004: 91). In terms of official rhetoric, the evidence of liminality is even more convincing. To provide

\footnotetext{
${ }^{9}$ The title of the authors' classic account of Canadian-American relations also serves to emphasize Canada's tenuous and ambiguous position within the American imaginary: Invisible and Inaudible in Washington: American Policies Toward Canada.
} 
just one example of many, former US Ambassador to Canada, Paul Cellucci gave an address to the $105^{\text {th }}$ American Assembly in 2005, in which he discussed the strength of the "shared values" that link Canada and the United States and asserted "that there are more differences within each country than there are between our two countries" (2005: 509). Cellucci's address concluded with a comment relating his emotional reaction to the outpouring of Canadian support at an event several days after 9/11: "I was reminded that day that we are great friends, we are family, and we always will be" (515).

Even among US scholars interested in Canada, liminal ambiguity remains a common framework for understanding the country's place vis-à-vis America. ${ }^{10}$ As one prominent US historian claims, "in so many ways [English-speaking] Canada did seem to be a milder, more pleasant somewhat slower version of the United States" (Winks, 1993: 10). A similar trend is found in several submissions to a collaborative reflection on a Canadian visit undertaken by US faculty members as part of the International Canadian Studies Institute (Capuozzo, et al., 2009) ${ }^{11}$ For example, a Political Scientist from LewisClark State College, who specializes in US foreign policy, relates her visit through the lens of 'image theory':

For those who have not yet journeyed through Canada and gained an understanding of Canadian politics, the perception looking north from the US side of the border is that of a good friend who is just not quite as

\footnotetext{
${ }^{10}$ In a discussion concerning how US universities might reinvent the academic discipline of Canadian Studies, Knowles (1995) advocates the self-conscious embrace of Canadian liminality as a way to further an understanding of both Canada and the United States. He suggests that Americans need to understand Canada in terms of its "liminality" and "indeterminacy," and that if instructors do so, they might be better able to appreciate that the unstable image of the Canadian 'other' contains what he calls, "a ghostly, distorted, fun-house-mirror resemblance" to the American self.

${ }^{11}$ Even the title of the article that collects the reflections is saturated with liminality: "So Close Yet So Far Away: American Academics on the Similarities and Differences Between the United States and Canada Following the International Canadian Studies Institute" (Capuozzo, et al., 2009).
} 
wealthy or as educated, and who just doesn't quite have what we do. While the United States may perceive developing states as 'pre-teens,' and rogue states or terrorist states as 'juvenile delinquents,' Canada is that pal who will always be there, right behind our left shoulder. (8)

A similar impression is effected by Lipset (1993) in a discussion concerning the lack of US scholars who focus their research on Canada. In his explanation of this paucity, Lipset effectively suggests that Canada is not foreign enough and, in doing so, evokes an image of the country that places it squarely within the American self: "To concentrate on Canada as a subject appears to be the equivalent of concentrating on the Midwest or Minnesota" (399).

The US news media provides multiple examples of the sense of irrelevance that issues from understanding Canada as liminal. Indeed, one useful indicator of irrelevance emerges from the very lack of coverage Canada receives in US news (Belch, 2004). As Buckley suggests, regardless of the importance of Canada's political and economic ties with the United States, "the American news media are content to pass over such matters in silence" (2003: 95). In a ranking that placed countries according to the frequency with which they were mentioned in US television news coverage, Canada was tied with Switzerland in $19^{\text {th }}$ place (Barton, 1990: xx). However, even when news coverage does address Canada, it typically does so with the ambiguity discussed above. In other words, Canada is often treated as though it were part of the United States. As Lipset claims, "Canadian news is dealt with in the same way as news from Minnesota or Nebraska" (1993: 398). Nativist CNN host Lou Dobb provides a lamenting example of this liminality: 
And our quote of the day tonight comes from a Delta spokesman. When we asked Delta about the decision to export this critically important maintenance work to Canada, Delta's response was telling. "The work in Canada is domestic. Because it's North America, that is part of our domestic operation." Now, that's worth repeating. A U.S. company exporting work to a foreign country, in this case Canada, saying the work in Canada is domestic. Our quote of the day. (CNN, 2005)

A final example, also drawn from the mainstream news media, provides such a telling example of the power and resilience of the liminal image of Canada that it deserves an extended treatment (Ferguson, 2010). Just before the launch of the Vancouver Olympic games of 2010, NBC's Tom Brokaw narrated a short feature that purported to give Americans a brief introduction to the host country. Timed at approximately five minutes and thirty seconds, and presumably watched by millions of Americans, the video ties Canada intimately with the United States in a wide variety of ways. The single most powerful message that issues from the presentation as a whole is one that scripts Canada as a loyal and enduring partner to the United States. ${ }^{12}$ In this sense, rather than introducing Canada to its audience as an independent entity, NBC frames the country in the context of the American self.

The presentation begins with images of the Peace Arch that straddles the British Columbia-Washington border, and a narration that explores the amity that has endured between the two countries since the end of the War of 1812. The camera lingers on two of the phrases etched into the stone structure: "Children of a common mother" and "May these gates never be closed." From this blatant opening statement of liminality, the presentation proceeds through a series of impressions that serve to link the countries

\footnotetext{
${ }^{12}$ Ferguson (2010) demurs with this assessment, suggesting that "what's got Canadians so excited is Brokaw's reverent tone throughout the video."
} 
together. For instance, the border itself is virtually effaced as part of a sentiment that claims shared ownership over North American resources: "We share more than a long border, of course - no dotted line could divide our joint stewardship of a treasure of natural riches." As the video progresses, this image of liminality is reinforced by a long series of similar impressions, each serving to frame Canada as a partner to the United States: "Canada and the United States share another unique quality..."; "Our two nations have the largest trading relationship in the world..."; "And we're so comfortable as neighbours..."; "Canadians are so generous, they share with us their brightest stars..."; “They've been America's most reliable partner in Afghanistan..."; "Even their diplomats have been there for us..."; "In our darkest hours, Canada has been with us..."

As the presentation nears its conclusion, Brokaw's narration provides another powerful statement of liminality: "In the long history of sovereign neighbours, there never has been a relationship as close, productive and peaceful as the US and Canada we share a continent and so much more." By this point in the video, Canada is clearly marked as fundamentally tied to the United States. In terms of visual depictions of partnership, the audience has been treated to at least seven different camera shots that feature the unmistakable symbolism of the Canadian and US flags fluttering side-by-side. Beyond the visual imagery, however, the narrative itself has rendered Canada a helper or loyal partner in a variety of international situations, including the Second World War, the Iranian hostage affair, 9/11 and the war in Afghanistan. As the conclusion approaches, virtually every aspect of Canadian life has been explored and framed in relation to the 
United States: natural resources, political and social values, settlement patterns, military accomplishments, geography, foreign relations, economy, sports and culture.

If, however, the viewer has somehow missed the sense of mutuality that has pervaded the presentation thus far, the conclusion itself leaves no room for doubt. The video closes with footage of US President Kennedy's 1961 speech to the Canadian parliament, in which he intones an extraordinary message of liminality that is suffused with a wide range of culturally accessible metaphors of belonging: "Geography has made us neighbours. History has made us friends. Economics has made us partners. And necessity has made us allies." The presentation closes with Brokaw himself uttering the final words of Kennedy's famous quotation, effectively marrying Canada off to her American groom: "Those whom nature hath so joined together, let no man put asunder." The overall effect of the presentation is to render Canada a feminine and junior partner to the United States and frame the country within the wider cultural understanding of the American experience. With a commanding narrative, and enhanced by evocative imagery and a stirring soundtrack, there is little doubt that the video tugs at the heartstrings of its viewers (Ferguson, 2010). It stands as a powerful example of the place that Canada occupies in the American imaginary.

\section{Otherness, Liminality and Threat}

Following the events of September 11, 2001, the Canadian border became a security concern in the eyes of many US media sources, citizens and policymakers. Not 
surprisingly, a number of commentators suggest this was a new occurrence, that the border's designation as a threat was a recent phenomenon. For example, Gecelovsky suggests that the "image of Canada as a security threat to the United States" was a new development that emerged after 9/11 (2007: 517). Similarly, Flynn claims that "the notion of the forty-ninth parallel as a security issue is a recent phenomenon that burst into the limelight just before the millennium" (2003: 115). Allan also contends that this understanding of Canada is of recent vintage, having resurfaced for the first time since the War of 1812 (2009: 77-78). In issuing these assertions of novelty, scholars tend to juxtapose the emerging post-9/11 security reality with the halcyon days of 'the world's longest undefended border.' For instance, Gecelovsky contrasts the new threatening image of the border with "the traditional image of Canada as a friendly, benign neighbor" (2007: 517). The radical shift that is effected by contrasting the new reality of terrorism against an era of innocence and cooperation does considerable work in conveying the sense of a distinct break with the past. In this sense, the novelty of Canada's status as a threat seems eminently plausible.

On closer consideration, however, there is a sense in which analyses that assert the novelty of Canada's role as a threat to the United States miss the mark. Throughout the history of the bilateral relationship, both Canada and the Canadian border have regularly been understood by Americans in terms that fall rather short of "benign" and "friendly." Mason makes this point clear in answering the titular question of his article, "Is Canada a threat to U.S. security?": "Yes, Canada has always been a place from which others could attack what is now the United States" (2007: 165). In The American 
Response to Canada Since 1776, Stewart (1992) disabuses his readers of the seemingly timeless myth that the US response to Canada is a largely benevolent one that issues from the United States' status as "good neighbor." Thompson and Randall are similarly set on dispelling the notion of the "special relationship." For these authors, the notion of a special relationship is a stubborn embellishment that serves to obfuscate a bilateral history brimming with conflict and tension. Such platitudes, which continue to link the countries as "friends," serve only to "belie the dissonance of the nineteenth century and exaggerate the harmony of the twentieth; as the twenty-first century unfolds, they seem archaic" (2008: 1).

Following a similar line of reasoning, this dissertation contends that Canada's status as a perceived threat to US security is not a new development. Indeed, I suggest that Canada's role as a threat is a historically persistent one. As critical IR scholars have demonstrated, threat is not a phenomenon that exists objectively in the external world, waiting to be simply identified as such by policy-makers and analysts. Rather, the specification of threat is part of a discursive process that works to define the self's identity and calcify the boundaries that set the self off from the external world (Dalby, 1990; Weldes, 1999a). I argue that this nuanced understanding of threat has considerable implications for Canada's relationship with the United States.

As discussed above, the version of Canada that resides within the American imaginary is conditioned by impressions of liminality. However, the US understanding of Canada is also freighted with an understanding of difference, a contention that is made evident by the ubiquitous popular representations that essentialize Canada in terms of the 
French language, wilderness, snow, politeness, natural resources and any number of other stereotypes. Clearly, this sense of difference is not unique to the US understanding of Canada. Indeed, it is integral to the very notion of identity - if the self does not perceive difference in other identities, it ceases to be a unique identity. As a pre-condition for independent existence, difference certainly does not necessarily imply otherness. However, as Connolly suggests, difference always retains the potential to shade into otherness: "Identity requires difference in order to be, and it converts difference into otherness in order to secure its own self-certainty" (1991: 64). For the most part, the sameness that is communicated by Canada's liminality militates against this slide towards otherness (Norton, 1988). After all, if Canada is understood to be virtually an extension of America, the likelihood of the country being represented as a threatening Other is limited.

However, in circumstances of perceived crisis or danger, when the American identity is scripting itself in opposition to a significant threat, Canada's liminality has the potential of directing this dynamic in a different direction. Under such threatening circumstances, when America is seeking to "secure its own self-certainty," the presence of difference in Canada serves to question the 'truth' of American identity claims. As a consequence, Canadian difference starts to take on threatening characteristics. To be clear, I am not suggesting that such a situation results in a fundamental reordering of the US impression of Canada, such that the country comes to be understood as actively hostile. Rather, I contend that Canadian differences make it possible for Americans to understand how elements of threat and danger are able to take hold in North America. 
At this point, impressions of Canada's liminality, which normally operate to reinforce American identity by providing an image of likeness, play a role in rendering Canada a threat. The impression that Canada is virtually an extension of America suggests that any trace of threat or danger in Canada is effectively within America as well. In this sense, representations of Canadian difference help to instantiate the threat from the dangerous 'outside' inside North America, while impressions of Canadian liminality act as a conduit through which that threat is directed to the United States. Thus, instead of being understood merely as a potentially dangerous place, where otherwise distance threats might conceivably find purchase, Canada acts to transmit that threat into the heart of the American self. In this way, Canada contributes to the specification of threat that helps to define and circumscribe American identity.

There is a history of incidents when the Canadian border was scripted as a threat to the United States. Similar to the War on Terror, these situations were not examples in which Canada played the role of an existential threat. However, they were moments when Canadian policies differed from their American counterparts in areas important to the definition of the American self. These policy differences acted as symbols of difference and, in so doing, detracted from the unity and 'truth' of American identity claims. In this context, although the United States was not threatened in any meaningful way, the social dynamics of identity reacted to secure the American self nonetheless.

The period of prohibition in the United States, from 1920 to 1933, provides one such example. This was a time when Canadian laws, which allowed for provincially regulated sale of alcohol, differed from a US legal environment that prohibited the 
production, sale or transport of such beverages. The nature of the diplomatic crisis that erupted over prohibition revolved around Canada's capacity to threaten US interests and security. In this sense, the dispute serves to question the supposed novelty of Canada's turn as a security threat during the War on Terror (Hataley, 2005). Indeed, the so-called 'Rum War' was attended by many of the same features that defined the US reaction to Canada after 9/11. As Moore (2004) demonstrates, the conflict engendered heightened political rhetoric, claims of national security, questions of sovereignty and even calls to militarize the border.

I would argue that the similarities do not end there, and that the Rum War serves as another example of the identity-driven dynamics discussed in this dissertation. The US temperance movement was a powerful force in US politics in the 1920s, and the question of prohibition was typically framed as a moral one. In this sense, Canadian laws that allowed the production of alcohol, and a Canadian refusal to hinder the export of alcohol to the United States, were represented as the product of a divergence in values. As Moore suggests, differences between Canadian and US approaches were often understood in terms of a dispute over the role of government in society: "Canada's divergent approach also stemmed from a set of social values that were less likely to use the power of the government to regulate social morality" (2004: 10). This was a situation in which Canada's intransigence served as an implicit rejection of the identity claims being propounded in the "moral experiment in the United States" (11). In this sense, as was the case during the War on Terror, a difference in policy resulted in Canada being understood as a threat to the United States. 
Canada was also portrayed as a threat to US security between the late 1800 s and early 1900 s as a consequence of the country's role as a gateway for illegal Chinese immigration into the United States. At the base of the conflict were immigration policy differences between the two countries that effectively meant that Chinese immigrants who would normally be prevented from entering the United States directly could instead gain entry illegally through Canada. As Hataley suggests, Americans believed these immigrants represented "a threat to the sovereignty of the United States" (2005: 64). ${ }^{13}$ The level of threat associated with an influx of Chinese immigrants is also reflected in the severity of the US legal response to the issue. The Chinese Exclusion Act of 1882 was the first time in US history that the government barred entry to an immigrant group on the basis of "race and class" (Lee, 2002: 55).

Like the example provided by the Rum War, the dispute over Chinese immigration recalls many of the same dynamics witnessed during the War on Terror. ${ }^{14}$ American frustration over the matter was often framed in the context of a lack of Canadian cooperation. As one American immigration inspector claimed: "much that appears menacing to us is regarded with comparative indifference by the Canadian government" (Lee, 2002: 69). The US Commissioner-General of immigration went as far as to suggest that Chinese immigration through Canada was "a threat to our very civilization" (73). Like the Rum War and the War on Terror, the threat in this case was

\footnotetext{
${ }^{13}$ See also Lee (2002: 73$)$.

${ }^{14}$ As Lee (2002) demonstrates, the similarities include depictions of "lax" Canadian border controls, an increased presence of border patrol agents, and sustained pressure for policy convergence. Unfortunately, while drawing out some of these similarities, the author herself contributes to the enduring misinformation surrounding 9/11: "Several of the suspected hijackers who took control of the commercial flights that crashed into the World Trade Center in New York City and the Pentagon in Washington, D.C. spent time in Canada and allegedly entered the United States from the north" (85).
} 
grounded in issues of American identity. US opposition to Chinese immigration was structured by racialized and inflammatory rhetoric steeped in notions of criminality and alienness. Paraphrasing Robert G. Lee's discussion on representations of Asians in popular culture, Lee suggests that media depictions "recreated and reinforced the popular representation of Chinese immigrants as both 'pollutants' who endangered American society with their alien presence and unfree, servile coolies who threatened the white working class" (2002: 63-64). This stress on racial images marks this historical episode as another example where the Canadian threat was scripted in reaction to a challenge to the purity and unity of the American self.

These examples show that it is important to interrogate analysis that claims Canada's recent status as a US security threat is a new development (Hataley, 2005). Such an approach is based on the notion that Canada has become a threat as a result of a change in objective security factors. While there can be little doubt that some quarters did indeed understand Canada as a security risk during the War on Terror, I argue that this shift was not the result of an objective re-evaluation of Canada's immigration policies or defence spending. Instead, the shift was a consequence of discursive representations of Canadian threat that emerged in conjunction with renewed efforts to script the American self in relation to the threat of terror.

An appreciation for the constructed and constitutive aspects of threat implies that Canada's recent turn as security threat needs to be understood as just the latest in a broader historical trend. Indeed, I would argue that Canada has long served as a site 
where Americans are able to imagine their fears. ${ }^{15}$ In the context of the self/Other dynamic, Canada's liminality marks the country as a variable signifier. It serves the role of a blank slate, accepting the features and characteristics of whatever threat is confronting America. In so doing, Canada provides an oppositional foil for the construction of the American self. Moreover, by serving as a threat, Canada also contributes to the discourse of danger that works to perpetuate American identity.

\section{Analytical Approach}

Within the confines of orthodox IR, the study of security is typically understood from a realist perspective that prioritizes the role of the state and defines power in terms of relative capabilities (Waltz, 1979). According to this approach, the state is a fixed and pre-given entity that acts with a unity of purpose. In the anarchical international arena, the insecurities that plague the state are largely the result of objective threats posed by rival states or violent transnational actors. In this sense, the orthodox view of international relations treats both states and threats as self-evident. Research undertaken within this framework is aligned largely with the positivist tradition of social science. Research questions from this tradition are often structured as 'why' questions (Doty, 1993: 298-299; Doty, 1996: 4). I argue that such questions are problematic in that they

\footnotetext{
${ }^{15}$ An argument could certainly be made that this dynamic was also in evidence at moments of crisis during the Cold War. Policy differences between the two countries during this period were easily explained through references that scripted Canada as 'weak' on defence or 'soft' on communism. Indeed, Allan's research hints that US newspaper coverage of Canada's reluctance to arm its Bomarc missiles with nuclear warheads was laced with representations that scripted Canada as both Other and liminal, and framed its decisions in terms of a threat to US security (2009: 36-45).
} 
are freighted with hidden epistemological and ontological assumptions. For example, a 'why' question dealing with some of the broad subject matter of this dissertation might ask the following kind of question: 'Why did the United States consider Canada a security threat after $9 / 11$ ?' Such a question could elicit a variety of responses, such as 'Canada's immigration policies allow too many terrorists into the country' or 'After the terrorist attacks of 9/11, US security needs and expectations increased.'

This approach assumes that one can speak of both states and threats as objective 'things' that can be observed and evaluated as though they are independent facts. For example, orthodox IR treats the identity of the state as a given reality that emerges from the state's position within an anarchic international system. The realist perspective similarly naturalizes the threats that are said to menace such states. It treats them as though they are neutral facts that emerge from the material capabilities of rivals and are capable of being apprehended and analyzed from an Archimedean perspective. I argue that this stance is problematic at both epistemological and ontological levels.

At an epistemological level, this approach bespeaks a commitment to the unity of science, wherein the methods of investigation used in the natural sciences are judged appropriate for research in other areas. In other words, it implies that scientific methods can be used to enable the analyst to make definitive knowledge claims about subjects of inquiry in the social realm. More specifically, because this approach treats states and threats as objective and self-evident, the analyst is able to make unproblematic claims about their nature and theorize causal relationships between threats (Canadian immigration policies or terrorism) and state reactions (reassessing Canada as a security 
risk). This approach conceives of knowledge as absolute instead of contingent. It cannot appreciate that our knowledge of the things around us is always necessarily incomplete because that knowledge is always the product of a negotiated, social process.

Similarly, at an ontological level, such a perspective fails to appreciate the intersubjective nature of the social world. It denies that the things we take to be objectively real, the so-called "furniture" of the world (Smith, 1996: 18), are only understood that way because of the meanings that we have attached to them. For instance, the political and social entity known as Canada does not exist in an intelligible way outside of the bundle of meanings that has been assigned to it. Similarly, like states, threats are also granted meaning in an explicitly social setting. They are perceived as threatening because they have been constituted as such within the context of an intersubjective negotiation that affixes a dangerous meaning to them. Moreover, not only do states and threats achieve meaning through social construction, they also achieve meaning in relation to one another. In other words, states and threats have a mutually constitutive relationship. When a state identifies something as threatening, that state is both giving definition to that threat and making a claim about the nature of its own identity. An entity cannot know what types of things threaten it unless it knows what kind of entity it is (Campbell, 1992: 85). Therefore, that act of identification, in which the state defines something - another state, a people, a phenomenon - as dangerous, also serves to define the state's own identity. The specification of threat, however, does more than simply shape the contours of the state's identity. It also acts as a societal coagulant, demanding increased loyalty to the identity claims that are said to encompass and define 
the nation. More specifically, in the face of declared danger, the state, which arrogates for itself responsibility for both identifying and forestalling threats, becomes the nation's primary source of refuge from the dangers the state itself specifies.

In light of the inadequacies that plague 'why' questions, this dissertation focuses instead on 'how' questions. Instead of simply asking 'why' a state reacted in a certain way, a 'how' question interrogates the conditions that made that reaction possible in the first place. Thus, they problematize and interrogate the very things that 'why' questions assume. As Doty phrases it, these questions "examine how meanings are produced and attached to various social subjects and objects, thus constituting particular interpretive dispositions that create certain possibilities and preclude others" (1996: 4). In terms of the study of foreign policy, these questions examine the ways in which we define and understand the international actors and phenomena around us, and the ways we situate our own state in relation to those actors and phenomena. It is these definitions and understandings that make it possible for us to render the judgments about other states that inform our specific reactions to those states. This is an appropriate starting place for analysis of international relations because, like Doty, "what I take to be problematic is the existence of subjects themselves, their position vis-à-vis one another, and the 'reality' that made certain structures and meanings possible" (1993: 305). Thus, returning to the original example above, instead of asking 'why' the United States considered Canada to be a security threat after 9/11, a 'how' question allows an understanding of how it was possible that Canada came to be understood as a security threat in the first place. This approach leads me to ask questions such as, 'How was Canada defined such that it 
became plausible for prominent US politicians to declare the Canadian border a liability to US security?' To answer this question requires attention to the various ways in which both Canada and the United States were defined and positioned in relation to one another.

An appreciation for the ways in which international subjects and objects are defined calls attention to the crucial role of representation. Like Doty, I contend that "representation is an inherent and important aspect of global political life and therefore a critical and legitimate area of inquiry" (1996, p. 5). Our understanding of the world is necessarily a mediated one. The ways in which we apprehend the world around us and the meanings that we take away from global actors and forces are all shaped by representations. In a social context, representational patterns serve to construct the reality that confronts us. As Shapiro claims, representations "are the practices through which things take on meaning and value; to the extent that a representation is regarded as realistic, it is because it is so familiar it operates transparently" (1988, p. xi). In this way, representations structure the way we think about subjects and provide the limits for our understanding about what particular subjects are like and how they might act.

However, representations are not solely about the social construction of the subject they purport to describe. They also have implications for the actor from which the representations emerge. That is, our depictions of other actors have a constitutive effect on our own identity. For instance, to portray a state as an ally inevitably makes an implicit statement about the nature of one's own society. The following quotation from George W. Bush provides a clear example of this dynamic: "I want to thank very much the Australian government and the Australian people for their willingness to help a young 
democracy such as Afghanistan" (quoted in Miles, 2008). In this example, Bush is doing more than simply scripting Australia as a loyal and valuable ally. In making his pronouncement, Bush assumes a position from which he is able to authoritatively confirm the mission in Afghanistan as a noble endeavour, while also thereby framing the United States as a selfless and democratic nation. Similarly, representing other states in negative terms also serves to script one's own society in positive terms. This dynamic is made plain by Bush's State of the Union address in 2002, in which he labels Iran, Iraq and North Korea as "evil":

States like these, and their terrorist allies, constitute an axis of evil, arming to threaten the peace of the world. By seeking weapons of mass destruction, these regimes pose a grave and growing danger. They could provide these arms to terrorists, giving them the means to match their hatred. They could attack our allies or attempt to blackmail the United States. In any of these cases, the price of indifference would be catastrophic. (Bush, 2002)

The depiction of the three countries in this short excerpt from the address is blatant: they associate with "terrorist allies;" they are "evil" and "threaten the peace of the world;" they are a "grave and growing danger;" they seek weapons of mass destruction; and they are opportunistic and belligerent. These representations work to present a specific version of reality to the wider audience, communicating a clear message about the nature of the enemies the United States is confronting. Working in a binary fashion, however, Bush's characterizations also script the United States in specific ways: it does not associate with terrorists; it is good; it does not threaten world peace and is not dangerous; and, it is not aggressive, although it is also not indifferent in the face of danger. In this sense, the act of representing other actors has constitutive significance for the self's identity. 
Beyond scripting the identities of subjects and objects, however, representations also provide a framework for understanding what types of postures and actions are appropriate. For example, the above scripting of Iran, Iraq and North Korea prompts an understanding of those countries that warrants certain types of responses and delegitimizes others. To be more specific, an understanding of these countries as threatening, dangerous and "evil" might predispose policymakers and citizens to forgo diplomacy in favour of a confrontational or militarized response. Similarly, the earlier representation of Australia as a helpful ally prompts an understanding of that country that makes it virtually inconceivable to consider an armed response. In this sense, representations not only define the self in relation to other identities; they also provide a framework that defines the range of appropriate reactions for the self in responding to these Others.

The importance of representations is particularly crucial when it comes to specifying threat (Campbell, 1992; Weldes, 1999a). This dissertation explores the role of US popular media in constructing an image of Canada as a threat and the consequences such representations imply for American identity. Interpretive approaches like this, which stress the constitutive nature of representations of threat, have not typically found substantial purchase within mainstream IR. Over the last two decades, however, the traditional foundations of the discipline have come under increasing criticism. In an extended bout of theoretical ferment variously referred to as the Third or Fourth Debate (Kurki and Wight, 2007), space has opened up for alternative approaches (Lapid, 1989). During this period, the sub-field of Security Studies has been witness to intense debate, 
its various adherents engaged in a prolonged discussion over the appropriate boundaries and definition of their subject matter (for example, see Walt, 1991; Dalby, 1997; Buzan et al., 1998; Eriksson, 1999; C.A.S.E. Collective, 2006; Dalby, 2009). One of the consequences of these ongoing deliberations is a more nuanced understanding of the relationship between threat and identity.

\section{$\underline{\text { Sources of Representations }}$}

It is interesting to note that even as some IR scholars attempt to undermine the discipline's orthodox assumptions by exposing the contingent and discursive nature of state identity, they often maintain a focus on the formal apparatus of state power as the primary agent responsible for constituting that identity. Indeed, much of the literature gives state-sanctioned actors a place of particular prominence in the relationship between the scripting of foreign threats and the constituting of national identity. Considering the power and authority of the state, particularly in the realm of security, such an approach may seem warranted. However, by continuously emphasizing state-sanctioned actors, this tendency serves to understate and, at times occlude, the important role of other agents in the production of insecurities and identities. At an implicit level, it also serves to reinforce the orthodox emphasis on the state as the primary actor in international relations. Sharp identifies this tendency and the tensions it creates:

In many ways...the literature that critically analyzes the national grounding of geopolitical discourse itself reinforces neorealism's privileging of the prime agency of the territorial national-state unit: the nation state is taken as a more or less single voice that constructs a national 'us' in contradistinction to a foreign 'them.' (2000: 29) 
An important example of this tendency to emphasize the state is found in David Campbell's Writing Security (1992). This work, which Iver Neumann (1999) correctly singles out as a "landmark" study, is rich in nuance and obviously understands othering as a process with multiple intersecting origins. Indeed, his distinction between "foreign policy" and "Foreign Policy" explicitly makes it clear that official discourse is premised upon prior conceptions of identity/difference that originate in the broad othering patterns that persist outside the domain of the state. Nonetheless, from Campbell's perspective, official government policy is the primary vehicle by which dangers are identified and identity reproduced: "Foreign Policy is only one of a number of discourses of dangers...but in the context of the modern nation-state, Foreign Policy has been granted a privileged position as the discourse to which we should turn as the source of the preeminent dangers to our society and ourselves" (Campbell, 1992: 77). With this assumption in hand, Campbell proceeds by devoting a significant share of his empirical work to an analysis of the official texts and policies of the state.

Weldes et al. (1999b) adopt a similar approach in the introductory chapter to their volume dedicated to exploring the relationship between insecurity and identity. Although they acknowledge the possibility that a variety of actors might be in a position to play a role in constructing insecurity, they single out state officials as the main constitutive agents: "Because identifying danger and providing security is, in modern politics, considered fundamentally to be the business of the state, those individuals who inhabit offices in the state play a central role in constructing insecurities" (17). For these authors, 
the agency of these state officials appears to derive largely from their institutional location:

All things being equal, the representations of state officials have immediate prima facie plausibility to the extent that these officials can be constructed as representatives who speak for 'us'. Such representations are likely to be so regarded not because they tell us what the world 'really' is like but because they issue from the institutional power matrix that is the state. (17-18)

A number of other important works in this field of study also prioritize the impact of policy-makers and state officials in scripting threats and selves. For example, Milliken and Sylvan (1996) explore how the words and phrases used by high-ranking US policymakers to represent the people of Southeast Asia helped to enable the US bombing campaign of that region in 1965. As they suggest, "those words helped create the world in which millions of other people lived, suffered, or died" (323). Nathanson (1988) examines the impact of US diplomat George Kennan's 'Long Telegram' of 1946. He demonstrates how Kennan represented the Soviet Union as a threatening Other, and how this script was instrumental in foreclosing US debate on both domestic and foreign policy alternatives in the years following the Second World War. Doty (1993) argues that the representations used by US foreign policy makers constructed American and Filipino identities in a hierarchical way that made possible the US counter-insurgency policies enacted in the Philippines in the 1950s.

Considering the authority and legitimacy invested in agents of the state, it is perhaps not unreasonable to focus on the impact of such actors. Analyses of this nature have proved invaluable in exposing the discursive nature of threat and the contingent nature of identity. However, state-empowered actors are only one source from which 
representational gestures emerge, and, as suggested above, a focus on them tends to obscure the existence, let alone the importance, of other sources. To take full advantage of the possibilities presented by an approach that acknowledges the importance of discourse and representational practices, analysts should be prepared to look beyond the sites of official power. Gramsci's understanding of hegemony is instructive in this respect. ${ }^{16}$ In his exploration of the persistence of unequal power relations in society, Gramsci contends that the traditional understanding of the state is insufficient. In order to grasp how a hegemonic ideological formulation can become so entrenched that it is able to elicit the support of even those who suffer under its terms, he points to the complicity of civil society. For such an ideology to maintain support among the general population that is, for the government to rule without constant recourse to coercion - it needs to find purchase in civil society (Cox, 1983). It needs to permeate the innocuous institutions that structure and give meaning to daily life. These institutions - social clubs, the media, educational organizations, religious establishments - are depoliticized; they have the appearance of being removed from the realm of official policy and governance. As such, once suffused with the ideology, these institutions reproduce and reinforce governing ideological codes in an unobtrusive manner. It is at this point, when the population is rendered agreeable and docile by civil society and the government is no longer required to enforce its will through coercive means, that an ideological form is said to be hegemonic.

\footnotetext{
${ }^{16}$ Much of the following analysis draws from Cox (1983). Sharp's reading of Gramscian hegemony, as it relates to the role of popular culture in reproducing cultural and political norms, is also useful (2000: 30 31); see also Said (1978); Dittmer (2010).
} 
Gramsci's ideas imply that any analysis of the governing codes that structure society should reach beyond the role of state actors (Sharp, 2000: 31). State-sourced representations of danger require reinforcement from other areas of society in order to gain currency with the population in whose name they are deployed. This is Doty's point when she claims that in order to achieve credibility, even official statements require a broader cultural framework within which they must find resonance (1993: 303). ${ }^{17}$ As Dalby suggests, security "is not only a matter of state action and formal politics but also a matter of civil society where policies and identities are argued, affirmed, and articulated in the routine quotidian practices of culture" (2002: 164).

In their examination of the use of geopolitical logic in US foreign policy, Ó Tuathail and Agnew (1992) tweak the state-centred understanding of constitutive agency somewhat. Their focus on "intellectuals of statecraft" expands the gamut by including academics and experts in its purview: "The notion of 'intellectuals of statecraft' refers to a whole community of state bureaucrats, leaders, foreign-policy experts and advisors throughout the world who comment upon, influence and conduct the activities of statecraft" (193). This wider approach, which admits to the authority and legitimacy of expert knowledge, is adopted by a number of other scholars in the field. For example, Dalby's (1990) assessment of the discursive origins of the second Cold War in the 1970s demonstrates the constitutive influence of expert commentators. In particular, he shows the considerable impact that "security intellectuals" had on US foreign policy and how "security discourses" of strategy, sovietology, realism and geopolitics were used to

\footnotetext{
${ }^{17}$ See also Sharp (2000: xii-xiii).
} 
portray the Soviet Union as a "dangerous and antagonistic Other" (11). ${ }^{18}$ In a similar vein, Klein (1994) examines how the field of Strategic Studies has played a crucial role in framing global dangers and threats in such a way as to valorize western identity and legitimize the deployment of "strategic violence" in its defence. Cohn $(1987,1989)$ explores how US defence intellectuals use gendered linguistic strategies and techniques in order to understand and rationalize concepts of nuclear threat and enmity. Mutimer (2000) examines the role of state officials and scholars in contributing to images of proliferation that serve to structure understandings of threat and identity.

\section{$\underline{\text { Popular Media }}$}

Other scholars and approaches have taken this trend even further, exploring ways in which representations from popular media sources also contribute to the construction of international subjects, objects and threats. Milliken (1999) points explicitly to popular culture as an area deserving of increased attention from discourse scholarship. She sees value in a popular culture approach that explores "the 'everyday' cultural conditions of novels, comic books, television and film and how they render sensible and legitimate particular state actions" (240). ${ }^{19}$ Campbell concurs with this assessment when he acknowledges that even though

\footnotetext{
${ }^{18}$ Dalby's (1990) empirical section focuses on the work of members of the Committee on the Present Danger.

${ }^{19}$ Despite this specific encouragement to explore popular culture, an area that Milliken contends "would largely be a new domain of inquiry for discourse scholarship in International Relations" (1999: 240), the thrust of her article deals with the research methods involved in analyzing official statements and policies. This emphasis implicitly serves to reinforce the pre-existing tendency that already dominates the discipline.
} 
the inscription of boundaries, the articulation of coherence, and the identification of threats to [the nation's] sense of self can be located in and driven by the official discourses of government...they can equally be located in and driven by the cultural discourses of the community, and represented in sites as 'unofficial' as art, film and literature. (2003: 57)

Over the past decade, an increasing number of scholars have conducted research in this growing area of study. Jutta Weldes (2003a), for example, examines the ways in which discourses of popular science fiction and international relations intertwine to create meaning for people. As she suggests, "popular culture helps to create and sustain the conditions for contemporary world politics" (Weldes, 2003b: 6). This edited work provides multiple examples of how identities are negotiated in the science fiction/world politics intertext, and how the genre of science fiction is complicit in structuring social understandings of alterity. Cynthia Weber (2006) provides another recent contribution that explores the relationship between Hollywood films and American identity. More specifically, she examines how films released after $9 / 11$ worked to create a variety of different understandings of morality in the American self.

Sharp's (2000) Condensing the Cold War provides another compelling example of the potential benefits to be found in the analysis of popular culture. Her examination of several decades of Reader's Digest coverage of the Soviet Union demonstrates the complicity of popular culture in the scripting of national identity. For instance, she shows how the Digest employed tropes of disease and perversity to render the Soviet Union a foreign Other that threatened the United States. However, as with the other authors under discussion, Sharp demonstrates that the depiction of threat goes beyond simply defining enmity; she shows how it also plays a crucial role in defining identity. Indeed, it is her 
stated intent to examine how the magazine's "changing representations of the communist threat to America produced a particular image of Americanness for its readers, and how readers were drawn into the story to become complicit subjects of this political identity" (xv).

One particularly promising intervention in this direction emerges from the study of critical geopolitics. Ó Tuathail and Dalby (1998a) attempt to redefine the traditional field of geopolitics such that it can better take account of the insights offered by critical scholarship. Although they recognize the crucial importance of government-sourced representations in structuring peoples' understanding of the world around them, theirs is a self-conscious attempt to broaden the scope of inquiry to include other sources:

critical geopolitics argues that geopolitics is not a singularity but a plurality. It refers to a plural ensemble of representational practices that are diffused throughout societies. While not denying the conventional notion of geopolitics as the practice of statecraft by leaders and their advisors, critical geopolitics complements this with an understanding of geopolitics as a broad social and cultural phenomenon. Geopolitics is thus not a centered but a decentered set of practices with elitist and popular forms and expressions. (Ó Tuathail and Dalby, 1998b: 4)

Following on this assumption, they propose a tripartite understanding of geopolitical reasoning in which representations and practices emerging from "practical" and "formal" spheres are joined by geopolitical depictions that circulate within the "popular" realm. ${ }^{20}$ Work in this area has multiplied in recent years (Dittmer and Dodds, 2008; Dalby, 2010), and includes analysis of an eclectic variety of popular media, including comic books

\footnotetext{
${ }^{20}$ They understand "practical" geopolitics as the realm of government leaders and foreign policy, and "formal" geopolitics to be the realm of academics and think tanks (Ó Tuathail and Dalby, 1998b: 5).
} 
(Dittmer, 2006), magazines (Sharp, 2000), editorial cartoons (Dodds, 2007), tabloid media (Debrix, 2008) and films (Dalby, 2008; Sharp, 1998; Power and Crampton, 2005).

One of the ways to better understand how popular culture plays a role in the construction of identities and threats is introduced by the concept of intertextuality. A increasing number of IR scholars employ this idea to demonstrate how modes of representation that draw on popular media are able to make foreign policy intelligible and reinforce identities and threats (Weldes, 2003a; Der Derian, 1989). Intertextuality refers to the idea that any given text purporting to describe a situation is only made intelligible through its ability to draw upon pre-existing meanings found and defined in a multitude of other sources. As Weldes suggests, individual "texts" do not make sense when read in isolation; they depend upon other texts to create meaning (2003b: 13). Doty refers to this multitude of reinforcing references as "a complex and infinitely expanding web of possible meanings" (1993: 302). According to this approach, language should be understood not as a "transparent" vehicle by which specific words accurately signify specific referents, but as an "opaque" casing that invites interpretive efforts to explore how representations serve to enact the very reality they purport to describe (Shapiro, 1989a: 14). In this sense, popular culture becomes just another forum where meanings are generated and circulated, although it is, by its nature, a forum that engages vast portions of society. It is in this intertextual matrix where Ó Tuathail's notion of geopolitical culture (2006) is developed, refined and perpetuated.

In an example of how this dynamic works, Der Derian (1992) explores the intertextuality found in the relationship between spy novels and the world of espionage 
and national security. In this reading, fictional characters and situations serve to articulate a dangerous world that calls out for a secretive and technological response from duly authorized state representatives:

Through intertextuality we can see how the American popular literature of international intrigue shares and privileges a narrative of the truthsayers of the security state: beyond our borders the world is alien, complex, practically incoherent - an enigma but one which can be unravelled by the expert story-teller. (41)

In a similar vein, Shapiro (1989b) details the relationship between figurations of sports and national security, in what he refers to as the "sport/war intertext." He suggests "the leaves from the sports and war text have been sorted together in human societies for centuries. Since early antiquity, the sporting and warrior dimensions of the social body have been intimately conjoined" (70). As a consequence, "sports discourse is now firmly institutionalized as a primary mode of representation for international conflict policy" (88). From Shapiro's perspective, this intertext creates a naturalized understanding of nations as competitors locked in a contest. In so doing, it situates the public as passive spectators, thereby serving to depoliticize militarized responses to international events. Sharpe's (2000) analysis of representations of the Soviet Union in Reader's Digest, discussed briefly above, proceeds from a similar perspective. In this work, she explicitly draws on the notion of intertextuality to show how repeated representations that emerge from a source as innocuous as Reader's Digest can both reinforce and contribute to the broader understandings of threat and identity that circulate at all levels of US society. As she claims, "although it is a seemingly mundane process, this narrative repetition of 
national belonging and national purpose is central to the reproduction of American identity" (165).

The embrace of intertextuality and the turn towards popular media sources is a welcome recognition that although the statements and representations that issue from sites of official authority and academic expertise are important, they need to be able to find purchase in the popular imagination if they are to play a role in structuring public perceptions. This line of theorizing goes beyond the simple claim that popular culture is an important area of analysis because it can provide a glimpse into the social setting at the time a particular foreign policy or posture was developed. Indeed, Weldes refers to the role of popular culture in

providing a background of meanings that helps to constitute public images of world politics and foreign policy... [It] helps to construct the reality of world politics for elites and the public alike and, to the extent that it reproduces the content and structure of dominant foreign-policy discourses, it helps to produce consent to foreign policy and state action. (2003b: 7)

Thus, this argument advances the notion that representations issued by public officials need to resonate within a broader cultural milieu if they are to provide the basis for political action. Beyond simply confirming the plausibility of representations that issue from sites of traditional authority, however, popular culture is itself increasingly being recognized as a site that generates images of the self, Others and threats.

Another area of popular media where attention is increasingly being devoted to the study of foreign policy and identity is the news media. As Rivenburgh (1997) argues, communication researchers have made sparing use of the concept of collective identity as a way to understand the processes by which the news media constructs the external 
world. Likewise, IR scholars interested in questions of identity and threat have been similarly reluctant to explore the constitutive role of the news media. ${ }^{21}$ Much of the credibility and legitimacy with which state and academic representations are received derives from the authority invested in those sources. Representations emerging from the news media also enjoy a degree of authority, although it emerges from a different, even oppositional, foundation. Impartiality remains an important principle within the news industry and most reporters and editors struggle hard to maintain their independence from government and other sources. The resulting air of objectivity, often bolstered by impressions of common-sense, serves to render the news as 'truth' (Cohen and Young, 1981; Fairclough, 1995). Therefore, despite the constructed nature of the reality it presents, the news media enjoys a high degree of respect within society. This legitimacy helps to imbue media portrayals of threat with a high degree of credibility and social salience.

As with other textual sources, news reports operate to define social boundaries (Chermak, 2002:13; Fairclough, 1995: 17). Therefore, despite the legitimacy with which the news media is revered, and the prevailing view that it functions as a crucial pillar of a democratic society, its main function is to script identities:

The primary political role of television news is thus not to ensure that the 'well-informed citizens' conceived of in democratic theory get their daily diet of facts on which to base their political views and behaviours, but to ensure that they can identify with the dominant political community to which they belong. (Robertson, 2001: 71-72)

${ }^{21}$ Though see Debrix (2001). 
This idea corresponds to Hartley's contention that the news media operates according to what he terms the "consensus principle" (1982: 82). This basic organizing principle suggests that the news media presents content in terms of a self/Other dichotomy in which the audience is referenced as belonging to a normalized self. In terms of international coverage, this suggests that the news media is engaged in constructing a national self in relation to global Others: "Once selected for coverage, nations are not simply described, but often positioned vis-à-vis the home nation in cooperative (friend, ally) oppositional (enemy, threat) or stratified (developing, admired) postures" (Rivenburgh, 1997: 81).

The presence of the self/Other dichotomy in reporting helps to highlight the role played by the news media in constructing threat. Edelman advances this idea with his notion of "problem construction," which he understands as "a complex and subtle occurrence, a facet of concurrent formation of the self and of the social sphere, integrally linked to the endless construction and reconstruction of political causes, role structures, and moral stances" (1988: 17). ${ }^{22}$ It is also a simplified version of several of the arguments put forward by Der Derian (1992) in Antidiplomacy. For example, in a section of this work entitled "Pure Terrorism" Der Derian theorizes an emerging version of terrorism as "an international political crisis in which the violent intimidation and manipulation of a global media audience creates a pervasive state of insecurity and fear" (115). And, in his final chapter, he explores the intersection of media, technology and simulation in preparing and presenting the spectacle of the 1991 Gulf War (174-199).

\footnotetext{
${ }^{22}$ See also Chermak's (2002) discussion on the relationship between perceptions of threat and the media coverage of crime.
} 


\section{Methodology}

This dissertation examines how Canada is represented in US popular media. More specifically, it attempts to uncover the role of popular media sources in making it possible for Americans to understand Canada as a threat to US security. My analysis reveals that the impression of Canadian threat is enabled by broad representational patterns that depict Canada as Other and liminal. The combination of these two intertwining representations enables audiences to appreciate how threatening individuals might reside in Canada and how they might find their way into the United States. These conclusions are based on an analysis of the US popular discourse on Canada. More specifically, using a discursive practices approach (Doty, 1993), I examine how this 'Canada' discourse operates as a system of signification (Milliken, 1999: 229) that positions Canada in relation to America. I explore how Canada serves as an intertextual signifier that conveys a series of mutable meanings to US audiences, across time and across popular media, that contributes to the scripting of American identity. A discursive practices approach allows me to examine how US popular media sources (cinema and news) are able to render the notion of Canadian threat coherent and intelligible.

The empirical analysis of the discourse proceeded in two parts. First, as a preliminary framing exercise, I analyzed textual sources for instances and patterns in which the narrative positions Canada as threatening to US audiences. Second, drawing on these depictions of threat as a frame of reference, I examined the textual strategies that 
made such a positioning possible. This second step revealed the presence of two interrelated representational patterns that combine to render the Canadian threat intelligible: Canada as Other and Canada as liminal.

The first pattern (Canada as Other) depicts Canada in ways that position it in relation to America. My analysis shows how these depictions of otherness enable an understanding of Canada as a country so different from America that it becomes seen as a potentially dangerous place - a place where unsavoury individuals or groups might be able to reside unmolested. These patterns of alterity are expressed through a variety of different tropes. For example, concepts of gender frequently structure representations such that Canada is figured as feminine in opposition to a masculinized America. Similarly, sources regularly employ descriptors of time and progress to script Canada as wild and primitive in contrast to a civilized and modern America. Other tropic patterns turn on such binary concepts as domestic/foreign, active/passive and conservative/liberal.

The depictions themselves are effected through a number of stylistic vehicles. In the case of Hollywood films, the visual and narrative representation of Canadian landscape, residents and social relations serves as a constant implicit comparison. More direct comparisons are invited by contrasting Canadian and American archetypal characters and highlighting differences between the two countries through both visual representations and dialogue. Representations of Canadian otherness in news media come in several forms as well, although they are largely more straight-forward. Explicit comparisons are perhaps the most common, in the case of both print and visual sources. These comparisons are typically used to frame Canadian policies or social values in 
contrast to American policies and values. Implicit comparisons are also frequently deployed in the form of simple predicates that describe Canada in negative ways to a primed and complicit American audience.

The second pattern frames Canada as liminal. This is an ambiguous representation of the country that scripts it as simultaneously part of and separate from the America experience. When combined with an understanding of Canada as a potentially dangerous place, this representational pattern effectively renders the country a conduit through which threats are able to enter the United States. The most prominent depiction of liminality emerges from representations of the Canada-United States border. Through a variety of techniques, both the films and news sources under examination frame the border in such a way that it communicates a sense of colocation and intermingling. Other prominent themes of liminality are found in depictions of Canada as an American frontier and representations that script the two countries as though they are part of the same cultural unit.

These depictions themselves are realized in a variety of ways. In terms of Hollywood productions, liminality is often communicated through stylistic features, such as introductory voiceovers, maps, titles and editing cuts. Liminal impressions are also advanced through filmic themes which feature the border prominently, both as a setting and as a plot device. Genre becomes an important vehicle for communicating liminality as well, considering the transplanting of the western genre to Canada serves to bring the American myth of the frontier to a Canadian setting. The news media's emphasis on liminality is revealed in several ways. One of the most prominent methods is the adoption 
of a narrative style that effectively 'tells stories' about the 'longest undefended border in the world' and the intertwined lives of Canadians and Americans who reside in shared communities along the boundary. Another prominent method of communicating liminality is to link Canada and the United States as though they are part of the same cultural unit. This is often accomplished through personification, in which the countries are rendered 'family,' 'friends' or 'neighbours,' or through the use of similes that reduce Canada to a subset of the United States.

To be clear, my analysis certainly revealed instances in which specific sources did not frame Canada in terms of a threat. Indeed, as one might well imagine, there were many examples in which Canada was framed in positive terms and lauded as a staunch ally of the United States. Moreover, even when depictions of threat were in evidence, they did not always rely on an intertwining of prior representations of otherness and liminality. Indeed, in some instances, news media representations of threat relied on depictions of Canadian otherness that were so extreme they precluded even a hint of liminality. All of this stands to reason. In no way do I conceive of US popular media depicting Canada through just a single framework. Indeed, the discourse on Canada clearly produces a multitude of various 'Canadas.' However, the existence of these alternative depictions in no way detracts from my findings. In the context of a research question that wonders how it is possible that Canada becomes scripted as a threat, my analysis looked for broad representational patterns that enable that image. As the empirical chapters will indicate, these patterns emerged from my research with striking consistency. 
The patterns of otherness and liminality explored in this dissertation reappear across both case studies. Considering these two empirical data sets are distinct in terms of both type of media source and time period, this reappearance of themes and patterns might not be expected. However, part of the intention of selecting dissimilar cases was to explore how representations from each might interact with the other. In short, the selection was based, at least in part, on a desire to see the intertextuality of these representational patterns in action. As discussed above, this interweaving of texts is one of the primary ways in which representations are able to structure both public perceptions and government action.

\section{Hollywood Films}

In her analysis of filmic representations of US borders, Brégent-Heald suggests that "the iconography of borders in mainstream film is a provocative way of examining national identity because it is precisely on the borderline where national identities are most strongly upheld, but also most strongly challenged" (2004: 20). Chapters 3 and 4 use this contention as a starting point in their exploration of representations of Canada and the Canadian border in Hollywood films. Unlike news sources, films make no pretence to communicate factual information; they narrate fictional or fictionalized stories. In this sense, this area of study was not selected to provide evidence of Canada's depiction as an explicit threat to US security (although some of the films certainly communicate this impression). Instead, what I sought to uncover was evidence of representational patterns that might communicate trends in American perceptions of 
Canada. More specifically I was looking for patterns of otherness and liminality and what such patterns might imply about the place that Canada occupies in the American imaginary. Following Brégent-Heald's insight, these chapters look for evidence of the filmic scripting of both Canadian and American identities.

The selection of films for this case study was narrowed by three factors. First, I limited my selection by periodization, choosing to focus on productions from a period spanning the late 1920s until the early 1960s, the so-called classical era of Hollywood. I choose this period for both practical and analytical reasons. From a practical perspective, the focus on the classical era allowed me to limit the otherwise unworkable number of films I would have to screen in order to get a representative sample. Moreover, the classical era was a time when Canada was in vogue as a filmic setting. This period saw the production of films in which Canada was not merely incidental to the story, but was held to be integral to the plot. This era embraced the 'northern' genre of film. ${ }^{23}$ These films were essentially westerns in most aspects, except that their traditional setting had been moved north across the Canadian border. This sub-genre was the typical vehicle for Hollywood's presentation of Canada until the $1960 \mathrm{~s}^{24}$ From an analytical perspective, I wanted to put 'distance' between my two case studies. In order to test the degree to which representations of Canada operate as intertextual linkages, I wanted my empirical work to represent different periods of history. In essence, the periodization was part of a dual

\footnotetext{
${ }^{23}$ To be clear, 'northerns' were also a common feature of the silent era as well.

${ }^{24}$ Although outside the scope of this research, it would be interesting to explore representations of Canada in more contemporary films. For instance, there is a group of 1990s films that adopts an ironic disposition to notions of Canadian threat and uses the idea to critique the role that threat and fear play in American society (Wag the Dog, 1998; Canadian Bacon, 1995; South Park: Bigger, Longer \& Uncut, 1999).
} 
effort to allow me to reach conclusions about both filmic representations from a particular era and the transportability of such patterns across time periods.

Berton numbers the total of Hollywood films made about Canada during this period at 136 (1975: 263-269); I screened 56 productions for this dissertation. I did not limit the selection according to genre or type. As a consequence, the range of productions used is broad, spanning award-winning feature films, like Johnny Belinda (1948), Bwesterns with singing cowboy stars like Gene Autry and Roy Rogers and obscure and melodramatic serials with names like Canadian Mounties versus Atomic Invaders (1953) and Perils of the Wilderness (1956). It was a self-conscious decision to ignore whatever line film critics might draw between these varieties. Although there are certainly clear differences in quality between them, they all connected with a wider American audience and they are largely united in terms of the consistency with which they depict Canada.

Second, as my project sets out to explore how Canada is represented, I looked only at films that were set in Canada. Although this may seem like a rather obvious limitation, it is worth emphasizing because in many cases it was not as simple a determination as might be expected. Films like River of No Return (1954) and Klondike Fury (1942), for example, although possessing all the trappings that normally attend the filmic version of Canada, did not make their setting explicit. Indeed, one of the points Berton makes is that Hollywood films often refused to label Canada explicitly: "Canada was never Hollywood's favourite word. In fact the moviemakers went out of their way not to use it. In scores of cases, the only way you knew a movie was about Canada was when a Mountie or a French-Canadian trapper hove into view" (1975: 19; emphasis in 
original). In a move saturated with ambiguity, filmmakers would instead deploy any number of euphemisms in their titles to fix their settings in Canada without actually having to declare it explicitly. Common titular references included north, northwest, wilderness, Mounties and Yukon.

Third, I only screened films produced in the United States. My intention was to limit the analysis to those films that were intentionally geared for US audiences. As a result, I excluded films produced outside of the United States, even those like the British Oscar-winning film $49^{\text {th }}$ Parallel (1941), which was both aimed specifically at a US audience and well-received in the United States. ${ }^{25}$

\section{$\underline{\text { News Media }}$}

Chapters 5 and 6 explore representations of Canada found in US news media during the War on Terror. Two specific issues are captured by the selection of this case study, both of which are intended to help to make the abstract analysis begun in the chapters on Hollywood films more concrete. First, unlike films, the news media explicitly purports to provide fact-based reporting, analysis and commentary. Second, unlike the four-decade period examined in the chapters on Hollywood films, this case focuses on a narrow period of time when commentators and government officials had explicitly securitized (Buzan et al., 1998) an issue as an existential threat. With these two elements

\footnotetext{
${ }^{25}$ It should be noted that I have included two early US productions, The Silent Enemy (1930) and The Viking (1936), despite Morris' contention that "in spirit, style, and feeling both are more Canadian" than many of the "quota quickies" that were produced in Canada in order to gain access to the British market (1992: 195).
} 
in mind, this case is intended to provide an opportunity to examine representations of Canada in the context of a more overt appreciation of American insecurity.

This research examines news stories from the period between January 1, 1995 and January 1,2009 . The beginning of this period predates the formal declaration of the War on Terror by more than six years. The intention in stretching the analysis back to this point was to both enable an analysis of representations that emerged at the time of Ahmed Ressam's arrest in 1999 and chart the inception of the Canadian threat.

In order to achieve a broad sampling of major news sources, I included both print and visual sources. In terms of print sources, I included both major newspapers and news magazines. In both cases, my primary criterion for selecting sources was circulation. The top newspapers in terms of overall circulation in the United States are Wall Street Journal, USA Today, New York Times, Los Angeles Times and Washington Post (Audit Bureau of Circulations, 2010). ${ }^{26}$ The most popular US weekly news magazines are Time, Newsweek and US News and World Report (Audit Bureau of Circulations, 2009). ${ }^{27}$ In terms of television sources, I analyzed all newscasts from the three main television networks ( $\mathrm{ABC}, \mathrm{CBS}$ and $\mathrm{NBC}$ ), as well as complete coverage from the main cable news networks (CNN, Fox News and MSNBC).

\footnotetext{
${ }^{26}$ For the six-month period ending March 31, 2009, the Audit Bureau of Circulations (2010) lists the average weekday circulation numbers for these papers as follows: Wall Street Journal - 2,092,523; USA Today - 1,826,622; New York Times - 951,063; Los Angeles Times - 616,606; Washington Post - 578,482. ${ }^{27}$ The Audit Bureau of Circulations (2009) includes within its 'News-Weeklies' category such titles as People, Sports Illustrated and TV Guide. I have excluded these magazines as they focus on narrower topics not necessarily associated with public affairs. The average circulation numbers for the six-month period ending December 31, 2009 for the three top news magazines focussing explicitly on public affairs were as follows: Time-3,329,429; Newsweek-1,972,219; US News and World Report-1,188,933.
} 
The first step in narrowing my research was to conduct a database search for each news source, within the chosen date range, using the keywords 'Canada' and 'terrorism. ${ }^{28}$ Second, a visual scan of each of the news 'pieces' that resulted from this search further reduced the sample size by excluding a large number of extraneous items. The goal of this exercise was not a quantitative attempt to distinguish comparative trends between various news outlets or chart the evolution of definitive trends that emerged over time (although both of these would be valuable exercises in themselves). Rather, the goal was to establish a broad-based, yet manageable, sample of news coverage from across the range of the most popular print and television news sources. Third, as the earlier section indicates, the resulting pieces were then categorized and analyzed on the basis of their depiction of Canada. In particular, pieces were analyzed in terms of both their specification of threat and the patterned representations and narratives that enabled that specification.

\section{Structure of the Dissertation}

Chapter 2 provides an overview of the main areas of scholarship upon which my argument is based. It specifies how my ideas both draw from the existing literature and contribute to its further development. In the first section of this chapter, I examine the

\footnotetext{
${ }^{28}$ Most of the sources were searched using Lexis/Nexis. Two of the sources, however, were not indexed on Lexis/Nexis and had to be searched through other means. Therefore, Wall Street Journal was searched using the ProQuest database and Time was searched using the magazine's online searchable database. Although the difference in search engines might theoretically cause irregularities, the very simple nature of the search terms should mitigate against that.
} 
binary concept of self/Other and how it has been used by critical IR scholars to understand the construction of international identities. In the second section, I explore the concept that Campbell refers to as the "discourse of danger" (1992: passim). More precisely, I turn to the work of critical IR scholars who explicate the sociological processes whereby states are better able to secure their national identities by specifying the presence of external threat. I then examine Norton's (1988) understanding of the concept of liminality. I indicate how this ambiguous notion of simultaneous belonging and exclusion can be used to lend nuance to our understanding of how international identities constitute themselves. The chapter concludes with a brief examination of relevant literature in the field of Canadian foreign policy in an attempt to better situate this work in the context of the study of Canadian-American relations.

Chapters 3 and 4 examine the ways in which Canada was represented by Hollywood films during the Classical period of cinema. In chapter 3, I explore the variety of othering patterns that films deployed in order to draw distinctions between Canada and the United States. The chapter focuses on three broad representational patterns: Canada as foreign, Canada as wilderness and Canada as passive. In each case, cinematic depictions scripted a version of Canada that helped to normalize American identity. In this sense, representations of Canadian difference played a role in reinforcing the content and contours of the American self. However, I argue that depictions of Canadian alterity did more than play a constitutive role. This chapter also explores how filmic representations of otherness made it possible for Americans to understand Canada as a potentially dangerous space. By scripting Canada as a foreign and wild place, and 
depicting Canadians as passive, Hollywood films made it reasonable for US audiences to understand Canada as a place where danger might lurk unchecked.

In chapter 4, I explore Hollywood's use of liminal representations to situate Canada in relation to the United States. I begin by emphasizing two recurring representational themes that serve to situate Canada within a broad understanding of the American experience. First, the chapter examines the tendency within Hollywood films set in Canada to emphasize the Canada-United States border and effectively co-locate the two countries. Second, the chapter demonstrates how Hollywood films understood Canada as frontier territory and intertwined representations of the country within the wider frontier narrative that dominates American consciousness. Having identified these two broad themes of Canadian liminality, I then provide three examples in which this impression combined with Canada's status as a dangerous space to render the country a threat to US security. More specifically, the chapter examines how films depicted Canada as a lawless anarchy, a criminal haven and a vulnerable ally. In each case, I show how this understanding of Canada implicitly defined the country as a potential (though certainly unintentional) source of threat to US security.

In these two chapters, I explore how Hollywood representations of Canadian otherness and liminality combined to render a threatening image of Canada. For the most part, however, this image was constituted in the abstract. Indeed, none of the films under review explicitly framed Canada as an enemy that intentionally threatened US security. Nonetheless, the way in which these films portrayed Canada made it possible for audiences to understand how threat could issue from the country. In this sense, 
Hollywood productions both drew from and contributed to the layers of intertextual meanings that make it possible for Americans to understand Canada as a place that might harbour danger. They reinforce this impression on the version of Canada that exists within the American imaginary. Chapters 5 and 6 expand on this idea by exploring how these same intertextual representational patterns function in a less abstract context. More specifically, they examine how US news media portrayals of Canada during the War on Terror intertwined depictions of Canadian otherness and liminality in such a way that the country was framed as a threat to the United States.

In chapter 5 , I start by examining two broad othering patterns by which US news sources scripted Canada: social values and gender. In the first pattern, Canada was portrayed as liberal; in the second pattern, Canada was portrayed as feminine. These representations functioned not only to define Canada, but also to reinforce American identity as conservative and masculine, two characteristics understood to be crucial in the struggle against terrorism. In addition to contributing to the definition of the American self, however, the othering of Canada also helped to introduce the threat of terror to North America. By scripting Canada as liberal and feminine, news reports made it possible for US audiences to understand the threat of terrorism in a more direct and immediate way. In effect, such depictions defined Canada as a dangerous space, a North American haven for terrorists seeking a place to set up operations.

Chapter 6 examines how the news media used representations of Canadian liminality to define Canada as a threat to US security during the War on Terror. It identifies four specific patterns in which depictions of Canadian liminality effectively 
transformed the country's latent potential for danger (enabled by the depictions of otherness discussed in chapter 5) into an existential threat to the United States. In the first section, I explore how impressions of colocation or shared space were used to communicate threat. In the second section, I identify how the news media transformed the trope of "the world's longest undefended border" from a marker of amity and security into one of danger and insecurity. The third section examines how the news media redefined the Canada-United States border from a place where US power and authority regulates movement to an empty space that facilitates illicit entry. The fourth section explores how the news media was able to convey a Canadian threat by intertwining impressions of Canada and the United State within a shared sense of identity. In each of these four cases, depictions of liminality were able to convey a sense of threat because they could draw upon the pre-scripted and intertextual understanding that Canada is a dangerous space, a place where terrorists might lurk. In this fashion, depictions of liminality were used to render Canada a proxy to make the threat of terror more real and more immediate to Americans.

Finally, chapter 7 briefly retraces the arguments made in the dissertation before turning to an examination of some of the implications that issue from my research. In particular, it expands on my reformulation of the concept of liminality to include a spatial component. The chapter also examines the implications this research poses for IR scholarship, both in terms of IR theory as well as the study of Canadian-American relations. It then comments on the questions that arise from my dissertation in terms of 
the practice of Canadian-American relations. The chapter closes with a brief look at some areas of future research that emerge from my dissertation. 


\section{Chapter 2 Self, Other and Liminar}

\section{Introduction}

This chapter identifies and explores the main theoretical impulses that guide this dissertation. In a general sense, it examines the accumulating body of work being produced by critical IR scholars who treat questions of national identity and threat as intimately connected. ${ }^{29}$ More specifically, it examines the interplay of three closely related aspects of national identity: the self/Other dichotomy, the 'discourse of danger' and liminality. The chapter also explores the field of Canadian foreign policy in order to chart the emerging critical literature in that area and better situate my research in the context of Canadian-American relations. The discussion that follows is divided into four sections, each corresponding to one of these aspects. It should be noted, however, that each section is directly concerned with the content and implications of representational practices deployed on behalf of national identities. Consequently, they all rely and build upon the previous chapter's discussion on the importance of discourse and representation in political life.

\footnotetext{
${ }^{29}$ In one sense, a focus on identity marks my project as part of a wider disciplinary 'return' to questions of identity and culture (Lapid and Kratochwil, 1995). Much of this shift has been powered by the increasing popularity of constructivist IR theory and the work of prominent scholars, such as Wendt $(1992,1999)$, Katzenstein (1996) and Adler (1997). In another sense, however, my emphasis on discourse and representations of threat serves to align my project with a narrower group of academics, comprised largely, though not exclusively, of poststructuralist and critical security scholars. Exemplary work from this group of scholars includes Der Derian and Shapiro (1989); Dalby (1990); Campbell (1992); Krause and Williams (1997); Weldes, et al. (1999a).
} 
In the first section, I trace briefly the development of the self/Other dichotomy as it has been understood among poststructuralists in the discipline of IR. In so doing, I pay particular attention to how depictions of the Other are deployed as foils against which national identities are defined. I also note the tendency within the literature to ignore the potential for other actors to play an important role within the context of the self/Other dynamic. In the second section, I explore the concept David Campbell (1992) refers to as the "discourse of danger." This phrase refers to the collection of representations that a state will deploy to depict the world outside its borders as dangerous and, in doing so, help to rigidify the national identity and borders of that state. ${ }^{30}$ In the discussion, I show how this process can best be understood as the culmination of three interrelated processes. The third section tackles the notion of liminality. Developed by Norton (1988), this under-theorized concept refers to those entities that exist on the borders, "betwixt and between" established orders. From their position on the margins, liminars are simultaneously representative of both self and Other. This ambiguity confers upon them a crucial constitutive function in processes of identity formation. In this section, I analyze how Norton and others understand this function and demonstrate how it can be utilized to further the comprehension of questions of identity in global politics. In the final section, I review the literature on the study of Canadian foreign policy and pay particular attention to the development of critical work in this field.

\footnotetext{
${ }^{30}$ For other early works that proceed from a similar basis, see Walker (1993); Shapiro (1988); Der Derian and Shapiro (1989); Dalby (1990).
} 


\section{Self and Other}

In a 1988 exchange that has since become almost de rigueur in discussions of both identity politics and US foreign policy at the close of the Cold War, a Soviet diplomat is reported to have told a US audience, "We are going to do something terrible to you - we are going to deprive you of an enemy" (cited in Nathanson, 1988). This statement's powerful phrasing makes it an apposite entry into the discussion of the role of the self and Other in questions of security and identity. This peripheral area of study has benefited from the "return of culture and identity" that has marked IR scholarship over the past two decades (Lapid and Kratochwil, 1995). Initially the preserve of "dissident" scholars who toiled on the margins of the discipline (Ashley and Walker, 1990), the concept has since managed to attract a limited measure of attention from mainstream audiences. $^{31}$ However, before exploring some of the important works that have contributed to this area of scholarship, this section first traces the set of general theoretical assumptions upon which my understanding of the self/Other dynamic is based.

The self needs to apprehend difference in order to distinguish itself as a discrete entity and secure its own existence. This process of differentiation is a negative one: "Definition begins in negations, in the designation of what a thing is not" (Norton, 1988: 3). Whether the marker of difference is skin colour, gender, language or one of any number of other characteristics, its inevitable presence in other actors serves to define the

\footnotetext{
${ }^{31}$ Examples of this work that have reached a somewhat broader audience include Campbell (1992) and Weldes et al. (1999a). For a useful discussion on the discipline's reception and interaction with poststructural work on identity and threat, see the epilogue from the 1998 edition of Writing Security (Campbell, 1998).
} 
self in its negation. And, as Connolly suggests, "these differences are essential to [the self's] being. If they did not coexist as differences, it would not exist in its distinctiveness and solidity" (2002: 64). To simply exist, however, is not enough; an identity also needs to conceive of its existence as meaningful and significant (Aho, 1994: 23-25). Unfortunately, even the mere presence of an "alternate mode of being" throws into doubt the purity and truth with which the self is scripted (Campbell, 1998: 3). When faced with the sense of doubt created by the very presence of difference, and its capacity to undermine the truth of the self's identity, the self seeks to secure itself. Its typical response is to shift its understanding of the encounter; difference is increasingly apprehended as something inherently foreign or evil. The presence of this innate foreignness or evil serves to reassure the goodness of the self. In effect, the purity of the self is strengthened in relation to an increasingly foreign Other. As a consequence, identities increasingly congeal into "fixed forms, thought and lived as if their structure expressed the true order of things" (Connolly, 2002: 64). Thus, in the course of the self's attempt to secure its identity, the othering process transforms an encounter with alterity from one of tentative uncertainty to one of enmity and ontological exploitation.

It is important to note that although difference is a crucial requirement for the independent existence of the self, otherness is not. In other words, it is possible for the self to define itself in relation to the differences recognized in other entities without recourse to demonizing those entities. However, as Connolly phrases it, otherness is a "temptation" that the self finds difficult to resist: "the definition of difference is a requirement built into the logic of identity, and the construction of otherness is a 
temptation that readily insinuates itself into that logic" (2002: 9). Therefore, although the process of othering is not a given in social relations, its effectiveness in securing the self's identity makes it a ubiquitous feature nonetheless. As Shapiro suggests, "antagonistic Others serve as objects to perpetuate the identity of those who locate them as oppositional" (1997: 44).

This contingent understanding of identity serves to question the tendency within IR to understand relations between states as premised on objective and readily perceivable facts. Indeed, an appreciation for the contingency of identity suggests that the specification of threat and enmity might be better understood as consequences of representational practices aimed at securing the self rather than the result of empirical analyses of objective material conditions.

Two early works by scholars of literary criticism stand out as having particularly lasting impact on the body of IR scholarship that explores questions of representation and the self/Other dichotomy. In his seminal book, Orientalism, Said (1978) details the process by which "the Orient" achieved a mythic position in the minds of Europeans. His analysis explores how official, academic and popular accounts of the Orient intertwine to produce an understanding of the region that is based on idealized and constructed notions. These notions script the Orient as a mysterious place that embodies a series of negative qualities, including femininity, savagery and irrationality. Following on Foucault's understanding of the intrinsic link between knowledge and power, Said contends that the ability to make claims about the intrinsic nature of the Orient issue, in part, from the reality of European colonialism. Of particular importance in this regard, colonialism was 
not just a matter of administrative and military occupation; it was also attended by scientific experts who were in a position to make definitive pronouncements on their object of inquiry. It was these expert pronouncements that helped lend European representations of the Orient a degree of believability and legitimacy. However, it is crucial to note that even though the phenomenon of Orientalism has had enormous consequences for people who live in the region, it is a process that is ultimately aimed not at an Oriental audience, but at a European one. The same process of negative scripting that positions the Orient as feminine, savage and irrational also serves to construct a version of Europe that embodies the opposite traits, a Europe that is masculine, civilized and rational. It is this development that reveals the othering process to be more concerned with the self than the Other. And this hierarchical dynamic that positions Europe as superior to the Orient continues to play a crucial role in structuring European relations with the peoples that make up that region.

The other significant work to emerge from the field of literary criticism is Todorov's The Conquest of America (1984). This volume examines the representations and understandings of the Other that emerged when Spanish explorers, clergy and soldiers 'discovered' the aboriginal inhabitants of Mexico and the Caribbean. Todorov shows that during the course of the Spanish discovery and conquest of the New World, the encounter with the aboriginal peoples was not about an attempt to understand a new and different people, as much as it was about settling the norms of European identity that were disturbed by the encounter itself. Like Said's insight concerning Orientalism, Todorov demonstrates that the Spaniards' written accounts of their interaction with local 
inhabitants reveal more about the former than the latter. So, although these accounts provided explicit descriptions of the locals, their implicit effect was to secure and define the identity of the authors. As Dalby (1990) and Neumann (1999) make clear, one of Todorov's most important contributions is his suggestion that the Other is perceived or defined along three axes: the axiological axis, which assigns a value judgment to the Other; the praxeological axis, which establishes the degree to which the self identifies with the Other; and the epistemic axis, along which the self apprehends its level of knowledge of the Other. This understanding has helped encourage a multifaceted approach to understanding encounters with alterity, one that is prepared to explore implications that stretch into varied aspects of the self's identity. It is important to note that this historical work also suggests that these encounters that constituted the discovery of the New World had lasting implications for European relations with other peoples.

Since the late 1980s, a growing body of work has emerged that frames the self/Other question as a focus of study explicitly within the discipline of IR. Of particular interest for this thesis, a number of authors demonstrate how mutually constitutive representations of the self and Other play a crucial role in structuring US foreign relations. In one of the most important works in this field, Campbell (1992) blends aspects of political theory into his account of identity politics in order to show how US Cold War foreign policy scripted the Soviet Union as Other. His most useful contribution is the explication of the "discourse of danger," the series of representations that render the 'outside' dangerous and necessitate state action to secure the 'inside.' He draws a useful distinction between two closely related processes: foreign policy, the normal and 
quotidian distinctions that people use to make their own daily lives understandable by rendering other people, things and events as strange or unknowable; and Foreign Policy, the representations deployed in official statements and policies of government officials that designate international dangers and threats. Importantly, he suggests that representations of Foreign Policy are dependent upon the prior matrix of foreign policy. In other words, the tendency for the state to define other international actors and phenomena as threats owes a debt of gratitude to people's penchant to react to difference with suspicion. In this sense, Foreign Policy does not constitute the self's identity, it reproduces it. From this line of reasoning, it follows that the mentality that structured US foreign policy during the Cold War was not an aspect of the Cold War itself, but rather an integral component of the ongoing dynamic that shapes American identity. ${ }^{32}$

In another of the important earlier works in this field, Dalby (1990) foreshadows Campbell by exploring how the hegemonic ascendancy of the field of Security Studies in the 1970s and 1980s scripted the Soviet Union as a threatening Other and helped propel the United States and Soviet Union into the "second Cold War." He also demonstrates the degree to which this process effectively silenced internal dissent and entrenched a firmer definition of American identity. A number of other early works provide similar contributions. For example, Shapiro (1988) explores representations of the Guatemalan Other that emerged from a US perspective fixated on Cold War geopolitics. Nathanson (1988) examines how specific representations of the Soviet Union in 1946 helped to

\footnotetext{
${ }^{32}$ Campbell's work on the relationship between US foreign policy and American identity extends beyond the Cold War. For example, other works explore this dynamic with respect to post-Cold War relations with Japan (1994) and the launching of the War on Terror (2001).
} 
establish a Cold War script that framed that country as a threatening and danger Other and prioritized a particular version of the American self. Ó Tuathail and Agnew (1992) explore similar themes relating to the American self and the Soviet Other in their analysis of US geopolitical reasoning. A variety of more recent works have explored this same dynamic in the context of the post-9/11 era. For example, Dittmer (2005) turns to popular culture in his examination of the role of comic book hero Captain America in scripting American identity in the wake of 9/11. Dalby (2003) explores how the scripting of American innocence served to obfuscate an imperial response to the terrorist attacks. Jackson (2005) examines how the US War on Terror was warranted by a self/Other framework that scripted terrorists as "evil," "non-human" and "alien" in contrast to virtuous and heroic Americans.

There are several important works that explore themes of representation and the self/Other dynamic outside the ambit of US foreign policy. Neumann's Uses of the Other (1999) examines the role of "the East" in processes of European identity formation. In an important contribution, he shows how the East becomes a variable signifier, like Said's Orient, that can be deployed in any number of situations to better define European identity. However, unlike Said's Orient, and despite its obviously geographic connotations, Neumann claims the East is not spatially established: "The East' then, is not necessarily spatially east; it may also be a social signifier cut loose from its geographical moorings" (206). Neumann also attempts to show how the East's constitutive value derives not primarily from scholarly representations, but from much wider practices that implicate society as a whole. Other important studies that reach 
beyond a specific focus on US foreign policy explore north-south relations and the manner in which imperial powers portray both their colonial subjects and themselves (Doty, 1996), and the range of representational strategies used to valorize and unite NATO during the Cold War (Klein, 1990).

As the above discussion contends, the past two decades of IR scholarship have been witness to the emergence of an increasingly influential strand of critical theorizing on questions of identity. In particular, an enhanced appreciation for the constitutive implications of representational practices that draw on widely-held and powerful understandings of corporate selves and Others has yielded increasingly sophisticated analyses of international relations and foreign policy. It is, in part, this appreciation for the social basis of identity that sets such work apart from orthodox IR scholarship.

However, a focus on the importance of the self/Other dichotomy in the creation of identities does not come without risks. Of particular concern, post-positivist scholars must take pains to avoid employing the same rigid, binary framework that they set out to expose in the first place. The opportunistic use of dichotomies by politicians, media personalities and other societal actors may be an obvious and ubiquitous feature in the landscape of politics (for example, us/them, good/evil, civilized/barbaric), but there is clearly much more that goes into creating and sustaining national identities. Indeed, if scholars are to take seriously the post-positivist insight that identities are relational phenomena that form as a result of immersion in a social setting, then there needs to be an acknowledgement that identities beyond the Other play a role in constituting the self. However, many critical IR theorists have been reluctant to make this acknowledgement 
and, as a consequence, the discipline continues to overestimate the importance of the threatening Other and ignore or marginalize the role of other identities. In order to achieve a wider perspective and avoid charges of reification, IR scholars must be prepared to move beyond the obvious ontological importance of those relations framed around the enmity of the Other and begin exploring the subtler implications of other relations, such as those represented in terms of amity, indifference or liminality. This thesis undertakes this challenge, demonstrating how the liminar plays an important role in complementing the power of the Other to act as a foil against which the self can script its identity.

\section{Discourse of Danger}

As the above section details, an identity requires difference in order to secure its independent existence. But, as Connolly cautions, the temptation to map otherness onto difference is great (2002: 9). Such a move is an attempt to remove ambiguity and contingency and replace them with certainty and predictability. It is an effort to reinforce those boundaries of identity that appear permeable. In the face of an alternate mode of existence, the shift from difference to otherness is the consequence of the self's need for reassurance that its own independent existence is worthy. This shift, therefore, is part of the self's attempt to secure its otherwise insecure identity.

The drift to otherness - that is, the re-scripting of another identity's ambiguity and difference into fundamental foreignness - suffuses that identity with a sense of danger or 
threat. Indeed, this is the primary function of otherness - rendering an ambiguous entity evil or foreign makes it threatening to the self. It is in this sense that specifying otherness can be understood as defining or locating threat. And it is the apprehension of this threat that prompts and enables the self to define itself with greater intensity: "to have a threat requires enforcing a closure upon the community that is threatened. A notion of what 'we' are is intrinsic to an understanding of what 'we' fear" (Campbell, 1992: 85; see also Weldes, et al., 1999b). Paradoxically, therefore, it is the identification of danger or threat that works to make the self secure. From this perspective, threat plays a crucial role in constituting national identities (Campbell, 1992, 1993, 1994; Weldes, 1999a; Weldes et al., 1999b; Walker, 1993; Der Derian, 1992). Specifying other international actors and global phenomena as dangerous helps the nation to define itself and mark the boundaries of its identity. Campbell captures this dynamic with admirable precision: "the constant articulation of danger through foreign policy is thus not a threat to a state's identity or existence; it is its condition of possibility" (1992: 12). This is the phenomenon that he refers to as the "discourse of danger."

The discourse of danger works to consolidate national identities through the interaction of three closely related processes. In the first process, the representation of a common threat sets into motion a trend wherein the group achieves a greater degree of coherence. From Campbell's perspective, identity is a relational phenomenon for which there is no pre-discursive basis or essence. As such, the identity of the state is always tenuous, and is in constant need of ontological reinforcement (Campbell, 1998: 9-13). Indeed, as Weber phrases it, states are merely "the ontological effects of practices that are 
performatively enacted" (1998: 78). ${ }^{33}$ Thus, in a ceaseless attempt to lend solidity to what is, ultimately, a purely relational phenomenon, the state needs to constitute itself through a constant repetition of statements and practices that define its nature. This performative enactment is accomplished, in no small part, through the ceaseless designation of danger.

At a political level, as H. L. Mencken suggested in 1920, this specification of danger is the very essence of politics: "The whole aim of practical politics is to keep the populace alarmed (and hence, clamorous to be led to safety) by menacing it with an endless series of hobgoblins, most of them imaginary" (quoted in Blum, 2000: 20). Within this process, the diversity of perspectives and opinions within the collective entity are silenced as people turn to the nation for belonging and the state for protection. The 'truth' of a group's identity claim is best evidenced by the unanimous voicing of that claim. The presence of dissent weakens the plausibility of the claim and threatens the integrity and shared sense of belonging upon which the group is premised:

Because our own identities are so entangled with those of the nation-state, the tendency, especially in a time of crisis, is for our spines to stiffen collectively and our voices to speak as one. When we perceive a threat to our honor, our security, or our way of life, most of us prefer not to hear discordance, and all too many among us construe dissent as disloyalty. (Elshtain, 1987: 120)

In the face of an explicit, external threat to the group, dissent takes on an increasingly menacing appearance. It not only detracts from the truth of the self's identity claim, it has the potential of lending support to that of the Other (Beck, 1997). Therefore, during times of crisis, the polity demands universal consensus on core identity claims and effectively forecloses debate on domestic and foreign policy options (Nathanson, 1988).

${ }^{33}$ See also Weber (1995). 
However, this first process slips easily into the second; in the presence of threat, there is a tendency to identify internal otherness with the external source of danger (Connolly, 2002: 40). In this sense, the discourse of danger does not focus solely on external targets as a source of threat. Indeed, by linking internal difference and dissent with an external threat, the discourse of danger is able to infect the interior of the polity with the danger that would otherwise remain part of the external realm. This fear of the internal enemy is an enduring feature of collective identity. Davies et al. makes this point with respect to medieval Europe's fascination with the "wild man": "he could potentially exist within the bounds of Europe itself, within the individual himself as a lurking force, always threatening to overcome and destroy him" (1993: 35). The actual reality of the wild man is irrelevant. Indeed, as with other manifestations of internal enmity throughout history, it is the potentiality of the wild man that makes him so useful as a societal coagulant.

Davis makes a related point with respect to the enduring tradition of identifying subversion in the United States:

there has been a continuity in the imagery of subversion that bears no necessary relation to any given enemy...we shall frequently encounter Trojan horses, entering wedges, blueprints for the destruction of liberty, and lists of names of supposedly loyal leaders who are exposed as the tools of a hostile power. This interchangeability of images and metaphors suggests that the phenomenon of countersubversion might be studied as a special language or cultural form, apart from any preconceptions of its truth or falsity. (1971: xv; emphasis added)

Davis' thesis suggests that specific instances in which charges of subversion have been laid are irrelevant; rather, what is important is the regularity with which the search for subversion is undertaken. This behaviour, what Davis labels the "phenomenon of 
countersubversion," can be understood as the act of articulating the always latent link between external otherness and internal difference. It is, in essence, an attempt to effect societal closure by invoking a domestic shadow of the foreign enemy. And it is, for Campbell, the very foundation upon which state identity is based: "State identity can be understood as the outcome of exclusionary practices in which resistant elements to a secure identity on the 'inside' are linked through a discourse of danger (such as Foreign Policy) with threats identified and located on the 'outside"' (1992: 239).

Associating manifestations of difference within the polity with the threat of the Other - in effect, exploiting the threat of the wild man - enables society to secure obedience to its identity norms. Those groups advancing identity claims at variance with the orthodoxy are labelled traitorous or subversive (Hofstadter, 1967; Davis, 1971; Beck, 1997: 77). As a result, alternative perspectives are effaced and the identity tends towards homogenization. According to Rieber and Kelly, this

is the logic of declaring public enemies. By particularizing certain individuals as a threat to the established social order, ultimately to civilization, a society gains license to perpetuate that order without further reflection on it. Debate ceases, the hour for discussion is past, and action begins. (1991: 19)

One of the most compelling examples of this phenomenon at work in the United States occurred during the Cold War. In the face of the threat represented by the Soviet Other, individuals and groups that harboured social or foreign policy views that dissented from the official approach of the mainstream parties risked being labelled traitorous. As Dalby suggests, this fear was employed

to marginalize not only the peace movement, but many advocates of détente and arms control with the USSR. Dissenters are vilified as giving 
support and assistance to the external enemy. The Other provides the axis on which acceptable and unacceptable political activities and identities are constructed. $(1990: 13)^{34}$

Dalby's final sentence is particularly effective in driving home the connection between the threat of the Other and the homogenization of identity. The axis provided by the Other acts like Foucault's panopticon: just as the unblinking eye of the watchtower induces prisoners to discipline themselves, so too does the threat of being tainted with an unseemly association with the Other induce the nation to discipline itself (Foucault, 1984: 188-193; see also Der Derian, 1992: 29-33).

In the third process, the perception of threat empowers, legitimizes and perpetuates the state as the dominant actor in society. The state is widely understood as the actor entrusted with primary responsibility for national security, but this role is enhanced considerably during times of crisis or threat. As Max Weber suggests, people look to the state for security even when national cohesion is diminished:

An existing state organization whose heroic age is not felt as such by the masses can nevertheless be decisive for a powerful sentiment of solidarity, in spite of the greatest internal antagonism. The state is valued as the agency that guarantees security, and this is above all the case in times of external danger, when sentiments of national solidarity flare up, at least intermittently. (1946: 177)

External threat, usually understood and defined in the form of the Other, is the ubiquitous rationale for the maintenance and expansion of the state's coercive power (Campbell, 1992; see also May, 1992). This is a point made by Der Derian with respect to the mutually reinforcing relationship between the state's military and intelligence apparatus and representations of the threat of terrorism (1992: 92-126). It is also the point Dalby

\footnotetext{
${ }^{34}$ See also Norton (1988); Campbell (1992); Nathanson (1988).
} 
(1990) makes concerning the relationship between the persistence of the "security state" and the origins of the second Cold War. The massive growth of state power following the Second World War, particularly evident in the expansion of the military establishment, required ideological rationalization. The foundation upon which this rationalization was rooted was the threat of the Other:

These perpetual military preparations require the creation of a permanent adversary, an Other whose threatening presence requires perpetual vigilance. The highest political objectives of the state are now phrased in terms of the maintenance of 'national security', a security usually defined in negative terms as the exclusion of the depredations of external 'Others.' (1990: 10)

Much of the above argument hints at a sense in which the apprehension of threat can be understood as an addiction that afflicts the state (Harvey, 2003/04: 38-40; Bathurst, 1993: 91-92). The state's primary responsibility, and that which legitimizes its very existence, is the protection of its citizens. However, it is the state itself that is charged with marking the official boundaries that define and enclose the community and denote the 'inside' as safe and the 'outside' as dangerous (Walker, 1993). In this sense, the state is also responsible for identifying possible threats to its citizens. In the resulting paradox, as long as the state continues to identify threats that imperil its citizens, it guarantees its own continued existence. As Edelman suggests, "if yearning for security and protection creates leaders, leaders themselves do more than their share to construct the threats to well-being that keep those aspirations alive" (1988: 38). Tilley provides an evocative metaphor that helps to capture a similar dynamic. He suggests that the process of state building is often marked by state behaviour that is essentially akin to protection rackets run by organized crime: 
Since governments themselves commonly simulate, stimulate, or even fabricate threats of external war and since the repressive and extractive activities of governments often constitute the largest current threats to the livelihoods of their own citizens, many governments operate in essentially the same way as racketeers. $(1985: 171)$

Wolfers provides a succinct discussion on the ultimate consequences of such a dynamic. He identifies a trend whereby nations will attempt to secure their core values by extending their military reach beyond their borders. The resulting bases and forward positions, however, are then subsequently redefined as part of those very core values that needed to be secured in the first place. As Wolfers suggests, "pushed to its logical conclusion, such spatial extension of the range of values does not stop short of world domination" (1962: 154). ${ }^{35}$

Campbell's $(1992,1993,1994)$ work helps to further explain the ontological basis of the state's existential conflict of interest. For Campbell, the state lacks a prediscursive foundation - its existence is dependent upon the continual scripting of identity and constant representation of external danger. This is not the same as claiming that the state has no material basis or that the discursive realm trumps the material realm. Such criticisms fail to appreciate the intent behind a focus on discourse. As Campbell clarifies, "the world exists independently of language, but we can never know that (beyond the fact of its assertion), because the existence of the world is literally inconceivable outside of language and our traditions of interpretation" (1998: 6). Thus, the purpose of an approach of this nature is to deny the very distinction between the material and discursive that the above criticisms implicitly rely upon. Indeed, Campbell's approach explicitly reaffirms

\footnotetext{
${ }^{35}$ In a similar vein, Jervis invokes John S. Galbraith's idea of the 'turbulent frontier' in exploring the potential future implications of the US invasions of Afghanistan and Iraq (2003: 382).
} 
that the material and discursive are inevitably interconnected. Thus, in the case of international relations, were a state to cease its discursive specifications of identity and danger, it would no longer exist as it is currently understood. Therefore, the state's own ontological survival precludes it from achieving "pure security." As Campbell contends, "the inability of the state project of security to succeed is the guarantor of the state's continued success as an impelling identity" (1992: 12). This argument demonstrates how the state, as a political actor, retains a vested interest in the identification of the Other. The act of representation that transforms the differences inherent to another identity into the threatening aspects of the Other perpetuates the dominance of the state.

Carl Schmitt's (1996) work has played an influential, though not uncontroversial, role in highlighting the relationship between the state and the identification of threat. In The Concept of the Political, he contends that the ability and willingness to identify threat, in the form of the enemy, is the foundational essence of the state. Indeed, for Schmitt, the ability to make the friend-enemy distinction is the fundamental nature of politics itself, and is the only mechanism through which national identity coalesces. If the state fails to make this core distinction, the collective identity as a whole ceases to exist: "If the political power...within a state is sufficiently strong to hinder the waging of wars against other states but incapable of assuming or lacking the will to assume the state's power and thereby decide on the friend-enemy distinction and, if necessary, make war, the political entity is destroyed" (1996: 38). Thus, it is the presence of enmity, explicitly defined as such by the state, that provides the sine qua non for the state's existence. 
It is crucial to note that Schmitt writes from a philosophical perspective that is at wide variance from the one employed in this dissertation. One crucial distinction is his insistence on the permanent and existential reality of enmity. For Schmitt, "the friend and enemy concepts are to be understood in their concrete and existential sense, not as metaphors or symbols" (1996: 27). Thus, the divide between friend and enemy is not the consequence of collective representation, nor is it the result of a particular set of political circumstances, like competition over resources. Instead, this divide is an expression of what Schmitt understands to be the fundamental truth that inhabits and enables politics and collective existence. For Schmitt, enmity is a foundational condition for the state's very existence. Perhaps even more importantly, Schmitt is in no way critical of the state's role in defining the enemy. Whereas most other scholars cited in this chapter (for example, Campbell, 1992; Connelly, 2002) attempt to expose the state's role in defining the threat of the Other as a deleterious tendency that perpetuates both internal suppression and external aggression, Schmitt is laudatory of the process. He celebrates the definition of the enemy as the essence of collective identity. However, by restricting the state's ability to define external identities to the confined straitjacket of his simplistic friendenemy binary, Schmitt effectively denies the ambiguity that pervades political life. His reductive approach, and his insistence that the state's fundamental raison d'etre is the identification of its own enemy, is complicit in reproducing the rigid self/Other dichotomy that this thesis critiques. Thus, although Schmitt offers a provocative interpretation of the relationship between the state and threat, it is, ultimately, unsatisfying. 
Each of these works contributes to my understanding of the discourse of danger and how it works to identify threats as part of the self's drive to secure its own identity. Crucial to this line of theorizing is the appreciation that both nations and threats must be understood from a social perspective. That is to say, the international arena is a social setting, a crowded forum where identities are crafted in relation to one another and interaction between these identities, whether based on amity or enmity, is implicated in these very acts of crafting. As the previous chapter contends, the articulation of threat is not the result of a single and authoritative specification of danger. Indeed, it is more likely that a wide variety of actors will be complicit in the process. Governmental representatives or agencies, explicitly charged with the task of keeping the state safe, are often the most obvious source of such specifications. In their elaboration of the notion of securitization, Buzan et al. expand this responsibility somewhat by including other societal elites and even the government itself as a corporate actor (1998: 40). However, as I contend in this thesis, there are a variety of other sources from which these representational patterns emanate, sources that have been largely ignored by scholars. In particular, the representations produced by popular media deserve greater attention because they are able to reflect and reiterate the scripts advanced by government officials and "intellectuals of statecraft" in such a way as to render them common-sense. This perspective finds it problematic to speak of representations of threat emerging from a single source. Instead, I understand specifications of threat to be representations that emerge from multiple sources. This intertextual web, in which a variety of scripts echo 
and reinforce the same images and representations, permeates society and ensures that depictions of threat are corroborated from multiple angles.

\section{Liminality}

A theoretical concept that has the potential to lend considerable nuance to the self/Other dichotomy, and is thus deserving of increased attention, is that of liminality (Rumelili, 2003: 241). The importance of liminality for the creation of national identities is illuminated by Norton (1988), although her own reflections are heavily indebted to Turner (1969). Writing from an anthropological perspective, Turner understands liminality in the context of societal rites of passage. Liminality is the uncertain phase entered into when an individual makes the transition from one social status to another via a rite of passage. In this ritual phase, liminars no longer belong to their previous social group, nor do they yet belong to their new grouping. This ambiguity is the crucial defining feature of liminality: "Liminal entities are neither here nor there; they are betwixt and between the positions assigned and arrayed by law, custom, convention, and ceremony" (Turner, 1969: 95). Liminars are stripped of all symbols and privileges of rank, and markings of belonging that serve to identify them as members of the structured society. In effect, they are reduced to a condition of homogeneous anonymity. However, the complete absence of belonging represented by this condition also hints at a sense of radical equality or comradeship. In effect, because a state of liminality represents a lack of structure, there is no mechanism by which people in this state are differentiated from 
one another. Consequently, their presence alludes to an alternate mode of being. Turner refers to this explicit absence of differentiated structure that attends the liminal condition as communitas. In a dialectic fashion, the ritual existence of an unstructured and homogeneous communitas allows for the recognition and legitimacy of a structured society, complete with markers of rank, privilege and inequality. As Turner suggests, "in such a process, the opposites, as it were, constitute one another and are mutually indispensable" (1969: 97).

Norton (1988) applies Turner's concept of liminality to a wider exploration of national identities. In this expanded treatment, the liminar is no longer an individual or group whose ambiguous position within society is precipitated by ritual transition. Rather, for Norton, liminal groups are those resistant subcultures that exist within the physical boundaries of the polity, yet toil on its territorial, intellectual and structural margins. Groups cited by Norton as examples of liminal identities include a variety of frontiersmen - the Bedouin, cowboys from the American west, Basques - as territorial liminars, "madmen" and Bohemians as intellectual liminars, and peasants, the poor and ethnic minorities as structural liminars. For the theoretical purposes of this dissertation, there are at least three related areas in which Norton's insight into liminality contributes to a more comprehensive understanding of national identity.

First, liminars assist in the definition of the self. Like Turner's ritual outcasts, Norton's liminars are in a state of simultaneous belonging and exclusion. From this ambiguous position on the periphery of the nation, they play a crucial role in the development of national identity. Although the wholly foreign Other or enemy provides 
an obvious foil against which the national self can be constituted in the abstract, the proximity of the liminar demands a more immediate act of inscription:

political identity is shown to emerge with the greatest clarity when the polity confronts individuals whose inclusion in the polity is ambiguous. In confronting the question of whether these people belong within or without the polity, those within it are obliged to enunciate those differences that distinguish them from all others, to consciously define the limits of their identity. The people on the boundaries - territorial, cultural, ideological thus serve to mark the boundaries they prompt the polity to draw. (1988: 4)

Thus, just as the communitas embodied by Turner's liminal outcasts enables the recognition of societal structure, so too does the liminar help to enable national identity. From their precarious perch on the edge of society, liminars act as a mirror for the nation against which identity is confirmed and difference recognized. Norton explains this role of the liminar in the context of a "triadic" relationship:

The recognition of the liminal marks the conscious differentiation of self and other, of the body politic from other bodies politic. The differentiation of subject and object, self and other, requires both an object of likeness and an object of difference. Liminars provide an object that is like, though demonstrably other than the subject. They thus provide an object with which the subject can identify even as it differentiates itself. (1988: 53)

As part of this process, the national self identifies with certain traits or aspects that it attributes to the liminar. Thus, the brave and unrelenting cowboy becomes a mythic representation of the American nation. However, through a simultaneous process of negation, the self also defines itself in opposition to the liminar. Thus, the antiauthoritarian lawlessness of the rough frontiersman demonstrates the need for law and order in society and helps to define civility for the nation. The presence of the liminar, therefore, helps the nation to define itself through both identification and differentiation. 
Second, Norton's understanding of liminality helps to explain how the nation becomes associated with both the notion of legitimacy and the advent of the formal apparatus of the state. By serving as an object of differentiation, liminars prompt an act of abstraction whereby the self constructs an idealized and mythic version of its pure nature. Norton refers to this act as "a moment of unparalleled political importance":

The recognition of qualities that distinguish the polity from all others entails the propagation of abstract principles against which the conduct of the regime and constitution of the nation may henceforth be measured. The qualities definitive of the nation are abstracted from it and made objective. The citizens, having before them an objective principle of nationality, may thereafter determine whether the regime, or the regime's actions, are appropriate to the nation. This is the beginning of legitimacy. (Norton, 1988: 53)

Norton suggests that the ability to make abstract distinctions, when associated with the legitimacy of the nation, is established as "authoritative in the organization and actions of the polity." She goes on to state, "this marks the beginning of rationalization. The abstraction attendant on the differentiation of subject and object is thus the origin of both the state's definition and its formal organization" (53-54).

Third, Norton's understanding of the liminar helps to explain how such actors can unwittingly contribute to the discourse of danger that constitutes the self. When the self is threatened by its Other, the ontological ambiguity of the liminar becomes a source of anxiety. During such times, the self tends to script its borders with increased rigour in an attempt to efface difference and affirm purity. This process is complicated, however, by the presence of the liminar. During times of crisis, when the self is trying to insulate and protect itself though homogenization, the liminar's potential for difference is accentuated and begins to embody the threat of the Other. In Norton's words, 
the presence of difference in the ambiguous other leads to its classification as wholly unlike and identifies it unqualifiedly with the archetypal other, denying its resemblance to the self...In political situations this appears as the identification of the liminal with the foreign, usually with the enemy. (1988: 55)

However, the original ambiguity of the liminar remains in play and continues to hint at a degree of sameness or belonging. This latent sameness makes it conceivable that the threat that has corrupted the liminar may also be seeping into and contaminating the self: "The perceptible presence of likeness (of one's self) in another threatens the dissolution of the self in the other that inevitably surrounds it. This gives rise to an overwhelming fear of all things surrounding" (55). In other words, the threat of the Other takes on greater proportions and achieves an intensified sense of immediacy. This heightened insecurity prompts a dramatic tightening of identity (Rumelili, 2003). External difference is rigidly defined in order to sharpen the divide between the safe 'inside' and the menacing 'outside' and reinforce the threatened identity. Internal difference is effaced in an attempt to purge the society of threatening otherness. In this sense, the liminar acts as a localized proxy for the Other, providing a more immediate basis upon which the self apprehends the threat of the enemy. ${ }^{36}$

Although the above selections from Norton's work make it clear that she appreciates the significance of the relationship between liminality and the perception of threat, her own priorities lead her to emphasize different aspects of liminality. For Norton, the primary political significance of the liminar lies in its capacity to act as a

\footnotetext{
${ }^{36}$ Edelman's understanding of marginalized groups in society is very similar to Norton's conception of the liminar: "people who are normally spoken of with affection and compassion but who are treated in many situations as though they are dangerous, immoral, and incompetent to live autonomous lives" (1988: 12).
} 
symbol for the nation. By providing a unifying symbol, the liminar enables existing constellations of power to consolidate their authority or new ones to establish theirs. While unifying symbols clearly play an important role in solidifying identity, I contend that the liminar's ability to represent a proximate and immediate threat is of greater significance. It is, after all, during times of crisis, or moments of insecurity, that the most furious and stark scripting occurs. As Doty suggests, "representational strategies are intensified in times of crisis, when naturalized identities and the existing order are at risk of being called into question" (1996: 12).

The link between the liminar and the Other is crucial for the scripting of the self's identity. Although the self defines itself primarily in opposition to the Other, it relies upon the liminar to present a more immediate instantiation of the threat of the Other. This implies that as the self/Other relationship evolves, so too does the self/liminar relationship. Substantial shifts in identity that result in the development of a new Other, or modifications in how an existing Other is represented, will be mirrored by changes in how the liminar is scripted. Thus, the liminar functions as a blank canvas, able to take on whatever image the self requires for its constitution. In some ways, therefore, the protean nature of the liminar means that it functions, in a manner similar to that of Neumann's (1999) "the East," as a variable signifier. As Norton suggests,

because liminars serve, in their marking of the borders, to distinguish the nation from other nations, rhetorical emphasis on liminal traits is influenced by perceptions of the central traits in the foreign nationality which the nation employs as a negative referent, and against which it seeks to define itself. These factors affect not only the designation of - or rhetorical emphasis upon - particular liminal groups, but also the traits that will be emphasized in the rhetorical characterization of these groups. (1988: 83) 
The above argument suggests that a deeper investigation into liminality may provide further insight and nuance to our understanding of how the self scripts its identity in relation to the Other.

Norton's exploration of liminality is a welcome and fruitful intervention that sheds considerable light on the processes associated with identity formation. However, two important areas where my own approach diverges from hers require clarification and expansion. First, although Norton explicitly defines liminars as "people on the borders" and goes to great lengths to detail how they reside "betwixt and between existing orders," they nonetheless reside physically within the formal, territorial boundaries that delimit the polity. Thus, although liminars may exist on the boundaries of the nation in a metaphoric sense, they reside within the boundaries in a jurisdictional sense. This is the case even for those groups Norton labels as territorial liminars. So, although such groups as the Basques and cowboys may occupy a nation's frontiers, they nonetheless reside within its claimed borders. One of the most important implications that flow from understanding the liminar as internal concerns its capacity to act as a mirror for the self. As Norton suggests, the liminar presents itself as an "object of likeness" that serves to reflect an image that the self can use to confirm or secure its identity. Examples of this phenomenon might include the adoption of the tough, aggressive and independent cowboy as a symbol of American identity or the use of an impoverished tribal group as a symbolic representation of a nation's struggle against colonial or neo-colonial exploitation. In these examples, the nation is able to claim the traits or symbols associated 
with the liminal group as its own because the group resides within the territorial claims of the nation.

This approach stands in contrast to the one adopted in this thesis. Because I am interested in exploring how notions of liminality play out in the international context, I do not focus on the role of internal minorities or subcultures. To put the point more clearly, this thesis is not concerned with how conceptions of American identity draw upon minority or sub-cultural groups; it is concerned with how conceptions of American identity draw upon a relatively insignificant country that exists within the shadow of the American experience. To that end, I examine the potential for a marginalized identity located outside the formal boundaries of the nation to serve as a liminar to the national self. ${ }^{37}$ In such a situation, where the liminar is shifted to the other side of the border outside the formal jurisdiction of the state - its constitutive effect as an "object of likeness" changes. Because the liminar does not belong to the nation, it is unable to serve as a source of images or symbols suitable for defining the national self. Indeed, if the nation were to adopt the symbols of an external liminar, it would effectively be valorizing another polity instead of itself. However, this does not mean that an external group is incapable of serving as a liminar to the nation. Rather, it means that the reflection cast by the external liminar is of a different type. Instead of providing a specific characteristic or trait for the valorization of the nation, the external liminar reinforces a general mode of being. Instead of providing a particular symbol for the nation to exploit in its efforts to secure itself, the external liminar provides an acknowledgement and reassurance that the

\footnotetext{
${ }^{37}$ Hereafter, in those situations where clarity demands definitional precision, I append the adjectives 'internal' and 'external' to distinguish between the approaches offered by Norton and me.
} 
self's mode of existence is legitimate. In other words, by providing an image of likeness from outside the boundaries of the nation, the external liminar provides confirmation for the self's identity. By appearing to embody qualities of the self, the liminar implies that those qualities have meaning and relevance outside of the confines of the self. ${ }^{38}$ In such a situation, one would expect to find representational patterns that affirm broad similarities between the external liminar and the self. As subsequent chapters will illustrate, such patterns draw upon a wide variety of markers of sameness, including notions of shared histories, cultural commonalities and tropes of family and friendship.

In addition to these markers, however, this dissertation concentrates on representations of shared space. In relocating the liminar outside the borders of the self, my research expands Norton's definition of liminality by giving it a spatial component. In this formulation, although the self acknowledges that the territorial setting of the external liminar is distinct, it nonetheless maintains an ambiguous connection to that territory. This territorial linkage can come about in a wide variety of ways, including historical claims on the territory, intermingled populations, ill-defined borders, unregulated crossings, shared cultural ties and expansionist ideologies (among others). Like other forms of liminality, spatial liminality provides a reflection of sameness for the self. The perception of likeness beyond the formal borders of the self serves to confirm the validity of the self's identity. It implies a capacity for expansion or reproduction of identity. Taken to extremes, spatial liminality might even lend credence to pretensions of universalism.

\footnotetext{
${ }^{38}$ Indeed, it is conceivable that the perception of likeness in an external liminar might even encourage the self to understand its own identity in universalistic terms.
} 
However, as with other forms of liminality, spatial liminality also holds within it the potential to reflect otherness. Therefore, in times of crisis, when the self is faced with the threat of the Other, the spatial liminar takes on the characteristics of the Other. Understood in spatial terms, this dynamic reveals itself in the belief that the spatial liminar has been infiltrated by the Other. In such a situation, the territorial connections and sense of shared space that once linked the self to the liminar through an image of reassuring sameness now becomes a source of anxiety. The perceived presence of the Other in the spatial liminar, when combined with the sobering awareness of shared space, implies that the Other is already present within the self. As is the case when the Other infects other forms of liminality, this results in a constriction of identity as the self tries to achieve security by expunging difference and fortifying borders.

Second, Norton appears to view liminality as a condition that operates through objective, universally recognized symbols and representations that transcend specific cultural and historical conditions. She begins by envisioning the existence of minority groups that reside on the territorial, intellectual and structural margins of the nation. These groups - living on the frontier, following different intellectual fashions and existing in poverty - are, by the very nature of their marginality, already freighted with ambiguity. Their ambiguity, however, does not yet have constitutive implications for the self. To play this constitutive role, the group's ambiguity needs to be transformed into liminality. This is accomplished when the nation ascribes to the group what Norton calls liminal traits. Borrowing from Turner, Norton theorizes that specific traits and concepts are symbolic of a lack of structure and order. The list of these traits, which includes 
egalitarianism, poverty, madness and silence, is an extensive one. When such traits are attributed to a marginal group, that group apparently becomes symbolic of the antistructure against which the nation differentiates and orders itself: "the anti-structuralism of liminality reveals the presence and significance of structures in the political order. Liminality reveals in its effects the constitutive power of contradiction, the order imposed on us by opposition" (Norton, 1988: 55). Thus, in defining a marginal group through the attribution of specific traits, the nation creates a liminar in order to better structure and define its own order.

Understanding liminality as representative of anti-structure is a welcome approach. It allows us to appreciate that identities are predicated on assumptions of structure, normality and hierarchy. However, Norton's approach does prompt two related caveats. First, to label certain specific traits as liminal and suggest that they are somehow able to embody the concept of anti-structure imposes a degree of universality on a process that is necessarily context-dependent. For instance, Norton goes to great lengths to demonstrate that frontiersmen from disparate regions of the world - Basque, Bedouin and cowboy, among others - are all portrayed in a similar manner: aggressive, boastful, animalistic and independent. Such pretensions to uniformity detract from the specificity involved in constituting identities as distinct as Spanish, Arab and American. Indeed, the degree to which any set of negative referents is useful in scripting an ordered self seems best understood as a question of historical and cultural context rather than universal applicability. 
The second caveat, which is also related to the first, emerges from the observation that Norton sometimes appears to understand ambiguity in an almost pre-discursive fashion. In claiming that ambiguous groups attain constitutive meaning only once they are labelled with liminal traits, Norton effectively suggests that their prior state of ambiguity was pre-discursive. I would contend that a pre-discursive understanding of ambiguity is almost meaningless. Within an ordered polity, difference is universal and ambiguity abounds. What is crucial for ordered existence is that some groups become the target of discursive practices that explicitly portray them as ambiguous and some do not. It is only through differing representational patterns that this primordial ambiguity becomes a salient identifying factor for some groups and an obfuscated and unrealized footnote for others.

In sum, Norton views liminality as the consequence of the nation ascribing particular traits to an objectively ambiguous group. However, as I am questioning the very possibility that ambiguity exists as a stable, pre-discursive concept, this requires a slight shift in the definition of liminality. The primary function of liminality is to help the nation script itself, which the liminar does by simultaneously acting as both an object of likeness and an object of difference. This inherently conflicted role suggests that liminality might be better understood as the very notion of ambiguity upon which Norton's definition depends. Therefore, instead of looking for instances in which discursive portrayals emphasize an objectively liminal trait, we would be better served by exploring entire arcs of discursive patterns, looking for conflicting tendencies that mark a group as simultaneously included and excluded in the polity. The presence of these 
conflicting patterns, serving to script a group as simultaneously self and Other, mark the origin of ambiguity and enable the group to function as a liminar. Understood in this fashion, liminality serves the same constitutive function envisioned by Norton. In particular, the ambiguity resulting from the intersection of broad, conflicting discursive patterns would still provide the sense of anti-structure the nation requires to construct itself. However, such an understanding allows for greater attention to historical and cultural specificity when it comes to analysing the interaction between self and liminar. It makes it possible to explore how representational patterns that define liminality change over time and how these patterns both reflect and enable changes in the nation's definition of itself. It also makes it possible to examine the relationship between the liminar and the Other, and understand how and why the self scripts the former in such a way as to taint it with the threat of the latter.

In his review of self/Other literature in IR, Neumann singles out Norton's work on liminality for its role in illuminating the importance of peripheral actors and identities. $\mathrm{He}$ concludes his article by exhorting readers to pay increased attention to such actors: 'Since strangers and other marginal elements of human collectives 'embody' their borders, the role played by these elements in the identity formation of the collective at large stands out as a particularly promising concern" (1996: 167). The discipline of IR, however, has not rushed to embrace Neumann's suggestion (Rumelili, 2003: 219). Indeed, for the most part, liminality itself remains on the margins of the discipline.

Beyond works that make only passing reference to liminality, I have found just two works in the field of IR in which the concept plays a key role in framing the author's 
analysis. In the first, an article entitled "The International Politics of Liminality: Relocating Australia in the Asia Pacific," Higgott and Nossal (1997) employ liminality as a tool to better understand Australia's ambiguous location between the West and Asia. In their theoretical section, the authors provide a brief outline of two different approaches to liminality. Anthropologists, they suggest, understand the concept as a transitional phase, one marked by a "necessarily dynamic" movement from one state or condition to another. The other approach, modified and adopted by scholars from such other fields of study as urban geography, identity theory, and literary criticism, lacks the anthropological emphasis on dynamic movement. Instead, these other disciplines conceptualize liminality as more of a static condition, "suggesting the possibility that one can get 'stuck' in a liminal location between 'two worlds', unable either to move forward to the 'new' or to retreat to the 'old"' (1997: 170). In their own argument, Higgott and Nossal adopt the second of these approaches. They explain how Australian elites, in response to changing economic and demographic realities in the 1980 s and $1990 \mathrm{~s}$, spearheaded an attempt to shift Australia's identity from its Anglo-American origins to an Asian Pacific future. They further reveal how such attempts were met with resistance from domestic political opponents, "anti-Asian" segments of Australian society and Asian political leaders. As a consequence, Australia has managed to go only part of the way; the country is now stalled between the two options in an ambiguous, hybrid position from which an exit appears difficult at best.

Higgott and Nossal neglect a crucial aspect of liminality in both their initial theoretical discussion and the course of their own argument. In their analysis of 
Australia's current situation, the authors understand liminality to be an objective condition. For them, Australian identity is perched objectively in a static position between Anglo-America and Asia Pacific. This approach fails to incorporate the core feature of liminality that lends it analytical utility. For Turner, the presence of the liminar is important because its anti-structure enables the very constitution and legitimization of structured society. Similarly, for Norton, liminal identity makes it possible for the self to comprehend itself as a distinct entity. For the most part, both of these authors understand liminality as a subjective label, assigned to the liminar by the structured self in order to distinguish and valorize itself. Thus, the degree to which an identity is objectively "inbetween" is largely irrelevant to a discussion on liminality. What is important is not the reality of ambiguous belonging, but the effectiveness with which an identity is scripted as such. This stress on the discursive nature of liminality reaffirms its constitutive function. Without an appreciation for this constitutive role, liminality becomes a purely descriptive term. And this is the manner in which Higgott and Nossal employ the term. For them, the concept has no implications for the constitution of identity - it is simply a scholarly synonym for "in-between."

The second instance of a sustained treatment of liminality within the IR literature is an article by Bahar Rumelili (2003) entitled "Liminality and Perpetuation of Conflicts: Turkish - Greek Relations in the Context of Community-Building by the EU." In this article, the author explores how representations of liminality contributed to the perpetuation of conflict between Greece and Turkey. He argues that the discourse of European community-building in the 1990s tended to represent Turkey in an uncertain 
relationship with Europe. This representational pattern effectively portrayed Turkey as liminal to Europe, simultaneously part of and separate from the European experience. This pattern provided a discursive framework that enabled the Greek media to challenge the legitimacy of Turkey's claim to membership in Europe and, ultimately, paint the country as a threat to the European project. The author also explores the opposite side of the relationship by showing how the discourse surrounding European communitybuilding tended to script Greece in a precarious position in relation to Europe. $\mathrm{He}$ suggests this fuelled those Turkish media representations of Greece that portrayed the country as undeserving of European membership. This discursive backdrop encouraged the two countries to define their identities in opposition to one another. Each bolstered its own claim to European membership by challenging the legitimacy of the other's claim. In effect, each used the perception of the other's liminality or precariousness to better establish the validity of its own relationship with Europe. Thus, at a time when the stated goals of European institutions and politicians would normally lead to the expectation of closer ties between Greece and Turkey, the competitive and antagonistic environment fostered by representations of liminality actually helped to perpetuate conflict between them.

Rumelili's understanding of liminality is similar to my own in a number of important and related ways. First, it appreciates that liminality is not best understood as a purely objective condition of existence whereby an actor exists genuinely between two distinct orders. Rather, liminality is better understood as a relative condition that obtains as a result of a subjective act of labelling that the self imposes on another while in the 
process of defining itself. Thus, liminality is not a quality that an actor necessarily embodies objectively; it is a quality ascribed to an actor by the self, for the self's own purposes. In Rumelili's words, “it is important to underscore that liminality is not an objective condition that is inherent in a group's history, culture, or identity; but rather a contextual position that is socially and discursively produced" (222).

Second, Rumelili appreciates that although the specific attributes that might define the contours of liminality in any given situation are contingent upon the relationship between self and Other, liminality itself is a constant feature of identity: "The theoretical significance of liminality stems not from its being a fixed identity category but from the fact that there is a liminal for every notion of collective identity" (222). Accepting liminality as a "contextual position" suggests that the qualities or traits that mark an actor as liminal are susceptible to change. Thus, as the identities of self and Other evolve, and as relations between these entities change over time, one would expect the definition of the liminal to shift in response. As Rumelili suggests in the above excerpt, this implies that as the identity of the self shifts, different actors may be targeted to take on the role of the self's new liminar.

Third, Rumelili places considerable importance on the role of discourse and representational practices. Since liminality is an attribute that is imposed subjectively rather than embodied objectively, attention must be focused on the manner in which this attribute is imposed. As previously discussed, most IR scholars tend to focus on the role of state officials or "intellectuals of statecraft" (Ó Tuathail and Agnew, 1992) when investigating the constitutive impact of discourse in scripting national identities. 
However, recognizing that elites operate within a broader social milieu that can limit their efficacy, Rumelili sees the need to expand his investigative scope:

the processes of social production of meaning are not reducible simply to rhetorical engineering/manipulation by the elites. In their rhetorical abilities, elites are constrained by the broader resonance their arguments are able to achieve. Therefore, it is necessary to analyse and trace changes in the broader discursive structures which simultaneously shape societal as well as elite understandings and constrain them in their rhetorical strategies. (227)

Despite these similarities, Rumelili's use of liminality diverges from mine in two notable areas. In neither case, however, is the difference one of fundamentally different understandings of what the concept entails or how it functions. Rather, the difference is largely limited to questions of empirical focus and the implications that can be drawn from representational patterns that portray another identity as liminal. The first difference concerns the implications for the liminal that might follow from a shift in the discourse that the self uses to construct its own identity. Rumelili claims that the discourse on European community-building shifted in the late 1990s towards a self-definition that was more inclusive. This redefinition of the European self, which was more receptive to the eventuality of Turkish membership, implied that representations of Turkish liminality would diminish. However, Rumelili acknowledges that even if Europe's shift in identity results in Turkey losing its liminal status, European identity will still require a liminar: "A change in the discourse on European identity may move Turkey away from a liminal status, but the changed European discourse will continue to have its own sites of liminality" (222). Although this argument acknowledges liminality to be a necessary corollary to collective identity, it implies that shifts in the identity of the self will 
typically result in the targeting of a new liminar. This emphasis on the emergence of a new liminar downplays the possibility that changes in the self's identity might instead result in the simple re-scripting of the current liminar. In such an instance, the self would continue to target the existing liminar, but those attributes that had previously defined that actor as liminal would change. Thus, representational patterns would continue to portray the actor as liminal, but would focus on different aspects or traits in order to make such a portrayal credible.

This re-scripting of an existing liminar presents itself as a plausible alternative because of the manner in which identities tend to change over time. Because identities rely on pre-existing stocks of images, myths and historical memories, they are not prone to rapid or extreme change. Moreover, even when an identity does undergo a major shift, it will typically continue to draw upon the same reservoir of images by simply reinterpreting them as necessary. Therefore, remembering that liminal identities are dependent upon the self's identity, one would expect slow and modest changes in the self's identity to be reflected in correspondingly slow and modest changes in how the liminar is portrayed. Similarly, because perceptions and portrayals of other identities, including liminars, also draw upon pre-existing pools of images and impressions, it is difficult to re-script them in fundamentally different ways. ${ }^{39}$ Attempts to re-script a neighbouring nation or group in a manner that contradicts previously held impressions would lack credibility. Therefore, these conservative tendencies militate against the

\footnotetext{
${ }^{39}$ Although such a re-scripting is difficult, it is certainly not impossible. The process is facilitated by certain conditions, particularly the presence of an immediate existential threat. One such example was the US rescripting of the Soviet Union following its invasion by Nazi Germany, complete with the 're-branding' of Stalin as 'Uncle Joe.'
} 
likelihood of the adoption of a completely new liminar. Rather than a process whereby one identity loses liminal status and another gains it, it seems more likely that the existing liminar would simply be redefined.

The second manner in which Rumelili's use of liminality diverges from mine concerns a question of empirical focus. As already noted, Rumelili recognizes that liminality is not an objective condition and that its primary purpose is to aid in the constitution of the self. However, instead of uncovering the specific constitutive implications that representations of liminality have for the self, he opts to explore the impact such representations have upon those actors that have been labelled as such. So, instead of exploring the impact that representations of Turkish or Greek liminality have on the European Community, he looks at the impact such representations have on Turkey and Greece. Therefore, although Rumelili's article is a valuable contribution to the scarce literature on liminality and provides an excellent explanation for the persistence of conflict on the edge of the European self, it does not expand greatly our understanding of the relationship between the self and the liminar.

\section{Canadian Foreign Policy}

This dissertation explores questions of American identity. As such, it does not fall neatly within the traditional scope of the academic field of Canadian foreign policy. However, it is still important to situate my research in the context of this area of study because my analysis does contribute to the scholarship in the subfield of Canadian- 
American relations. Most work in this area is conducted by Canadian scholars and tends to explore the bilateral relationship from the Canadian perspective (Mahant and Mount, 1999). By this I mean to suggest that the scholarship tends to further an understanding of Canada in relation to the United States. ${ }^{40}$ Therefore, although it examines the significance for Canada of various US actions and attitudes, questions concerning Canada's impact on the United States have traditionally been given little attention. ${ }^{41}$ The implications that derive from my own work have the effect of reversing this trend. More specifically, by drawing on Campbell's redefinition of American foreign policy as constitutive of the American self, my work on liminality demonstrates how Canada 'matters' to the United States. In this way, my research opens up a new avenue to understand CanadianAmerican relations through the lens of identity.

The orthodox understanding of Canadian foreign policy contends that the field has developed within the context of three distinct images of Canada's position in the international system (Molot, 1990: 77; Bratt and Kukucha, 2007: 3; Kirton, 2007: 12-14; Nossal et al., 2011: 50). The first perspective in this debate understands Canada's position as that of a middle power (Hynek and Bosold, 2010). Long considered the dominant approach to understanding Canadian foreign policy (Nossal et al., 2011: 60; Bratt and Kukucha, 2007: 3), the middle power perspective tends to emphasize the

\footnotetext{
${ }^{40}$ For notable exceptions that examine the bilateral relationship from the US perspective, see Stewart (1992), Thompson and Randall (2008), Mahant and Mount (1999) and Callahan (1937).

${ }^{41}$ In the wake of $9 / 11$ and the sense of exposure and insecurity the attacks engendered among Americans, scholarly attention increasingly focused on Canada's real and potential impact on US security and defence efforts (for example, see Mason, 2003; Charbonneau and Cox, 2008; Clarkson and Fitzgerald, 2009). However, it is important to note that in many cases, the goal of this scholarship was often to understand the implications for Canada of suddenly 'mattering' to the United States. In this sense, although this new work ostensibly looked at how Canada impacted the United States, much of it continued to focus on the implications this new salience had for Canada's economy and security.
} 
country's commitment to functionalism and liberal internationalism. This view contends that Canada, though not among the great powers, possesses enough power and influence to maintain a distinctive and effective foreign policy. As Tomlin et al. suggest, this tradition holds that "Canada has generally tended to advance its interests by promoting a rules-based international order through effective diplomacy and its membership in international organizations" (2008: 15). ${ }^{42}$

The second perspective considers Canada to be a "principal" power (Dewitt and Kirton, 1983; Kirton, 2007). ${ }^{43}$ Emerging from a largely realist framework, and typically understood in the context of both US decline and a generous appraisal of Canada's relative capabilities, this vantage conceives of Canada as a "top-tier country" in the international hierarchy (Kirton, 2007: 82). As such, this approach contends that Canada enjoys a place of international prominence and is able to exert considerable influence in its drive to secure its own national interests.

A third approach, considering the subject from a political economy perspective, is concerned primarily with Canada's function and position in the international economic system. A varied and interdisciplinary approach, this view typically understands questions of power in a very different way as it attempts to draw connections "between the economic, political, and cultural/ideational moments of social life in a holistic way" (Clement and Williams, 1989: 10). Often framed within the context of Canada's

\footnotetext{
${ }^{42}$ One of the seminal accounts of this view is Holmes (1970); a historical retelling of Canada's adoption of the role can be found in Chapnick (2005).

${ }^{43}$ The primary adherents to this approach label their theoretical framework Complex Neorealism.
} 
subordinate or satellite relationship with the United States (Nossal et al., 2011: 60), this view contends that the country's range of international options is structurally limited. ${ }^{44}$

As much as this tripartite division has served as an effective platform for exploring Canada's place in international affairs, it has also failed to ask some types of questions and implicitly directed discussion away from other perspectives (Molot, 1990; Black and Smith, 1993). Defining the field in such rigid and simplified terms serves to overlook the variety of permutations within each of the three perspectives and renders other analyses that do not fit into one of the three categories as "non-traditional" (see Bratt and Kukucha, 2007: 5). In this sense, the traditional representation and historiography of the field of Canadian foreign policy implicitly defines what questions are worthy of study. Indeed, even within the context of the three perspectives, the ubiquitous middle power approach is sometimes celebrated with such a sense of triumphalism that it serves to dismiss the other two approaches: "While the image of Canada as a middle power has been, and continues to be, dominant in the discourse of international policy in Canada, there have been two other visions of Canadian power, one self-denigrating and the other self-flattering" (Nossal et al., 2011: 60). Again, statements such as this effectively define what is appropriate to study in Canadian foreign policy.

In her discussion on the notion of "discipline" within the study of Canadian foreign policy, Smith refers to the existence of "traditional literature" and "mainstream texts" in backing her contention that there is a body of work that constitutes "traditional Canadian foreign policy" $(2010: 6,7)$. As she points out, this work is characterized by its

\footnotetext{
${ }^{44}$ Important early works in this tradition include Grant (1965) and Clarkson (1968).
} 
adherence to a problem-solving perspective (Cox, 1981). Understood from this perspective, this work accepts the readily-apparent structure of the international system at face-value and simply describes and prescribes action within that context (Beier and Wylie, 2010b: xi-xii). Such an approach arrogates for itself a position of analytical neutrality, proceeding on the basis that it can apprehend the truth of things. Even more importantly, by implicitly upholding the status quo, the adoption of a problem-solving approach effectively helps to obfuscate the exercise of power and sustain relations of inequality (Cox, 1981: 129-130).

For Cox, the alternative to the problem-solving approach is what he calls critical theory. A critical approach does not take the current international structure as given and immutable. Instead, it seeks both to expose the multiple unseen ways in which power is exercised and, ultimately, to transform human relations (1981: 130). Scholars of Canadian foreign policy were among some of the early advocates for critical IR theory (Turenne Sjolander and Cox, 1994; Whitworth; 1995; Neufeld, 1995b). Moreover, beyond contributing to the early metatheoretical debates within IR, these and other scholars also made important contributions to the study of Canadian foreign policy. In this sense, these scholars helped to set the stage for further developments in this direction.

Much of the critical work that has developed since the early 1990s is devoted to exposing Canadian foreign policy as something considerably less than it appears. It explores how a wide variety of treasured foreign policy traditions or accomplishments, cloaked invariably in the reassuring rhetoric of altruism and good international citizenship (Macdonald, 1995: 111), mask foreign policy practices saturated in self- 
interest and functioning to sustain hegemonic structures. For example, early work in this tradition includes Neufeld's (1995a) use of Gramsci to explore how Canada's status as a middle power has implications for political order at both the international and domestic levels. Macdonald (1995) adopts a post-colonial perspective to explore how Canada's involvement with the 'Third World' is structured by embedded relations of inequality that belie the rhetoric of partnership. Black and Turenne Sjolander (1996) adopt a Gramscian framework to deconstruct the concept of multilateralism, another fundamental pillar of both the practice and scholarship of Canadian foreign policy. They expose how the principle has been used to foster domestic consensus on Canada's international involvement while helping to sustain hegemonic structures both within Canada and internationally.

This work has questioned a number of other areas of Canadian foreign policy that might otherwise be understood as unproblematic or, in many cases, even cause for collective self-satisfaction. Thus, in addition to multilateralism and Canada's muchtreasured status as a middle power, critical scholars have also queried the implications behind Canada's shift to niche diplomacy (Smith, 1999), its internationalist posture (Smith, 2003), its attempt to democratize its foreign policy (Neufeld, 1999) and the much-vaunted Ottawa process to ban land mines (de Larrinaga and Turenne Sjolander, 1998). Even those aspects of Canadian foreign policy that are largely understood by the public as sources of national pride, such as human security (Neufeld, 2004; Crosby, 2003; Grayson, 2010) and peacekeeping (Whitworth, 2003) are exposed as deeply flawed practices with unseen consequences. More recently, scholars have turned to 
deconstructing the myths that have been deployed in the service of explaining and 'selling' Canada's involvement in Afghanistan (Turenne Sjolander and Trevenen, 2010; Turenne Sjolander, 2010; Neufeld, 2010).

As Beier and Wylie note, feminist scholarship has been at the forefront of this move towards an increasingly critical approach (2010b: xiii). Indeed, among the variety of perspectives seeking to problematize the unquestioned pillars of Canadian foreign policy, the critical feminist approach is arguably the most developed. This area of scholarship has benefitted from two volumes (Keeble and Smith, 1999; Turenne Sjolander et al., 2003) and a dedicated special issue of Canadian Foreign Policy (Smith and Turenne Sjolander, 2005). Moreover, a number of the authors cited in the above review have approached their topics from an explicitly feminist perspective (Crosby, 2003; Whitworth, 2003; Turenne Sjolander and Trevenen, 2010).

To a large extent, the study of Canadian-American relations has remained cordoned off from this increasing move towards critical scholarship. Indeed, outside of the field of political economy, much of this area of inquiry remains largely the preserve of historical reflection and realist analysis. Moreover, the field's focus on traditional understandings of diplomatic and military relations intensified considerably after the events of 9/11. In terms of political economy, however, Williams' (1988) discussion of Canada's status within the international system is relevant to my research.

Contrasting rival theories of Canadian political economy that assume states to be the appropriate units of analysis, Williams suggests that Canada should instead be conceptualized as a region within the US economy. In reaching this conclusion, he draws 
on Innis' understanding of Canada as a subordinate region, complete with imagery that depicts Canada and the United States as Siamese twins ("a very small twin and a very large one") (Williams, 1988: 115). Using the insights of Panitch and others, Williams suggests that Canada's continued participation as a component of the US economy does not emerge from the state simply acquiescing as a US client, but from a cultural affinity. More specifically, he suggests that the encroachment of US culture has helped to shift Canadian understandings of what defines the country's national interest. With closer integration, Canadian civil society and elites have been inundated with US popular culture and have come to adopt a continentalist culture modeled on US thinking. This has helped to structure the functioning of Canadian perceptions, politics and institutions to sustain Canada's place as a US region: "Canada is seen to mirror in her own particular fashion the political and socio-economic formations characteristic of the centre of these empires" (109).

Williams' formulation hints at several of the issues that $I$ touch on in this dissertation. In exploring Canada's capacity to act as a region within the US economy, Williams implies a level of ambiguity and indeterminacy that mirrors that of the liminar. Even more importantly, his treatment of popular culture as the vehicle by which Canadians come to embrace a liminal notion of continental belonging provides insight into how Canadians become complicit in the scripting of their own liminality. Finally, a political economy approach such as this sheds light on how some of the discursive processes that I detail in this dissertation are reinforced by the forces of continental integration. 
Elsewhere within the field of Canadian-American relations, new scholarship is beginning to emerge. For example, constructivist work is now achieving greater prominence (Golob, 2002; Beier, 2005; Massie, 2009; Clarkson and Fitzgerald, 2009). Similarly, more critical approaches to understanding and reshaping Canadian-American relations are also being generated. For instance, Grondin and de Larrinaga (2009) explore how the process of North American integration is unfolding in the context of the Security and Prosperity Partnership (SPP). More specifically, they contend that the partnership is instituting a regime of governmentality to manage North American populations and reborder North America as a performative security community. They caution that because this re-bordering has been depoliticized under the SPP it represents an undermining of democracy. In response, they advocate that the process be re-politicized in order to allow people a voice. Crosby (2010) explores the increasing integration of Canadian-American defence relations and the drift towards Canadian involvement in a national missile defence programme through NORAD. Her response is to advocate for radical resistance, to challenge nothing less than "the world views in which contemporary US-led Western security practices are rooted." Finally, Charbonneau and Cox (2008) explore the implications of increasing interoperability of Canadian and US military forces and the ongoing integration of Canadian and American defence planning. They suggest that this integration has resulted in Canadian forces disregarding directives from civilian leaders and has positioned Canada as a partner in sustaining US hegemony. They also expose factors that enable Canada's role in this process, including the propagation of myths 
about the country's appropriate international role and the sense of 'naturalness' that pervades cooperation between the countries.

My own work seeks to contribute to this growing trend in critical scholarship. By helping to problematize the 'common-sense' nature of the problem-solving approaches that dominate the study of Canadian foreign policy and Canadian-American relations, I hope to cement our understanding that national identities are always in process. By demonstrating that Canada is implicated in the discourse of danger that helps to constitute American identity, I hope to contribute to a more nuanced understanding of some of the social dynamics that underwrite Canadian-American relations.

In a sign of its increasing acceptance in the field, critical work has recently begun appearing in edited volumes on Canadian foreign policy (Bratt and Kukucha, 2007; Hynek and Bosold, 2010). Beier and Wylie's (2010a) recent edited volume, dedicated explicitly to the approach, marks another important step in the development of critical work. The scholarship reviewed above serves as a valuable antidote to the long-standing tendency to view Canadian foreign policy as something other than the pursuit of narrowly-defined national interest (Molot, 1990: 80). It is also an important move towards redefining the field away from its preoccupation with Canada's 'three images.' Having said that, Bratt and Kukucha remind us that the "vast majority of the thinking about Canadian foreign policy" remains focused on those three perspectives (2007: 3). Therefore, although critical scholarship certainly contributes an increasingly rich and varied perspective to the study of Canadian foreign policy and Canadian-American 
relations, it is safe to say that its takeover of the mainstream is not yet imminent (Nossal, 2000: 108).

\section{Conclusion}

IR scholars working on the self/Other dynamic in global politics tend to focus their efforts on understanding how that dynamic functions to script national identities in opposition to foreign and threatening Others. While this approach has certainly opened up new avenues of scholarship, it threatens to reify the very dichotomy that these scholars are otherwise trying to expose. This tendency also serves to conceal the potentially important role that other identities play within the context of the self/Other dynamic. The notion of liminality, largely unexplored thus far, holds considerable potential for yielding a better understanding of national identities in global politics. When expanded beyond Norton's primary emphasis on internal subcultures, the concept promises to shed light on bilateral and regional relations marked by asymmetry. Moreover, by understanding liminality as a discursive status imposed on another actor as a consequence of the self's representational practices, as opposed to an objective state of 'real' hybridity, this project hopes to provide an innovative explanation of how the constitutive dynamic of the self/Other relationship is actuated. Moreover, by situating these ideas in the context of Canadian-American relations, I hope to illuminate some of the basic social dynamics that structure the US response to Canada. 
In addressing each of these areas, this chapter reveals my debt to the existing IR scholarship on the relationship between threat and identity. The discussion has attempted to show how my own thinking both builds upon and contributes to this scholarship. Taken as a whole, these reflections serve as the theoretical basis for my examination of US representations of Canada, and the constitutive role they play in scripting American identity. 


\section{Chapter 3 Hollywood Films and Themes of Canadian Otherness}

\section{Introduction}

Hollywood films regularly portray Canada as an exotic place, marked by strange people and extreme geography. In effect, the country is othered as a place that is foreign and unlike the normalized world with which Americans are familiar. Certainly, some of this strategy can be understood as part of the film industry's attempt to construct an unfamiliar place in order to better capture both the imagination and disposable income of the US movie-going public. These creative and economic imperatives of US cinema do not, however, detract from the significant contribution this representational trend makes to the sociological processes that act to define and reaffirm American identity. Indeed, the fact that Americans are willing to support such Hollywood productions is perhaps an indication of the degree to which such identity processes find traction among the country's general population.

As the argument in chapter 1 contends, cinematic representations can provide IR scholars with a valuable trove of research opportunities. For instance, as Lipschutz (2001) suggests, films can provide a glimpse into the national insecurities that prevail at the time of their making. Similarly, as Power and Crampton note with respect to the events of 9/11, "Hollywood movies provided a language and imagery that commentators drew upon in making sense of the attacks and their geopolitical implications" (2005: 193). Corkin, in his analysis of post-Second World War westerns (2000), contends that such 
films served to uphold aggressive US foreign and military policy postures during the Cold War. While each of these insights is certainly a valuable addition to our understanding of international relations, my own approach differs. Thus, I do not look for evidence of specific societal concerns that spill over onto the big screen, nor examine the use of filmic narrative to interpret international events or rationalize foreign policy. Instead, I look to Hollywood films in order to uncover culturally-based evidence of the social dynamics that work to situate identities in relation to one another. More specifically, I turn to Hollywood productions to look for the presence and content of broad patterns that represent Canada as Other in relation to an American self.

In no way do I claim that filmic representations of Canada are part of a direct and obvious causal chain that leads to specific types of foreign policy responses from the US government. Rather, I suggest that these representations are part of a broader cultural reflection of how Americans understand Canada. In this sense, they are an important contribution to the social processes that define American identity. Indeed, as with all representations, these images of otherness say more about the source of the representations than they do their target. In other words, I hold that Hollywood's representations of Canada have important implications for the construction of the American self. Cinematic patterns that define Canada in negative terms are deployed as part of a binary logic that results in the definition of America in positive terms. Regardless of whether such definitional processes are enacted implicitly or explicitly, they have considerable implications in terms of reinforcing prevailing notions of American identity. In other words, when Hollywood films depict Canada in foreign or 
strange terms, they effectively confirm prevalent conceptions of American identity as normal. This argument does not suggest that Canada stands in as some kind of archrival or primary foil against which American identity is scripted. Rather, I argue that Canada's role in this regard is a comparatively minor one; it acts as a more immediate and proximate instantiation of difference, working to confirm those pre-existing social processes that define American identity.

This chapter also explores an important implication that emerges from these patterned depictions of Canadian otherness. Cinematic visions of otherness do more than simply situate America in relation to Canada. They also enable an understanding of Canada as a place so unlike the United States that it harbours the potential for danger. In other words, these depictions render Canada an "outside" to the American "inside" (Walker, 1993). I do not claim that Hollywood advances an image of Canada as an overt threat to the United States. However, the representational patterns that I explore in this chapter clearly script Canada as a potentially dangerous place. I contend that this ambiguous sense of danger, which lingers around Hollywood's version of Canada, is another defining feature of the cultural meaning that Canada represents for Americans. The next chapter picks up on this argument to demonstrate how cinematic representations of Canadian liminality work to transform Canada into a source of US insecurity.

Hollywood others Canada using a wide variety of representational schemes. Indeed, when understood through the lens of Norton's definition of liminality (1988), Canada becomes a blank slate; in other words, it is capable of absorbing and projecting whatever images are required to uphold and reinforce the various traits that make up the 
American self. This chapter will focus on three such examples. The first pattern depicts Canada as an alien land, one that is loosely governed by a foreign power and populated by a motley combination of wild savages, untrustworthy Frenchmen and scheming 'halfbreeds.' The second representational pattern presents an image of Canada as a wilderness, an isolated, primitive and rural place, removed from civilization and dominated by foreboding geography and untamed, dangerous wildlife. The third pattern depicts Canadians as passive, effectively suggesting that they are unable to police their territory effectively and incapable of developing their land themselves.

\section{Canada as Foreign}

Hollywood tends to populate Canada with an encompassing variety of ethnic and cultural stereotypes, with the effect of portraying the country itself as an exotic and foreign land. Together and separately, Hollywood's diverse and polyglot Canadians serve as a foil for a united and normalized American identity. Moreover, as this chapter will explore in depth, the depictions that script Canadians as foreign are also freighted with suspicious and threatening overtones. Consequently, Canada itself is understood as a place where dangerous characters are seemingly at home. This section explores Hollywood's depiction of those groups that appear on-screen with the most regularity. It examines four specific groups, each of which can be understood as occupying a distinct place on a spectrum of increasing foreignness: British, French, Métis and Indians. 
The British Other

Hollywood communicates the British presence in Canada through a wide variety of symbols and characters. For example, many films are liberal in deploying images of the Union Jack (The Canadians, 1961; Pony Soldier, 1952). References to the British monarchy, especially with respect to characters' duty and loyalty to the Queen, are also ubiquitous (Susannah of the Mounties, 1939; Royal Mounted Rides Again, 1945). A prominent example of this pattern involves an American cowboy accepting deputization with a sober nod to the authority of the Crown: "I do hereby solemnly swear to uphold the law of her majesty" (God's Country and the Man, 1937). Another example is found in a Mountie's earnest declaration as he enters a town run by criminals: "In the name of her majesty the Queen, I order you to surrender. Come out with your hands up" (Where the North Begins, 1947). Other films allude to the importance of the British Commonwealth or empire, or to the impact of British imperialism in North America (Quebec, 1951; Niagara, 1953; Northern Pursuit, 1943). In a related vein, films produced around the time of the Second World War make explicit references to Winston Churchill's leadership or Canada's war effort to help Britain (King of the Mounties, 1942; King of the Royal Mounted, 1941; The Scarlet Claw, 1944).

The combined impact of this emphasis on all things British is to tie Canada to the United Kingdom, thereby denying the country a 'natural' presence in North America. It reminds US viewers of Canada's refusal to claim its own independence, choosing instead to remain a colonial dependency. In this sense, it draws upon an early self/Other dichotomy, originally propagated in the US colonies at the time of the American 
Revolution, which framed US republicanism in opposition to British monarchism (Heideking, 1997). Omnipresent references to Britain serve to draw a stark comparison, often made explicit by the interaction between transplanted US heroes and their Canadian counterparts, between the origins of the two nations. In effect, Canada's continued and subordinate association with the United Kingdom is juxtaposed against the conclusive severing of ties effected by the United States in the War of Independence. This comparison helps to confirm strength and independence as crucial and defining aspects of the American identity and serves to normalize and naturalize US dominance on the continent.

In terms of a spectrum of foreignness, Canada's British component is obviously not entirely foreign to US viewers. The United States shares historical and linguistic ties with Britain to such a degree that a British presence in Canada is not conceived as completely alien. However, Hollywood's emphasis on colonial trappings and the British presence certainly figures Canada as a local manifestation of a foreign empire. In this sense, Canada's very existence serves the interests of an external power. Therefore, even though the United Kingdom was certainly not considered a threat to the United States during Hollywood's Classical era, its Canadian proxy does serve to remind US viewers of a distinctly foreign presence in North America, with interests and objectives potentially at odds with those of the United States.

\section{The French Other}


The French presence in Canada provides a more substantial marker of difference than that provided by the British. Some of this presence is demonstrated in the frequency with which names like St. Pierre (Danger Ahead, 1940), Dominique (North of the Border, 1948) and Port LeBeau (Yukon Gold, 1952) appear among the rural outposts that punctuate the country's wilderness. Some of the presence flows from filmmakers' tendency to exaggerate accents and stereotype clothing. However, even more important, and unlike the English-speaking British, French characters are usually cast as villains. It is this felonious bent to Canada's French citizens that maximizes the foreign aura that surrounds them.

To be sure, Canada's French appear in a variety of guises. They are sometimes portrayed as noble freedom fighters (Quebec) or ordinary townsfolk (I Confess, 1953). They come across as both suspicious provincials (The Scarlet Claw) and cosmopolitan sophisticates (Rose-Marie, 1936). Sometimes they even assist the Canadian hero in their role as a subordinate lawmaker (Royal Mounted Rides Again). However, the French appear most comfortably in their element in the role of trapper. Indeed, outfitted with the seemingly inevitable toque, plaid shirt and outrageous accent, these men appear to make up a considerable percentage of Canada's population. Among these trappers, many are jovial and well-meaning. However, even more prominent in Canada's harsh and unforgiving wilderness is the renegade French trapper. Such villains are common in many Hollywood films, including Trail of the Mounties (1948), Nikki, Wild Dog of the North (1960) and Phantom Patrol (1936). In this role, the French villain steals, kidnaps and murders, all in pursuit of valuable fur pelts. 
The criminal ways of Canada's French are not, however, limited to simply stealing furs. For instance, in King of the Royal Mounted, the French henchmen are quislings, intent on subverting Canada's war effort. In Trail of the Royal Mounted (1931), though Jean Gregg masquerades as the simple manager of a fur trading outpost, he is actually the head of a large gang of criminals looking for a lost gold mine. Gold is also the motivating factor behind the villain's decision to contract a US gangster in Northwest Trail (1942): "As for Pierre, he was a French Canadian who originally discovered the claim, but there were government restrictions against working it. So, he went to the States and contacted your uncle."

Like Hollywood's emphasis on British characters and themes, the exaggeration of the French presence in Canada has the effect of making the country more foreign and exotic in the eyes of moviegoers. In the case of the British presence, however, the United Kingdom was at least part of the US experience. This sense of shared origins and experience is almost entirely absent in the case of the French. Indeed, because France's language, culture and foreign policy did not permeate the American experience in a meaningful way, the French presence in Canada is imbued with considerably more foreignness.

A French presence in North America acts as a challenge to the British cultural origins of the United States. Similarly, Hollywood's clear identification of French Canadians with Roman Catholicism serves to further entrench impressions of foreignness. And the French language, of which audiences are constantly reminded by the recurrence of comical and exaggerated accents, cements this othering process. This 
essentialized French Canadian presence contributes to the definition of American identity not just by providing an image of otherness, but also by showing audiences a tangible example of schism. In this sense, it provides a foil against which the myth of the US melting pot can be perpetuated. In opposition to the spectre of a strong minority presence, which is itself often a disruptive force on society, American identity is rendered pure and united, free of ethnic, linguistic and religious cleavages. Thus, a polyglot and multi-ethnic Canada helps to perpetuate an image of America where immigrants leave their preexisting connections behind in order to forge a united country.

One of the primary markers of the heightened sense of otherness with which Hollywood imbues Canada's French population is the degree to which French characters are understood to represent a threat. Although many films feature villains whose first language is clearly English, few of these villains are explicitly identified as British. Moreover, among the lawmakers that populate Hollywood's version of Canada, a clearly disproportionate amount feature Irish, Scottish or English names and accents. The French Canadian villain, on the other hand, is ubiquitous. He and his undifferentiated gang of renegade trappers terrorize communities, police, women and the very fabric of the social order. As the above quotation about hapless Pierre from Northwest Trail implies, the explicit labelling of a villain as French in the context of explaining his role in a criminal scheme is not an uncommon feature in the films screened for this thesis. Such films effectively suggest that being French is a contributing factor to villainy.

\section{The Métis Other}


The third group that Hollywood uses to emphasize Canada's foreign nature is the Métis. Pictured as a group that emerged from the intermingling of provincial European settlers with savages from the wild, the Métis embody the fears of miscegenation that have long plagued US society. This spectre of the 'half-breed,' one of the most powerful markers of liminality, living on the very fringes of society, works to portray Canada as a wild place where propriety and morality are in short supply. The prominence of the Métis in films set in Canada is a substantial contributor to the othering of Canada as foreign.

There are a few films in which the Métis are not pictured in all-together negative terms. For example, in The Trail Beyond (1934), the hero's loyal sidekick, Wabi, is a "half-breed," although his parentage is, for the most part, a non-issue in the film. In Saskatchewan (1954), Inspector O'Rourke's scout, Batouche, though certainly exhibiting a certain shifty quality, is both loyal and helpful. A character similar to Batouche is also present in Pony Soldier. In this film, although Natayo is knowledgeable of the wilderness, he also has a fondness for liquor and is superstitious, cowardly and, as is virtually obligatory for the filmic Métis, sneaky.

Despite these examples of somewhat redeemable Métis, most of Hollywood's Canadian 'half-breeds' are fundamentally dishonest and contemptuous. For example, in Rose-Marie, the heroine is led into the wilds by a shifty Métis guide named Boniface who abandons her, leaving her to drown. As a shopkeeper later tells Rose-Marie, "That's the trouble with those half-breeds. You can't trust them." In another film, the gallant and brave hero rebukes a junior Mountie for falling in love with a Métis woman: "I told you to stay away from that klootch. She's poison....Never trust a blue-eyed squaw" (North 
West Mounted Police, 1940). Such depictions of Métis women were not unusual. As Brégent-Heald (2004) contends, Hollywood films tended to script the Métis woman as "a duplicitous half breed" (25), both "toxic and morally bankrupt" (131). Moreover, in these and other films, depictions of Métis dishonesty are often associated with violent intentions.

The Métis are almost universally portrayed as determined foes of progress. For instance, in Canadian Pacific (1949) the Métis organize in violent opposition to the coming of the railroad because they are convinced it will ruin their way of life. In one scene, they are provoked by the inflammatory rhetoric of their scheming leader, Rourke: "I tell you the railroad means the end of free life and open country for all of you. The country is ours, let's keep it!" The introductory voiceover to North West Mounted Police tells a similar story of simplicity and resistance:

The Canadian northwest - here, the first traders from the old world intermarried with the Indians of the plains and the forests to found a new race, the Métis of Canada. Here for two centuries, these half-breed hunters and trappers multiplied and prospered, a law unto themselves. Then surveyors and home-builders pushed westward, bringing laws of land and property which threatened to end forever the free ways of the wild trails. In 1885, resentful and confused, the half-breeds, under the leadership of Louis Riel, revolted against the advance of unwelcome law.

One of the most prominent representational patterns shows the Métis to be a hottempered and tempestuous people, quick to take offence and prone to violence. In both Canadian Pacific and North West Mounted Police, they are portrayed as an unthinking and volatile mob, easily swayed to action by their leaders. In the former, the Métis prefer the inflammatory rhetoric of their deceitful leader to the reasoned counsel presented by a number of characters, including the story's hero, the daughter of one of the main 
conspirators and even the influential and well-regarded local priest. In the latter, the settlement of Batoche is presented as a den of scheming villainy, teeming with hateful scoundrels and led by ambitious and untrustworthy men, including one whose main goal is to establish a monopoly on the liquor trade with the region's Aboriginal people. The film makes it clear that no amount of negotiation or debate would be enough to deter these men from enacting their murderous plans.

Understood as part of a comprehensive pattern of othering, Hollywood's depiction of Canada's Métis does considerable ontological work in helping to script American identity. The Métis are portrayed as a wild and sometimes bestial people who are easily duped, unreasonable and governed almost entirely by their emotions. They are also almost universally represented as a people mired in the past and, oftentimes, violently opposed to the spread of civilization. To audiences watching from theatres in the United States, such depictions serve as a foil to normalize an American identity that stands in opposition to such barbarism. In this sense, the otherness of Canada's Métis helps to reinforce dominant readings of American identity that are steeped in self-assured claims of rationality, civilization and an unswerving and naturalized linkage with progress. Perhaps even more importantly, the Métis also stand in as a warning against racial intermingling. Their simplistic and passionate lives and their proclivity to violence are the implied products of indigenous blood and wilderness living. Thus, in this sense, the Métis of Canada provide US audiences with a cautionary tale against miscegenation and act as a foil against which the American identity is confirmed as homogeneous and European. 
Although Hollywood films typically identify the Métis explicitly as halfEuropean, and might therefore be reasonably expected to depict them according to patterns otherwise reserved for European characters, such is not the case. Indeed, the Métis are shown to embody an entirely different order of foreignness from their European counterparts. This extreme otherness renders these characters particularly threatening. For instance, their passionate nature makes the Métis prone to violence, while their simple-mindedness leaves them vulnerable to the manipulations of scheming villains. As a consequence, the Métis are frequently shown to be either on the verge or already engaged in violent activities, including open rebellion. However, the threat posed by the Métis is not limited to the realm of physical violence and insurrection. Because they are the offspring of European settlers and Aboriginal peoples, Canada's Métis, like the Mexican 'half-breeds' of Hollywood's western genre, serve as a symbol of the unravelling of social order. ${ }^{45}$ They represent the social threat of miscegenation and the possibility that the foreign Other may lurk undetected within the bounds of civilized society.

\section{The Indian Other}

Aboriginal people, as they are portrayed by Hollywood, represent the most extreme manifestation of foreignness within Canada. Their association with wilderness, savagery and a primitive way of life serves to remove them from the mainstream society of the audience. Thus, even though a film may picture them at home in the wilderness or

\footnotetext{
${ }^{45}$ Brégent-Heald contends that Hollywood's Métis were "often indistinguishable" from its Mexican "halfBreeds" (2004: 134).
} 
in primitive settlements, Canada's Indigenous peoples are presented to the viewer as aliens.

As a primary component of this approach, pictures set in Canada usually portray Aboriginal people as exotic. This is the impact engineered by a scene in Rose-Marie, in which the two main characters observe the local people's Thanksgiving ceremony:

Sergeant Bruce: "You're just in time."

Marie de Flor: "Oh, but there's hundreds of them! I never dreamed things like this were still going on."

Sergeant Bruce: "They do this every year. It's like a Mardi Gras to them."

Marie de Flor: "What's that they're carrying? Corn?"

Sergeant Bruce: "Yes, it's their corn festival - to show their appreciation for a good crop."

Marie de Flor: "Oh, like our Thanksgiving?"

Sergeant Bruce: "Yes, but we only thank one god. They thank everybody: the corn, the sun, the rain, the birds, their ancestors. They do a thorough job."

The images and dialogue presented in this scene, and in similar scenes from a myriad of other Hollywood films, render Canada's Aboriginal people as an exotic people. Their exoticism, however, is not just born of their foreignness. Much of the exotic feel that attends representations of Aboriginal people emerges from a complementary sense of primitiveness that clings to the characters as a primary attribute. They are, in essence, depicted as a throwback to a simpler time, inhabitants of an era when humans were more superstitious.

As part of this othering process, Aboriginal people are typically portrayed as simple and gullible (Pony Soldier). This gullibility, however, often has a more sinister side. In a number of films, Aboriginal people fall victim to the charismatic machinations of a scheming villain or otherwise become pawns in a wider plot. As a result, they might be framed for the murder of a Mountie (North of the Great Divide, 1950), tricked into 
attacking white settlements (Gunfighters of the Northwest, 1954), or even duped by a Nazi saboteur (Northern Pursuit). In Where the North Begins, Mountie Dave Sanderson uncovers a scheme in which local tribe members are convinced to trade their furs for alcohol, prompting him to highlight the seriousness of the situation: "You ever see a bunch of Indians liquored up and on the warpath? Well, I have."

For the most part, however, the Aboriginal people that populate Hollywood's version of Canada do not need to be tricked into violence. Indeed, they are often willing participants in all manner of deadly connivance. The list of films in which Aboriginal characters are employed as simple thugs or murderers is long (Fighting Mad, 1939; Snow Dog, 1950). Even more sinister, however, are those examples in which Aboriginal warriors gather together and attack the agents of civilization in a desperate attempt to maintain control of their territory. Savage attacks against innocent wagon trains occur in Susannah of the Mounties and Saskatchewan. In other instances, local tribes launch attacks designed to sabotage the westward progress of the railroad (Perils of the Royal Mounted, 1942; Canadian Pacific) or deter settlement in their area (Perils of the Wilderness). The savagery and ferocity of such warriors is never in doubt, although a cautionary exchange between characters in The Cariboo Trail (1950) makes this point clear:

Jim Redfern: "I wanna see what's on the other side of those peaks." Grizzly: "Nothing, Jim. Take my word for it - nothing but nothing." Jim Redfern: "Have you been there?"

Grizzly: "I've still got my hair, ain't I? And that's why. All there's on the other side is Injuns. It's the Chilkootin country, Jim, and that means Injuns. Stay out." 
These filmic representations of the "Injun" and his supposed propensity to bloodthirsty violence speak to what Slotkin refers to as the "savage war" symbol (1992: 12-13). As part of this trope, the bloodthirsty nature of North America's Indigenous peoples ensures that the conflict that inevitably emerges from the confrontation between Native and European cultures becomes a war in which each side seeks the total annihilation of the Other. This understanding of "Indian" savagery finds regular expression in the wilds of Hollywood's Canada.

It should be mentioned that there are films which feature Aboriginal people in a less negative light. Thus, such productions as Saskatchewan and Trail of the Royal Mounted feature non-threatening sidekicks who remain loyal (though obviously still subordinate) to the hero. Another example, The Silent Enemy, explores a tribe's struggle to find food in the harsh conditions of winter. This film appears to be motivated, at least in part, by a desire to provide audiences with a more even-handed portrayal of early Aboriginal life and, therefore, manages to avoid portrayals of excessive savagery. Such films, however, are certainly not the norm. Indeed, they are isolated instances, virtually lost in a wider body of work that, as a whole, not only depicts Canada's Aboriginal people as foreign, but does so in such a way as to emphasize a threatening and dangerous component.

Hollywood films from the Classical era present the otherness of Canada's Aboriginal people in much the same way that they present the otherness of US Indigenous peoples. And indeed, both sets of depictions serve the same ontological purpose. Canada's native inhabitants are represented as an utterly foreign people; 
everything about them is radically alien, including their way of life, belief structures and behavioural norms. They lead simple, primitive lives in which they are immersed in the natural world around them, typically opposing the advance of civilization into their territory. They adhere to a decidedly communal style of social organization, regularly acting as an undifferentiated mass and frequently displaying a marked lack of respect for human life. Their resort to violence appears instinctual and primal, often lacking the mark of strategic or rational thought.

These and other similar depictions of North American Aboriginal peoples have long played a crucial role in constructing the American self. They enable an understanding of American identity based on sophistication and the embrace and mastery of technology and civilization. They collaborate in defining the rugged and independent individual as the natural actor in political and social life and as the primary agent for effecting progressive change. Such depictions also prompt an understanding of America in which violence is understood as a necessary tool for expanding civilization.

As discussed above, much of the threat communicated by the Métis of Hollywood's Canada emanates from their liminal character. In the case of the Canada's cinematic Aboriginal people, however, the understanding of threat issues from an utterly foreign character. Thus, there is no danger of infiltration; instead, the fear is one based on an unfathomable culture bent on the violent repudiation of US society and norms. Moreover, the symbiotic relationship of the savages with the wilderness in which they live implies that the outposts of US civilization are isolated and tenuous. They are constantly surrounded and besieged by a mercurial and implacable foe. And the savage 
and inhumane violence employed by the Aboriginal people in their war against progress serves as a constant reminder of the need for society to expand the reach of civilization into all corners of the wilderness.

Hollywood portrays each of the four above groups in exaggerated and stereotypical ways. The immediate effect of this othering strategy is to populate Canada with exotic and foreign people. As a whole, this approach tends to render Canada as an alien land removed from the predictability and civility of a homogeneous America. In so doing, it helps to define the content and contours of American identity and normalizes the American self. Hollywood's othering strategy also renders Canada as unknown territory, a shadowy place that audiences can better picture as a source of instability and danger. As the next chapter will make clear, when this instability and danger within Canada is teamed with depictions of liminality, Canada itself becomes a source of threat to US security.

\section{Canada as Wilderness}

One of the most consistent representational pattern with which Hollywood depicts Canada is that of unmitigated wilderness. This pattern depicts Canada as an underpopulated and almost exclusively rural place, and reduces its people to a simple and gullible folk. These othering portrayals have constitutive implications for the definition of a modern and civilized American self. The virtually uniform representation of wilderness also contributes to the wider cinematic tendency to define Canada in such a way that it 
becomes increasingly plausible for audiences to conceive of the country as a potential source of danger or threat. ${ }^{46}$ This wilderness representational pattern manifests in a variety of ways, finding expression as an element of setting, plot and characterization.

\section{Wilderness as Setting}

Hollywood films set in Canada typically portray the country as an exclusively rural space. Indeed, urban centres are almost entirely absent from these films. ${ }^{47}$ This contention is one of Berton's most compelling arguments:

There is something else missing from the movies about Canada. It was only after viewing several score of them and after reading the storylines of several hundred more that I came to the startling realization: there were no cities shown. In fact, there weren't even many small towns. Well over 90 per cent of pictures made about this country were set either out of doors or inside log cabins or saloons. (1975: 44)

Although audiences sometimes hear references to urban centres like Ottawa and Toronto, and on rare occasions are even treated to glimpses of such cities as Winnipeg and Halifax, the vast majority of films portray Canada as entirely rural. However, as Berton's quotation suggests, portrayals of Canada are more than simply an expression of rural life; they are almost always an expression of wilderness. Thus, Canada is shown as a place where rugged physical geography takes centre stage in the form of some combination of soaring mountains, vast forests, roaring rivers, rolling plains or icy wastes (BrégentHeald, 2004: 48). As Smith contends in his discussion of films about Mounties, "the

\footnotetext{
${ }^{46}$ The next chapter explores how this notion of Canada as a wilderness frontier also serves as an invitation to a wide variety of Americans, both heroes and villains alike.

${ }^{47}$ Although, see The Iron Curtain (1948); I Confess; Niagara.
} 
producers of these films, it seemed, had come to view Canada as a series of cultural metaphors - northern lakes and woods, canoes, the wilderness, and of course mountains" (2006). Indeed, even before audience members have taken their seats, the very title of a film often helps to convey this very impression. For example, film titles often serve to highlight Canada's status as a rugged and distant land (The Country Doctor, 1936; The Far Country, 1954) or emphasize locations popularly associated with extreme physical hardship (Yukon Flight, 1940; Yukon Gold). In a similar vein, the recurring use of the word 'trail' in Hollywood film titles also serves to communicate a sense of removal from civilized, populated areas. For example, audiences are invited to travel on The Cariboo Trail and the Northwest Trail, as well as the Trail of the Mounties, the Trail of the Royal Mounted and even The Trail Beyond. Finally, titular references to the 'north' are also common among Hollywood films. Drawing on popularly-held associations that link the concept of 'the north' with cold, rugged and inhospitable conditions, such titles further cement the impression that Canada is such a place. Notable examples of this trend include North of the Great Divide and Northern Pursuit.

Building on the ruggedness implied by a film's title, representations of wilderness are frequently confirmed from the very moment a film begins. Spectacular wilderness shots often decorate the background while opening credits play across the screen. Similar shots also regularly accompany the introductory titles or voiceovers that often set the stage before the action begins. Indeed, these voiceovers themselves frequently complement such images by stressing wilderness as Canada's defining feature. For example, the opening narration for Northwest Stampede (1948) informs its audience that 
the proceeding story takes place in "a region of cool, crystal lakes and towering, snowcapped mountains, where rim-rock ledges climb upward toward the timberline." Other films provide similar descriptions, defining Canada as a "land of majestic mountains and frozen wastes" (The Cariboo Trail) or a "land of prairies and lakes and mountains" (Pony Soldier). This prefatory emphasis on physical geography and the natural world, often to the complete exclusion of images featuring humans or urban scenes, helps to prime audiences to expect a wilderness story. In this sense, beyond simply implying that the forthcoming story takes place in the wilderness, this emphasis also serves to essentialize Canada itself as a wild frontier. ${ }^{48}$ Moreover, as Allison suggests, title sequences "help to shape audience expectations by invoking intertextual and extratextual features" (2008: 108). In the case of most northerns, opening sequences typically draw on widely recognized themes and imagery that helps audiences to understand that they are about to watch a western - that is, a story that is essentially a retelling of the myth of the founding of America. These intertextual links that serve to mingle audience expectations for a western story with a Canadian setting have implications for framing Canada within an understanding of the American experience.

Although Canada's status as a wilderness is certainly communicated to audiences through a filmic emphasis on an omnipresent physical geography, it is also conveyed by a parallel stress on complementary notions of scale and isolation. For example, Canada's vast size is emphasized in an opening title from Where the North Begins, which describes

\footnotetext{
${ }^{48}$ A similar pattern also plays out in theatrical trailers for films set in Canada. For instance, in a preview for The Far Country, shots of rugged, wilderness scenery are accompanied by a series of massive, scrolling titles that fill the screen with one-word descriptors: "AWESOME... FORBIDDING... SPECTACULAR." In a similar vein, the trailer for Island in the Sky describes its setting as "a world that time forgot."
} 
"a vast territory stretching from ocean to ocean." In Perils of the Wilderness, the opening voiceover describes its setting as "more than a million square miles of wilderness." Other productions proceed from a similar assumption, defining the country as "a vast dominion...from the United States border to the Arctic ice pack, and from the Atlantic to the Pacific" (King of the Royal Mounted) or "300,000 square miles of virgin prairie and forest, set in the grandeur of the towering Rockies...vast wilderness" (Gunfighters of the Northwest).

In this sense, not only are Canada's inhabitants and visitors confronted by the hardships brought on by the severity of their physical surroundings, they are also challenged by a wide-open country that leaves them separated from other humans. As Berton suggests, "this theme of isolation was very strong in the Hollywood view of Canada. Again and again moviegoers throughout the world were introduced to men who lived totally alone, cut off from civilization, stranded as on a desert island from any contact with their fellows" (1975: 53). This sense of isolation is found in The Country Doctor, for example, when a broken telegraph machine prompts a character to express his frustration: "This thing is deader than a salt mackerel...if we get a message out of here inside of a month we're lucky." Many other films portray Canada in similar terms: "a barren, desolate land...many miles north of civilization's last outpost" (Perils of the Wilderness); a "wild and desolate land" (Susannah of the Mounties); a place "where the footprint of man is seldom seen" (Northwest Stampede). This sense of removal is also integral to the setting of Canadian Mounties versus Atomic Invaders, a film in which the 
villains are able to effect their murderous scheme by taking advantage of the isolation and remoteness of Canada's population.

Even the names of Canadian settlements in Hollywood films often contribute to the impression of wilderness and isolation. Frequently, such names draw on animals (Caribou, Moosehead, Moosetown), climatic conditions (Chinook) or geographic features (Bleak River, Black River, Elks River). This naming trend helps to imply both that Canada's population is distributed in small, quaint settlements and that these centres that pass for Canadian civilization are little more than outposts, surrounded and under siege by an omnipresent wilderness.

\section{Wilderness as Plot}

For many films, Canada's harsh wilderness performs a dual role; not only does the wilderness provide a setting for the story, it often provides an integral element of the story itself. Thus, storylines regularly revolve around journeying or escorting individuals across trackless wilderness (Saskatchewan; Nikki, Wild Dog of the North). In other cases, Canada's wilderness provides a profound obstacle against which the protagonists battle (Island in the Sky, 1953; The Silent Enemy). As part of this process, the awe-inspiring and breathtaking wilderness quickly becomes treacherous and deadly. This intertwining of geography and danger is captured in a line delivered by a character named Grizzly in The Cariboo Trail: "This here's the Cariboo Trail, mister. A broken heart for every rock, a dead man for every tree." 
One of the main dangers that menace Canada's wilderness is the fierce and untamed wildlife that populates the country's hinterland, including bears (Trail of the Royal Mounted), wolves (Snow Dog) and wild dogs (Canadian Mounties versus Atomic Invaders). However, Canada's most pressing wilderness danger emerges from the country's status as a land of snow and ice. For example, in an implicit warning about the dangerous power wielded by nature, blinding and intense snow storms are responsible for plane crashes in both Klondike Fury and Island in the Sky. Massive avalanches are also common in Hollywood's Canada, threatening or killing characters in a number of productions, including Northern Pursuit and Canadian Mounties versus Atomic Invaders. Even more threatening is the danger of extreme cold. For example, The Viking follows the treacherous journey of sealers from Newfoundland as they traverse the dangerous ice floes of the North Atlantic in search of seals, an undertaking the production bills as "the world's most dangerous adventure." From start to finish, the film functions as a showcase for the hardships implied by Canada's harsh Atlantic wilderness. The action opens with a struggling mail carrier who nearly dies from the extreme temperatures brought on by a howling blizzard. And, later in the film, when the sealers embark on their quest, the severe conditions against which they battle transform their efforts into a life and death struggle in which they "must fight the frozen hell of Arctic ice-fields for their lives."

The Silent Enemy, a film about an Aboriginal tribe's quest for food during Canada's winter months, is similarly structured around notions of the awesome power of the country's unforgiving physical conditions. Indeed, the entirety of the picture's images and dialogue act as a showcase for the country's harsh winter. The threat of the extreme 
cold is made plain to the audience in one title: "earlier than ever came Keewatin, - the North Wind, howling his warning." Island in the Sky details the harrowing ordeal faced by a group of US flyers who crash land in Canada's north and must survive against the odds in the hopes of being rescued. In a nod to Canada's severe geography and climate, the film's trailer describes the region where the men are stranded as a place "where all civilization ended." When the leader of the rescue effort questions his "Arctic expert" about the likelihood of the men surviving by hunting wild animals, he receives a sober response: "No one knows, Colonel. No one's ever been up there before. If [the pilot] flew to the end of his gas supply, he's at least two hundred miles in uncharted territory. Why, even the Eskimos won't have it."

Even in those films in which treacherous and frigid weather is not featured as a plot device, the audience is almost always presented with an implicit reminder of the certainty of a severe winter. Most frequently, this reminder takes the form of a seemingly inevitable pair of snow shoes hanging on the wall of the local trading post, Mountie detachment or general store. Even in those films considered to be of the northern genre, which in most important aspects is simply a Canadian version of the standard, dusty western, this unmistakable symbol of winter is sure to make an appearance. ${ }^{49}$

\section{Wilderness as Characterization}

\footnotetext{
${ }^{49}$ As Beaudreau shows, Hollywood's filmic emphasis on Canada's status as a snow-bound nation is mirrored in National Geographic's pictorial representations of Canada (2002: 523-524). As they are portrayed in the pages of the magazine, Canadians "seem not to see ice and snow as an inconvenience that keeps them housebound for half the year, but as an opportunity for joyous winter adventure (524).
} 
Canada's status as a wilderness speaks not only to its physical setting, but also to the kind of people that live there. More specifically, Hollywood's Canada appears to be populated by people with a simple and unassuming demeanour, a demeanour that is made to appear as though it issues from the natural environment in which the people are immersed. Thus, apart from the villains, who are inevitably othered as foreign, Canadians are depicted as largely free of the jaded and cynical mindset implied by urban living. Indeed, for Hollywood, the simplicity of life in a rural setting ensures that Canadians remain, for the most part, an unsophisticated and guileless lot. Hollywood's portrayal of Canadians as though they lack sophistication is one of the arguments Berton makes at length:

Anybody introduced to Canada entirely through motion pictures - and that includes hundreds of thousands of people around the world - would find it impossible to believe that since the mid-1920's this has been predominantly an urban country. The physical symbols of a sophisticated society - skyscrapers, bridges, neon signs, traffic lights, university campuses, football fields, suburban streetscapes, department stores simply did not exist in movies about Canada. (1975: 44)

Examples of this trend include The Scarlet Claw, in which the rural Québécois are depicted as superstitious and provincial in the wake of Sherlock Holmes' investigative acumen. A more explicit example of this othering dynamic at work is found in Trail of the Royal Mounted, when the US hero dazzles a wide-eyed Canadian child with stories of civilization: "And I'll tell you Billy, they've got buildings there as high as that pine tree up on the hill." A similar dynamic is on display when Peg communicates the depth of her sheltered existence to the hero in Klondike Fury: "Do you realize I've never been to a 
concert in my life? I've never seen the curtain go up on the show. I've never seen a building that had an elevator in it. Tell me about them."

A related aspect of this trend also presents Canada as a unique place for individuals looking to commune with nature. For many visitors, this suggests Canada as a land of vacation. In this capacity, not only does the country boast its traditional tourist attractions, like Niagara Falls (Niagara; Niagara Falls, 1941) and the Calgary Stampede (Northwest Stampede), it also plays host to an abundance of remote vacation lodges (Renfrew of the Royal Mounted, 1937). In more extreme cases, however, Canada attracts people in need of something more than a vacation. And, for such individuals, the wilds of Canada afford an unparalleled opportunity to rediscover some essential part of their being (Berton, 1975). As Brégent-Heald contends, "the vast mythical northwest region of Canada offer[ed] opportunities for redemption...Far from the suffocating and decadent city life, isolated forest cabins and the stillness of snowfields provided the perfect tranquil backdrop for introspection and renewal" (2004: 9). For example, in Klondike Fury, the rugged beauty and serenity of the Canadian northwest provides the protagonist with an escape from the pressures of urban living and the strength and confidence he needs to return to his calling as a brilliant brain surgeon. In The Viking, surviving the harrowing snow and ice of the North Atlantic transforms Luke into "a real man." The wilds of northern Quebec enable the title character in Rose-Marie to finally realize her true values and, ultimately, entice her to leave a chaotic life in the urban world. Similar stories, in which the naturalness of Canada serves to remind characters of what is really important 
in life, are told in a wide variety of other films, including Reunion (1936) and Phantom Patrol.

These three intersecting representational patterns do more than simply portray Canada as wilderness. As suggested above, they also serve to define and normalize American identity. For example, US audience members watching a film set in Canada's wilderness are implicitly encouraged to understand their own nation as a civilized and modern place (Brégent-Heald, 2004: 27). This dynamic is at work in Crashing Thru' (1939), when a visitor to Canada is entranced by the beauty of the country's wilderness: "I've often tried to picture this north country. Big trees and swift streams. Picturesque people. Ahh, it's beautiful." Such a description, made by an American character, can only be sustained if the audience assumes that the character's home nation, and their own, is representative of civilization and modernity. Canadian Pacific provides another example of this dichotomous logic when a US railroad worker explains why he relocated to Canada: "When they started pushing that iron into civilization it got too tame, so I just sneezed it off and came up here to Canada." Again, the implication that Canada is uncivilized only makes sense if the audience agrees with the character's preliminary assumption that America is civilized.

Several films explicitly drawn upon an urban/rural dichotomy in which an urbanized America is reaffirmed in relation to a rural Canada. Such films often open in a US setting that is dependably represented as urban and modern, though a subsequent relocation to Canada transports the characters to an invariably rustic and isolated backcountry (Phantom Patrol; Trail of the Royal Mounted). This technique, in which the 
audience is exposed to back-to-back representations that explicitly contrast an urban America against a rural Canada, serves as an effective device for removing the audience to a different place and time. This urban/rural dichotomy is a particularly prominent pattern in those films in which Canada is represented as a place where people can find rejuvenation, such as Klondike Fury and Rose-Marie. Thus, even when Canada's wilderness is understood in a positive light, as a place where the ills of civilization can be cured, it is still effectively being essentialized as primitive. And this depiction of a primitive Canada only makes sense in the context of a modern and developed America.

Depictions of Canadians as quaint and guileless ${ }^{50}$ are only made intelligible by a complementary understanding of Americans as a sophisticated and modern people. For instance, in Northwest Trail, an urbane US woman patronizes a Mountie as some kind of oddity or local curiosity after he comes to her rescue: "I thought I recognized the uniform. Course I've only seen it in movies. Say, uh, tell me, is this 'always gets his man' stuff true or just a lot of movie hokum?" A number of films make this point in terms of education. In The Trail Beyond and Phantom Patrol, for example, characters are shown returning to Canada after having relocated to the United States in order to receive an education. The unspoken suggestion that Canada is incapable of providing a modern education to its citizens is made understandable by a parallel implication that America is a more advanced and developed nation.

In a similar vein, Hollywood also takes steps to address Canada's seeming dearth of scientific expertise by importing US scientists. For example, in Sky Bandits (1940),

\footnotetext{
${ }^{50}$ Brégent-Heald uses the phrase "backwoods bumpkins" (2004: 47).
} 
when the villain feels the need to improve on the lethal creation of a local inventor, he looks to the south for additional acumen: "You discovered a new principle for power wave transmission. But you couldn't advance it fast enough so I paid plenty to bring the best electrical brains in America brought up here." In King of the Mounties, when Canada finds itself defenceless against merciless bombardment by a secret Axis airplane, the country is saved by the intervention of a US scientist and his daughter, and their 'detector machine.' Following the defeat of the Axis plot to invade Canada, the serial concludes with the Commissioner of the Mounties honouring the Professor's daughter in a private ceremony in which he admits, "It was your heroic cooperation which made all this possible, and I assure you Canada deeply appreciates your services." The clear implication of these films is that Canada simply does not produce people with the level of intellectual development that can be found in the United States. The dichotomy at work in these examples clearly establishes America as a land of sophisticates in relation to a more crude and backward Canada.

A number of dangers are found to issue from Hollywood's wilderness version of Canada. The climate, physical geography and wildlife that help to define the country as hinterland all pose significant dangers to any who dare to travel through or live in Canada. As great as this danger is, however, a far greater threat emerges from the type of people who are most at home in such an unforgiving landscape. The Canadian wilderness is populated by savage Indians and scheming Métis. These groups, living as one with the natural world that surrounds them, seem to embody the tempestuous and dangerous qualities of the wilderness. Moreover, both groups are intent on preserving their wild and 
free way of life and are quick to embrace violent means to overthrow western society and stem the expansion of civilization into their territories.

The wilderness also acts as host to a different class of dangerous people, individuals not necessarily understood as indigenous or natural extensions of the harsh Canadian wilds. These people are attracted to Canada, and are able to thrive in its untamed environment, because of the country's combination of sheer size and sparse and isolated settlement patterns. The potential for lawlessness implied by Canada's underpopulated frontier serves as an incentive for a range of undesirable characters, from petty thugs looking to make it rich, to ruthless criminal gangs seeking to create their own empire. This rugged and isolated wilderness even attracts the operatives and spies of foreign nations, bent on destroying Canada and the United States.

Hollywood's understanding of Canada is dominated by impressions of wilderness, isolation and backwardness. These, and other related concepts, provide the structure for much of the setting, plot and characterization that make up films set in Canada. This othering strategy also plays a role in defining American identity, helping to reinforce an image of the nation founded on notions of civilization, sophistication, urbanization and mastery over mankind's natural surroundings. As a corollary, this pattern that others Canada as wilderness also portrays the country in such a way that US audiences are better able to imagine the country as an untamed place that hosts unknown dangers. As the next chapter explores in depth, patterned depictions of liminality serve to transform Canada's status as a dangerous setting to one of emerging threat. 


\section{Canada as Passive}

One of the most pronounced themes running through filmic representations of Canada is that of passivity. This pattern depicts Canadians as unwilling or unable to establish control over their social domain or mastery over their physical surroundings. This othering pattern helps to construct an active and powerful American self, possessed of the drive, strength and ingenuity to establish dominance over both the social and natural world. The construction of Canadians as passive also enables the portrayal of Canada as a place where threats to the social order are allowed to roil unchecked.

Although there are a variety of ways in which the impression of passivity is conveyed to US audiences, this section will focus on just two prominent examples. The first example emerges from the regularity with which non-Canadian characters, most frequently the American cowboy, play crucial roles in a Canadian setting. The second example is witnessed in the repeated deployment of natural resource extraction and exploitation as an integral plot component. Together, these patterns render Canada an empty stage upon which other actors perform. To be sure, Canada is portrayed as an interesting and adventurous setting - a vast and rugged land, rich in natural resources and populated by exotic peoples. However, when considered on their own merits, Canada's land, resources and people are seldom deemed worthy of sustained attention. Rather, it is the injection of other people that creates a noteworthy story. Indeed, for Hollywood, stories about Canada regularly involve Americans challenging the rugged and untamed land, exploiting the vast natural wealth and interacting with the quaint local inhabitants. 
The result of this pattern is to render Canadians passive and Canada a place where other people realize their dreams or otherwise achieve greatness.

\section{The Cowboy in Canada}

One of the main ways in which Hollywood others Canada as passive is by portraying the country as a place where other people come to do great things. Indeed, Hollywood regularly inserts Americans into the most important roles in films that otherwise purport to tell stories about Canada. However, considering that the Canadian setting often functions as an exotic locale to assist filmmakers in their quest to renew and retell quintessentially American stories, it is not surprising that US characters are a staple feature in Hollywood stories set in Canada. Of these characters, villains, love interests and sidekicks are all common. The US hero, however, plays a particularly prominent role in Hollywood's Canada. Among those heroes who travel to Canada to seek their destiny, none is more conspicuous than the American cowboy. As one of the most culturally resonant symbols of American identity and US agency, the cowboy's arrival in Canada serves as a blatant assertion of Canadian passivity. By inserting the cowboy into a Canadian setting, and having him bring justice to Canada's lawless wilderness, Hollywood both draws from and perpetuates a self/Other dichotomy with constitutive implications for American identity. The framing of this dichotomy uses the impression of Canadian passivity to reinforce the exaggerated sense of agency that dominates popular impressions of American identity. Moreover, beyond its impact on the content of American identity, Hollywood's dichotomous vision of Canada and Canadians as passive 
also make it possible to understand how crime and disorder are able to roil unchecked within Canada's borders. As the next chapter explores, this location of threat in Canada has important implications for American identity.

Although there is a rich variety of ways in which Hollywood uses the Canadian adventures of the American cowboy to script Canada and Canadians as passive, this section will explore only two. First, it will examine how the presence and exploits of the cowboy in Canada serve to both confirm that country as a lawless place and imply that Canadians are unable or unwilling to take the steps necessary to improve their situation. In effect, relocating the cowboy and his timeless quest to establish justice in the Canadian wilds portrays Canada as a place lacking in homegrown actors equipped with the initiative, dedication and agency needed to create and maintain a secure environment. Second, this section will explore the cultural meanings generated by Hollywood's frequent on-screen comparison of the American cowboy and the Canadian Mountie. Each of these two characters occupies a place of considerable importance in its respective culture and boasts a long and storied tradition as a classic icon of national identity (Coyne, 1997; Dawson, 1998). As a consequence, the consistently unflattering portrayal of the Mountie in relation to the cowboy has implications for film audiences' perception of Canada in relation to the United States. More specifically, in the context of stories that feature the cowboy upstaging the Mountie, in Canada no less, this trend serves to diminish Canada's capacity for agency in relation to that of the United States.

Films from Hollywood's Classical era portray Canada as a place where injustice and disorder are either rampant or just about to flare out of control. It is into this chaotic 
setting that filmmakers insert the American cowboy. That the lawless situation soon compels the cowboy to take on a prominent role in effecting justice in this Canadian setting serves to underscore the lack of effective leaders within the domestic population. In effect, positioning the cowboy as an agent of law and order in Canada implies that Canadians themselves are a passive lot. The apparent need for the American cowboy to establish order implies that Canadians are either unable or unwilling to play an active role in ordering their own wilderness society.

A variety of Hollywood films feature a cowboy travelling to Canada with the express purpose of pursuing a criminal from the United States who has fled north. Not only do these heroes typically find and arrest the fugitive they are chasing, they also tend to play a wider role in bringing order to the country in which they find themselves. In Perils of the Wilderness, for example, Montana Deputy Marshal Dan Mason tracks a murderer to Canada. While in the process of successfully apprehending the criminal, Mason also repeatedly saves a Mountie from seemingly certain doom and breaks up an entire outlaw gang. In a slight twist on this theme, Royal Mounted Rides Again features an odd, scruffy prospector named Buckett, who is eventually revealed to be an undercover US Treasury agent on the trail of a counterfeiter. This unlikely cowboy not only brings his quarry to justice, but also plays a crucial and recurring role in helping the Mounties defeat a larger gang of criminals. As his cryptic one-word response to a friendly question suggests, Buckett's singular contribution comes not from his strength or daring, but from his vastly superior grasp of intelligence:

Constable 'Frenchy' Moselle: "That cigar - back and forth in your mouth - she tell me that you know something we do not know, n'est pas?" 
Buckett: "Oui."

Canada's passivity is confirmed in these kinds of films in two ways. First, the very fact that the villains choose to operate out of Canada in the first place implies that the country is a logical hiding place because of its unsettled and lawless nature. As a local quisling confirms to his boss, "that's pretty wild country - not much chance of anyone bothering us" (Canadian Mounties versus Atomic Invaders). Second, the prominent role played by the cowboy underscores, often explicitly, the shortcomings of Canadian law enforcement. Indeed, the contributions of the cowboy are usually of such critical importance that justice would likely go unserved if not for his presence and the particular attributes he brings with him.

It is more common for the cowboy to find himself thrust into a leadership role unexpectedly after arriving in Canada than it is for the cowboy to journey north for the express purpose of effecting justice. For example, North of the Border features a heroic cowboy, with the conspicuous nickname 'Utah,' who comes to Canada in search of his friend. It is only upon his arrival that Utah becomes aware that his friend has been murdered. He quickly takes matters into his own hands and proceeds to track down the killer, break up the gang of thugs and ensure that the load of stolen fur pelts is recovered. By the film's conclusion, the cowboy is even offered a job as a Mountie. ${ }^{51}$ Similarly, in The Trail Beyond, John Wayne's character comes to Canada in search of the niece of a family friend. However, by the time the action draws to an end, he has not only found the niece, but also solved the murder of the woman's father, located a lost gold mine and

\footnotetext{
${ }^{51}$ As it turns out, the cowboy ultimately passes on the opportunity to join the Mounties, choosing instead to return to the United States with his new Canadian sweetheart obligingly in tow.
} 
captured the villains. In Blue Canadian Rockies (1952) Gene Autry is a ranch foreman from Montana who travels to Canada to look after the daughter of his employer. Once there, however, he soon finds himself playing the main role in defusing a dangerous confrontation between Canadian lumberjacks and the US owner of a dude ranch.

Other films play on the notion of Canada's liminality, and feature cowboys that criss-cross back and forth across the border as they mete out justice on both sides. For example, in North of the Rockies (1942), Tex Ritter stars as a US ranch foreman who is instrumental in uncovering and defeating a fur smuggling ring operating on both sides of the border. North of the Great Divide features Roy Rogers as a US Indian agent who is able to bring peace and order to both sides of Canada-United States border. He solves the murder of a Mountie, proves the innocence of his blood-brother, safeguards the livelihood of the region's Indigenous people and even initiates a political process that culminates in an international agreement between Canada and the United States.

All of these films cement the impression that Canadians are simply waiting for a man of action to make them safe from anarchy and criminal predation. Indeed, even when a Canadian law enforcement official makes an appearance, his presence in the face of the unchecked injustice only serves to highlight Canada's inability to defeat the criminals. This impression is even further reinforced when the introduction of the cowboy, with his active, no-nonsense approach and disdainful disregard for stifling rules and procedure, is invariably found to be the corrective Canada needs.

One of the most powerful expressions of Canada as a passive Other can be glimpsed in a series of films which insert the cowboy as an integral character in crucial 
episodes in Canada's historical development. These films create the impression that even in those defining moments of Canadian history, the nation required the assistance of US heroes. As a consequence, not only is American agency and power reconfirmed, but Canada is defined as a passive, junior partner in its own development. One example of this pattern, North West Mounted Police, insinuates the cowboy into the Northwest Rebellion of 1885, one of Canada's most important foundational episodes. In this retelling, Gary Cooper plays Dusty Rivers, a Texas Ranger who comes to Canada to track down a killer. For the new nation of Canada, the Ranger's arrival turns out to be fortuitous, as he not only captures the killer he has been tracking, but also faces down a volatile Indian chief and, ultimately, plays a crucial role in putting down the rebellion. The Cariboo Trail provides a similar endorsement of the values trumpeted by the American western. Its depiction of a Montana cowboy single-handedly paving the way for the settlement of the interior of British Columbia is largely beholden to the character's quick recourse to physical violence. In a bold affirmation of the importance of the United States to Canada's development, the film's introductory voiceover even goes so far as to hail the Montana cowboy as "a man who helped to build a nation."

As the above examples make clear, the presence of the American cowboy in the wilds of Canada is typically made understandable to audiences through the representation of Canada as a passive society that is simply unable to provide law and order across its territory. As Berland suggests with respect to the image of Canada presented by the "Northwoods" pictures, "this was obviously a childhood civilization: a landscape in need of conquest, industry and law" (1999: 214). Although this is a theme that is played out in 
a large number of films, one production in particular, The Far Country, exemplifies this situation so precisely that it merits an extended analysis.

In a pivotal scene that sets the stage for the film's intertwining of Canadian passivity and American agency, the local Mountie is confronted by a restless group of townspeople upset by the lawlessness in their growing community. When challenged on his inability to provide protection, the Mountie blames the size of the territory and the lack of resources:

Dusty: "You're the law up here. Why don't you do something about them killings?"

Constable Kingman: "Yes, I'm the law. At least I represent the law in Yukon Territory - about fifty thousand square miles of it.

Miner: "Well, why aren't there more of ya?"

Constable Kingman: "Because yesterday this was a wilderness. We didn't expect you to pour in here by the thousands. But now that you're here, we'll protect you."

The scene continues with the people unmoved by the Mountie's promise and reiterating their lack of faith in his reassurances. His hands tied, the constable ultimately responds by advocating what can only be understood as a typically 'American' response to the problem:

Constable Kingman: "There'll be a post established here in Dawson early in May."

Yukon: "What happens between now and May? You gonna be here to keep order?"

Constable Kingman: "Part of the time."

Dusty: "What about the rest of the time?"

Constable Kingman: "Pick yourselves a good man. Swear him in. Have him act as marshal 'til you pull out in the Fall."

The implications of a Mountie, the archetypal symbol of Canada, advocating that the townspeople select someone to serve as a town marshal, the archetypal symbol of 
America, are clear: the universal problem represented by Canadian disorder can best be pacified by a quintessentially American response. Indeed, the Mountie acquiesces even further to the American western genre's understanding of agency when the townspeople ask him who they should select for their marshal. His simple response to their plea for advice, phrased in the form of his own question, confirms that frontier justice rules the day in Canada: "Who's handy with a gun?"

The film continues to reinforce this interpretation as it progresses towards its climax. When Jimmy Stewart's protagonist, a gun-slinging cowboy from Wyoming, refuses the town's request to serve as marshal, the position is filled by two lesser men in rapid succession. The first man, Rube, steps down from the position in shame, having failed to stand up to the villain's main henchman. The second man, Yukon, is physically beaten when he confronts the main villain about several false mining claims. It is not until the film's final sequence, when Stewart's character finally takes the law into his own hands, that the villain is defeated and the townspeople emboldened to chase off his cronies.

This film leaves the audience with three successive interpretations of how justice and agency relate in Canada. First, Canadian law enforcement, though perhaps wellintentioned, is simply unable to provide adequate protection. The Mountie's absence from the settlement of Dawson plays a structuring role in the development of the plot. Indeed, the Mountie is defined more by his absence than his presence, with the novelty of his brief on-screen appearances being used to emphasize that his absence is the normal state of affairs. Second, the forgettable tenures of both Rube and Yukon as the elected marshal 
make it clear that good intentions are of little help in effecting justice if they are not backed up by strength, bravery and initiative. Moreover, the reluctance of the townspeople to take action themselves or lend meaningful support to the tepid efforts of their elected lawmakers exposes them as passive and cowardly. The third interpretation is revealed in the gunfight at the conclusion of the film. This epic confrontation, pitting the American cowboy against the despotic villain, provides a sharp contrast to the passivity of the Canadian townsfolk. In this vein, Gittings suggests that The Far Country acts to extend the US principle of Manifest Destiny across the border to Canada. He contends that the images at work in the film function to discipline the audience to "see the United States as a strong and righteous country that sometimes must expand its frontier to bring morality, law and order to other lands that are bereft of such uniquely American commodities" (2002: 163-164). Indeed, the conclusion to the film leaves no doubt that a willingness and ability to resort to violence remains the ultimate remedy against a lawless frontier. It is this vision of justice, a simple reiteration of the version made popular by the western genre, that is shown to be appropriate for Canada.

The northern genre of films, for the most part, provides audiences with a more exotic retelling of the standard western narrative of the creation of America. This implied overwriting of American identity onto Canada's development serves to reduce Canada to an inert setting and Canadians to a passive and helpless people. However, when the main hero is himself an American cowboy, the archetypal icon for American identity, this overwriting is made even more explicit. 
The second way in which Hollywood uses the archetypical US hero to frame Canada as passive is through an on-screen comparison in which the cowboy is contrasted with the Mountie. Each of these two characters holds iconic status within its respective popular culture and stands in as a symbolic representative of its nation's identity. Jeffrey Richards notes the cowboy's iconic status in his preface to Coyne's The Crowded Prairie: "For the United States, the Western film and the national identity have been inextricably linked. The cowboy has been recognized world-wide as one of the most potent and enduring symbols of America" (1997: ix). Similarly, with respect to the Mountie, Thacker claims he "has become synonymous with Canada in the eyes of the world and, indeed, so he has to Canadians themselves" (1980: 298). As a result of their powerful association with national identity, the pairing of these two characters in the same film inevitably leads to implicit generalizations that serve to compare the two countries. In most cases, films that feature this pairing tend to depict the cowboy in a favourable light, framing the Mountie as somehow less able or competent. ${ }^{52}$ More specifically, the cowboy is typically portrayed as more daring, aggressive and active than his Canadian counterpart. Moreover, he stands in direct opposition to the tradition of formality that the Mountie typifies, and refuses to be bound by restrictive rules and restrictions. However, beyond possessing mental and physical characteristics that are better suited to the frontier, the cowboy is also invariably shown playing a crucial role in

\footnotetext{
52 There are certainly films in which Canadians are explicitly framed favourably in relation to US characters. Indeed, films such as The Canadians and North West Mounted Police sometimes use dichotomous logic to expose perceived flaws in US policies and mainstream impressions of American identity. However, such films are small in number and do not, on balance, detract from the wider impact made by the corpus of Hollywood films.
} 
effecting justice in the Canadian setting. This leading role for the cowboy is typically made necessary in light of a lack of meaningful Canadian law enforcement, which is itself made apparent by incompetent or subservient Mounties.

The impression of the Mountie's incompetence is conveyed in a variety of ways. For example, in Trail of the Royal Mounted, the Mounties are portrayed as an undifferentiated mass. A Canadian version of a mindless posse from the western genre, these Mounties ride frantically and en masse from scene to scene, appearing largely incapable of independent thought or action. Such a characterization is particularly telling when juxtaposed against a more favourable depiction of the US hero. Indeed, no other aspect of this film is as effective in highlighting the power and agency that derives from the cowboy's individualism than his constant comparison with the mindless, galloping crowd of nameless and ineffectual Mounties.

Another manifestation of this pattern of incompetence involves the Mountie mistaking the cowboy for a villain and trying to apprehend him. An example of this unflattering error is emphasized in North of the Rockies when a falsely-accused cowboy lampoons a well-known catchphrase popularly associated with the Mounties: "I believe they have a saying about you Mounties - you always get your man. I guess that means just any man that happens along, huh?" The Mountie is even further deflated when the cowboy makes him the butt of a parodical song that he sings in front of a crowd of Canadian onlookers. The Mountie's comparative lack of competence is further cemented in situations in which the cowboy bests him in a physical confrontation and renders him a prisoner. This theme plays a prominent role in framing both the cowboy and Mountie 
characters in North of the Border, as evidenced in a scene in which the Mountie is called to task for letting the cowboy escape custody:

Inspector Swanson: "Well, it sounds like carelessness on your part, Craig." Craig: "Yeah, I guess it was my own fault, Inspector. I shouldn't have put as much faith in him as I did. But he seemed like a man you could trust. Doggonit, I'd still take a chance on him!"

To cement this impression even further, the American cowboy in this film is also regularly called upon to rescue the Mountie from a variety of dangers. A similar pattern is played out in a wide variety of films: in The Trail Beyond, the US hero saves his Canadian counterpart from drowning; in God's Country and the Man, the cowboy prevents the Mountie from going over a waterfall; in Perils of the Wilderness, the US lawman saves the Mountie from being shot in an ambush. Indeed, even when it is too late to effect a rescue because a Mountie has already been murdered, it is frequently the cowboy who solves the crime (Blue Canadian Rockies).

In other cases, although the Mountie may be portrayed as generally competent, he is nonetheless seen to be dependent upon the cowboy for crucial assistance (North of the Rockies; North West Mounted Police). In effect, these productions often render the Mountie a junior partner to the more decisive and determined cowboy. For example, in God's Country and the Man, it is a deputized American cowboy who rouses the nearest Mountie detachment and leads their charge against the villains with considerable authority: "There they are, men! Let's take them!" In The Trail Beyond, after rescuing, subduing and detaining the Mountie who is wrongfully pursuing him, John Wayne is ultimately deputized and then takes charge of a group of Mounties that routes the villains. Perhaps the desperate need for such decisive leadership from the cowboy should be 
expected when the film's poster refers to Canada as a place "where life was raw and might was law!" An extreme example of this pattern involves the cowboy explicitly refusing to respect Canadian law enforcement, as demonstrated in an early exchange between the cowboy and the Canadian love interest in North of the Border:

Ruth: "But you're not the law. If you think a crime has been committed then we should report it to [Sergeant] Jack Craig."

Utah: "We went all through that this morning. You promised to let me handle it my way."

As a reward for the cowboy's willingness and capacity to effect justice, and an implicit confirmation of the cowboy's superiority, the US protagonist is often rewarded handsomely. For instance, he frequently wins the affections of the Canadian leading lady (The Far Country). Moreover, in what amounts to a formal recognition of his effectiveness, the cowboy is often deputized by a Mountie (God's Country and the Man; The Trail Beyond) or even offered a permanent job with the Mounties (North of the Border). These scenarios, in which the archetypal American hero succeeds in the Canadian context to such a degree that he wins the affection of a local woman or is offered a position with the Mounties, imply a kind of national overwriting. In effect, such resolutions serve to highlight a deficiency in Canada's national character and convey the country's need for American agency and power. The suggestion that issues from this is that Canada needs to be more 'American' in order to succeed in its efforts to bring order to the wilderness.

Canada's status as a passive Other has implications beyond merely helping to sustain the dominant understanding of the American nation as one built on and infused with an abundance of agency. It also plays a role in introducing the spectre of danger on 
the borders of the nation. The implicit message from Hollywood films is that Canada's passivity enables the forces of chaos and criminality to endure within its borders. ${ }^{53}$ The effectiveness of the American cowboy in neutralizing these threats suggest that if Canadians were more like Americans, then such threats would either be avoided or overcome without the need for external assistance.

As the American experience shows, especially that version of the American experience articulated by Hollywood westerns, nations need to be able and willing to take strong and decisive measures to ensure their own future against the uncertainties of the frontier. For example, the lesson communicated by such productions as North of the Border and Trail of the Royal Mounted is that criminality and injustice will prevail in Canada unless swift, independent and decisive action is undertaken by a cowboy figure. Films like North West Mounted Police imply that violent insurrection and threats to national sovereignty are a fact of nature on the northern side of the border and can only be stemmed if confronted by someone with the disposition of a Texas Ranger. US audiences are reminded that the struggling, incipient pockets of civilization that dot Canada's frontier are under constant threat from violent savages bent on forestalling the advance of modernity. Only through the will and determination of decisive men, like the Montana cowboy protagonist of The Cariboo Trail, will Canada be made safe.

\footnotetext{
${ }^{53}$ As the following chapter shows, Hollywood's introduction of this threat to Canada contributes to the widespread impression that the world outside US borders is a dangerous place. The chapter builds on this introduction and examines how Canada's portrayal as a host to such threats, when combined with an understanding of the country as liminal, contributes to the rigidification of the borders of American identity.
} 
Canada has served as a destination for some of the most prominent leading men of the western genre. It has hosted a wide variety of stars, including Gene Autry, Roy Rogers, Randolph Scott, Jimmy Stewart, Garry Cooper and John Wayne. Each of these stars is an iconic actor that not only exemplifies the Hollywood cowboy, but also stands in as a symbol of America itself. Their relocation to Canada, therefore, has implications for how US audiences understand Canada's place in relation to the United States. In particular, their presence in Canada and the great deeds of strength and bravery that they are required to perform serve to depict Canadians as passive and confirm America as a nation defined by its agency.

The broad implication that flows from Hollywood's understanding of Canada is that the country is a place that requires Americans to effect positive change and establish order. Films sometimes allow for a Canadian role in this process, but the inclusion of a prominent US presence serves to reduce the fundamentally Canadian nature of the unfolding events. Instead, the stories presented by Hollywood are portrayed as part of a wider understanding of the American experience. In effect, by deploying American cowboys as the heroes, such films valorize the culture and values promoted by the western genre, imbuing them with a kind of universal mission by having them play an important role in resolving events critical to the development of Canada. Of these values, the much-lauded belief in American agency is given particular support. A passive Canada not only enables the definition of the active and decisive American cowboy, it recreates a northern version of the American west. In this sense, Canada stands in as a reproduction of the original geographic and temporal condition that compelled the cowboy's very 
existence in the first place. These portrayals of passivity also help to make it possible for audiences to understand Canada as a place where threats and dangers are left unchecked. As the next chapter makes clear, the presence of these dangers in Canada has implications for US security.

\section{Canada and Resource Extraction}

While it is undeniable that much of Canada's historical economic development can be linked to the country's primary industrial sector, Hollywood's image of Canada allows for precious little else. Indeed, a considerable majority of the films screened for this dissertation are explicitly based on themes of resource extraction. Their array of plots is diverse, ranging from gold strikes in the northwest to the seal hunt off the Labrador coast; from pitchblende mining operations in central Canada to salmon canning on the rivers of coastal British Columbia. Taken individually, such plots serve to highlight the predictable image of Canada as a land rich in natural resources. Taken as a whole, however, and understood in the context of a depiction of Canada that is almost entirely one of wilderness, this thematic trend reduces Canada to a simple repository of natural resources. Such an understanding of Canada is rendered even more problematic when one considers that those responsible for the extraction are usually US citizens. Canadians themselves, as it turns out, seldom play a meaningful role in the extraction process, beyond that of simple labourer or henchman. These representational patterns encourage audiences to understand Canada as a passive entity, blessed with abundant resources, but 
saddled with a population that is either indifferent to the riches around it or incapable of extracting them.

These portrayals of Canada as a passive Other, especially when framed in the context of Americans who travel to Canada to extract or otherwise exploit the country's resources, contribute to the existing dominant impression of an American self centred on notions of agency. Moreover, as a place that effectively invites any manner of dubious outsiders to sate their economic appetites on its resources, Hollywood's version of Canada also helps US audiences to understand how the country's passive nature acts to attract dangerous characters.

This section explores two prominent themes of passivity that emerge from Hollywood's treatment of Canada's natural resources. First, it examines the consistency with which film plots depict Canada as an inert and physical setting, rather than a dynamic human society. In so doing, these films deny Canada an identity based on modern understandings of urban settlement patterns or industrial development. Second, this section details the prominent role Hollywood accords to Americans in the exploitation of Canada's resources. As a result of this trend, films that ostensibly tell stories about Canada are exposed as vehicles for relating stories about Americans in Canada.

Hollywood films display a fixation on Canada's physical features that verges on obsession. Beyond depicting Canada as simply rural, films also stress the diversity of an expansive and extreme geography. As discussed earlier in this chapter, much of this fixation can be understood in terms of othering Canada as wilderness. However, another 
related impression also emerges from this trend. Beyond providing a foreign and picturesque setting in which plots might better unfold, Canada's wilderness backdrop also frequently provides a crucial aspect of the plot itself. More specifically, Canada's geography is not just stunning to look at; it also contains a vast storehouse of valuable natural resources. This impression of Canada as a depository of natural wealth plays a structuring role in many films, and contributes considerably to the impression that Canada's inherent worth derives not from its human resources, but from its natural resources. It also serves to link Canada ever more securely to the image of the American frontier, a mythic destination that has long been associated with the idea of a "space with unlimited, unexploited resources" (Gouge, 2007). This impression, in turn, contributes to an understanding of Canada premised on an aura of passivity.

Hollywood films tend to portray Canada as a land of virtually limitless opportunity, with natural resources in such abundant supply that untold wealth appears to be waiting just around the corner. Hollywood characters seek their Canadian fortune in a wide variety of resources, including oil (Red Blood of Courage, 1935), timber (Blue Canadian Rockies), salmon (North of the Great Divide), cattle (The Far Country), pitchblende (Perils of the Wilderness) and horses (Northwest Stampede). Beyond this remarkable diversity, however, two particular resources stand out as the most popular means to a life of luxury: gold and fur.

From the perspective of Hollywood's Classical era, Canada is virtually awash in gold. Indeed, a disproportionate number of films revolve around finding, stealing or searching for gold. In a few cases, the hero finds gold and strikes it rich (God's Country 
and the Man). More often, however, movie plots hinge upon schemes in which the villain attempts to steal gold from its rightful owners. For instance, the B-films from the Renfrew line of pictures regularly involve gangsters trying to hijack gold shipments through a mixture of cunning subterfuge and advanced technology (Yukon Flight, Sky Bandits, Danger Ahead). Even more common is the plot in which the rightful owner of a gold mine is killed, cheated or intimidated by a villain who then claims the gold for himself (Murder on the Yukon, 1939; Yukon Gold). Within this trend, there is even a pair of Columbia serials in which ruthless gangs of villains attempt to bankroll grandiose schemes to establish control over large sections of Canada by first muscling in on local gold miners (Gunfighters of the Northwest; Perils of the Royal Mounted).

Beyond its fixation on Canada's non-renewable resources, Hollywood also grants considerable prominence to the country's renewable resource base. For instance, Canada presents an ideal opportunity to make a fortune by importing cattle in order to either sell beef to hungry prospectors (The Far Country) or establish "the great cattle empire of central British Columbia" (The Cariboo Trail). Similarly, vast timberlands beckon to the hardy (Mysterious Pilot, 1937) and deep fish stocks promise a comfortable lifestyle (Johnny Belinda; Renfrew of the Royal Mounted).

Although the above suggests considerable diversity in Hollywood's representation of Canada's renewable resource base, the fur industry garners the most attention by far. Indeed, Canada's historical fur industry appears to play a vastly disproportionate role in shaping Hollywood's depictions of the country. Several films focus directly on the fur trade itself. For instance, The Viking explores the seal hunt off the coast of Labrador. In 
Nikki, Wild Dog of the North, a Walt Disney production, the story follows the adventures of a trapper and his dog. For many other films, the standard story involves a villain trying to get rich by stealing the furs of hard-working and honest trappers (Trail of the Mounties; The Fighting Trooper, 1934). Variations on this theme include villains who trade liquor to local Indigenous people in exchange for furs (Where the North Begins) or smuggle stolen furs across the border (North of the Rockies). Even films whose plots are completely unrelated to the fur industry regularly feature fur trappers, trading posts or some other implicit nod to the industry. For instance, in Canadian Mounties versus Atomic Invaders, an ostensibly modern storyline in which foreign agents are plotting to destroy US cities with nuclear weapons launched from Canada, fur trappers and other quaint outdoorsmen appear to make up a considerable proportion of the Canadian population.

The overall pattern revealed by the above evidence highlights Canada's status as a physical location. It is foregrounded as a geographic space, blessed with an abundance of natural wealth. The corollary to this impression is that, from Hollywood's perspective, Canada's population is neither as interesting, nor as valuable, as its resources. One of the main implications that issue from such a pattern is that Canada is effectively denied a social component. Reduced to a simple, physical place, Canada and Canadians are denied any meaningful kind of agency.

Within Hollywood pictures that treat the subject of resource exploitation in Canada, US characters figure prominently. These characters sometimes play the role of law-abiding and sympathetic protagonists, and sometimes appear as scheming and 
criminal antagonists. Regardless of their motives, however, they are always men of action, prepared to assume the risks and take the measures needed to claim their fortune from the surplus of Canadian resources. In some films, Americans travel to Canada for legitimate reasons and their pursuit of Canadian resources is understood to be perfectly legal. In God's Country and the Man, for example, the main characters discover a rich gold claim on their way into Canada and decide to settle down. In Northwest Stampede, the main character comes to Canada in order to sell his family's ranching operation before returning to the rodeo circuit in the United States. In Trail of the Royal Mounted, an American comes to Canada to find his uncle's lost gold mine. In a second set of films, the viewer is treated to a US protagonist whose methods and intentions appear questionable, but is ultimately confirmed as a legitimate hero by the end of the picture (North of the Border). Within this category, films such as The Far Country and The Cariboo Trail feature archetypal American cowboys whose quest to strike it rich by driving cattle into the interior of British Columbia is ultimately achieved thanks to their fierce, unwavering independence and willingness to resort to violence.

A third set of films, however, features a less-than-heroic breed of American who travels north under questionable circumstances in order to simply commandeer Canadian resources for his own nefarious purposes. Although some of these films portray US criminals stealing and smuggling resources like fur (North of the Rockies) or pitchblende (Perils of the Wilderness), most focus on gold. The gold is stolen from a variety of sources, including the Canadian government (Northwest Trail), gold companies (Sky Bandits) and airmail shipments (Yukon Flight). The most common target for gold thieves, 
however, is the hapless, local miner. An array of productions, including Murder on the Yukon and Royal Mounted Rides Again, feature US villains stealing or trying to steal gold claims from honest prospectors and mine owners.

Beyond simple larceny, however, Hollywood's US criminals regularly commit terrible acts of violence in their attempts to claim their wealth in Canadian resources. For example, they do not hesitate to engage in kidnapping (Trail of the Royal Mounted), arson (North of the Great Divide) and extortion (The Far Country). Their resort to murder is commonplace, with a list of victims that includes settlers (Perils of the Wilderness), miners (Murder on the Yukon), Mounties (Northwest Trail) and even the entire population of an Aboriginal settlement (The Canadians).

As common as it is for US characters to be featured in the exploitation of Canadian resources, it is even more common for the United States to be identified as the final destination for those resources. Sometimes, the transfer of resources is represented in simple terms, such as US owners of a Canadian gold mine (Crashing Thru') or lumber and profits from Canadian timberland making their way to a Montana ranch owner (Blue Canadian Rockies). Although films such as these, in which Canadian resources are transferred to the United States in a legal and straightforward manner, are not uncommon, they are certainly outnumbered by films featuring some kind of an illegal scheme or smuggling operation. In The Canadians, for instance, a US rancher and classic 'Indianhater' crosses into Canada in order to capture and return with forty horses in retaliation for horses that were stolen from him. When he is confronted by Mounties after he and his men wipe out an Aboriginal settlement, the man asks with a sneer, "since when is killin" 
Indians a crime?" In North of the Great Divide, the US owner of a salmon cannery plots murder, sabotage and arson in order to maximize his salmon catch and fill a lucrative contract in the United States. And in The Far Country, a corrupt US sheriff extends his murderous and tyrannical control into a neighbouring Canadian settlement and bullies local miners into giving up their claims.

Some of the schemes involving smuggling are even more elaborate and circuitous. For example, the simple export of Canadian rainbow trout to the United States in Renfrew of the Royal Mounted is complicated considerably by the presence of counterfeit US funds secreted within the frozen fish. In Royal Mounted Rides Again, the villains use a stolen coin die to convert looted gold into counterfeit \$20 coins and then plot to smuggle their stash into the United States aboard a riverboat. In Perils of the Wilderness, the villains use an airplane to trick a local Aboriginal tribe into attacking white settlers in order to cause a distraction that enables the gang to mine pitchblende and smuggle it into the United States.

The regularity with which Americans are featured as the agents responsible for the extraction of Canadian resources solidifies the impression that Canadians are either unaware of the potential of their natural surroundings or unable to take the lead in securing this wealth. This othering of Canadians as passive actors is further reinforced by Hollywood's complimentary depiction of Canada as a physical place, rather than a social entity. Together, these representational patterns act to other Canada as passive and, in so doing, contribute to the intersubjective and constitutive processes that act to define American identity in terms of agency. 
It is also important to note how these patterns, at the same time, also contribute to an understanding of Canada as a place that attracts and harbours unsavoury characters (Northwest Trail; Murder on the Yukon). Canada's status as a storehouse of untapped riches, when combined with impressions of sparse population and limited law enforcement, transforms the country into an irresistible lure to any number of dangerous criminals. As a consequence, US thieves and murderers come to Canada to make their fortune, with their schemes contributing greatly to the disorder and lawlessness that so often pervades the Hollywood version of Canada. Indeed, it is often these disreputable criminals and the anarchy they leave in their wake that beckon to the American cowboy; they frequently draw him north to Canada, and compel him to take the law into his own hands, ensure that justice prevails and facilitate the extraction of Canadian resources in an orderly fashion. As the next chapter will explore, the criminality and disorder that follows on the heels of Canada's passivity contributes to the sense of lawlessness that pervades Hollywood's depiction of the country and works to render Canada a dangerous place that poses a threat to US interests.

The impression of passivity is a regular feature of Hollywood productions set in Canada. These films picture Canada as a lawless place, desperately in need of people who can 'take charge' with the skills and disposition of the American cowboy. They also represent Canada as an inert, physical place, one that is rich in natural resources that are freely accessible to men of action willing to make the effort and take the risk. The two examples detailed in the above section are representative of the tendency for Hollywood to utilize a binary logic in its depiction of Canada. By othering Canada as a passive 
entity, foregrounding its physicality and minimizing its social nature, Hollywood implicitly contributes to the dominant impression of the American self as an entity imbued with agency. These depictions of passivity also have implications in terms of framing audiences' understanding of the nature of the continental relationship between Canada and the United States. The interwoven combination of depictions that feature Canada as a resource depository and Americans as those responsible for effecting extraction contributes to the impression that Canada serves as a secure place from which the United States can obtain crucial resources. This impression is enabled by that same underlying binary logic that presents Americans as endowed with limitless agency and Canadians as passive bystanders. These representational patterns also make it possible for US audiences to understand Canada as a place where lawlessness and disorder has taken hold. The passivity that enables this situation makes the country a likely destination or home for individuals and groups whose motives and interests may represent a threat to US security. In this context, a liminal Canada serves to magnify this threat.

\section{Conclusion}

Hollywood's version of Canada is an alien and unknowable location that boasts a physical landscape of awe-inspiring beauty and terrible danger. Although it is only sparsely populated, its people, either simple or fearsome, are both strange and exotic. In another way, however, this depiction of Canada does not present the country as entirely unknowable. To some degree, Canada's foreignness can be understood in a temporal 
manner. In other words, when Hollywood presents its viewers with a vision of Canada, it effectively transports them back in time, exposing them to an early version of the American west, complete with its tenuous grasp on civilization, isolated and rural settlement patterns and lack of sophistication.

These depictions of Canada, however, do more than simply describe the country that lies to the north of the $49^{\text {th }}$ parallel. They also have constitutive implications for American identity. By adhering to a binary logic in its representations of Canada, Hollywood acts to reinforce some of the most resilient aspects of the American identity. For example, a Canada populated by subordinate colonials and a polyglot mélange of savages helps to reinforce an independent and united America. A version of Canada built on the assumption of wilderness, in terms of both physical and human geography, contributes to an America that embraces and embodies sophistication, civilization and modernity. And a passive and ineffectual Canadian Other supports an American self built on agency and effectiveness. These othering representational patterns also make it possible for US audiences to understand Canada as a place where danger lurks unchecked. As the next chapter explores in greater depth, this notion of danger is amplified by patterned depictions of liminality that act to minimize or efface the border between Canada and the United States. This combination effectively allows the danger in Canada to seep through its southern border and threaten the United States. 


\section{Chapter 4 Hollywood Films and Themes of Canadian Liminality}

\section{Introduction}

Hollywood, like other major vehicles of US popular culture, tends to portray Canada in pastoral and unpretentious terms. For instance, in The Country Doctor, both the village of Moosetown and its inhabitants are portrayed as quaint and backward. Beyond the very name of the setting, this characterization is also in evidence when the titular physician explains the rewards of his calling to his 'big city' colleagues: "There is another comforting thing about being a country doctor - he gets paid. Mrs. Jessop's twins got me two hogs, one a piece. Mrs. Granby's ulcerated tooth got me a chicken - an eight

pound Plymouth Rock. I also collected about one hundred and eighty-seven dollars in cash during the year." As the last chapter demonstrated, similar stereotypes, almost uniformly emphasizing Canada as an exclusively rural or wilderness setting, populated by simple and unassuming people, are typical of Hollywood's vision of the country. However, to focus solely on the most obvious elements of Hollywood's portrayal of Canada, and thereby concentrate on bucolic and picturesque images, serves to obscure the presence of an overlooked representational pattern that implies a very different impression of Canada.

As with chapter 3 , this chapter operates from the premise that cinematic representations are appropriate places to look for evidence of the scripting of national identities and international threats. One field of study that has increasingly embraced the 
use of popular culture as a means to better understand the complex relationship between identity, borders and security is critical geopolitics. ${ }^{54}$ Drawing inspiration from this emerging tradition, my work in this chapter explores the ways in which Hollywood films portray Canada as liminal to the United States. More specifically, I contend that Hollywood films set in Canada depict the country in such a way as to minimize the Canadian-American border and frame Canada within the larger context of the American experience. When understood against a backdrop of danger created by depictions of Canadian otherness (detailed in chapter 3), these cinematic representations of liminality serve to transform Canada into a threat to the United States.

I argue that depictions of liminality, which intertwine Canada with the United States in an ambiguous relationship of simultaneous belonging and exclusion, act as a conduit through which dangers residing in Canada are transformed into threats to the United States. In essence, liminality implies that dangers already resident in Canada are effectively threatening the United States as well. It means there is a constant possibility that any dangers present in Canada might spill over into the United States. Dodds recognizes the potential for cinematic representations of space to contribute to our understanding of threat: "Within films places provide opportunities not only to locate activities but also to shape narrative structures. In other words, places are rarely simply

\footnotetext{
${ }^{54}$ For example, see the special issue of Geopolitics devoted to the relationship between film and geopolitics, edited by Power and Crampton (2005); also see Ó Tuathail and Dalby (1998) and Sharpe (2000).
} 
passive backdrops. They help to shape story lines and...they often function to draw attention to prevailing dangers and threats" (2005: 285). ${ }^{55}$

The image of Canadian threat that emerges from depictions scripting Canada as both Other and liminal is not, however, an overt one. In other words, I do not claim that Hollywood depicts Canada as a malicious or overtly threatening enemy. Indeed, as might be assumed, Hollywood films do not picture Canada or Canadians as harbouring ill-will of any kind for the United States, let alone any intent to harm. Similarly, my argument does not suggest that Canada is used as some kind of threatening arch-rival or foil against which fundamental contours of American identity take shape. Indeed, it is worth stating explicitly that this argument does not suggest that Canada serves as an American Other in the same way that perhaps the Soviet Union once did. Rather, I argue that portrayals of Canada as a threat act to reinforce the unity of American identity claims by serving as a proximate reminder of the differences and dangers that exist outside the boundaries of the United States.

It is also important to clarify that my argument does not claim the existence of a causal relationship whereby these depictions of Canadian threat elicit any kind of specific response from US government actors. Rather, I contend that filmic depictions of Canadian threat both reflect and contribute to a wider set of meanings that Americans have attached to Canada. So, although the vast majority of Americans would likely be

\footnotetext{
55 To be clear, this quotation is referring to the importance of international places featured in James Bond films and their function in the context of the Cold War. However, the wider point Dodds is making, and one that this dissertation seeks to demonstrate as well, is that filmic depictions of place based on the "exotic" or the "foreign" have important implications for how we interpret stories, understand threat and situate ourselves.
} 
hard pressed to view Canada itself as threatening in any way, the country nonetheless has the capacity to represent danger to those Americans. It is this capacity to embody threat that positions Canada as a modest contributor to the social processes that define the American self during times of crisis. Like other manifestations of the discourse of danger,' the depiction of Canadian threat works to rigidify the borders of American identity.

The argument in this chapter proceeds in two main sections. The first part examines two themes that Hollywood films draw on in portraying Canada as liminal: colocation and frontier. Although these themes link Canada and the United States together in different ways, they both reveal Canada as a subordinate component within the wider context of the American experience, rather than as an independent territory or entity. The second part examines examples of the process whereby Hollywood reimagines Canada as threat to US security. More specifically, this section details three different versions of Canada that are produced by the intertwining of representations of otherness and liminality: unstable and dangerous anarchy, haven for criminals and tempting target for foreign enemies.

\section{Themes of Liminality}

As chapter 2 makes clear, liminality is a condition defined by ambiguity. The liminar is neither completely self, nor completely Other. Thus, liminal entities and liminal space are understood to be hybridic - simultaneously part of and separate from 
the self. Hollywood films about Canada are rife with liminal themes, images and plots. Indeed, only very rarely is Canada portrayed without some kind of powerful, structuring reference to the United States, whether in the form of a shared boundary for a setting, border-jumping characters, or some other marker that draws Canada into the orbit of American culture. As Berton suggests, "if Americans keep telling us 'you're the same as we are' - and they do - it is because the movies have convinced them of that fact" (1975: 12).

Despite the tendency for Hollywood promoters to highlight the Canadian-ness of their films, including blatant emphases on Canadian geography, people and history, truly 'Canadian' stories are rare. Although this may be an understandable, even obvious, directorial ploy to engage and satisfy the US theatre-going public, this pattern has significant implications for individuals' understanding of Canada and for American identity. By portraying Canada in the context of a pre-existing popular understanding of the American experience, this pattern diminishes Canada's distinctiveness. This section explores two prominent examples of this trend, demonstrating how each employs a variety of techniques to intertwine Canada with the United States: colocation and 'frontierness'.

\section{Colocation}

One of the most effective techniques Hollywood films use to blur the distinction between Canada and the United States revolves around representations of the border between the two countries. The Canada-United States border is a regular component in 
films about Canada. Indeed, even those few films that focus almost exclusively on Canada, and have little to do with the United States, frequently feature the border itself in a telling fashion. In most cases, the border is treated not as a line that divides, but as a line that joins. In effect, the border signifies the presence of a shared region, rather than mutually exclusive districts. In this fashion, the border serves as a marker of colocation. Films use the border to communicate colocation in at least four different ways. First, the introductory elements of a film are often used to frame the story in the context of colocation from the outset. Thus, such elements as film titles, opening scenes, and prefatory maps, titles and voiceovers all contribute to a sense of hybridity. Second, films frequently deploy the border as a plot device, with the typical effect of transforming it into a shared region. Third, the border's relevance as an obstacle or division is often minimized, through both representational patterns and editing techniques. Fourth, films regularly blur the division between Canada and the United States by utilizing the border itself as the actual setting for the story.

In many films, the border plays a prominent role as an establishing device, helping to frame entire stories in the context of colocation. For example, films that implicitly incorporate the notion of the Canadian border into their titles summon the home country of the audience as the referent subject. Thus, Hollywood titles such as, North of the Border, North of the Great Divide and North of the Rockies conjure locales that only make sense when understood in the context of their proximity and relationship to the United States. Consequently, such titles communicate to US audiences a sense of contiguity and connection rather than distance and separation. The same is true for film 
titles that borrow from geographic features that serve as borders between the United States and Canada (Niagara Falls; Niagara).

A similar effect is realized through the use of introductory maps that highlight the border. Introductory maps are a common tool for setting the stage of any story and help to provide the audience with an overview of where the action will occur. In the case of films set in Canada, however, such maps invariably do more than mark Canada's geographic presence as integral to the film. They also provide an American context for the Canadian setting by depicting and labelling the United States in a prominent fashion. Even such films as The Silent Enemy and Johnny Belinda, with virtually no mention or reference to the United States, begin with maps that feature US territory. Other films, however, particularly those in which the United States figures more prominently, deploy maps that do more than simply indicate the geographic presence of that country; they direct the audience's attention to the border region as a whole. For example, Chapter One of Royal Mounted Rides Again opens with a map depicting Alaska and Canada on either side of a border. The camera zooms in on this map, focusing increasingly on the border itself, until finally switching to a scene in a dusty, border town. This pattern, in which the opening map focuses on the border as a discrete region, or even on a town that straddles the border, is repeated in a variety of films: Blue Canadian Rockies opens with a map of Montana and Alberta before zooming tight on a border region; Pony Soldier opens with a map of the Dominion of Canada that focuses on the border between Saskatchewan and the US states of Montana and North Dakota; North of the Border displays a map depicting the border region between Canada's four western provinces and the United 
States before opening on an action scene in a frontier town. The border's prominence in these introductory maps contributes greatly to an overall impression of colocation.

Introductory maps are regularly complemented by voiceovers or scrolling titles that help to establish the story's initial backdrop. These opening words regularly make explicit reference to the Canada-United States border and, like the use of maps, often do more than provide mere context for the forthcoming story. By emphasizing the border in their introductions, films hint that the border is crucial to the story and, by extension, to the subject of the story - Canada. One particularly striking example of this trend occurs in the introductory titles of Dangers of the Canadian Mounted (1948). In this instance, the scrolling introduction does not simply make a reference to the border. Instead, it elevates the border, making it the focus of the discussion: "A symbol of good will in a troubled and suspicious world. The International border-line between Canada and the United States territory of Alaska. A border guarded only by trust, yet never crossed in a war-like spirit by either of these great and friendly nations." Such an introduction signals to the audience that Canada, as the subject of the film, is inextricably linked with the United States border and with the United States itself. Contextualizing stories about Canada through continuous references to the US border serves to intertwine the two countries as though they are part of a single, shared experience.

The act of crossing the Canada-United States border also figures prominently in the opening scenes of Hollywood films set in Canada. This tendency complements the prominence often accorded the border in movie titles and introductory material, and further emphasizes the impression of colocation. For example, one of the earliest scenes 
in Northern Pursuit features a man crossing the border into Canada at a 'Customs and Excise Station.' Similar scenes are repeated in Renfrew of the Royal Mounted and Niagara. Less official border crossings are also common fare in Hollywood films. For instance, Fighting Mad opens with two men and a woman walking through a forest, and one of the men exclaiming, "Well, this is the first time I've ever walked from the United States to Canada." The first action sequence in Klondike Fury features an airplane flying over the Canada-United States border and subsequently crashing to earth. North of the Rockies opens with a group of fur thieves being pursued by a Mountie down a dirt road and past a pole that indicates the presence of the international border. Highlighting the border, in the context of stories purportedly about Canada, ensures that Canada is understood within a framework that includes the United States.

Considering the films under discussion are set almost entirely in Canada, and tell ostensibly 'Canadian' stories, the rationale behind the prominence accorded the US border in their opening minutes is not readily apparent. What this introductory material implicitly communicates, however, is the importance of the US border to the Canadian experience. It demonstrates and perpetuates the impression that Canada is linked intrinsically to the United States and shares with its southern neighbour a common space and experience.

A second way Hollywood films use the border to emphasize colocation is by assigning it a crucial role in key storylines or plots. This tactic helps to convey the impression that the border, and the United States itself, is crucial to the people and stories that make up the Canadian experience. For example, plots dealing with larceny and 
counterfeiting often do not stay in Canada; instead, they take an international turn by having the villains try to smuggle their goods across the border into the United States. In Northwest Trail and Royal Mounted Rides Again, for instance, the antagonists plot to smuggle gold from Canada into the United States. Other goods destined for smuggling across the border include counterfeit money (Renfrew of the Royal Mounted), furs (North of the Rockies) and pitchblende (Perils of the Wilderness).

The interaction between crime and the border is not restricted to smuggling. The linkage plays a particularly prominent role in Dangers of the Canadian Mounted. In this film, a villainous gang is terrorizing the people from a town that straddles the AlaskaCanada border, but the protagonist is unable to apprehend the culprits because of jurisdictional issues arising from the town's hybridic position. Skagway Kate, the criminal mastermind, reminds the hero of the importance of the border: "Sergeant Royal, what brings you over the line into Alaska? You can't make a pinch over here, you know." The issue is later resolved when Royal picks a fight with the villain he is seeking and punches him repeatedly until he lands on the Canadian side of the border. As his Mountie colleagues hoist the beaten criminal from the ground, Royal says to him, "Welcome to Canada, Fowler."

In Niagara, a film noir starring Marilyn Monroe, the border frames much of the plot. Both of the couples that dominate the story have crossed into Canada from the United States, with the border effectively acting as a symbol of their attempts to enter a new phase in their lives. The border returns as a formidable obstacle later in the story, both when Monroe's character dies after having been thwarted in her attempt to cross 
back into the United States and when the male lead dies on the river that divides the two countries. In God's Country and the Man a film saturated with markers of colocation, the border acts as bookends to the plot. The story begins with the villain fleeing across the border to Canada after having robbed and killed a shopkeeper in the United States. And, in a nod to filmic symmetry, the picture ends with the same villain trying to flee to the US side of the border after having killed the main female character in Canada. Finally, even one of the world's foremost detectives apparently sees the border as a reasonable and convincing accomplice. In The Scarlet Claw, Sherlock Holmes tries to draw his criminal adversary out of hiding by informing Canadian police that the suspect has left the country: "Mr. Holmes is of the opinion that he's escaped across the border to the United States. It may be years before we can trace him, if ever."

Beyond mere criminality, the border is also frequently implicated in incidents or crises with major international implications. In the wartime classic Northern Pursuit, Errol Flynn's character matches wits against a Nazi infiltrator and a band of quislings led by a spy who crosses into Canada by posing as an innocent US tourist. The villains' plan in this film is to disrupt allied support for the war effort by bombing the St. Lawrence Seaway, one of the most recognizable markers of North American colocation: "One of the most vital waterways connecting the United States and Canada. A main artery of all war supplies going to England. Eight bombs, placed with scientific precision will destroy the canal and the locks and block shipping for months." In effect, the film involves a plot to bomb the border itself. Alan Ladd's character is able to forestall an historic US crisis from spilling over the border in Saskatchewan. After slaughtering General Custer's men, 
the Sioux cross into Canada with the intent of allying with the Cree and attacking Canadian law enforcement. Luckily, Ladd's character is able to force the Sioux back across the border and restore the peace.

In these films, the Canada-United States border provides the core element around which plots unfold. Such films, that purport to tell Canadian stories, but only do so in the context of the US border, effectively redefine the Canadian experience. This process of redefinition serves to implicate the United States as a qualifying variable in Canadian history and development. This development makes it increasingly difficult for audiences to conceive of Canada in the absence of the United States, thereby advancing an impression of colocation.

A third way in which Hollywood films employ the border to emphasize colocation is by minimizing its impact and relevance. In effect, this trend portrays the border not as an official marker of difference, but as an abstract and virtually inconsequential 'line' to be crossed at will. The result is an impression of the border that combines triviality with quaintness. Ultimately, the border loses its traditional functions as marker of difference and point of control, and becomes an area of shared belonging. This shift communicates a sense of colocation and diminishes the distinction between the countries on either side of the border.

Filmic depictions of the border as an official outpost of Canadian authority are relatively uncommon. ${ }^{56}$ Instead, the border is typically presented as an ambiguous and protean concept, defined only fleetingly by geographic landmarks, dialogic references or

\footnotetext{
${ }^{56}$ Though see Northern Pursuit and Renfrew of the Royal Mounted.
} 
unassuming markers of quotidian life. For instance, characters are able to traverse the border by any number of commonplace means: some swim, walk or drive across; others ride trains, fly airplanes, pilot boats or ride horses. The border may appear to audiences as a river or mountain pass (Saskatchewan; The Far Country). Sometimes, its otherwise imperceptible presence is revealed only through comments and observations made by characters (Klondike Fury). On other occasions it adopts a thoroughly mundane form, like that of a city street (Dangers of the Canadian Mounted) or signpost (North of the Rockies). In these cases, the border is essentially camouflaged, its presence only made apparent through explicit emphasis. This manner of representation pushes the border towards irrelevance. Ultimately, the filmic tendency to camouflage the border implies a fundamental contiguity of geography and experience on either side of the Canada-United States divide.

Even when the border is explicitly portrayed as a marker of Canadian sovereignty, it typically fails to convey any sense of gravitas or power. For example, in The Far Country, the border crossing is pictured as an isolated shack perched beside a scraggly path between mountain peaks. Outside of a fluttering Union Jack, the shack is devoid of any symbols of authority. Even the Mountie who ostensibly staffs the shack is absent, leaving only his wife behind (sometimes for stretches of up to three months). Other examples of this trend include Niagara, Renfrew of the Royal Mounted and Northern Pursuit. In each of these films, transiting through a border crossing is portrayed as a casual, even jovial, affair. This relaxed atmosphere is particularly poignant in the latter 
two cases because the audience soon becomes aware that the people being waived through the crossing are dangerous criminals.

One of the most subtle ways in which films minimize the border depends on their use of establishing shots. Hollywood films set in Canada regularly feature characters from the United States who must travel to Canada for some reason. In some cases, these characters are introduced by an establishing shot that shows them in a US setting. The next time the audience sees them, whether in the very next scene or several scenes later, the characters are pictured in a Canadian setting. In these instances, the trip to Canada is implied by the cut in scenes. For example, in Trail of the Royal Mounted, the protagonist is introduced in an urban setting in the south-western United States. When the audience next sees Logan, he is already fully immersed in a rustic, Canadian setting, clad in cowboy gear and riding a horse. In a variation of this technique, Northwest Stampede opens with a letter being sent to a character in the United States. The letter does not initially reach its intended addressee in Texas and is subsequently shown being sent on to one forwarding address after another, from Texas to Oregon, to New Mexico, to Wyoming. When the audience finally catches a glimpse of the elusive recipient of the letter, he has already been abruptly transferred to a Canadian setting. Other films introduce US characters through establishing shots that picture them already in Canada, but still engaged in the act of travelling to their final destination. In these cases, the audience is made to understand that the characters have just recently arrived in Canada from the United States. In The Cariboo Trail, for example, the action opens on two mounted cowboys driving a herd of cattle through rough terrain. The audience quickly 
learns that the men are ranchers from Montana who have travelled to Canada to make new lives for themselves.

Both of these establishing techniques implicitly downplay the reality of official entry requirements, and even the very existence of Canadian authority along the border. Moreover, a lack of attention to the transitioning or acclimatization of US characters grants such characters a sense of immediate belonging in their new Canadian setting. Furthermore, staging the characters' international travel off-camera serves to minimize impressions of distance; in essence, it compresses time and space. All of these effects combine to diminish the importance and relevance of the Canada-United States border and further a sense of colocation.

Hollywood films question the very relevance of the Canada-United States border in several ways. Sometimes they camouflage the border, and the act of crossing the border, by rendering it completely mundane and commonplace. Other times they minimize the border's importance by denying it an official role as a marker of Canadian law and sovereignty. Films also employ editing techniques that effectively efface the border and minimize the spatial and legal divide that it otherwise connotes. In all of these cases, the border becomes, either through its absence or presence, a marker of colocation rather than division.

The final manner in which Hollywood uses the border to highlight colocation is by deploying it as a filmic setting. Although a majority of films are set near the border, and oftentimes inhabit the border implicitly, there is a subset of films in which the border serves as the explicit setting of the story. Perhaps more than any other patterned use of 
the border, this tendency demonstrates the cinematic shading and intermingling of Canada and the United States. Indeed, this trend goes well beyond simply suggesting colocation; it purposefully accentuates colocation as fact and transforms it into the very subject of the films in question.

One such film, Niagara, is set in the archetypical shared region - Niagara Falls. In this film, repeated verbal and symbolic references reinforce the impression of colocation. For example, at one point in the film a tour guide is overheard saying "Now, the tower is under the control of both countries. Just the same, a lot of Americans claim them bells don't play the Star Spangled Banner as well as they do God Save the Queen." Much of the dramatic tension in the film builds while the main characters attempt to cross the border, with the climax itself occurring on the very river that separates the two countries. The film is saturated with statements and symbols referring to shared experiences, all of which help to concretize the sense of colocation. The liminality implied by the film was confirmed and enhanced by the considerable border-themed publicity that attended the film's release. As part of this pageantry, a helicopter transported prints of the film to the middle of the Rainbow Bridge, where they were met by members of the Royal Canadian Mounted Police and New York State Police, who then brought them to premiers on either side of the border (Brégent-Heald, 2006b). As Brégent-Heald suggests, "the civic fanfare surrounding the film's opening echoed the intimate relationship between Canada and the United States in the 1950s" (198).

Some films are set in dusty, frontier towns or regions with hybridized names that reflect the ambiguity of their locations. The name Canaska is given to the setting in both 
Trail of the Mounties and Royal Mounted Rides Again. Similarly, the serial Dangers of the Canadian Mounted is set in Alcana, a town that not only lies in a border region, but actually straddles the border itself. In a discussion that mirrors in some ways my own understanding of liminality, Gittings (1998) refers to this hybridization of names and setting as the "annexing reinvention of the Canadian landscape." He refers to the hybridization as part of an "odd paradox" which serves to simultaneously harmonize Canada with the United States and define Canada as a "foreign location." Other films eschew a setting with a hybridized name, but are, nonetheless, similarly positioned on the border. In North of the Great Divide, for instance, the story revolves around salmon canning operations on a river that divides Canada and the United States. North of the Rockies relates a story concerning a ring of fur smugglers that operates on both sides of the border. God's Country and the Man is set in and around a border town called Starbuck, but it is the border, not the town, which is emphasized as a discrete setting. For example, the local newspaper is titled The Border News and includes an article with the headline, "Girl's 'Lucky Horseshoe' mine is richest in border history". Early in the story, one of the main characters builds "The biggest dance hall the border has ever seen." Ownership of this building is later transferred to the local clergyman, who vows, "I'm going to have the finest house of worship along the border." In each of these films, the action takes the audience back and forth across the border, sometimes at a dizzying pace, and regularly leaves viewers unsure if a particular scene is occurring in Canada or the United States. Indeed, the action often ends up occurring on the border itself. 
The films discussed above purport to tell Canadian stories. However, they give such prominence to the US border that these Canadian stories are invariably intertwined with the narratives and characters that populate the US imaginary. For example, the voiceover at the beginning of Pony Soldier claims, "This is a story of the old northwest territories of Canada..." This film relates a Canadian story in that it begins in Canada and features the heroic exploits of that staple figure of Canadian history and popular culture the Mountie. However, the plot unfolds against the backdrop of Custer's defeat at Little Bighorn, one of the most influential and resonant episodes in US history, and the action itself occurs not in Canada, but in the northern United States. This intertwining of the US border with Canadian stories conveys the sense that the two are inseparable. It implies that the stories about Canada that are important enough to be told have an important US component.

Hollywood films blur the distinction between Canada and the United States through their selective representation of the border between the two countries. A variety of narrative, representational and editing techniques are employed to transform the nature of the border. Instead of a line symbolizing the presence of Canadian authority and the division between the two countries, the border becomes a marker of mutual space. Consequently, the resulting 'Canadian' stories are invariably infiltrated by US characters and influences. The ultimate filmic impression is one of colocation and shared experience, rather than separateness.

Frontier 
Audiences watching The Far Country are given their first glimpse of Canada almost thirty minutes into the film. The story's hero, played by iconic western star Jimmy Stewart, rides out from the Alaskan town of Skagway on a craggy path that eventually crests the mountain border separating the United States from Canada. As Stewart and his companions pass the lonely Mountie outpost that marks the border, one of the cowboy's sidekicks gives a sympathetic nod to the absent officer: "He got a real tough job, that Constable. He patrols some ten, twenty thousand square miles, full of nothin' but hill and hollow. Sometime he don't get home for two and three months at a time, ridin' up in that far country." The scene, laden with images of foreboding geography, vast distances and social isolation, introduces Canada as a wilderness. The country is shown to be perched on the edge of US territory, menaced by hostile savages, populated with few civilized inhabitants and suffering from an almost non-existent police presence. In short, it frames Canada as frontier. ${ }^{57}$

Such imagery is not just common fare in Hollywood productions set in Canada, it is ubiquitous. Indeed, the standard northern plot relies heavily on an understanding of Canada as frontier. For example, these productions typically draw on such themes as porous or unguarded borders; vast, unpopulated wilderness; and, dangerous, lawless settings where might makes right. Drawing from such themes, Hollywood effects a simple northern repackaging of the classic American western. When defined through this lens, Canada provides a new setting for the standard frontier narrative that is foundational to the very definition of America. Such representational patterns are significant for the

\footnotetext{
${ }^{57}$ The voice-over from the production's theatrical trailer explicitly promotes the film as "the epic saga of a far frontier."
} 
purposes of this discussion because depictions of Canada as frontier make it possible to understand Canada as liminal space. That is to say, by portraying Canada as frontier, Hollywood prompts US audiences to relate to Canada not as a purely independent entity, but as a space that is inextricably entwined with US history, culture and geography.

In his seminal work, The Significance of the Frontier in American History, Turner (1966) [1894] explains the importance of the frontier for American culture. For Turner, it is the frontier, that point where civilization meets wilderness and savagery, that defines the American character. The frontier is a uniquely American experience and is what marks the political and social development of the United States as distinct from that experienced by other countries. Turner sees the development of US political institutions and culture as a product of the ongoing availability of land and the unique conditions that grew out of the settlement of that land. He suggests that development did not stagnate in the United States as it did elsewhere because the country was constantly experiencing regeneration as its frontier pushed further and further to the west. With each advance of the frontier, the United States came into contact with a primitive world, a recurring situation that served as an impetus for the periodic renewal of creativity, ruggedness and individualism.

Since it was first published, Turner's thesis has generated considerable attention and provoked both sympathetic and critical responses from commentators. However, and regardless of the plausibility of Turner's argument, the degree to which the presence of the frontier actually contributed to the development of a uniquely American character is less important than the considerable extent to which this idea has come to dominate the 
narratives that Americans use to define and understand themselves (Campbell, 1994: 156162). In his celebrated trilogy, Slotkin $(1973 ; 1985 ; 1992)$ traces the history and endurance of this narrative, providing meticulous detail on how the frontier has served as the primary vehicle for defining American identity and structuring political action as far back as the 1600 s. For this author, expressions of the frontier are ubiquitous within all forms of American popular culture:

The Myth of the Frontier has found expression through media as varied as the pamphlet, the dime novel, the nineteenth-century historical romance, the stage melodrama, the Wild West show, the movie, the modern paperback, and the TV miniseries. (1992: 25)

Film, one of the media that Slotkin treats in depth (1992), is a decidedly effective vehicle for the transmission of the frontier myth. Indeed, this medium, particularly in the form of the Hollywood western, has played a dominant role in broadcasting and reinforcing the importance of the frontier to US audiences for decades.

It would not be an exaggeration to describe the frontier as the inevitable backdrop to the Hollywood western. As Savage claims, "the most important theme emerging from the Western revolves about the very basis of its setting, the frontier" (1990: 125; emphasis in original). Indeed, the entire premise of the western rests on its frontier setting. This bleak landscape, devoid of the trappings of law and civilization, is the only place where the cowboy truly belongs. But not only does the cowboy belong here, he is the sine qua non for the frontier's transformation into civilization. It is the very presence of the frontier that makes it possible for the cowboy to exist as the hero of US history; it demands his presence to help pave the way for civilization's advance by enabling him to establish mastery over both the human and physical challenges that populate the 
wilderness. The frontier provides the omnipresent vehicle to highlight the nobility and strength of this individual and the seeming inevitability of America's mission to establish order out of chaos and morality out of arbitrary lawlessness. As Bazin suggests in his meditation on the western's status as a specifically 'American' form of cinema, "the white Christian...is truly the conqueror of a new world. The grass sprouts where his horse has passed. He imposes his moral and his technical order, the one linked to the other and the former guaranteeing the latter" (1971a: 145). In this sense, Turner's view of the frontier - a motor for social renewal that is reactivated each time US society expands westward - is reinforced for US audiences every time a western is screened.

It is precisely this focus on the frontier and its regenerative power that lends westerns a prominent role in sustaining core identity claims that have dominated American culture for decades. Bazin alludes to this idea when he asserts "the western does not age" (1971a: 141). In making this claim, he is suggesting that the messages conveyed by westerns are all drawn from and reinforce a mythical and timeless understanding of America's origin. Thus, regardless of the period in which a particular film is set or produced, it communicates a familiar story. For Bazin, whether a western portrays the struggle of settlers as they battle against primitive savages, the completion of the railroad or the brutality of the Civil War, it communicates a national narrative that prizes the victory of good over evil and order over chaos. It also acknowledges that the men able to bring about such victories, though they are themselves symbols of law and 
civilization, owe their strength, courage and, ultimately, their success, to an unseemly association with the very savagery and lawlessness against which they battle. ${ }^{58}$

For Bazin, westerns are "evocations" of the pivotal moments, ideological touchstones and ongoing struggles that define the American experience (1971a). Of primary importance for Bazin is the western's ability to portray and sustain the generative myths that help to define America. This understanding of the genre is shared by Corkin, who suggests "the western has the mythical power to define the past not simply as a body of material and ideological events that are recognizable and subject to analysis but as a triumphal moment when a compendium of quintessentially American traditions took hold" (2000: 68). This view is also hinted at, from a critical perspective, by Winks in his discussion on the significance of the frontier for American culture and questions of identity: "the average American today appears to think he is still engaged in a personal shoot-out at the O.K. Corral. He is still Gary Cooper in High Noon, a rugged individualist, a loner standing tall against the sky, alone amidst the forces of evil" (1971: 8).

These narratives, constitutive of the American ideal, are present not only in standard westerns set in the US west; they are also evident in an overwhelming majority of Hollywood westerns set in Canada. These northerns retain the stories and themes audiences expect from a western, differing from their counterparts only in terms of setting. As Berton contends,

\footnotetext{
${ }^{58}$ Slotkin emphasizes the hero's association with savagery and lawlessness, suggesting that recourse to violence as a tool for national regeneration has become "the structuring narrative of the American experience" (1973: 5).
} 
the differences that Hollywood showed were always superficial ones: instead of desert sands, the movie audience got snowy wastes; instead of typhoons, thundering avalanches. Jungles became pine forests; American sheriffs were transformed into mounted policemen; Mexican villains switched accents and became French-Canadian bad guys. (1975: 18)

Thus, even though the northern may explore a more exotic location and showcase characters that evoke more colour and foreignness, its plot and main themes remain essentially unchanged from those of the traditional western.

Hollywood's choice of the western as the primary vehicle for relating stories set in Canada has consequences for audiences' understanding and interpretation of that country. As "the American film par excellence," (Bazin, 1971a) the western is associated with American culture and identity narratives. It is "rooted in the history of the American nation which it exalts directly or indirectly" (Bazin, 1971b: 150). And, just as Bazin suggests that westerns do not age, I contend that neither do they travel. Thus, although westerns may be set in a wide variety of geographic and geopolitical locations, the metaphoric space within which their stories unfold, the frontier, stays the same. So, regardless of the frontier's geographic location, it remains a symbol of the pursuit and realization of the American dream.

By setting this frontier in Canada, however, Hollywood draws on existing historical tensions that mark the relationship between Canada's west and the limits of the US frontier. As Drache suggests, "In the rearview mirror of history, a single idea has stood out for Americans: Canada's west should be the US's north" (2004: 38). So, by setting westerns in Canada, and intertwining stories about Canadian geography, history and culture with this particular medium, Hollywood throws into question the 
Canadianness of the very stories it is engaged in telling. The use of the western genre serves to inject Canadian stories, implicitly and explicitly, with a wide variety of American myths, ideals and narratives. The effect of this cinematic overlay of American ideology and culture on top of Canadian stories is to blur the distinctions between the two countries. It dilutes those features that might otherwise act to clearly define Canada and effectively renders the country a refection or subset of the American experience.

A wide variety of frontier markers inhabit the harsh world of the Hollywood western. These markers are often physical in nature, relating to a rugged landscape, inhospitable climate or sparsely settled area. On other occasions, the frontier is marked by liminal peoples, usually Mexicans or 'Indians', who are not widely accepted as members of civilized society. The frontier is also signalled by the tough and fiercely independent individuals that make the land safe for those that follow in their footsteps. All of these markers, standard fare in the western's depiction of the frontier, are also prominent in Hollywood's portrayal of Canada. Indeed, just like their traditional cousins, northerns draw ceaselessly upon the frontier. Unpopulated and imposing wilderness is a constant in the northern, sometimes portrayed as soaring, snow-covered mountains or impenetrable forests, but also frequently portrayed by the bleak and dusty landscapes more familiar to fans of the western. In terms of the liminal peoples who populate the frontier, the northern certainly has its share of 'Indians,' but it replaces the Mexican with the French-Canadian and the classic Hollywood 'half-breed' with the scheming Métis. Isolated trading posts, lonely Mountie detachments and frontier towns also serve as constant reminders of the limits of Canadian civilization. So too does the inevitable 
conflict between the short-handed and underappreciated agents of law and order, usually represented by either a US lawman or a Canadian Mountie, and the agents of chaos and despotism, typically found in the guise of bloodthirsty savages or ruthless criminals. These and other reminders serve to underscore the fragility of civilization in the Canadian setting and reinforce the omnipresence of the frontier in ways immediately recognizable to US audiences.

Sometimes, the rugged hero who advances the cause of civilization in the northern is a Canadian Mountie; however, just as often, he is a transplanted US cowboy or lawman. In either case, the characteristics and actions of this male hero, along with the plot and outcome of the story itself, reflect the ideals championed by the standard Hollywood western. For example, in North of the Border, it is only through the efforts of Utah, a fiercely individualistic cowboy from the United States, that justice is ultimately effected. It is Utah's willingness to not only defy the orders of the local authorities, but actually subdue and detain a Mountie, which allows him the freedom to solve the crimes and capture the criminals plaguing the region. Similarly, John Wayne's rugged and masculine character in The Trail Beyond is a classic American cowboy, quick with his fists and guns and determined in his quest to establish frontier justice in Canada.

These two films provide typical examples of how northerns tend to project the American ideals usually associated with standard Hollywood westerns. However, in his discussion on the evolution of the western, Bazin (1971b) actually singles out two northerns, Saskatchewan and The Far Country, as exemplars of the quintessentially American genre. The first film, Saskatchewan, recounts the story of a wilful and 
insubordinate Mountie who was raised by a Cree family, and his successful efforts to forestall conflict between government forces and his adopted people. With respect to The Far Country, Berton effectively makes the case for liminality: “it was a shoot-'em-up American western, which helped to perpetuate the easy assumption that there is no essential difference between Canadians and Americans" (1975: 11). In the film, it is only Jimmy Stewart's character, a selfish and rugged loner from the United States, who has the strength and conviction necessary to confront a despotic lawman and his cronies. It is his intervention that enables the local townspeople to realize their dream of establishing an oasis of civilization in the midst of lawlessness and wilderness. Of this film, set in the Yukon, Bazin asserts, "Anyone who wants to know what a real western is... has to have seen ...The Far Country with James Stewart" (1971b: 156). Bazin's contention that these two films, set in Canada and treating Canadian stories, are exemplars of the "American" genre is an indication of how the northern communicates idealized narratives of the birth of America in the same way that the western does.

Though the frontier found in Hollywood westerns is certainly represented as liminal space, the frontier depicted in northerns accentuates this sense of liminality. This change in setting, from western to northern, transforms the frontier from its vague and unspecified concept of 'the west' to a more explicit expression of ambiguity: the CanadaUnited States border. Thus, the shift from western to northern highlights the role of the frontier, both as setting and metaphor, and pushes the sense of liminality from an implicit to an explicit footing. In terms of setting, the northern transforms the frontier from its traditional role in western films as a marker of domesticated ambiguity towards an 
increasingly foreign understanding of ambiguity. In westerns, the effectiveness of the frontier as a tool for constructing identity claims issues from the array of factors that it brings together to challenge the advance of civilization, including sparse population, limited governmental presence, foreboding geography and climate and antagonistic indigenous populations. In northerns, each of these factors remains in evidence, but the ambiguity of the frontier setting is furthered enhanced by the presence of a foreign power. Thus, beyond plots that are explicitly dependent on a foreign setting, northerns also employ a wide variety of markers of difference to intensify the impression of foreignness, including British flags, the red serge of the Mounties, references to the British monarchy, characters with French-sounding names and such songs as "The Maple Leaf Forever." The imprint of this foreign presence serves to render the frontier setting as something more than conceptual; in effect, the northern makes the frontier more explicit, more real.

A similar shift is also apparent in the frontier's role as a metaphor for the resolution of the American myth. In the western, the American myth plays out within the confines of an area where the projection of US power is confronted by a combination of natural obstacles and savage peoples whose claim to the space is considered illegitimate. In such a setting, where there is no legitimate authority that opposes the advance of American civilization, the realization of the American myth is made to appear natural to audiences. Northerns, however, are not set in a vacuum of legitimate authority; they play out in a territory to which another recognized and sovereign entity has a claim. For the American myth to be realized under these circumstances, in territory belonging to another 
sovereign power, the effect is more striking. It confers upon the myth an increased sense of righteousness and inevitability and, in a sense, serves to generalize its applicability beyond the confines of the United States.

As the above argument contends, in order for northerns to continue the work of the western, and engage in the telling of essentially American stories, they need to define their setting as frontier. However, to clarify, these films do not suggest that the Canadian locales where the stories take place just happen to be located on Canada's frontier. Rather, they imply that Canada, as a whole, is composed of undifferentiated frontier. In other words, for Hollywood, Canada does not have a frontier; it is a frontier. More specifically, Canada is an American frontier. And, when defined as the frontier in the context of the Hollywood western, Canada is effectively enveloped as part of the primordial setting that underwrites the popular narratives of American identity. The country becomes part of the arena in which epic struggles, such as those between good and evil and between order and chaos, are ultimately decided by American virtues of strength, freedom and individualism. In the end, these films contribute to an understanding of Canada as a fragment of the American experience, a new frontier where the origins of America can be replayed and the core elements of the American character renewed.

\section{Canada as a Threat}

As suggested above, it would not be unexpected for observers to respond with scepticism to the claim that Hollywood films tend to portray Canada as a threat to the 
United States. Indeed, such scepticism might be justified considering the broad and benign strokes with which the country and its people are generally painted. For instance, films frequently highlight the beauty and magnificence of Canada's physical geography and, for the most part, showcase Canadians themselves as innocent, generous and friendly people. However, as Brégent-Heald suggests with respect to a set of films she labels border noir, "border landscapes are routinely depicted as dangerous territories for Americans" (2006a: 135-136). In the case of Canada, the beautiful physical surroundings are also found to be isolating and dangerous, and the sweet disposition of the country's people can render them susceptible to the intrigues of shady characters and ill-equipped to rise up when confronted with lawlessness or despotism. It is the existence of these otherwise positive characteristics that enables the spectre of threat to take hold in Canada and menace the United States.

Hollywood creates a variety of roles for Canada which effectively prompt audiences to imagine the country as somehow contributing to US insecurity. This section details three such images: lawless anarchy, criminal haven and vulnerable ally. It explores the themes and imagery associated with these roles and demonstrates how films deploy them to communicate a plausible impression of threat to US audiences.

\section{Canada as Lawless Anarchy}

The first example in which Hollywood films transform Canada into a threat to the United States emerges from a representational pattern whereby the country is portrayed as rife with discontent and primed for full-scale rebellion. This turn as a region of lawless 
anarchy derives largely from the country's portrayal as wilderness, a frontier land with vast and rugged territory and a limited police presence. These and other images combine to create the impression of a wild territory that roils outside the reach of effective and legitimate governance. The country is pictured as a lawless territory with little or none of the trappings of civilization, precariously balanced and ready to plunge at any moment into a cauldron of violence and chaos.

This pattern is evident in North West Mounted Police, a Gary Cooper vehicle that charts the origins of the North-West Rebellion of the 1880 s. It is also apparent in such films as Saskatchewan and The Canadians, which explore the purportedly incendiary impact of the arrival of the Sioux in Canada following their confrontation with the US cavalry. Canada's Aboriginal people are also shown to be willing to plunge the country into violent upheaval in order to stop the westward expansion of the railroad (Susannah of the Mounties; Canadian Pacific). The pattern even finds expression in shadowy conspiracies to overthrow the government's power. For example, in Perils of the Royal Mounted the villains launch a destabilizing campaign of violence and intimidation in order to "control the richest fur territory on the continent and make millions from [their] own railroad contract." In a similar vein, Gunfighters of the Northwest features a group of villains who want to establish their own state, the Whitehorse Republic.

As suggested above, this pattern draws from and contributes to an understanding of Canada that is rooted in lawlessness. For the most part, the nature of the threat posed by a lawless Canada is communicated implicitly. The unspoken worry is that Canada's proximity to the United States, and the porous and uncontrolled border that separates the 
two nations, makes the existence of political and social unrest in the former a dangerous concern for the latter. The implicit nature of this threat, however, is substantiated by the frequency with which US cowboys or lawmen play a lead role in confronting and defeating the agents of lawlessness in Canada. Indeed, their presence serves to define the establishment of order in Canada as a US interest.

Moreover, even though these films may only imply that chaos on the US frontier is dangerous, the apprehension of such dangers has long played a crucial role in structuring actual US foreign policy towards its neighbours (Gaddis, 2004: 16-22). In essence, the fact that a fear of chaos and disorder on US borders has conditioned actual US foreign policy responses encourages audiences to view Hollywood's lawless version of Canada through a prism of potential insecurity.

Case Study: Pony Soldier (1952)

Standing Bear: "Long Knives coming, horse soldiers, thunder guns. We must go north, back to the country of the Great White Mother."

Konah: "Here there are many buffalo. Here the hunting is good. Konah says fight the Long Knives!"

Standing Bear: "We cannot. The Long Knives are as many as the pine needles of summer. We must go north swiftly."

Konah: "For what? To starve? It is our right to hunt where we like. Will you let the Long Knives drive you back to a land of hunger? Konah says fight!"

Set in 1876 , this production portrays Canada within the wider context of the frontier chaos and violence that threatened the United States around the time of General Custer's defeat at the Battle of the Little Bighorn. In this sense, it draws on wellestablished tropes about the 'Indian savage' that have haunted American culture for 
centuries and, all too often, conditioned a violent response (Drinnon, 1980; see also Slotkin, 1973). This context is established clearly in the opening moments of the film through the use of an introductory voiceover that explicitly draws Canada into the uncertainty and violence that surrounded the US campaign against the Sioux nation:

In those days [the Canadian west] was a powder keg. The savage tribes of plain and mountain were ready to explode into bloody war...I was sent to join Troop B at Fort Walsh in Saskatchewan close by the Montana line. We prepared for trouble. South of the boundary, the Sioux and the American cavalry, called Long Knives by the Indians because of their sabres, were fighting bloody skirmishes. And our own warrior Canadian tribes were restless.

The film's story unfolds in a manner consistent with the tone of this introduction; it is a time of great tension and there is an omnipresent sense that a violent outbreak or insurrection in Canada is all but inevitable.

Canada's unchecked turmoil, however, does not remain secure within the confines of the country's borders. Indeed, the entire Cree nation ends up leaving its reserves in Canada to slip illegally into the United States in order to hunt Buffalo. Although this transgression is certainly ominous on its own merits, the situation becomes explicitly threatening to US security after the US cavalry mistakes the Cree for Sioux and kills several of them. The Canadian Cree retaliate by ambushing the US cavalry, with their chief, Standing Bear, exhorting his followers to attack by declaring, "We will teach them the difference!"

The threat from Canada takes on an additional dimension once the Cree have decided to return to Canada. At this juncture, they opt to capture US hostages in order to help them with negotiations in the event the US cavalry intercepts them before they reach 
the border. As a consequence, a Cree war party attacks a small homestead family, killing a father and son, and capturing the man's daughter and a hired man. This scene showcases the extent of the barbarism and threat embodied by the Canadian Cree by juxtaposing it against the innocence of the settlers. Before the attack, the smiling father is driving the wagon and showing his excited daughter where they will build their new home: "Nice spot over there. Plenty of water. Build our cabin on that rise, corrals below." This picturesque and idyllic image is then shattered when the camera shows the man's young son take an arrow in the back of the neck while happily waving his father and sister across a shallow river. The existential nature of the danger is further heightened as the savage Cree capture and drag away the screaming young woman. This plot device, drawing on one of the frontier myth's most evocative and venerable staples, the captivity narrative (Slotkin, 1973), ultimately culminates in a scene in which the woman is tied up while her captors light a bonfire that is intended to burn her alive. Thus, although the Cree's unimpeded romp across the border is clear evidence of the dangers that lurk in Canada, their subsequent attacks against the cavalry and the homesteaders, both enduring symbols of the westward march of American civilization, are even more concrete and more powerful representations of that threat.

The film's depiction of Canada as a source of US insecurity is primed through complementary representations that portray Canada as a place capable of producing such a danger. For example, the film's depiction of Canada as a desolate and wild territory enables the audience to picture the country as home to a wilful and savage people that harbours suspicion and resentment against the advance of civilization. Such impressions 
are advanced by continuous footage of undifferentiated frontier, rocky outcrops and a desolate and lifeless landscape. The film's opening voiceover refers to the region as "the great lone land," and the only hint the audience is given of any form of civilization is an opening reference to several scattered North-West Mounted Police forts. Indeed, as it turns out, such depictions are a foregone conclusion in the film for, although the story is set in western Canada, the picture itself was actually shot against the backdrop of the Arizona desert. And this lifeless backdrop even contributes to the plot itself, as it is a lack of Buffalo that drives the Cree south across the border into the United States in search of better hunting opportunities.

The film's plot, images and dialogue also portray Canada as a lawless place, where authorities are limited in their resources and their ability to effectively police their domain. Indeed, it is the Mounties' inability to police effectively the vast and lawless territory of western Canada that lies at the very core of the story's plot. Early in the film, the Inspector makes it clear that although the Mounties were aware the Cree had left their reservations, they did not know where they had gone or what their intentions were. More specifically, the Mounties are shown to be completely ignorant that the Cree had crossed into the United States and attacked US soldiers and homesteaders. As detailed above, the opening voiceover contributes to the impression of a lawless country through references that label western Canada a "powder keg" and the area's indigenous people as "ready to explode into bloody war". The region's lawless nature is confirmed explicitly by Inspector Fraser when he admonishes the main character, Constable Duncan MacDonald, for not taking his duty seriously: "You get paid seventy-five cents a day to carry the law 
where there is none." The film's opening provides an effective visual contrast between a minimal police presence and an enormous swath of territory. It features a uniformed constable sticking lonely pins into an empty map of western Canada as the voiceover names each of the isolated North-West Mounted Police detachments: "The force was only three years old and in scattered posts from Edmonton, to Fort Calgary, to Fort McLeod, from Battleford, to Maple Creek, to Fort Walsh, we were trying to bring the law and keep the peace throughout thousands of square miles of Indian country." The voiceover's reference to the inexperience of the force is repeated and reinforced on several occasions throughout the film. Indeed, the film's Mountie protagonist is himself a new recruit to the force, and his relative inexperience is featured throughout the film, standing in as a symbol of the inexperience of the force as a whole.

The film employs a number of liminal representational patterns that act to minimize the distinctions between Canada and the United States and portray the two countries as sharing the same space and history. For example, the narration that opens the film suggests that "this is a story about the old northwest territories of Canada." However, the initial shot employs a camera narrowing its focus on a large map of western Canada and the United States. The view continues to zoom in until finally resting on a marker for Fort Walsh, a detachment whose location adjacent to the Montana border is clearly indicated. Moreover, as the narration continues, the United States is given a prominent role as the illegal destination for the Cree tribes that leave their Canadian reservations in search of food. In fact, the crossing of the Cree into the United States, which is the pivotal moment in the elaboration of the plot and the event which initiates 
the crisis on which the entire story is based, is itself an act that confirms the colocation of Canada and the United States. Thus, while the opening narrative contends that the story is about the Canadian west, the introductory map and the very premise of the film marks the story as one that belongs to both Canada and the United States.

Another blatant indication of the film's preoccupation with Canada's liminality relates to the seeming insignificance with which the characters view the border between Canada and the United States. Certainly the Cree do not consider the importance of the border in their decision to travel south in search of buffalo. More important to them is the overriding need for food and a prior understanding of traditional hunting grounds that does not include an international boundary. The protagonist's 'half-breed' scout, himself a living symbol of a different kind of liminality, drifts effortlessly across the border on at least two occasions. Similarly, the story's secondary villain, a Canadian bank robber, has stolen across the border at some point before the adventures described in this film and is then forced back into Canada as a captive of the Cree. At one point, even MacDonald's superior officer expresses disdain for the border, as he upbraids the constable for letting the boundary stand in the way of his duties. When MacDonald explains that he did not pursue a horse thief because he believed the suspect had escaped across the US border, Inspector Fraser's responds with anger: "What's the border got to do with it!" The irrelevance with which the film's characters consider the border is particularly telling considering the gravity of the story is supposed to derive from the importance of the border and its role as a restraint on the mobility of the Cree. Indeed, the cumulative effect 
of this pattern is an excellent example of how the border can be reconfigured as a line that joins rather than divides.

The effect of these representations of liminality is to diminish the distinctions between Canada and the United States and link the two countries together, both historically and geographically, as parts of a single unit. Moreover, understanding Canada in terms of this linkage makes it easier for audiences to conceive of the threat of a lawless Canada infecting US security.

\section{Canada as Criminal Haven}

Hollywood's Canada also poses a threat to the United States through its status as a haven for US lawbreakers. Indeed, as Brégent-Heald notes, "the Canadian northwest borderlands were apparently teeming with criminals" (2004: 51$)$. This status as a criminal haven derives from the impressions created by a variety of othering patterns. For example, presented as unvariegated wilderness, Canada's vast territory poses difficulties for the country in terms of border control. As a consequence, criminals are drawn to the country because they are able to enter with ease. Moreover, Canada's sparse and rural population provides villains with the isolation and anonymity necessary to plan and effect their schemes. They are further emboldened by an unsophisticated and gullible citizenry. ${ }^{59}$

\footnotetext{
${ }^{59}$ All of these same themes were also deployed by the news media to depict Canada as a haven for terrorists during the War on Terror (see chapters 5 and 6 ).
} 
These factors make Canada an ideal location for US criminals fleeing lawmen from their home country (Berton, 1975: 54). This dynamic is evident in such films as God's Country and the Man, in which the villain robs and kills a shop owner and then flees across the border to Canada in order to avoid the posse that is formed to pursue him. Canada plays a similar role in a number of other productions, including Perils of the Wilderness and Phantom Patrol. Hollywood also portrays Canada as a perfect location from which lawbreakers can perpetrate inventive cross-border crimes. For example, North of the Rockies features a gang that steals furs in Canada and returns them to a base across the border. In O'Malley of the Mounted (1936) the criminals are raiding US towns from their base in Canada. Canada is also advanced as an ideal setting for villains and gangsters to commit heinous crimes or amass illegitimate fortunes before eventually trying to sneak across the border to the United States. In Niagara, a film Brégent-Heald highlights for its treatment of liminality (2006a), the lead character travels to Canada as part of a nefarious scheme to kill her husband. ${ }^{60}$ In Royal Mounted Rides Again one of the villains is a US counterfeiter who is stealing gold and converting it into twenty dollar coins with the intent of smuggling them back into the United States by riverboat.

Case Study: The Renfrew series (1937-1940) ${ }^{61}$

Inspector Newcomb:"It is apparent then, by the finding of a counterfeit banknote

\footnotetext{
${ }^{60}$ Brégent-Heald suggests that the sense of threat that issues from Niagara derives from the "anticommunist hysteria" ascendant at the time of the film's release combined with Canada's proximity to the Soviet Union (2006a).

${ }^{61}$ This section reviews the following Renfrew films: Danger Ahead (1940), Crashing Thru' (1939), Fighting Mad (1939), Murder on the Yukon (1939), Renfrew of the Royal Mounted (1937), Sky Bandits (1940) and Yukon Flight (1940).
} 
under the body, that the Constable was killed by a member of the ring we are seeking. It may be one of these three [US gangsters] whose pictures you have. And it may be some of our own countrymen aiding them. At any rate, we stand challenged by a dangerous gang who have adopted methods vary rare in the Dominion." (Renfrew of the Royal Mounted, 1937)

The Renfrew series of B-pictures pits Sergeant Renfrew, one of Hollywood's most famous singing Mounties, against scheming villains in the wilds of Canada. The pictures are inevitably set adjacent to the Canada-US border and frequently draw upon this international divide as a plot device. They usually feature US characters in prominent roles, often in the form of the love interest or the villain.

The threat posed by Canada in the Renfrew series of films is threefold. First, the criminal activity on display in these films is representative of a delay or denial of US justice. In some cases, the villains are explicitly defined as US criminals who have come to Canada to escape justice. For instance, in Fighting Mad, the villains come to Canada after having robbed a bank in the United States. In Renfrew of the Royal Mounted the villains are convicts being hunted by US authorities who have come to a secluded Canadian lodge in order to work in a counterfeiting ring. In both of these examples, it is clear that Canada serves as a refuge for these criminals. In several other cases, although the films may not explicitly confirm the villains as Americans, they are clearly represented as the traditional US gangster. Implicit in these stories is the impression that these men have led shady, dubious lives in the United State prior to coming to Canada. As the flagship picture in this series, Renfrew of the Royal Mounted helps to make this association clear in later films. This original film, with its gangster villains and crossborder themes, provides a stock of plots and characters from which later productions in 
the series draw liberally. The ultimate effect is to represent the villains as transplanted Americans. In either case, whether the antagonists are explicitly labelled as US criminals or implicitly styled as US gangsters, Canada provides a ready haven for cross-border villains. In this sense, the Renfrew films effectively portray Canada as harbouring US criminals and unintentionally thwarting the administration of US justice.

The second manner in which the Renfrew films portray Canada as a security risk to the United States is their depiction of the country as a secure base of operations from which US criminals are able to engage in cross-border crime. These criminals are typically engaged in smuggling schemes in which the border features prominently. For instance, in Renfrew of the Royal Mounted, US gangsters are helping to run a counterfeiting ring from an isolated lodge in Canada that packages the fake bills in frozen trout in order to smuggle them across the US border. In Yukon Flight, the gang of criminals adopts a more forthright plot, opting to simply steal gold and fly it to the United States. And, in Murder on the Yukon, the villain Hawkes reveals the US connection behind a spree involving counterfeiting, murder and robbery: "We'll never have to worry once we get that gold dust back to the States." Moreover, even in those films in which there is no actual attempt to smuggle stolen goods into the United States, the border often features prominently in the criminals' plans. In Danger Ahead and Sky Bandits, for example, the villains attempt to mislead the Mounties by making it look like gold shipments were hijacked and smuggled across the border. In these cases, even though the criminals did not actually plan to cross into the United States, such a plan was presented to audiences as a plausible plot twist. 
The third manner in which Canada is depicted as a threat relates to the dangers visited upon Americans when visiting the country. For instance, in Crashing Thru', a US woman and her brother are wrapped up in a dangerous plot to recover gold that was stolen from them. In Sky Bandits, the villains bring an innocent and kindly US scientist to Canada under false pretences and hold him against his will, threatening his life if he does not complete work on a weapon for shooting down airplanes. The scientist's daughter, the film's love interest, is also endangered by the villains. Fighting Mad features an innocent US woman who is kidnapped by US bank robbers and forced to accompany them across the border. And, in Renfrew of the Royal Mounted, the villains trick a reformed exconvict into travelling to Canada and then force him to help them produce counterfeit currency. Both he and his daughter are captured by the villains and held at gunpoint. Through these sub-plots, each of these films contributes to a wider understanding of Canada as an unsafe place for Americans.

The insecurity engendered by the Canada portrayed in the Renfrew films is made possible through filmic representations of the country that define it as fundamentally different from the United States. These representations portray Canada as the kind of place where danger is not only believable, but commonplace. For example, in a conversation about a man who apparently killed his own brother for money, one character comes across as positively blasé: "Oh, I'm not surprised. During my years in the northwest woods I've seen some very strange things happen" (Murder on the Yukon). Canada is shown to be almost exclusively rural, a place where the wilderness is punctuated only by rustic and backward lodges and trading posts. Depictions of the 
country's lack of civilization are further reinforced by representations of a simple, unsophisticated citizenry. For example, the gullibility of Canadians is evident in the mocking, sneering smile a criminal makes as he proceeds through border security, having fooled border guards with his cache of counterfeit bills hidden inside frozen fish (Renfrew of the Royal Mounted). It is also evident in this same villain's response to his associate when asked if he had any trouble coming across the border: "No, it's getting so easy I'm ashamed to draw my salary."

The threat that Canada embodies is made salient to US audiences through representational patterns that tie Canada and the United States together. This strategy, whereby the Renfrew films depict Canada as liminal to the United States, operates primarily through two patterns: depictions of intimate interpersonal relations between the Canadian hero and the US heroine; and depictions of the border as an area of colocation, rather than a line of division.

It is not unusual for B-westerns to conclude with the hero and the picture's female lead in an embrace or some other indicator of future bliss; the Renfrew series is no different in this regard. What makes these films different, however, is the frequency with which the female lead is from the United States. In four of the seven Renfrew films reviewed (Sky Bandits; Fighting Mad; Crashing Thru'; Renfrew of the Royal Mounted), the heroine is an American and, in each case, initially appears to be mixed up in the criminal scheme Renfrew is investigating. Also in each case, Renfrew manages to confirm the woman's innocence and sweep her off her feet. Beyond a simple adherence to formulaic plots common to B-westerns, this pattern hints at a degree of compatibility 
between Americans and Canadians. Moreover, without betraying a single hint at the logistical difficulties that might emerge from a cross-border romance, the films effectively bless them with an aura of naturalness. The image of an iconic Canadian in the traditional role of winning the American heroine's heart also suggests that Canada and Canadians can be understood within the context of the American experience.

The sense of liminality advanced through the binational romance between Renfrew and his US sweetheart is heightened dramatically through the series' reliance on the notion of colocation. Although each of these films draws upon the border as an important plot device, they tend to minimize its role as a marker that acts as a fundamental divide between Canada and the United States. In Renfrew of the Royal Mounted, for example, criminals move back and forth across the border at will, smuggling their counterfeit currency without arousing the slightest suspicion from obliging Canadian border guards. Moreover, as mentioned above, several of the films employ plot devices involving the smuggling of gold across the border, either by car or plane (Danger Ahead; Sky Bandits; Yukon Flight). In none of these cases is the border itself understood as an impediment of any seriousness. Indeed, the difficulties and implications of illegal border crossing are not even hinted at, and the border itself is mentioned only in matter-of-fact terms. Fighting Mad provides a particularly effective example of how these films minimize the border when it opens with two US bank robbers simply walking across the unseen border as they trek through a forest. The absence of any kind of border control and the ease with which the villains are walking serve to mark the border as little more than an imaginary line. The cumulative effect of these portrayals of 
the border serves to minimize the legal and official distinctions between Canadian and US territory; the two countries are depicted as effectively sharing the same space. Considering the importance of the United States in terms of both the plots and characters of these films, a minimized border also helps to imply that the two countries are partners in the story unfolding on the screen.

These depictions of liminality help to transfer the danger that resides in Canada to the United States itself. They imply that the countries are intertwined to such a degree that both US citizens and principles are threatened by the state of affairs in Canada.

\section{Canada as Vulnerable Ally}

A final example of Hollywood's construction of the Canadian threat is found in a set of films and serials that portray Canada as a conduit through which enemy nations are able to threaten or attack the United States. As Brégent-Heald suggests, this filmic trend emerged in the lead-up to the Second World War. In the years before the Japanese attack on Pearl Harbor these "alarmist" films

depicted both the Mexican and Canadian borderlands as the soft underbelly of the United States, a place where enemy agents could smuggle war-related resources, conduct acts of sabotage, or relay vital defense secrets back to the German homeland. Canada and Mexico were, by association, somehow held responsible for the now seemingly compromised national security of the United States. (2004: 12) 
These same trends and themes would reignite again in films produced during the early Cold War, in which Canada would figure prominently in plots involving communist infiltration and threats to US security (Brégent-Heald, 2004: 384-389). ${ }^{62}$

In these films, although Canada is undoubtedly understood to be a trusted ally of the United States, it is nonetheless othered as possessing characteristics that render it a weak link that hostile powers can exploit. For example, the country's vast and rugged wilderness makes it easy for foreign agents to infiltrate the country. This frontier setting also makes the country an ideal location from which foreign spies can plot attacks in anonymity. The gullibility of Canadians is another factor that enables foreign agents to operate and recruit local quislings with little fear of discovery. Finally, Canada's limited military strength, relative to that of the United States, also renders the country an obvious preliminary target for villains bent on invading the United States.

Canada's remoteness plays a pivotal role in enabling foreign agents to infiltrate the country via submarine in both Northern Pursuit and King of the Royal Mounted. In the former, sinister music sets the stage while the submarine is shown surfacing in an empty, arctic wasteland. A German officer emerges from the vessel and confirms his surroundings with a contemptuous sneer: "So das is America, huh?" In the latter, the German submarine evades detection and is able to put an operative ashore in the rugged "MacKenzie Inlet." In these and other films, the enemy spies are aided by considerable operations already extant in Canada. For instance, the villains in King of the Royal

\footnotetext{
${ }^{62}$ These films included a series of 'creature features' in which Canada and the United States were menaced by monsters or aliens emerging from Canada's north. As Brégent-Heald contends, such creatures "are a metaphor for the seemingly imminent threat of communist invasion and a reminder that the North American hemisphere is not safe" (2004: 388).
} 
Mounted are part of the "the largest international espionage ring in the world." In Northern Pursuit, the German agents make their way to an isolated mineshaft where they unearth the secreted parts and equipment needed to build a bomber that were shipped there "long before the war." Canadian Mounties versus Atomic Invaders features a gang of agents with superior technology and a protean leader who is able to operate in plain view of citizens and police alike. Most of these films also show the foreign agents being aided by an unending parade of local patsies and quislings. This pattern is evident in The Iron Curtain, for example, when the leader of the Canadian traitors details the type of people he will turn for his Soviet masters: "You need people in the right places: in the army, the air forces, the navy, the National Research Council, the Department of External Affairs."

This set of films portrays Canada as a threat to the United States in a variety of ways. In The Iron Curtain, for instance, Soviet agents are able to infiltrate all levels of Canadian government and, by exploiting Canada's close relationship to the United States, expand their reach into US research institutes. Ultimately, these agents "were able to invade the most secret of diplomatic files, in that way getting at important information other governments were entrusting to Canada." As Brégent-Heald suggests, this film "reveals that the U.S.-Canadian border during the Cold War was potentially a door through which dangerous communists could enter the United States" (2004: 385). Moreover, in terms of its capacity to portray Canada as a threat, Swann reveals that The Iron Curtain was intentionally produced with the intent of depicting a menace serious enough to "arouse the public to vigilance" (1995). 
In several films, Canada is portrayed as a staging ground for a military attack against the United States. ${ }^{63}$ For instance, in Canadian Mounties versus Atomic Invaders, enemy operatives plan to use Canadian territory in order to launch guided missiles against US targets. In this instance, Canada's location adjacent to the United States is crucial to the plan of attack, as the country's proximity will ensure that "every important American city will be in ruins within a few hours." In Northern Pursuit, Canada provides the staging ground for Germans to build a bomber that will attack a waterway that forms part of the border between Canada and the United States. The vulnerability of the border is also emphasized near the beginning of the film when the leader of the North American traitors is waived through a border crossing by claiming simply, "I'm a tourist." While it is important to note that these films typically emphasize the close nature of the CanadaUnited States relationship, their explicit treatment of an existential danger to the United States opens the door to an understanding of Canada as a threat. Thus, beyond simple outward expressions of alliance, these films communicate a subtle reminder to viewers that despite Canada's loyalty, the country inadvertently poses a danger to the United States. In this sense, these films provide a powerful vehicle for understanding Canada itself as a security threat.

Case Study: King of the Mounties (1942)

Count Baroni: "We cannot fail. Soon we will drink a victory toast in Ottawa."

${ }^{63}$ This trend is another common feature in news media depictions of Canada during the War on Terror (see chapters 5 and 6). This fear also occupied the attention of US policymakers in the lead-up to the Second World War, prompting President Roosevelt to inform Prime Minister Mackenzie King that the United States would protect Canada from invasion by other powers (Fortmann and Haglund, 2002). 
Admiral Yamata: "And soon thereafter, as our Admiral Yamamoto predicts, we will dictate the terms of final peace in the White House!"

Marshal von Horst: "Heil Hitler!"

Count Baroni: "Viva Il Duce!"

Admiral Yamata: "Banzai, Hirohito!"

In King of the Mounties, Canada is being bombed by a mysterious aircraft that manages to elude all standard means of detection. The aircraft, dubbed the Falcon plane, is managed jointly by a trio of high-ranking Axis villains: Admiral Yamata of Japan, Marshal von Horst of Germany, and Count Baroni of Italy. These same Axis commanders also direct a "well-organized group of saboteurs" within Canada through the intermediate leadership of a Canadian quisling.

The villains' plan in King of the Mounties is to weaken Canada's defences through a combination of local sabotage and the Falcon's bombing raids until such time as they are prepared to mount a full-scale invasion of the country. However, as the above ominous dialogue between the villains makes clear, the ultimate goal is an invasion of the United States itself. Understood in the context of the Second World War, especially in light of Japan's military presence in the Pacific Ocean and its recent attack on Pearl Harbor, an invasion of US territory would have been seen as a palpable concern. Indeed, the danger of Canada being used as a conduit by the Japanese was a primary impetus for a series of US wartime measures undertaken on Canadian soil: "By the end of the war, the United States had built airfields, an oil pipeline, weather stations, and a host of other installations on Canadian territory" (Clarkson and Fitzgerald, 2009: 6).

The introduction of the Axis threat into Canada is made plausible through the use of representational strategies that portray the country as susceptible. For example, 
Canada's vast size is highlighted as a shortcoming; the country is simply too large for law enforcement officials to monitor effectively or prevent the treasonous activities of the saboteurs. The serial's hero, Sergeant King, makes this situation abundantly clear when expressing his worries to the Commissioner: "We're doing all we can, sir. We've got a lot of territory to cover and our men are spread out pretty thin. Somehow, the saboteurs seem to discover our weak spots and always attack them." The size of the country is also a problem in terms of trying to pinpoint the location of the Falcon and defend against its attacks. Another contributor to the impression of susceptibility derives from Canada's lack of sophistication. For example, though the film is set in the 1940s, the Canadian heroes are often seen riding horses as if they were in the old west. This understanding of Canada as a technologically backward, almost primitive, society is part of a pronounced tendency within Hollywood films. Canada's diminished capacity for technological innovation is also demonstrated by the prominent role accorded two US scientists and their "Brent Detector invention," without which Canada might already have fallen to the Axis powers. In a complementary nod to the country's rural and simple nature, the community where the Mounties' detachment is located is given the rustic name of Tombstone Landing. Finally, Canada is pictured as simply too weak to defend itself effectively. Without the assistance of Professor Brent and his daughter, Canada would be at the mercy of the Falcon's bombing campaign. Even more importantly, at one point in the serial the RCMP Commissioner makes it clear that Canada would not have the strength to hold back Axis troops if they were to launch an invasion. Moreover, these deficiencies in Canada's defences are also implicit in the Axis plan itself; attacking 
Canada first only makes sense if the country is understood to be more susceptible than the United States.

That the United States might face invasion from Axis forces via Canada is made plausible through the portrayal of Canada as liminal. In essence, Canada and the United States are treated as though they are fundamentally intertwined, as though an attack upon the former is essentially equivalent to an attack on the latter. For instance, the film opens with a map of North America that shows Canada and the United States coloured in similar light shades (and without a line marking the border between Canada and Alaska). The effect of this shading, when contrasted by darkened images of Mexico and Cuba that serve to reduce these neighbouring countries to obscurity, is to group Canada and the United States together at the outset of the film. Such an impression would have been heightened by the actual military cooperation that was developing between the two countries at the time of the film's production in 1942. Beyond this visual depiction of colocation, however, the two countries are also linked through repeated framing efforts that suggest they share the same essential qualities. One of the most telling examples of this occurs when Marshal von Horst explains to his co-conspirators why Canada does not fall as easily as their other enemies: "But this is part of the American continent, where independence was first conceived and where people have always fought to the death for their liberty. America..." This intermingling theme is emphasized again in the last scene of the film, during a conversation involving Canadian officials and the US heroine:

Commissioner Morrison: "Miss Brent, I wish I might present you the decoration also. It was your heroic cooperation which made all this possible, and I assure you Canada deeply appreciates your services."

Carol Brent: "Thank you, Commissioner. I was glad to do all I could. After all, 
helping Canada means helping my own country too."

Marshal Carleton: "Well said, Miss Brent. As long as the people of our two great nations realize the responsibilities they bear together, we may rest assured that freedom and democracy shall not perish on this earth."

The coinciding interests of the two countries, expressed by Carole Brent in the above dialogue, is accentuated even more as the film ends, with the camera focusing on side by side portraits of US President Franklin Roosevelt and British Prime Minister Winston Churchill as the strains of God Save the Queen are heard playing in the background.

The overall effect of this pattern is to link Canada and the United States together. As a result, King of the Mounties shows the two countries sharing the same space, exhibiting the same characteristics and embodying the same principles. In effect, the film portrays Canada as a reflection or subset of the American experience. As a consequence, it implies that attacks or threats against Canada can be understood as sources of insecurity for the United States. The British propaganda film $49^{\text {th }}$ Parallel was a popular Oscarwinning film from 1941 that was based on similar themes of enemy infiltration and sabotage in Canada. Of his film, the director once said, "I want to make a film in Canada to scare the pants off the Americans, and bring them into the war sooner" (BrégentHeald, 2004: 166). I would contend that King of the Mounties, Northern Pursuit and the other films examined in this section functioned in a similar way. Although they were not necessarily designed to make Americans afraid of Canada, their capacity to generate fear in their audiences was based on their use of tropes and broad cultural impressions about the geography and people of that country. 


\section{Conclusion}

This dissertation contends that US media sources script Canada using two broad representational patterns: Canada as Other and Canada as liminal. Berton provides one example of this process in terms of Hollywood's depiction of Canada: "there's little doubt that the bludgeoning effect of the motion picture first distorted [Canada's] image by making [Canadians] appear as a nation of primitives, and then blurred it by confusing it with the American image" (1975: 204). Chapter 3 detailed the variety of ways in which Hollywood films deploy representational patterns that serve to other Canada. It also demonstrated how these images of otherness are used to introduce the possibility that threat and danger reside within the borders of the country. Starting from this premise, this chapter has examined those representational patterns that script Canada as liminal to the United States. I contend that these depictions of liminality help to transform Canada from a simple host of latent dangers into a conduit that serves to channel those dangers towards the United States. These depictions attach a specific meaning to the version of Canada that resides within the American imaginary. More precisely, they create a threatening version of Canada that emerges when the United States is challenged or when the American identity is threatened.

In demonstrating these contentions, the chapter has explored how patterned representations of liminality contribute to Hollywood's scripting of three 'dangerous' versions of Canada: lawless anarchy, criminal haven and vulnerable ally. By acting as both host and conduit for danger, these renderings of Canada become sources of 
insecurity for the United States. Though its role remains limited when compared to those entities scripted as unambiguously Other, Canada's ability to provide a proximate source of threat suggests that the country contributes to the "discourse of danger" that works to delimit American identity.

There is a sense in which Hollywood films examined in this dissertation advocate two possible responses to the threat that Canada poses to the United States: colonization and confrontation. In the first response, a lawless and uncivilized Canada is transformed into a vision of American sameness through the vehicle of the Mountie. As part of this response, the Mountie is rendered into a Canadian version of the archetypal hero of the American west, the cowboy. As Berton suggests, "Hollywood Mounties were never Canadians; they were simply hard-riding, hard-shooting cowboys from the American wild west, thinly disguised in scarlet and gold" (1975: 123). In this process, the contingent and resistant aspects of Canada are effectively colonized by a character whose characteristics and behaviour are obviously styled after the cowboy. In this sense, Canadians are shown to be able to conquer their own environment only by adopting those traits that enabled the cowboy to master his American west.

In the second response, disorder in Canada is confronted by an aggressive American intervention. This response, understood as an unyielding American reaction to the otherness of the Canadian wilderness, invariably comes in the form of a cowboy who travels north to personally domesticate the Canadian frontier. As chapters 3 and 4 make clear, the American cowboy is an effective force for order when transplanted to Canada. His response to the unruly Canadian environment is a masculinized affair in which he 
takes the lead in effecting justice. Although the cowboy may find himself cooperating with the local Mountie, he only does so on his own terms. More typically, however, films that feature the cowboy taking an active role in bringing order to Canada's frontier are only made plausible in the face of Canadian inability or inaction. In this sense, the dangers and chaos of the Canadian wilderness are confronted and tamed by direct American action. As chapters 5 and 6 will demonstrate, these two responses have an intertextual linkage to the kinds of responses floated by the US news media in its scripting of Canadian threat during the War on Terror. This is a theme that I also return to in the conclusion in order to draw out some of the implications that liminality has for the practice of Canadian-American relations.

The next two chapters chart the presence of the otherness-liminality dynamic in the context of the US news media's coverage of Canada during the War on Terror. Chapter 5 examines how news representations of Canada are structured by tropes of social values and gender, and how these representations make it possible for audiences to understand the presence of terrorists in North America. Chapter 6 then shows how representational patterns that script Canada as liminal serve to transform the presence of terrorists in Canada into an immediate and existential threat to the United States. 


\section{Chapter 5 US News Media and Themes of Canadian Otherness}

\section{Introduction}

In December of 1999, Ahmed Ressam was apprehended while attempting to cross the Canada-United States border on a mission to detonate an explosive device at the Los Angeles International Airport. Occurring at a time of increased concern for terrorism and a general sense of anxiety that accompanied the coming of the new millennium, this event generated considerable news coverage in the United States. It also resulted in a heightened sense of insecurity in the United States and increased attention towards Canada's role in allowing Ressam a North American base of operations. Although Ressam's arrest was a watershed of sorts, in terms of generating a sharper focus on both the threat of domestic terrorism in the United States and the possibility of a Canadian connection, the news media's reaction to the dramatic events of September 11, 2001 eclipsed these previous trends. As Flynn suggests, "the jitters surrounding the Ressam arrest turned into near panic immediately following the attacks of September 11" (2003: 115). The pervading sense of national insecurity engendered by $9 / 11$ pushed the United States towards a war footing, while increasingly accusatory misgivings directed at Canada began to find expression in the utterances of US media, academic and government elite.

The events of $9 / 11$ ultimately precipitated a militarized response from the United States in the form of the War on Terror. However, launched while the collective question 
"Why do they hate us?" still hung in the air, this war would become a struggle that involved American identity every bit as much as it did US military assets (Campbell, 2001). This chapter contends that Canada played an important role in the struggle over American identity that was being waged at the same time western countries fought in places like Afghanistan and Iraq. In the following pages, I explore the patterned ways in which the US news media depicted Canada during the War on Terror. More specifically, I examine how, during this extended period of US insecurity, Canada was portrayed as different from the United States. These portrayals of Canadian difference functioned in two interrelated ways, both of which had important implications for American identity.

First, news media portrayals of Canadian alterity allowed for the specification and confirmation of what constitutes the American identity. Hartley (1982) refers to the news media's role in the scripting of identities as the "consensus" principle. According to this principle, the primary audience for a news story is referenced as a normalized self. In effect, national news sources present international coverage according to a basic organizing principle built on a self/Other dichotomy. Therefore, when the US news media covers events, people and policies from other countries, those countries are defined not in isolation, but in relation to an American self (Rivenburgh, 1997). For example, when news reports or commentary define Canada in terms of age, as though it is a young or immature nation, the corollary implication that flows from the use of dichotomous logic is that America is a mature or seasoned nation. Similarly, if Canada is portrayed as a wild and rugged hinterland, America is typically represented, either implicitly or explicitly, as a civilized and urban setting. In this sense, depictions of Canadian alterity help to 
reassure prevailing perceptions of America. To be clear, I am not suggesting that Canada serves as some kind of quintessential Other against which fundamental contours of American identity are created. Rather, I contend that Canada serves as a minor instance of alterity; it is a proximate manifestation of difference that acts like a blank canvas, capable of taking on whatever image is needed in order to confirm American identity. Thus, although Canada plays a role in terms of American identity, it is most certainly cast in a supporting position, not a lead role.

The second function served by the news media's othering of Canada is to enable the introduction of threat to North America. As the introductory chapter notes, critical IR scholarship holds that impressions of threat play a crucial role in helping to define and rigidify national identities (Campbell, 1992; Dalby, 1990). The presence of otherness within Canada makes it conceivable for US audiences to understand Canada as a space where dangerous actors or forces might find purchase. Thus, although representational patterns of otherness do not render Canada itself as an enemy to the United States, they do make it seem reasonable that the country could host dangerous or threatening elements. In effect, instances of difference generated by the news media serve as cracks through which threats from the 'outside' are able to seep into North America. ${ }^{64}$

In exploring the constitutive implications of the news media's representations of Canada, this chapter explores the same patterns and social processes examined in the previous chapters devoted to Hollywood cinema. It is important, however, to draw a

\footnotetext{
${ }^{64}$ The next chapter provides an in-depth analysis of how portrayals of Canadian liminality are able to transform the supposed presence of these dangerous forces or actors in North America into a more immediate threat to US security.
} 
distinction between the two forms of popular media. Hollywood filmmakers were selfconsciously engaged in acts of story-telling. They were presenting fictional or fictionalized stories about Canada to their American audiences. These stories did not typically depict Canada as an explicit threat, nor did they incite Americans to look over their northern border with fear or suspicion. Rather, Hollywood's representational practices helped to reinforce an abstract understanding of Canada that already resides within the American imaginary. As chapters 5 and 6 will show, this level of abstraction fades considerably when looking at representations of Canada in the news media. There are two main reasons for this shift towards more concrete definitions. First, unlike films, news reports are not self-consciously engaged in story-telling. Rather, the news media is understood, and understands itself, as dealing with 'facts' and 'reality' (Cohen and Young, 1981; Fairclough, 1995). Second, the news coverage examined in these chapters is explicitly concerned with reporting on terrorism, a threat that was understood as objectively real and imminent. As a consequence, the definition of Canada that emerged from depictions produced at that time was not done in an abstract sense. Instead, the differences that news reports highlighted when drawing distinctions between Canada and the United States were made crucial and meaningful. Moreover, the inherent potential for threat that flowed from Canada's constructed status as a dangerous space was actualized. In this sense, although the filmic depictions discussed in the previous chapters served to reaffirm the abstract place that Canada occupies in the American imaginary, the images propagated by the news media during the War on Terror drew from this abstract version of Canada and presented it to Americans as real. 
It is important to emphasize that the news coverage analyzed in this dissertation intentionally includes reports from both conservative and liberal outlets. My research indicates that there is no substantial difference of kind that distinguishes liberal and conservative representations of Canada. In other words, both viewpoints deploy the same kinds of representational patterns that construct Canada in terms of otherness. Similarly, both perspectives use this impression of otherness to communicate the presence of potential danger within Canada. This consistency suggests that the representational dynamics at work are not driven by simple media bias, but are instead informed by deeper social processes working to define American identity. In this sense, these different viewpoints are united within the context of Hartley's consensus principle. It is equally important to note, however, that despite the broad similarity in the kind of coverage that emerges from divergent news outlets, there are distinct differences in the degree. In other words, the degree of Canadian otherness communicated by the rhetoric of John Gibson from Fox News will often outstrip that conveyed in a typical New York Times article. Similarly, the degree of danger implied by a terrorist presence in Canada might be very different between a Wall Street Journal editorial and a broadcast of NBC's Nightly News. I return to this question of similarities and differences across coverage's political spectrum in the conclusion.

To reiterate, my analysis limits itself to exploring the discourse that links Canada with terrorism. Therefore, a wide variety of other discourses that might frame Canada in more positive terms is intentionally excluded (for example, Canada as a vacation destination or Canada as a source of comedians). Although I certainly do not deny such 
representations exist (indeed, it is abundantly clear they do), they nonetheless fall outside the scope of my analysis. Similarly, even within the bounds of the discourse that links Canada and terrorism, I readily admit that there are depictions that frame Canada in positive terms. However, as I indicate in the introduction, their presence does not detract from my overall argument. Depictions of Canadian otherness and threat persist regardless of the existence of contrary images. Indeed, the very fact that depictions of Canadian otherness and threat are able to continue circulating as prominent narratives in the face of contradictory representations serves to demonstrate their resilience.

The news media deploys a variety of representational patterns to depict Canada as different from the United States. For example, in addition to the examples cited above (age and physical geography), the news media often frames Canada in terms of climate, technological development or sophistication. ${ }^{65}$ There are two other patterns, however, that play a particularly prominent role in defining Canada. This first section of this chapter examines depictions of Canada through the lens of social values, demonstrating how news outlets script the country as a bastion of liberal policy. Building on this evidence, the section also explores how this othering pattern acts to simultaneously reaffirm a conservative American identity and frame Canada as a space that harbours terrorists. The second section explores how the US news media uses a gendered script to depict Canada in feminine terms. It also shows how this feminization strategy culminates

\footnotetext{
${ }^{65}$ It should be noted that this scripting of difference does not function solely as a definitional exercise. As Todorov (1984) demonstrates, it also serves to position actors in terms of relative value and knowledge claims.
} 
in both a masculinization of American identity and a rendering of Canada as an access point for terrorists wanting to set up operations in North America.

\section{Social Values}

The most prevalent of the othering patterns deployed by the US news media to represent Canada during the War on Terror framed the country in terms of social values. More specifically, Canada was depicted as a bastion of liberalism. Two crucial implications issued from this pattern. First, the representation of Canada as liberal had constitutive significance for American identity. In the face of the insecurity engendered by the War on Terror and the broader 'culture war' in the United States, political dialogue in that country experienced a surge in calls for a return to traditional American values. These efforts to re-script America's essence as conservative were assisted by implicit and explicit comparisons to a liberal version of Canada. ${ }^{66}$

Second, the patterned depiction of Canada as liberal played a critical role in concretizing the threat of terror. The corpus of the news coverage conveyed the impression that Canada's social values had swung so far to the left on the political spectrum that the country had effectively lost its way. It implied that an unthinking embrace of liberalism had left the country's political culture enervated and debilitated. Hamstrung by knee-jerk tolerance and political correctness, Canada's decision-makers

\footnotetext{
${ }^{66}$ Although not directly related to the War on Terror, these efforts to emphasize conservative values as a crucial framework for American identity have taken aim at a wide variety of Canadian policy areas, including marijuana decriminalization, same-sex marriage and socialized healthcare. For example, see Kraus (2003).
} 
were apparently unable to take the restrictive steps necessary to prevent dangerous individuals from entering their country. In effect, the embrace of unfettered liberalism had rendered Canada a haven for terrorists.

Although the news coverage identified the Canadian swing towards liberalism in a wide variety of policy areas, this section will explore three examples in depth: social welfare, immigration and multiculturalism. The following argument will explore news media depictions of Canada in each of these three areas, with a specific focus on identifying and explicating both the othering tendencies at work and the patterns that depicted Canada as complicit in allowing the terrorist threat to take hold in North America.

Social Welfare

Canada's social welfare policies were a frequent target of the US news media during the War on Terror. Indeed, the Canadian decision to provide new immigrants and refugee claimants with the same range of social benefits enjoyed by Canadian citizens was a matter of serious concern for many US news commentators. Proceeding from a binary perspective, the US coverage regularly faulted Canada for the naïveté of its policies in this area and compared the country's liberal approach with an invariably more stringent US policy. Beyond othering Canada as liberal, however, these depictions of Canadian policy played another role. The critique of Canadian policy, and the very rationale against the extension of social benefits to new and potential Canadians, was largely based on the belief that terrorists were drawn to Canada by the lure of state 
funding. In this way, the news media's negative representation of Canadian social welfare policy effectively provided US audiences with a plausible explanation for the presence of terrorists in North America.

In some cases, news reports highlight Canadian welfare policies that extend benefits to newcomers, but they fall short of explicitly linking such policies to terrorist infiltration. In these instances, when the connection is only implicit, the audience is left to come to its own conclusions. In a Los Angeles Times article, for instance, readers are informed that "asylum seekers are treated well here [in Canada], with single people receiving about $\$ 318$ a month and families getting up to $\$ 637$ to help pay for an apartment and other costs - even if their applications have been rejected and they are appealing" (Smith, 2001). This article carries the implicit message that refugees are treated more generously in Canada than their counterparts in the United States. Such an account might well be understood as an even-handed description of simple national differences, were it not embedded in an article that purports to explore the debate in Canada over the number of refugees the country should be accepting. By including information about the amount of money that immigrants are able to receive in Canada, the report shifts the topic of debate. Instead of a discussion about the moral and philosophical issues surrounding the granting of asylum, the article becomes a discussion about the motives and types of people who claim refugee status in Canada. More precisely, instead of a discussion on the wisdom of taking in refugees during the War on Terror, the article is transformed into an implicit criticism and warning about the dangers of social benefits. A Wall Street Journal article published one month after $9 / 11$ provides 
a similar example of how the coverage of Canada's approach to welfare is structured by both a comparison to the United States and a suggestion of naïveté:

Canada...takes in proportionally more immigrants than the U.S. and has long prided itself on welcoming refugees from oppressed overseas regimes. But critics complain that asylum seekers who arrive in Canada with dubious claims are allowed to live in the country for years, often collecting welfare benefits, while they drag out legal proceedings - or simply vanish from the system. (Baglole, 2001a)

Even though this report stops short of drawing an explicit connection to terrorism, the implicit link between liberal social welfare policies and the presence of "dubious" individuals in Canada is clear nonetheless. Indeed, it is difficult to imagine drawing any other connection from this section of the report.

Most reports, however, are more straightforward in drawing a link between Canada's provision of social services and the presence of terrorists in the country. For example, a Washington Post report cites the "scathing" declaration of a French counterterrorism judge who claims Canada has developed a "very good reputation among terrorists for its immigration rules and welfare system" (Dobbs, 2001). A Fox News report that criticizes Canadian officials for maintaining a high rate of immigration "even though it raises security concerns with their American neighbours" is contextualized by a reference to Canada's welfare policies: "The refugee claimants in Canada are entitled to medical coverage, they're entitled to social assistance and work permits rather quickly after they've made their claims" (Fox News, 2003a). In this report, which effectively joins the phenomena of immigration and terrorism into a single, seamless concept, and which excoriates Canadian policy for endangering the United States, the only plausible 
meaning that accompanies a discussion of Canada's provision of benefits to refugees is that it contributes to the presence of terrorists in Canada.

In many cases, Canada's provision of social benefits to newcomers is viewed as the outgrowth of a dangerous and irresponsibly liberal perspective. In such instances, the linkage of social benefits and terrorism is often conveyed with a sense of incredulity and, oftentimes, even betrayal. This heated and rhetorical line of argumentation is particularly prevalent among the ranks of conservative television news commentators. Bill O'Reilly, for instance, lampoons Canada's approach by professing disbelief that terrorists would ever seek to harm Canada when they are clearly treated so well by the Canadian state:

Here's what I don't understand. Canada has been one of the most friendly nations on earth to wandering Muslims...Canadian authorities will usually allow you asylum in the country, will pay your cab fair to the local mosque, will set you up in an apartment and give you welfare. So why would they want to attack you guys? (Fox News, 2006d)

John Gibson provides a variety of compelling examples of this pattern in a series of Fox News programmes from 2004 and 2005. In these broadcasts, the host makes a number of heated comments that confirm the link between Canada's welfare policies and the presence of terrorists in that country. For example, in a 2004 broadcast of The Big Story, Gibson rails against Canada's "super-liberal immigration policy," which he claims allows terrorists "to arrive in Canada, get government help with apartments, food, health care, and lets them plot and scheme north of the border for activities down here" (Fox News, 2004d). While obviously making the case that Canada's welfare policy welcomes terrorists and provides them with a base in North America, Gibson's argument can also be understood as an example of the wider discursive pattern that deploys the self/Other 
dichotomy that works to frame identities. This pattern is evident in the use of the phrase "super-liberal" in describing Canadian policy. The meaning of such a description can only be interpreted in relation to an implied US policy that is more conservative, particularly when it is framed in the context of threats facing the United States ("down here"). However, Gibson goes on to make an even more explicit othering statement later in the segment when he discusses the US release of Canadian terrorism suspect Abdurahman Khadr: "[he was] welcomed home to Canada with welfare and Canadian protection as if he were coming home from summer camp. We're doing the best we can, but we need Canada to do the same." The self/Other dichotomy evident in the "we" phrasing found in Gibson's dialogue does considerable work in framing American identity in relation to Canadian policies.

In a series of subsequent shows, Gibson made a number of similar comments. For instance, in August of 2005, he asks a Canadian guest a sarcastic question about Canada's counter-terrorism efforts: "We're supposed to be comfortable that you are maintaining, that is giving them welfare, apartments and stuff, to keep an eye on them and we'll feel better about it?" (Fox News, 2005d) Unsatisfied with his guest's response, Gibson draws a stark distinction between the Canadian and US approaches: "sell that in Canada. I don't think you're going to find many takers here." This othering technique and the unquestioned link between social benefits and terrorism are deployed again during another show four months later, in which Gibson returns to a discussion of the dangers posed to the United States by the Khadr family: "The Khadrs have run back and forth to Canada for years, collecting Canadian welfare, rent support, medical care to recover from 
their battle wounds. Canadians have not thrown them out of the country yet and probably never would" (Fox News, 2005e).

The above examples demonstrate how the US news media portrayed Canada's social welfare policy as not only different from the US approach, but as naïve. By portraying Canadian policy as an extreme manifestation of a liberal mindset, these representational patterns helped to script an American identity premised on a conservative emphasis on personal responsibility over state obligations. Moreover, the depiction of Canada's social welfare policy as liberal also provided a plausible explanation of why terrorists were attracted to Canada and how they were able to set up operations in North America. In effect, the news showed Americans how Canada's liberal social welfare policies turned the country into a dangerous space.

$\underline{\text { Immigration }}$

The Canadian policy area that received the most coverage from US news outlets during the War on Terror was that of immigration. News depictions of Canada's immigration policy were remarkably consistent in defining the country's approach as a manifestation of liberal political values. This section explores how the coverage of Canada's immigration and refugee policy drew upon a binary logic. In effect, the news othered Canada as a bastion of liberalism in order to reaffirm a more guarded and conservative vision of America. Moreover, this same othering process that defined Canada as radically liberal also made it possible for US audiences to conceive of Canada as an entry point for terrorists wanting to establish themselves in North America. 
The rhetoric and hyperbole that infused US coverage of Canada's immigration and refugee policies during the War on Terror leaves little doubt that the broad message was that Canadian policy was simply too liberal. Some of the tamer coverage describes Canadian policy with such phrases as "incredibly liberal," (MSNBC, 2006a) "famously liberal" (CBS, 2003b) and "notoriously liberal" (Mehren, 2001). In the same vein, Canadian immigration policy is also referred to as a "generous open-door policy" (Smith, 2001) and a "no-questions-asked" policy (Willing and Johnson, 2001). Some of the more extreme discussion, often emerging from conservative television news shows, includes contentions that Canada has experienced a "hard drift to the left in government policy in recent years" (Fox News, 2004f) and implemented "asylum policies over the years that have, in effect, let all these crazies into Canada" (MSNBC, 2007). This pattern plays a prominent role in a conversation between Bill O'Reilly and his guest on a 2005 broadcast of The O'Reilly Factor. In the exchange, O'Reilly claims, "Americans are confused about Canada. The lenient immigration policies they have...you know, they let people in there that are very dubious people, terrorist backgrounds." When he then asks his guest, a correspondent for Newsweek, whether the rationale for Canada's policy is liberalism or anti-Americanism, the guest responds by confirming "it's based on their liberalism" (Fox News, 2005a).

Descriptions such as these only make sense in the context of a more conservative US policy, one that by its very nature is better able to keep Americans safe. Although US policy is sometimes scripted implicitly as conservative, it is also common for news reports to make the comparison explicit. In some cases, the comparison is a relatively 
simple one. Examples includes statements like "Canada has much more liberal asylum policies than the United States" (Grunwald, 2001) or "Canada and the United States...have often differed over the treatment of asylum seekers, refugees and immigrants" (Crossette, 2001a). An article from the Wall Street Journal provides another example of this kind of comparison: "Controversy is growing in socially liberal Canada over the police powers contained in the [country's new] antiterrorism bill, although the bill is less stringent than similar measures in force in the U.S." (Baglole, 2001c).

Many reports make the comparison more explicit by drawing on statistics that serve to quantify the differences between the two countries' approaches. In this vein, one newspaper article reports that "critics of Canada's liberal immigration and refugee policies say the country's large influx of newcomers [is] proportionally twice the U.S. level" (Chipello and Baglole, 2002). A broadcast of ABC's Good Morning America makes a similar comparison: "There are differences on the continent...One is Canada has this rich tradition of humanitarian assistance. Canada approves forty percent...of all asylum requests, the US only seventeen percent" (ABC, 2003). In a limited number of cases, the comparison is presented in a more nuanced fashion. For example, a Los Angeles Times article discusses the issue from the perspective of "Canada's traditional commitment to provide sanctuary for many of the world's victims of torture, civil wars and political strife" (Smith, 2001). The report goes on to provide historical and normative rationales for Canadian policy before ultimately concluding that such a policy is deficient from a US perspective:

Canada and a number of other countries respect a norm developed under the 50-year-old Geneva convention on refugees that allows asylum seekers 
to arrive in a country with false papers. The logic is that many persecuted people have no legal way of leaving their homeland. The U.S. and some other countries, however, frequently detain applicants who arrive with false papers, putting Canada at odds with its southern neighbor on this policy.

Regardless of the form the comparison takes (implicit versus explicit; statistical versus nuanced), the context provided by the War on Terror ensures that Canada's approach is found wanting in relation to the more restrictive policy apparently favoured by the United States. In this sense, the coverage tends to champion and confirm a conservative vision for US immigration and refugee policy. As suggested earlier, this policy area is just one of multiples sites where conservative and liberal forces in the United States clash over the meaning and content of American values. The dichotomous logic embedded in the US news media's depiction of Canadian immigration and refugee policy serves to other Canada as liberal, an image or foil that is subsequently used as ammunition in the ongoing struggle over the definition of American identity.

As the introduction to this section suggests, the news media's depiction of Canadian immigration policy did more than simply other Canada as liberal. The othering process also defined Canada in such a way that US audiences were primed to see the country as a place where terrorists could operate. In effect, the coverage suggested that the liberal nature of Canada's policies was responsible for a terrorist infiltration of that country. $^{67}$

\footnotetext{
${ }^{67}$ As the next chapter explores in considerable detail, media depictions of liminality build on this process by blurring the distinctions between Canada and the United States and conveying to US audiences the impression that if terrorists are in Canada then they are effectively in the United States as well.
} 
Canada is apparently attractive to terrorists because of its "long tradition of liberal immigration" (CNN, 2004a) and "generous political asylum laws" (Grimaldi et al., 2001). As the Los Angeles Times contends, the existence of such policies "makes it easier for terrorism suspects to move in and out of [Canada] undetected" (Turner and Wright, 1997). A Wall Street Journal report appears to corroborate this theory with its claim that Canada's "overly generous asylum policies have invited terrorists to use Canada as a back office" (Chipello and Bilefsky, 2002). Other reports similarly contend that Canada's immigration and refugee laws have transformed Canada into a "safe haven" for members of al Qaeda and other foreign extremist groups (ABC, 2003; Brown and Connolly, 2001). A terrorism analyst for MSNBC provides nuance to the problem of terrorists exploiting Canada's immigration system by exploring the capacity of radical groups to lobby the country's immigration bureaucracy: "[Canada is] definitely a place where dissidents are able to get asylum, much easier than they can in the United States, where refugees have a lobby basically created for them. And in that lobby, you have radical Islamic groups basically getting citizenship for their members" (MSNBC, 2006b).

Some of the coverage is more specific in terms of the kind of terrorists that are attracted by Canada's immigration policies. One report suggests that Canada's "liberal immigration laws" have turned the country into "a natural haven for Algerian extremists" (Pearlstein, 2000). Another makes the similar claim that Canada's "liberal immigration laws" not only attract terrorists from the Middle East and Asia, but also help to render Canada "an easy place for terrorists to get in, fit in and hide out" (CBS, 2003b). Congressman Peter King informs CNN's viewers that Canada's "liberal asylum laws" 
have meant that the country is plagued by "a significant number of al Qaeda supporters" (CNN, 2006k). This charge is confirmed by a Los Angeles Times article that draws a seamless and unquestioning connection between Canada's "liberal policy of political asylum" and the presence within the country of "dozens of terrorist groups, including those with ties to Osama bin Laden" (Peterson, 2001a).

In drawing the link between Canada's immigration policies and terrorism, many reports start from a stance that appears to be sympathetic towards the Canadian approach. These reports begin in an almost conciliatory fashion, providing the audience with an understanding of how Canada's liberal policies originated with good intentions. This flattering opening, however, is typically followed up by the revelation that such policies are actually responsible for allowing terrorists to sneak into North America. The Washington Post, perhaps more than any other outlet, regularly uses this whiplash pattern to structure its coverage. As the following quotations reveal, this publication has sustained a similar pattern over an extended period of time:

Defenders of Canada's political asylum laws say they give oppressed people protection and a chance to make a new life. Canada has long been proud of taking a humanitarian role; its soldiers are particularly active in U.N. peace-keeping operations. But security experts have for years accused Canada of being an easy staging ground for terrorists who come to the country with false passports, claim refugee status and then - while their cases are being processed - raise money and make plans for terrorist attacks. (Brown and Connolly, 2001)

Canadians pride themselves on ideals of tolerance, inclusion and the belief that immigrants should have the same rights as Canadian citizens. At the same time, the country is wrestling with how to protect national security and answer critics who contend that the country's liberal immigration policies make Canada easy prey for terrorists. (Brown, 2003) 
The country in modern times has opened its arms to the world, offering shelter to tens of thousands of refugees seeking protection under United Nations conventions, encouraging the immigration of skilled workers and investors, and transforming the nation's cities into a polyglot mosaic. But in doing so, Canada has also imported the political struggles of those refugee and immigrant groups, and, some security analysts feel, offered too passive a response. (Schneider, 1997)

In each of these examples, Canada is initially pictured as a country with a noble history and honourable intentions. It is portrayed as embracing ideals of "tolerance" and "inclusion," feeling pride at "[giving] oppressed people...a chance to make a new life" and "offering shelter to tens of thousands of refugees." But the final sentence from each quoted section abruptly turns this sentiment on its head by demonstrating how these noble intentions are actually naïve and misguided. Serving as an indictment against liberalism, these sentences implicate Canadian policy in importing the "political struggles" of immigrant groups and rendering the country as "easy prey" and a "staging ground" for terrorists. Taken individually or as a whole, articles of this nature serve as powerful reminders of the dangers of liberalism.

Questions relating to which peoples are suitable for inclusion within a polity, and under what conditions they might be accepted, go to the very heart of national identities. As such, immigration and refugee policy is an area that always threatens to become an issue of politically and socially contentious debate. This is particularly the case when the nation in question is understood to be challenged or under threat, and potential newcomers might be identified with that external threat. These volatile dynamics were certainly in evidence in the United States during the War on Terror, and they played a crucial role in structuring public debate in that country around the costs and benefits of 
immigration. As this thesis contends, this same set of dynamics was also directed at Canada, finding expression in the US news media's treatment of the country's immigration and refugee policy. At a time when Islamic terrorism was being scripted as a threat to the United States, traces of difference found in Canadian policy were magnified, judged and exploited by the coverage in such a way that Canada came to serve as a liberal Other against which a conservative American identity was reassured. Moreover, as a complementary part of this process, depictions of Canadian policy as too liberal also invited audiences to understand how Canada could be blamed for the instantiation of the terrorist threat within North America.

Multiculturalism

Another area that received considerable attention within the US news coverage of Canada during the War on Terror revolved around the country's policy response to ethnicity. The news media's depiction of the Canadian approach to this area was structured around the same two themes explored earlier in this chapter. First, Canada's approach was seldom conveyed to audiences in isolation. Instead, news reports and commentary tended to define the Canadian approach, either implicitly or explicitly, in relation to the US approach. Thus, Canada's active promotion of diversity under broad policies relating to multiculturalism was contrasted against the reputed imperative of American culture to require newcomers to forgo their cultural and linguistic backgrounds in favour of a single, unifying American identity. However, Canada's multicultural policy was not defined as simply different from that of the United States. Rather, it was 
evaluated as somehow inferior or deficient in relation to the US notion of the 'melting pot' and its pursuit of homogeneity. In this sense, this representational pattern had implications for American identity, in that it served to other the Canadian approach as inferior in order to confirm the virtues of the US approach.

Second, the context provided by the US War on Terror acted to transform these representational patterns into more than acts of definition. The threat of terror provided a lens through which the news media came to view Canadian policy as not simply inferior to US policy, but as problematic or dangerous. In effect, the coverage conveyed the impression that liberal policies advocating and encouraging ethnic diversity in Canada served to induce terrorists to establish themselves in North America. Therefore, not only did US news coverage portray Canadian multiculturalism in such a way as to reinforce American identity, it also implied that Canada's liberal desire to foster tolerance had rendered the country a dangerous space by providing terrorists with a foothold on the continent.

The intertwining of these two structuring themes is evident in a wide variety of news reports. It is present, for example, in the analysis of an MSNBC terrorism expert who cites Canada's multiculturalism as a reason for the country's tendency to attract Islamic extremists (MSNBC, 2006a). It is also found in a Washington Post article, which imbues the concept with extra legitimacy by quoting a Canadian expert:

Canada portrays itself as a socially liberal society. It is a nation of immigrants, legal and illegal, who are seen as essential to its growth...Unlike in the United States, where many immigrants feel pressure to assimilate, Canada encourages people to maintain their cultural identities. 'It gives us great strength, but also exposes several 
vulnerabilities,' said [Martin] Rudner, who said terrorist groups have exploited Canada's tolerance. (Brown, 2003)

A broadcast of NBC's Nightly News contextualizes Canada's arrest of 17 terror suspects with references to naïveté and an explicit link to the dangers of diversity: "On the streets of Toronto today, shock over terror-related arrests in a country that prides itself on cultural diversity" (NBC, 2006b). In a Washington Post article, which notes that many Canadians are "pondering how a country so proud of its diverse culture and political moderation could spawn such an apparent interest in violence," the reporter turns to multiculturalism as the villain: "some people here [are] asking if Canada's attempt to accommodate all faiths and backgrounds...is encouraging religious divisions" (Struck, 2006b).

This dual idea is sometimes communicated effectively through just the headline of an article. For instance, A New York Times article tracing Ahmed Ressam's history in Canada is entitled, "Terrorists Said to Hide in Canada's Melting Pot." The article itself discusses Montreal's "rich ethnic bouillabaisse," Canada's "rich ethnic mix" and Quebec's language-based immigration policy, all in the context of exploring how these priorities have made the country "a haven for terrorists" (Kifner, 1999). This same dynamic is on display in the title of a report that explores the arrest of multiple terrorist suspects in Canada: 'Canada's Social Stance Is Tested by Arrests; Critics Say 'Mosaic' Model Is Cracking Under Immigration Program, Imams' Growing Sway" (Cherney and Chipello, 2006). Needless to say, the content of the article confirms the title's contentions: 
News of an alleged homegrown terrorist plot has shocked Canadians and stirred questions about the country's liberal immigration program and its policy of multiculturalism. Even on the left, some Canadians are now questioning whether the country's 'mosaic' approach to cultural communities has encouraged some to resist embracing values broadly shared by other Canadians.

The power of an article of this nature derives, at least in part, from an appearance of objectivity. This kind of analysis purports to relate the genuine reactions of Canadians themselves to the failings of their own multicultural policies, as opposed to official reactions from US politicians or experts. As such, the article is able to effectively transcend national boundaries and position itself to make objective claims on the facts of the situation.

Other reports contrast the Canadian and US approaches to diversity with a rhetorical strategy that exposes Canadian smugness on the topic. For instance, a Washington Post article claims that Canada "trumpets" its multicultural approach and sometimes touts it as superior to the US approach (Struck, 2006a). However, the report begins to turn the table on Canadian self-assuredness by implying that the sensitivity of the Canadian approach is little more than political correctness ("public figures treat references to distinct ethnicities or religions as anathema"; "police statements on the arrests [of terrorism suspects] Friday did not use the word Muslim"). The article comes full circle by claiming that terrorism arrests in Canada support "the warnings of some that the growing ethnic communities can be a source of hidden passions and underground politics." In the end, therefore, this analysis both exposes the liberal basis of Canadian policy as deluded and dangerous while also implicitly confirming the US approach as more realistic and effective. 
Similar accusations of the dangers of political correctness are found in a variety of other reports. For example, a Wall Street Journal article dismisses the utility of a US "crackdown" against terrorism unless Canadians address "a major problem": "the country views openness as a virtue and it is considered 'rude to discuss ethnicity"' (O'Grady, 2001). A Washington Post article suggests that in Canada, "a country that prides itself on diversity, the risk of offending any particular nationality, when there is no imminent danger to Canadians, can weigh heavily" (Schneider, 1997). A CNN report on Canada's response to terrorism provides another example of this perspective, with the correspondent claiming that "some analysts say part of the security challenge is, unlike most Americans, Canadians simply don't feel they're in the cross hairs" (CNN, 2004a). The report then quotes a Canadian security expert who confirms this understanding with colourful language that effectively lampoons Canada as politically correct: "I think the Canadian approach would be, if you have Osama bin Laden prisoner, what you want to do is, you want to give him a lecture in both official languages of Canada about sustainable development, gender equity, our charter of rights and freedoms." Finally, in a New York Times article entitled "Saudi Case Casting a Light on How Militants Infiltrate and Exploit Canada," the reporter contends that Canadians are engaged in a "sensitive debate...that pits national security against the concerns of a multicultural society" (DePalma, 1997). The zero-sum logic of this analysis effectively assumes that multiculturalism and national security are mutually exclusive. The article also offers a criticism of Canadian counter-terrorism, including a quote from an expert who claims that the "the situation in Canada is somewhat confused by the multicultural aspect." This 
criticism is implicitly transformed into an affirmation of the US approach when the article later claims that "the United States, France and other countries with big ethnic populations" are better able to pursue suspects than Canada because "Canadians are particularly sensitive about offending immigrants." The implication that issues from this argument is that the United States can manage its ethnic populations more effectively than Canada, either because they are more integrated or because the government itself is not hamstrung by liberal misgivings about accommodation and tolerance.

The US news coverage of Quebec during the War on Terror was eclectic. It tended to span multiple related policy areas, including immigration and multiculturalism. The cumulative effect of the coverage, however, was to pass judgment on Quebec's desire and effort to sustain the 'French fact' in Canada. Within the broader scope of the news media's commentary on Quebec, the province's immigration and language policies came under particular scrutiny. In this sense, the representational patterns that worked to normalize American identity by othering Canada as liberal were aided by complementary patterns that also drew on Canada's French-speaking minority. Moreover, within this process, the coverage frequently faulted the political and cultural disposition in Quebec that led to policies designed to seek out French-speaking immigrants. In essence, Quebec's desire to sustain its French-speaking population base (and, implicitly, Canada's status as a bilingual nation) was represented by the news media as a primary source of Canada's terrorist 'problem.' Because these policies encouraged immigration from North African and the Middle East, places where terrorist groups are known to operate, Canada 
and Quebec were depicted as having prioritized the politics of language over the needs of national security. ${ }^{68}$

A wide variety of sources confirm the impression that Quebec's language-based immigration efforts are ill-conceived and dangerous. For example, the Wall Street Journal decries such policies as having "unwittingly helped create an ethnic backdrop in Montreal that makes it easier for Islamist radicals from such countries as Algeria to blend in" (Chipello and Bilefsky, 2002). A Los Angeles Times article explains how extremists are able to exploit "Quebec's eagerness for French-speaking immigrants such as Algerians" and describes the development of "an international terrorist network [that] grew and ultimately stretched from the Middle East to Canada" (Pyes et al., 2001). The New York Times displays a similar concern: "Many terrorism experts say that Canada's liberal refugee and immigrations policies are of particular concern. These include Quebec's enduring efforts to increase its French-speaking population by encouraging immigration from Algeria and other French-speaking countries" (Krauss, 2002).

CNN host Glenn Beck provides a particularly compelling example of this dynamic in which the othering of Canada enables the narrative that transforms the country into a terrorist haven (CNN, 2007b). In this broadcast, Beck's guest explains how the presence of terrorists in Canada can be understood as a consequence of Quebec's search for immigrants in the countries of North Africa and the Middle East:

the province of Quebec has its own immigration policy, so it favours French-speaking countries. There aren't a lot of French-speaking countries in the world and most of them that have residual French connections are in

\footnotetext{
${ }^{68}$ This discussion may have had implications in terms of the ongoing debate in the United States over the increasing profile of the Spanish language in some regions of the country.
} 
North Africa, the Middle East. So you get a lot of people from Algeria, you get a lot of people from Syria.

The guest then goes on to provide additional context for these comments by referencing the Algerian origins of Ahmed Ressam, the so-called Millennium Bomber who lived in Montreal, and the ease with which Canadian citizens from Montreal can gain entry into the United States. Within this discussion of Canadian policies that supposedly pose a danger to the United States is the implicit contention that US immigration policies are not liberal and, therefore, do not result in similar dangers. Beck makes this point explicitly when he extols the virtues of the US melting pot approach: "That actually helps us, does it not, on the fight on terror?"

The above cases provide illustrative examples of how the US news media depicted the Canadian policy approach to societal diversity during the War on Terror. The overall sense provided by the coverage was that Canada's desire to accept and encourage diversity was inherently flawed and problematic. Indeed, from the perspective of mainstream US news outlets, the liberal policy of multiculturalism was a misguided misadventure. The above examples identify two intertwining themes within the coverage. The first theme, which served to other Canada as liberal, was part of a wider sociological process concerned with reinforcing American identity. It referenced the purported flaws of Canadian multiculturalism as a way of reinforcing the value of homogeneity and the 'truth' of the foundational myth of the American melting pot. The second theme depicted multiculturalism as a contributing factor in Canada's apparent tendency to allow terrorists to infiltrate the country. One of the main consequences to issue from these representations was the implication that cultural and linguistic accommodation was 
dangerous. Such a portrayal effectively revealed liberalism to be a source of danger to the United States and invited the conclusion that the United States was safer than Canada because it had no societal or policy desire to cater to subgroups.

It is perhaps not entirely surprising that US news coverage portrays Canada as a liberal society. There are, after all, very real differences in the various policy approaches pursued by the two countries, many of which are clearly inspired by different ideological perspectives. Indeed, such depictions might be assumed to be the norm when they originate from conservative-oriented news outlets. However, as the evidence shows, this pattern is not restricted to sources like Fox News and the Wall Street Journal. It is also widely promoted by other outlets, including those that conventional wisdom has labelled liberal, such as the New York Times. What is important to note is that the act of identifying differences between the countries is not necessarily a simple and objective act of reporting. Indeed, the manner in which news outlets portray differences between countries can have profound consequences on the construction of national identities. In the case of the Canada-United States relationship, I contend that the US coverage that others Canada as liberal does so as part of a wider set of sociological processes that is constantly working at reproducing American identity. In other words, the US news media is an active participant in scripting the American self, with its daily coverage of Canada contributing to the wider self/Other dynamic that helps to shape that American identity.

This is certainly not intended to suggest that the news media acts as a single, coherent entity, issuing univocal pronouncements on matters of fact and identity. It is, of course, just like any other broad social institution - a diverse establishment with multiple 
competing perspectives and voices. Moreover, not only is the US news media multifaceted and diverse, so too is the very concept of American identity. Therefore, just as there is no single voice of the news media, neither is there a single, uncontested version of American identity. Indeed, both the US media and the American self are sites where multiple meanings compete for broad acceptance from the American public. However, both the news media, which provides the content of identity through the representations it disperses, and the American national self, which acts as an ontological receptacle into which these representations are poured, are subject to broader trends in society. In other words, some perspectives, despite the existence of a multitude of competing options, are able to find more traction in society. To the extent that these perspectives become more broadly accepted, they play a more dominant role. At moments of perceived crisis or danger, when external actors are scripted as threatening the country, popular narratives about the national identity proceed with greater intensity (Doty, 1996: 12) and are able to achieve a greater degree of acceptance. In effect, the self/Other dynamic, which is always present in international reportage, becomes more pronounced during times of war or threat. Thus, in the case of the War on Terror, for example, the broad spectrum of news outlets, including those understood to be liberal in outlook, tend to converge on a narrower portrayal of Canada. This narrower depiction of Canada, in turn, helps to construct a more cohesive understanding of the American self. As this section contends, a liberal version of Canada enables a more conservative version of America. This is true in the case of a variety of policy areas, including social welfare, immigration and ethnicity. 
US news media depictions of Canada as liberal go beyond a supporting role in reaffirming a socially conservative American identity. In the context of the ongoing War on Terror, such portrayals also make it possible for US audiences to understand how it is that the threat of terrorism is able to find purchase on the North American continent. Extreme depictions of Canadian policies in the areas of welfare, immigration and multiculturalism act to interpret the presence of terrorists in Canada for US audiences. They help to render Canada a dangerous space by bringing the distant and abstract threat of the terrorist Other closer to 'home.' As the next chapter explores in greater depth, this instantiation of the terrorist threat in Canada, when combined with depictions of Canada as liminal, plays a crucial role in rendering Canada a threat to US security.

\section{Gender}

As feminist and critical IR scholarship has documented, gender plays a crucial role in constructing international identities. Gendered tropes are deployed within the wider range of binary social dynamics that construct national selves in relation to international Others (Elshtain, 1992; Campbell, 1992). These tropes draw on a pervasive and naturalized tendency to use sex differences between men and women as a structure to condition our understanding of identities in terms of constructed notions of masculinity and femininity. The tendency for this sense of naturalness to adhere to the masculine/feminine dichotomy serves to render gender a powerful organizing principle that helps people to make sense of their world. As an organizing principle, gender 
provides a guide for attributing meaning and value to the people, ideas, institutions and objects we encounter (Harding, 1986: 17; Cohn, 1993: 228). It erects a filter of preconceived and unquestioned suppositions that colour our interpretation of reality. As Cohn phrases it, "gender discourse acts as a preemptive deterrent to thought" (1993: 235). ${ }^{69}$ Therefore, by structuring the world in 'natural' terms, gender provides a preexisting set of expectations of how the various actors and institutions that make up our social world will behave.

At the international level, gender conditions perceptions and expectations of nations and other international actors. Of critical importance is the manner in which the masculine/feminine dichotomy structures international relations by insinuating itself into the self/Other mechanism. As Campbell suggests,

if we consider how our understanding of politics is heavily indebted to a discursive economy in which reason, rationality and masculinity are licensed as superior to unreason, irrationality and femininity, it is not difficult to appreciate that gender norms have also helped constitute the norms of statecraft. (1992: 10)

Shapiro also makes the connection between gender and foreign policy explicit:

Gender policy, as it is practiced in everyday life is thus foreign policy; it is the predominance and acceptance of a discourse with which one makes strange something which one could instead identify or accord the status of another self with equal dignity and importance. (1988: 101)

A variety of feminist scholars explore how gender is deployed as a device for structuring relations between countries according to the masculine/feminine dichotomy. For example, Peterson shows how gender can be used to explain the phenomenon of nationalism. She contends that the domination of 'us' over 'them,' which is implicit in

\footnotetext{
${ }^{69}$ See also Cohn (1989).
} 
nationalism, is rendered natural through the "prior naturalization of men/masculinity over women/femininity" (1995: 184). Weber (1999) demonstrates how American foreign policy towards the Caribbean can be explained in terms of an ongoing attempt to script the region as feminine in order to stabilize a masculine American identity. With respect to pre-1959 Cuba, for instance, she claims: "Playing a role in the U.S. imaginary as a sort of trophy mistress, [it] was the near colony and certain feminine complement the United States relied on to forestall any pending midlife/hegemonic/masculine identity crisis" (1999: 1). Doty (1996) examines how gender served to structure debate over the American response to the Philippines in the wake of the Spanish-American War. The debate over the question of annexation, she claims, revolved around the issue of "American manhood" and what the appropriate masculine response should be to the feminine Other that was the Philippines (1996: 30-33). In each of these cases, the act of defining a global actor according to feminine traits has a mutually constitutive effect that functions to simultaneously define the self as masculine.

This same dynamic is also present in the case of the Canada-United States relationship, in which patterned depictions of Canada as feminine help to reaffirm prevailing notions of a masculinized American identity. ${ }^{70}$ This section explores the US news media's contribution to this constitutive process. More specifically, it examines the presence and impact of two prevalent representational patterns that scripted Canada as feminine during the War on Terror: weakness and passivity. In the following pages, I

\footnotetext{
${ }^{70}$ See Keeble and Smith for a related discussion on how Canadian-American relations are understood in terms of a "protector"/"protected" dynamic, which is itself enabled by the masculine/feminine dichotomy (1999: 47-51).
} 
demonstrate not only that the US news media portrayed Canada as weak and passive, but that such portrayals also worked to masculinize American identity in terms of strength and agency. ${ }^{71}$ The chapter also details how the feminization of Canada worked to define the country in such a way that US consumers of news coverage were prompted to understand it as a dangerous space - a place where the forces of terrorism were able to establish a North American presence. ${ }^{72}$

\section{$\underline{\text { Weakness }}$}

One of the primary ways in which the US news coverage othered Canada as feminine was through its portrayals of Canadian weakness. Understood in terms of a gender dichotomy, representations of Canada as 'weak' were invariably accompanied by portrayals of America as 'strong' or 'tough.' Considering the context of the War on Terror, such portrayals might be expected. Indeed, in a social environment in which the terrorist threat was constructed as omnipresent, traditionally masculine qualities, like strength and toughness, were widely understood as essential for victory (Young, 2003). ${ }^{73}$ This section will explore how this othering pattern both masculinized America and made it possible for US audiences to understand how Canada allowed the threat of terror to take root in

\footnotetext{
${ }^{71}$ As Hooper (2001) demonstrates, understandings of what constitutes masculinity are contingent, giving rise to "multiple masculinities."

${ }^{72}$ The identification of the feminine with danger or threat is certainly not new. Indeed, as Hartsock suggests, "throughout the history of Western political thought, the shape of the political world was defined in opposition to threatening and powerful female forces" (1983: 285).

${ }^{73}$ Although Young (2003) confirms that the US response to $9 / 11$ was framed in terms of traditional masculine traits, she also demonstrates that the United States was scripted not as an aggressor, but as a "protector."
} 
North America. In particular, it examines how these patterns were deployed in relation to the country's immigration and border policies and its ability and readiness to contribute to the War on Terror.

As the previous section on Canadian political and social values demonstrates, Canada's immigration policies were common targets of the US news media. However, in addition to being portrayed as dangerously liberal, Canada's approach to immigration was also depicted as weak. Such portrayals acted to both confirm a masculine American identity and expose Canada as a haven for terrorists. For example, news sources regularly make claims to the effect that Canada has "very weak immigration policies" (MSNBC, 2006a) or that "the Canadian government has really got to toughen up their immigration policies" (CNN, 2002a). Most often, however, such accusations are not made in isolation. Instead, they are framed in the comparative context of a 'stronger' or 'tougher' US approach. For instance, viewers of Fox News are informed that "Canadian immigration policy may not be tough enough in the eyes of some Americans" (Fox News, 2003b). A New York Times analysis reveals a comparable understanding of Canada: "Many Canadians fear that bringing their asylum or immigration policies in line with those of the United States will mean hardening the Canadian heart...Some conservatives have criticized that attitude as soft-hearted naiveté" (Crossette, 2001a) ${ }^{74}$ A similar comparison of the two countries is revealed in the aftermath of September 11, when the Los Angeles Times comments on President Bush's decision to refrain from insisting "that Canada

\footnotetext{
${ }^{74}$ Depictions of Canadian naïvete are so common within the coverage that they are deserving of their own independent analysis. Unfortunately, space limitations prevent me from exploring this particular gendered representational pattern in this dissertation.
} 
toughen its liberal immigration and refugee policies to match the U.S." (Anonymous, 2001a).

In addition to supporting the ideal of American masculinity, Canada's feminine weakness in the area of immigration also makes it possible for the US public to understand Canada as a haven for terrorists. For instance, an $\mathrm{ABC}$ news report notes "growing concern" at the US State Department that "weak immigration laws in Canada make that country a safe haven for terrorists" (ABC, 2006). Similarly, in a television interview that links the presence of terrorists in Canada to the country's immigration policies, an analyst emasculates Canadian counter-terrorism efforts with his references to a "milquetoast effort" and "toothless legislation" (Fox News, 2002e).

In a large number of cases, explanations of the terrorist presence in Canada are presented in terms of a gendered framework that explicitly compares Canada to the United States. For instance, in a television news broadcast, a Minnesota politician's explanation of how terrorists are able to enter Canada is framed in both gendered and comparative terms: "The Canadians don't have the tough immigration laws coming into their country that we have" (Fox News, 2002h). A New York Times article that links Canada's approach to immigration with its apparent status as "an unwitting haven for terrorists" makes its case by using gendered imagery that compares Canada to the United States: "Several recent investigations of Canadian terror suspects underscore what are widely perceived in the United States as weaknesses in the Canadian system" (DePalma, 2001a). Anchor Julie Chen provides another emblematic example of this dynamic in a broadcast of the CBS Morning News (CBS, 1999d). In this instance, she draws on the 
views of US officials to provide her audience with an analysis of Canada that both denigrates the country in relation to the United States and renders it a home for terrorists: "Some US officials point the finger at Canada. They claim our neighbour to the north needs tougher immigration laws to keep terrorists out." In an even more explicit confirmation of the superiority of the US approach, Chen goes on to suggest that Canada needs to adopt "American-style refugee laws."

Impressions of Canadian weakness are also conveyed through news coverage that emphasizes the fact that the Canadian approach to border management has not traditionally allowed border guards to carry firearms. Like other areas examined in this chapter, the coverage tends to treat this topic through a comparative framework that evaluates Canada in relation to the United States. Thus, CNN viewers are informed that "US customs officers have greater powers to search, inspect and arrest than their Canadian counterparts and the Americans carry guns" (CNN, 2004c). Similarly, the CBS Evening News informs its audience that the Canadian approach represents "quite a different view of law enforcement than we have on this side of the border" (CBS, 2006c). These national differences are even confirmed by the Secretary of Homeland Security, Asa Hutchinson, who claims that Canadian policies do not "allow the same type of inspections as our inspectors are used to" (CNN, 2004b). This comparative approach tends to structure Canada and the United States in terms of a gendered relationship that simultaneously feminizes Canada and masculinizes America. For example, audiences are reminded how "Canada has been under increasing pressure from the United States to toughen security at the border" (Struck, 2006c). They are also advised that were US 
guards to operate from Canadian territory, "they would have to adhere to Canadian law, potentially weakening their authority" (CNN, 2004c). This use of gendered language helps to enable the related trend in the coverage that implies Canadian border policy endangers the United States. A feminized understanding of Canadian policy as 'weak' makes it possible for US audiences to understand the country as a liability in the War on Terror. Thus, news stories that discuss the issue of unarmed Canadian border guards, like those quoted above, are often framed by references to the "longstanding American concern" that terrorists located Canada will travel to the United States (CBS, 2006c).

Commentary of this nature is particularly interesting because to the extent the unarmed status of Canadian border guards raises national security concerns they are concerns that relate primarily to Canadian security, not US security. To be more precise, considering the Canadian border guards under discussion in these reports are charged with screening individuals entering Canada, not those entering the United States, their unarmed status is relevant to Canadian security concerns, not US security concerns. In this sense, it is telling that the coverage is able to conjure a Canadian threat to the United States, even though the link it uses to connect Canadian border policy with US security is almost entirely spurious. ${ }^{75}$

\footnotetext{
${ }^{75}$ It is certainly true that some of the criticism of Canadian policy in this area derives from the notion that Canadian laws prohibiting the use of firearms by border guards act as a disincentive to US pre-screening on the Canadian side of the border. In this sense, Canadian policies are understood to be detrimental to US security interests because they either prevent US pre-screening on Canadian territory or prevent US officers from carrying firearms when engaged in pre-screening. None of this, however, detracts from the overall effect of the bulk of the coverage, which does not even concern itself with questions of firearms and prescreening. This coverage typically provides general criticism of unspecified aspects of Canadian border security. In so doing, it simply assumes a linkage between the apparent deficiencies of Canadian border policy and a threat to US security, and ignores the more logical connection between Canadian border policies and Canadian security.
} 
The feminization of Canada as weak is also evident in the news coverage devoted to the country's contribution to the US-led War on Terror. This coverage tends to depict Canada as weak in at least three major ways: a lack of physical capacity to contribute meaningfully to the war, a penchant for effete free-riding and diminished resolve and toughness in the face of the political challenges associated with the war. Crucially, it is these expressions of weakness that are typically understood as either allowing terrorists into Canada or somehow otherwise endangering the United States or undercutting US efforts against global terrorism.

In terms of physical capacity, Pat Buchanan invokes a gendered approach when he asks, "why there is such a tender skin up in Canada when we simply suggest that, look, maybe you guys could have a better defence effort than Iceland" (MSNBC, 2002e). In a similar vein, Tucker Carlson exposes Canada as a "potentially weak link in the system." As he goes on to elaborate, "you need to have countries that have their acts together and who are on your side in the fight against terrorism. I'm not sure Canada always is" (CNN, 2003c). This view is shared by a Canadian journalist who worries about Canada's inability to contribute to the War on Terror: "There's a wide-scale feeling that we haven't done much and we haven't carried our weight...we don't have any military left these days" (Fox News, 2002i) ${ }^{76}$ In a discussion about Canada's involvement in the

\footnotetext{
${ }^{76}$ It was not uncommon for Canadian journalist to appear on such shows and corroborate the views of the host. The voicing of such concerns from Canadian guests would presumably lend enhanced credibility to the perspectives being presented on the show. Even more common, however, were appearances from former Canadian government officials who were frequently quite damning in their criticisms of Canadian policies and efforts. Once such official, David Harris, once held the position of Chief of Strategic Planning for the Canadian Security Intelligence Service. Following the attacks of September 11, Harris and his vocal criticism of Canadian immigration policy became a fixture on US news shows reporting on Canada's role in the War on Terror. Similarly, Joe Bissett, a former immigration official, also made a number of
} 
War on Terror, the Wall Street Journal explains to its readers that "Canada's underfunded military is stretched so thin that concern is mounting...that its decline could jeopardize the defense of North America" (Baglole, 2002). It warns that the defence of North America is dependent upon Canada being able to "pull its military weight," a prospect revealed as unlikely in the face of an explicit comparison showing Canada's per capita expenditure on defence to be one-fifth that of the United States. Finally, the Washington Post questions Canada's ability to support the United States in the conflict against terrorism, suggesting that "drastic budget cuts have so weakened Canada's military that the country could not defend itself in war or contribute significantly to international security" (Brown, 2001).

In a closely-related vein, Canadian weakness is often tied to the presence of terrorists in Canada through portrayals of Canada as a free-rider. For example, a New York Times article that explores Canadian reactions to September 11 finds Canadians finally willing to "give the Americans what they need to make North America safer," including the adoption of "tougher immigration and asylum laws" (Crossette, 2001c). Moreover, it finds that Canadians, in addition to acknowledging that their "weak" laws contribute to US insecurity, also accept that "the only reason Canadians can live as they do is because they are sheltered by the might of the United States." Another news story cites a report claiming "Canada's military had been so weakened by spending cuts that it could not defend the country in a war" as part of its explanation for the adoption of a bilateral mechanism that enables each country to send troops to the other in the event of a

appearances in which he decried the laxity of Canada's immigration and refugee policies. The presence of former Canadian officials serves to further enhance the credibility of the host's claims by providing not just a Canadian perspective, but a perspective steeped in expert knowledge and professional experience. 
terrorist strike (Brown, 2002). In effect, the article suggests that the danger of terrorists in Canada is the result of a depleted Canadian military, itself the consequence of an overreliance on US protection.

Conservative news commentators often highlight the presence of terrorists in Canada by intertwining mocking derision of Canadian weakness with indignation over Canadian free-riding. For example, John Gibson uses this approach during an appearance on The O'Reilly Factor: "Canada's a joke. I mean, they're rife with terrorists, they can't find them up there. They can't even provide for their own defence. If it wasn't for the U.S., anybody could invade them...small guy in big pants" (Fox News, 2004b). Pat Buchanan adopts almost precisely the same approach:

The Canadians...have been defended by the United States, they pay nothing for defence. That place is a complete haven for international terrorists. Even their own retired security guys say it's a complete haven. We don't have-we need lectures maybe from some people but not from Soviet Canuckistan. (MSNBC, 2002c)

There is little doubt that commentary of this nature is intentionally rhetorical and designed to play to its audience with a theatrical flair. This tongue-in-cheek style does not mean, however, that the commentary itself is without constitutive implications. Indeed, as this chapter demonstrates, the difference in how Canada is represented in this style of commentary versus more professional reportage is one of degree, not kind. Moreover, although commentators like John Gibson, Pat Buchanan and Bill O'Reilly may use exaggerated rhetoric, the fact that they appear on news networks implies a considerable degree of legitimacy. Their contributions may sometimes serve to mark the extreme limits of a given debate, but there is little doubt that they do indeed contribute to that 
debate in a fundamental way. Indeed, as Debrix notes in his evaluation of the critical role that 'tabloid' culture plays in creating fear and situating American identity, "like it or not, O'Reilly's opinion on the world out there and on culture and politics in here seems to matter to many Americans" (2008: 145).

US news coverage also relies on gendered imagery in terms of commenting on the perceived need for Canada to demonstrate more resolve in confronting the political challenges associated with prosecuting the War on Terror. For example, a New York Times article that explores how Canada "has unwittingly become a haven for terrorists and groups that support them" explains that the country has since "tried to toughen antiterrorism efforts" (DePalma, 2001b). Similarly, in a CNN clip in which he advises Americans to be "very concerned [about] the large al Qaeda presence in Canada," the chair of the House Committee on Homeland Security explains, "I don't think [the government in Canada] was tough enough, as far as going after terrorism" (CNN, 2006d). And in an $\mathrm{ABC}$ news report that explores how Canada "has long been considered a political haven of sorts, harboring troublesome and sometimes dangerous groups," a reporter laments a US inability to "persuade Canada to strengthen its terrorism laws." (ABC, 1999) Other reports decry Canada's "lack of political will" (Chipello and Bilefsky, 2002) or its "very tentative" nature (MSNBC, 2003b) when explaining Canada's deficient counter-terrorism efforts.

A Wall Street Journal article, written in the immediate aftermath of September 11, provides a particularly compelling example of this dynamic (O'Grady, 2001). Presaged by its provocative title, "Canada Needs to Toughen up on Terrorists," the article 
employs a number of gendered concepts. For example, the article quotes a former Canadian ambassador who dismisses Canada for lacking the hardened and resolute leadership needed to defeat terrorism: "we don't have the political will to get rid of [terrorist suspects]." In a later passage, the article reinforces American masculinity while simultaneously hinting at Canadian femininity: "Tuesday's events changed the U.S. forever and adapting to the change will require strong counter-terrorism policies. Without a firm commitment from Canada to do the same, the only other option would be to close the border." Other examples of Canada's weakness in this area abound. For example, a Time article excoriates Canada's approach to terrorism by citing French counter-terrorism officials who "complain bitterly about the 'weak' and 'passive' attitude of the Canadians" (McGeary et al., 1999). Similarly, Jonah Goldberg claims that Canada has "basically turned into a northern franchise of the U.N....the problem with Canada is they don't respect power, they don't understand power politics, and they want the world to turn into a debating society" (CNN, 2003d). Other outlets confirm similar impressions, suggesting Canada is reluctant to deal with the threat of terrorism because of "political correctitude" (MSNBC, 2002a) or that the country has forgone a strong military in favour of becoming "the world's 'moral superpower"' (Brown, 2001). When John Gibson discusses how "our neighbour to the north is dragging its feet in the war on terror [and] becoming a possible staging ground for new attacks," he also employs an explicit comparison to a masculine US approach: "this guy [Canada has] arrested today, they're just going to deport rather than charging him. Now, we wouldn't do that here. He might find himself in Gitmo" (Fox News, 2002j). 
An exchange on MSNBC's Scarborough Country, dealing with "the disturbing trend of terrorists going in Canada," uses a variety of expressions to demonstrate a lack of resolve among Canada's political leaders (MSNBC, 2006c). For example, viewers are informed that a previous Canadian government was "almost playing footsie with radicals" and refused to "[get] tough," "come to grips," or "get serious" when it came to the threat of terror. A piece from the Washington Post claims that this lackadaisical attitude among Canada's political leaders also afflicts the Canadian public in general, which is apparently "disinclined to take seriously the country's problems with terrorism" (Morgan, 2006). As a consequence of this lack of concern, the author suggests, "Canada is starting to look like a safe haven for America's Most Wanted" and "a less-than-benign neighbor."

In each of the above areas, the US news media draws on a dichotomous framework to construct gendered depictions of both Canada and America. As this section contends, not only does this pattern reaffirm a masculinized America during a time of war, it also enables a version of Canada that is so weak and enervated that it has been reduced to a security liability for the United States.

\section{$\underline{\text { Passivity }}$}

Impressions of passivity were a hallmark of the news media's reportage of Canada during the War on Terror. This trend was particularly prominent in the case of conservative news commentary, although it was also highly visible within other sources as well. This section explores how US news coverage used the same gender dynamic 
explored in the previous section to also construct Canada as a passive actor. This representational pattern served to reinforce the masculinity of the American identity by imbuing it with a sense of abundant agency. Moreover, as this section will explore, gendered representations of Canadian passivity also played a crucial role in explaining the presence of terrorists in North America and defining Canada as dangerous space.

Canada's passivity was portrayed in a number of interrelated ways. The most prevalent of these expressions emerged from coverage that found the country's policies and standards to be simply insufficient. In this trend, Canada was found to be lax, lenient and permissive in a variety of ways judged dangerous in the context of the War on Terror. The second trend, drawing on the first, suggested that Canada's passivity had reached such a level that the situation facing the country was effectively out of control. Finally, in a complement to the first two trends, the news media also portrayed Canadians as essentially indifferent to the catastrophic danger that both Canadians and Americans faced as a consequence of lapses in Canadian policies.

The US news media's coverage of the War on Terror tended to frame Canada as a jurisdiction with lenient standards. The ultimate impression conveyed by the coverage, which especially stressed the apparent laxity of Canada's legal and immigration policy frameworks, was that the country's response to the War on Terror was decidedly passive. In effect, whether as a result of knee-jerk permissiveness or a simple lack of concern, Canada's policies were portrayed as failing to meet both US expectations and the tougher 
standards apparently in place in the United States. ${ }^{77}$ This othering strategy, in addition to masculinizing the US approach in relation to a feminized Canadian response, also provided an intuitive explanation for the presence of terrorists in North America.

News media portrayals of Canada's immigration policies are structured by impressions of laxity. Indeed, the adjective 'lax' is a ubiquitous descriptor within the coverage of Canada's immigration policies. It emerges from both print and television outlets (Chen and Reynolds, 2001; NBC, 2001c) as well as from both conservative and liberal ends of the political spectrum (Chipello et al., 2001; Pyes et al., 1999). For example, a Canadian expert appearing on CNN claims that in the case of Canada, "immigration is lax, horribly lax" (CNN, 20061). A Washington Post article discusses "lax safeguards along one of the world's most loosely monitored political boundaries" (Eggen, 2001b). Prominent International Relations scholar Edward Luttwak provides a colourful example of this trend in an opinion piece in the Los Angeles Times: "Security controls are famously lax because politically correct Canadians do not differentiate between 76-year-old Madame Dupont coming to visit her grandchildren and bearded young men from Islamic countries" (Luttwak, 1999).

Canada's approach to immigration is confirmed as lax through the use of a wide range of synonyms, all to similar effect. Thus, Canadian standards are frequently described as lenient ["no western nation, by its own admission, has a more lenient immigration policy than Canada" (CBS, 2002b)], loose [“Canada has very loose

\footnotetext{
${ }^{77}$ A previous section of this chapter identified the news media's tendency to view Canada's immigration policies through a lens of social and political values. Although this section also examines immigration policy, it does from the perspective of a gendered lens.
} 
immigration laws" (CNN, 2001d)], low ["the Canadian standards are...shockingly low as far as letting people into Canada" (NBC, 2001a)], and permissive ["the US is at the mercy of Canada's more permissive handling of foreign visitors" (NBC, 2002b)]. As part of this same trend, a USA Today report suggests that terrorists are able to take root in Canada as a result of the country's "relatively easy-going attitude toward asylum" (Kasindorf, 1998). This pattern is so widespread that even casual consumers of news reportage would likely be exposed to it.

Discussion on these perceived shortcomings of Canadian policy is almost always framed in relation to US policy. More specifically, Canadian policy is typically depicted in such a way that US policy is set up as 'tougher,' 'tighter' or 'more strict.' This impression is sometimes conveyed implicitly, as suggested by the following quotation from a Washington Post article: "Some U.S. officials contend that Canada has been too lenient toward international criminals and is becoming a haven for them" (Brown, 2000). A similar dynamic is at work in a Time magazine article, which explains that "some Americans...accuse Canadian immigration workers of inexcusable laxity" (Reaves, 2001). By drawing on the authoritative judgment of "U.S. officials" or the folksy wisdom of "some Americans," the reportage positions itself to judge Canadian policy, while also implicitly framing US policies as stricter.

Just as often, however, the comparison between Canadian and US policies is made explicit. For instance, readers of the Los Angeles Times are informed that "the Canadian border has long been a concern, in part because that country's visa requirements are not as strict as in the United States" (Wright and Murphy, 1999). Prominent US 
diplomat Richard Holbrooke makes a similar comparison during an $\mathrm{ABC}$ interview: "I'm not an expert on this, but as I understand it, the Canadian standards are often laxer" (ABC, 2001d) Similarly, an NBC report explains that "an advocate of tighter immigration rules says the US is at the mercy of Canada's more permissive handling of foreign visitors." (NBC, 2002b).

The last of the above examples, in addition to rendering Canada's approach "more permissive," also implies that such an approach serves to imperil the United States ("the US is at the mercy of Canada's more permissive handling of foreign visitors" [emphasis added]). This impression that US insecurity derives from Canadian policies plays a prominent role in the news coverage. More specifically, representational patterns structured around such notions as lenience, laxity and permissiveness contribute to a broader understanding of Canada as a passive actor. This 'passive' label does not, however, function simply as a neutral or value-free adjective. Indeed, when understood in the context of the War on Terror, passivity has important security implications concerning the entry of terrorists into North America. Thus, by gendering Canada as a passive actor, the news coverage is able to weave together a plausible explanation for the terrorist presence in North America.

This dynamic, in which Canadian passivity is both constructed in relation to US agency and linked seamlessly with the threat of terror, is a pervasive feature of the coverage. A 2002 column from Newsweek provides an example of this trend (Brill, 2002). In just a single sentence, this column manages to assert that Canada is "known to be a base for numerous terrorist groups" and "has more lenient immigration policies and 
looser borders than we [the United States] do." The article then goes on to expand upon the nature and extent of the threat posed by Canada: "Saudis don't need visas to come to Canada. All it takes is a valid-looking Saudi passport. So a Saudi terrorist with a dirty nuclear suitcase-bomb could come to Canada first, then cross over into the United States on, say a pleasure boat on the Great Lakes.” In this example, Canadian immigration policy serves as a foil against which US policy is confirmed as both stricter and tighter. Moreover, it is the apparent passivity of this Canadian policy approach that is blamed for the presence of Saudi terrorists in North America.

This trend, common throughout the news media's coverage of Canada, is particularly evident in television news programming. Fox News commentator Bill O'Reilly employs this pattern to great effect. For instance, while informing his audience about a pending interview with the Canadian ambassador to the United States, O'Reilly makes intertwining assertions that Canada is both "much too lax when it comes to immigration" and "making the US more vulnerable to a terrorist attack" (Fox News, 2002f). Although even the two sentences that make up this introduction provide a concise example of the dynamic under discussion here, the interview segment itself serves to confirm the example in greater detail. O'Reilly begins the segment by referring to "what some believe are incredibly lax immigration policies up north of the border." He later goes on to profess surprise at the "lenience" of the Canadian approach in comparison to that of the United States, before again drawing a direct link between Canadian refugee policy and the threat of terror:

You have an incredibly lenient policy towards so-called refugees. You're taking in a lot of people. And I'm frankly shocked. Why do you need all 
these refugees? Why do you want to do this? It's much easier to get into Canada than it is to the United States...I don't have confidence that the Canadian government can keep terrorists out at the rate you let refugees in.

This same trend is present in other news broadcasts. For example, CNN viewers learn that there are "some who view Canada's immigration policies as too lax, one that allows potential terrorists a North American staging ground" (CNN, 1999b). The same network also claims that "Canada has immigration and refugee laws much looser than those in the United States, and it admits an estimated quarter of a million people each year, a lot for a country of thirty million, and it has fifty terrorist organizations active on its soil, according to one expert" (CNN, 2001i). CBS informs its audience that "US authorities blame lax Canadian immigration policies for giving terrorists a chance to get into this country [the United States]" (CBS, 1999c). The same network also cites Canada's "very lenient visa policy" in the context of a story that asserts "the US has long had its eye on a portion of the Middle Eastern population in Canada" and warns viewers that "up to fifty suspected terrorist organizations have set up shop in Montreal alone" (CBS, 2002d). This seamless intertwining of Canadian passivity and the presence of terrorists in North America is common throughout the coverage.

In many cases, the news coverage goes beyond drawing a simple connection between feminized Canadian policies and a terrorist presence in North America. Indeed, a second trend in the coverage involves reports depicting the situation in Canada in more dire terms. In these cases, impressions of passivity are heightened to such an extent that Canada's immigration and counter-terrorism policies appear to be spiralling out of 
control. Depictions of this lack of control serve to further implicate Canada in what is viewed as an increasingly dangerous terrorist presence in North America.

The impression that Canadian laxity has resulted in a loss of control is widespread. For example, with respect to Canada's immigration programme, Bill O'Reilly asserts, "it's not hard to get Canadian papers...they give everybody who shows up on their shores papers, which is ridiculous" (Fox News, 2004c). In a New York Times article that explores Canada's approach to counter-terrorism, the country is pilloried for a passive approach that favours surveillance over arrests:

Not a single suspect has been preventively detained to avert a terrorist act. The relatively sparse activity contrasts sharply with efforts in the United States and several European countries, which have detained or arrested scores of suspects and frozen tens of millions of dollars. That has some Canadian and American authorities wondering if Canada has a handle on the total picture. (Krauss, 2003a)

The notion that Canada may not have a "handle on the total picture" is further cemented by revelations that Canada "has been under pressure from Washington to tighten its immigration policies and close loopholes." The article also uses threatening imagery to transform Canadian passivity into a North American security with its claim that US officials "wonder what kind of terror threat may be lurking from the north." With the arrest of eighteen Canadian terrorism suspects in 2006, news commentary frequently turned to the threat of domestic terrorism. In the wake of those arrests, Canada was frequently depicted in a negative light. On June 7, for example, CNN viewers were informed that Canada's "immigration and refugee situation...is largely out of control, with gigantic numbers, almost incomparable to those taken in by Western countries" (CNN, $2006 \mathrm{j}$ ). On the previous day, June 6, the audience of NBC's Nightly News was exposed to 
a similar argument: "The Canadian government has got to consider a moratorium on immigration and refugee intake. That's a situation that's out of control" (NBC, 2006c). In both of the above cases, the severity of the situation was further accentuated because the expert making the claims was a former intelligence officer from Canada.

One of the most common techniques for news programming to communicate the apparent severity of the situation in Canada is to label the country a 'safe haven' for terrorists. This phrase, used by a wide variety of outlets to describe Canada, connotes a level of passivity so extreme that terrorists are not only able to enter the country with ease, but are also able to raise funds, recruit, plan and conduct operations with virtual immunity. For example, the Washington Post claims that "U.S. officials have expressed concern about whether Canada, because of its relatively lenient immigration policies, has become a 'safe haven' for terrorists" (Pianin and Brown, 2001). This is a concern that is also apparently shared by Canadians: "Canadian experts are conceding that their country appears to be an attractive safe haven for terrorists" (MSNBC, 1999). Pat Buchanan expresses this sentiment on his MSNBC programme: "Canada has been severely criticized, even by its own retired security agents, as being...a haven for terrorists. An awful lot of groups have been operating with immunity up there for a long time" (MSNBC, 2002f). A US News and World Report article asks if Canada is a "terrorist haven," and warns that "most Canadians are in denial" (Strobel et al., 2000). And, as the Los Angeles Times implies in a 2006 article, this situation is not a recent development: "[Canada] has long been considered a haven for terrorists bent on launching attacks on U.S. soil" (Meyer and Barry, 2006). 
In the wake of Ahmed Ressam's arrest at the border in 1999, a dramatic expression of this trend emerged. This trend portrays Canada as not just an extremist safe haven, but as a luxury vacation resort perfect for terrorists. After Canadian police officer Claude Paquette claimed that Canada had become a 'Club Med for terrorists,' a variety of US news outlets picked up on the investigator's colourful language. For instance, Paquette's phrase found its way into a Los Angeles Times article: "Thanks to loose immigration control and interagency fumbling, Canada is turning into 'a club Med for terrorists'" (Farley, 1999a). The New York Times also cited Paquette's claim:

Canadian officials acknowledged yesterday that Mr. Ressam had taken advantage of lax procedures and loose cooperation between the police and immigration authorities to obtain his false papers. Reviewing the case, one Montreal police investigator, Claude Paquette, this week said that the loose rules had turned Canada into 'a Club Med for terrorists.' (Burns, 1999)

The phrase was even incorporated into the headline of a news magazine article entitled "North of the Border, terror's 'Club Med"' (Roane, 2000). Devoted to an examination of the problems generated by Canadian political culture and policy responses, the article contrasts Canada's "tradition of open borders and laissez-fair inclusion" with "a growing fear that Canada has become what some authorities call a 'Club Med for terrorists'." In cementing the impression that Canadian passivity is contributing to an ungovernable situation, the article discusses "lax policies on travel documents," "tax laws that make it easy to fund questionable organizations," and the claim that "Canadians don't have that frontline mentality; it's not bred in our bone."

The above representations of Canadian officials allowing their country to become the equivalent of a luxury resort for terrorists speak to a third trend in the news media's 
coverage of Canada. There is a tendency whereby news reports depict Canada and Canadians as unconcerned at the degree to which their country's passive approach to the War on Terror has spiralled out of control. In effect, Canadians are portrayed as indifferent to terrorism and, even more troubling from a US perspective, unconcerned that Canadian policies have made the United States insecure.

Impressions of a lack of Canadian concern are often communicated through coverage that faults Canada for insufficient vigilance. For example, as the Washington Post contends, "the American side...worries that Canada is not being vigilant enough" (Pomfret, 2006a). This lack of confidence in Canadian vigilance is also evident in an MSNBC discussion concerning rumours of illegal immigrants entering the United States from Canada as part of human smuggling ring (MSNBC, 2002g). In this exchange, the host appears to be blaming Canada for allowing suspicious individuals to leave the country: "Well, despite the help that the Canadian government gave us, how did they get through? And if Canada were a vigilant partner, how did they get out?" Brit Hume also highlights Canada's apparent lack of concern with his claim that "while the Bush administration is putting a renewed emphasis on tightening US borders and toughening homeland security, Canadian leaders have not" (Fox News, 2002b). His analysis of Canada's response also asserts that Canadian officials "have retained a virtual open-door policy on their borders, which means immigrants from all countries are welcomed with virtually no screening." Much of the criticism of Canada's seeming lack of vigilance is generated by the impression that Canadians do not appreciate the significance of terrorism and the danger it represents. MSNBC's Chris Matthews expresses his 
frustration at this Canadian indifference when he asks, "how do we get the Canadians to share the same kind of view we have about bringing terrorists into North America?" (MSNBC, 2001b)

These impressions of Canadian indifference are mirrored in reports that claim Canadians understand the struggle against terrorism as a low priority. For example, an Op-Ed piece in the Wall Street Journal claims that "Canada has rarely been a target of terrorism, and combating terrorism has not generally been regarded as a top priority" (Livingstone, 1999). It claims that Canada is in need of "a wakeup call," and blames the country's "lax immigration laws and small and underfunded police and intelligence organizations" for its extensive terrorist problem. Another report labels Canada "a great golden goose" for terrorists, and suggests that issues of national security and terrorism rate "a little bit below forestry management for some Canadian officials" (Fox News, 2004a). In an explicit indictment of Canadian passivity, this same segment asserts that "the Canadian government has not been aggressive yet in terms of stopping Canada from being this great safe haven."

Among other outlets, Fox News frequently emphasizes the degree to which Canadian indifference appears to be rendering the United States insecure. John Gibson, for example, invokes both indifference and the spectre of anti-American sentiment to explain the danger that Canada poses to the United States:

If the Canadian government didn't spend all its time trying to stick a finger in the eye of its giant southern neighbour...it would be a good thing. It would be nice if the Canadians worried as much about our border security as we do. It would be nice if the Canadian government didn't give sanctuary to terrorists, especially if their main claim to fame is they have actually killed Americans on the field of battle. (Fox News, 2006a) 
On The O'Reilly Factor, Canadian indifference and passivity is featured prominently in a segment the host introduces as the "Most Ridiculous Item of the Day" (Fox News, 2002g). In this feature, O'Reilly rails against Canada's use of summer students:

The Canadian government is putting the United States and Canada at risk by employing summer students to check the credentials of people trying to enter the country. Is this ridiculous or what? Of course, a spokesman for the Canadian government defends the practice saying the program works well. Yes, for the terrorists maybe. Totally ridiculous. Kids on summer vacation checking credentials. Unbelievable.

These portrayals of Canadian indifference in the face of an existential threat to the United States are the culmination of a broad pattern. This pattern not only frames Canada as a passive actor, it weaves a compelling narrative about a country that is so quiescent that it has effectively lost control of its own immigration and counter-terrorism efforts.

Like the coverage that portrayed Canada in terms of weakness, these depictions of passivity served to feminize Canada. In so doing, they engaged a binary logic that simultaneously reaffirmed a masculinized version of the American identity. In this sense, these patterned depictions were more concerned with creating a version of America that could better confront the threat of terrorism than they were concerned with providing a valid and objective description of Canada. The scripting of a feminine Canada, however, also played another crucial role. By rendering Canada a weak and passive actor, the US news media assigned the country a crucial role in introducing threat to North America. More specifically, because of its weakness and passivity, Canada was judged incapable of taking the steps necessary to secure itself from terrorist infiltration. Thus, as a 
consequence of its femininity, Canada had unwittingly become a dangerous space by allowing terrorists entry into North America.

\section{Conclusion}

During the War on Terror, the US news media deployed a variety of representational patterns to portray Canada. However, by using binary frameworks structured around such concepts as social values and gender, these representations did more than simply describe the country. Understanding the social world as an arena where meaning adheres as a consequence of discourse and representation means that our perceptions of the forces and identities that make up that world are contingent. In other words, there are multiple ways in which 'Canada' might be scripted and apprehended as 'real.' The representational patterns discussed in this chapter constructed versions of Canada that were positioned in relation to specific versions of America. Thus, depictions of Canada as a bastion of liberal policy did not just define Canada as such; they also created a foil against which America was defined as a nation both connected to its past and conservative in its outlook. Similarly, portrayals of Canada as a weak and passive actor did more than simply feminize Canada; they also helped to reinforce widely-held impressions of a masculine America that is both tough and aggressive. In effect, when understood in the context of the War on Terror, the news media's coverage of Canada reflected a social imperative that America return to its conservative roots and conduct itself with a masculinized approach steeped in strength and agency. In this sense, the 
framing of Canada serves as a coded assault against liberalism in the United States, linking its American advocates to its apparently deleterious effects in Canada. This move works to delegitimize the approach as dangerous for the United States and encourages Americans to embrace a conservative perspective.

These same representational strategies also defined Canada as a place so different from the United States that revelations about the country hosting dangerous elements made sense to Americans. In effect, portrayals of Canada as a feminine actor with liberal values made it possible for US audiences to understand how terrorists were able to find their way into North America. By tracing the threat of North American terrorism to perceived shortcomings in the Canadian character, the US news media helped to shift blame away from the United States and forestall a comprehensive debate on the factors that had made the country vulnerable to terrorism in the first place. ${ }^{78}$ As the next chapter explores, this depiction of Canada as a space where terrorists reside, when combined with ubiquitous representations of Canada as liminal to the United States, plays a crucial role in scripting Canada as a threat to US security.

\footnotetext{
${ }^{78}$ In the broader context of its overall examination of the threat of terrorism, the US news media certainly does explore a wide variety of shortcomings in US policy. However, I am suggesting that when understood in the specific context of Canada, the US news media's coverage of the War on Terror engages in a surplus of 'finger-pointing' and only a limited amount of thoughtful comparative analysis.
} 


\section{Chapter 6 US News Media and Themes of Canadian Liminality}

\section{Introduction}

As the previous chapter explored in depth, the news media's coverage of Canada during the War on Terror was structured by representations of otherness that made it possible for Americans to understand Canada as a space made dangerous by the infiltration of terrorists. Considering this, Canada's proximity alone might very well have been enough to convince Americans that Canada posed a danger to their country's security. However, as this chapter will demonstrate, the news media covered Canada in such a way that it enhanced the likelihood of this impression. More specifically, the television and print news media tended to portray Canada as liminal to the United States, as part of the American experience. Thus, even though it might have conceded that the two countries were separate entities, the pattern served to frame Canada's distinctiveness with a sheen of ambiguity that linked it inescapably to the United States.

Depictions of Canada as liminal to the United States made it increasingly possible for Americans to equate the presence of terrorists in Canada with the otherwise distinct notion that Canada itself represented a threat to the United States. As Hristoulas phrases it, "for Canada, the issue is not so much the existence of terrorists in Canadian territory, but rather the somewhat ill-begotten U. S. perception that Canada might somehow represent a terrorist threat" (2003: 31). If news audiences could see that Canada hosted terrorists while also understanding the country to be essentially an extension of the 
United States, then it would have been a simple step for them to imagine that terrorists were also in the United States. In this fashion, Canada served as a local and tangible proxy for the otherwise more distant and nebulous danger of terrorism. In so doing, Canada helped to make the fear of terror more immediate and relevant for Americans. Therefore, these depictions of liminality resulted in a threatening version of Canada that contributed to the 'discourse of danger' that works to congeal and rigidify the contours of American identity.

As chapter 5 noted, there is considerable consistency in the kinds of representations that emerge from the coverage. Thus, in the context of this chapter's discussion, conservative and liberal outlets both depict Canada in terms of liminality and threat. However, as was shown in the previous chapter, there are differences in degree. More specifically, conservative news sources tend to employ heated rhetoric and hype the immediacy and enormity of the Canadian threat more than their liberal counterparts.

This chapter explores four broad patterns by which the news media depicted Canada as liminal. The first section examines the theme of colocation, and the various ways in which the coverage emphasized the two countries as occupying both a shared space and an intertwined existence. The second section explores the news media's manipulation of the ubiquitous phrase, "the world's longest undefended border," and how visions of the shared border enabled the projection of fears related to imminent attack from Canada. The third section details how the coverage redefined the border itself in such a way as to render it a threat to the United States. The fourth section charts a trend within the coverage that framed Canada as belonging to the same social or cultural unit as 
America. In examining each of these patterns, the chapter makes it clear how the news media exploited the various representations of liminality in order to depict Canada as a threat and make the threat of terror more immediate for Americans.

\section{Colocation}

The US media coverage of the War on Terror was replete with stories that focused on US towns or regions located adjacent to the border with Canada. The most prominent common feature among these news items was their tendency to frame these geographic locations in the context of liminality. In effect, these towns were seldom understood as purely American locations. Rather, the coverage presented them in such a way as to link them to a Canadian counterpart on the other side of the border. Such stories were among the most powerful statements of liminality; there are few other examples that communicated the intermingling and overlapping of the two countries in such an explicit fashion. Moreover, even when reporters focused on analysing a single, specific border town or area, their coverage tended to transcend the specific locale they were discussing. As a result, instead of a narrow analysis of how the War on Terror impacts Americans living in a border town, the story was quietly generalized and transformed, either implicitly or explicitly, into a metaphor for the larger relationship between Canada and the United States.

Considered on their own merits, stories about border communities did not necessarily need to communicate a sense of danger or threat. Indeed, most of them 
operated from the very dissimilar premise of close kinship and cooperation between Canadians and Americans. However, when presented alongside a simultaneous exposure of Canada as a safe haven for terrorists, images of physical and cultural colocation in a shared community tended to evoke responses steeped in a sense of imminent danger and, oftentimes, shocked betrayal. Thus, news coverage of these shared communities during the War on Terror typically provided both elements necessary to understand Canada as a threat to the United States: first, the country was scripted as a dangerous space by virtue of the terrorists lurking within its borders; second, representations of liminality suggested that Canada served as a conduit that facilitated the entry of those same terrorists into the United States.

This section explores how the news media represented those shared border communities. The first part examines the extent to which the coverage portrayed Canadian and American lives as fundamentally intertwined. The second section examines the coverage of US border regions and how it tended to portray such places as shared spaces. The third section provides a more in-depth examination of the coverage of one particular border town, Derby Line, Vermont, which is split in two by the Canada-US border.

$\underline{\text { Intertwined Lives }}$

Media outlets drew on the towns and regions that populate the Canada-US border presumably in an effort to explore the various ways that terrorism affects the lives of Americans who live along that border. However, as part of this coverage, significant 
attention was typically devoted to showing the considerable degree to which the lives of these Americans were intertwined with Canadians. For instance, a New York Times article entitled "A Nation at War: The Canadian Border," references "golf courses with tees on one side of the border and the greens on the other" (Krauss, 2003b). A Fox News report discusses Piney Creek airport, "maybe the only airfield in the world where the runway is international, the south end is in the US, the north end in Canada" (Fox News, 2002h). Another report by the same network explores another instance of liminality: "And there are some areas where farmers farm on both sides...the Canadian side and the United States side, and they have to go back and forth all the time to farm their land" (Fox News, 2002d). A similar expression is evident in an excerpt from a USA Today article that explores the impact of the threat of terrorism on an area of the Minnesota-Ontario border:

The Rainy River separates International Falls from Fort Francis, Ontario. To many people, the towns seem like one community. Paper mills nestle up to the river banks on both sides. The movie theater is in Minnesota; skating and curling rinks are in Ontario. In the summer, fishing boats dot the river. In the winter, it's easy to walk, skate or snowmobile across. (Keen, 2006)

Despite the quaint images presented in each of the above cases, the intertwining of Canadians and Americans is not presented as a purely positive phenomenon. Rather, it is presented in conjunction with dire warnings about what lurks on the other side of the non-border. For example, the New York Times (Krauss, 2003b) article, which is focussed on the difficulties of securing the Canada-US border against the threat of terrorism, cites the international golf course as a factor that makes the border "hard to defend." And it concludes with a statement from a Canadian historian who says, "it's an undefended border, and it always will be." Similarly, the otherwise neighbourly image of a small 
town airport that spans an international border presented in the Fox News report (Fox News, 2002h) is transformed into something sinister. The piece, which explores the holes in air security on the border, cites an admission from NORAD officials that radar coverage on the Canadian border is incomplete, and then goes on to explain why this should concern the television audience: "The Canadian government's open-door immigration policy...allows in people from terrorism hotbeds around the world even without proper identification." For authoritative flair, the report also cites former CSIS official David Harris: "Well, I think it's fair to say that the anti-American, the Americantargeting terrorists, like the Islamists, among others, regard Canada as an ideally situated place for some of their operations against the States." Similarly, in the report that discusses border-crossing farmers (Fox News, 2002d), host Greta Van Susteren introduces her topic with an evocative remark: "We're talking about Canada's immigration policy and whether or not we face terrorists north of the border." She goes on to make another ominous remark about the implications of the shared border: "It's not really the border between the United States and Canada that we're worried about...it's about what's coming into Canada." Finally, the USA Today article (Keen, 2006) on picturesque International Falls was written in reaction to the discovery of a 'home-grown' terror group in Canada that was plotting to bomb several sites in Ontario. Although it purports to explain the economic costs that might accompany a crackdown on border security, the article also contextualizes the situation by reminding readers of the 1999 capture of Ahmed Ressam as he crossed the border into the United States. As such, although this report, and dozens of others like it, may not explicitly outline a current 
threat, its reference to Ressam serves to remind its readers of the persistence of the threat from Canada.

In each of these cases, the portrayal of Canada as liminal serves a similar purpose. The country is rendered at once both reassuring and threatening. It is the liminal portrayal of reassurance, the quaint images of shared golf courses, farms and airports, that helps to enhance the realization of threat. In effect, the reader or viewer is lulled by pleasing and reaffirming images of Canada as familiar, only to be subsequently informed the country is actually the proximate cause of great danger. This whiplash effect communicates that Canada does not simply host a threat; it also funnels that threat into the United States. As a consequence, Canada itself is transformed into a threat. Perhaps even more powerful, the media's use of imagery related to comfort and amity lends the coverage an emotional component that makes it easier for audience members to understand Canada's role as a conduit for terrorists to be the equivalent of an act of betrayal. This emotional and personalized aspect helps to heighten Canada's threatening aspect.

\section{$\underline{\text { Shared Communities }}$}

One border area that seems to have captured the attention of the US news media is the St. Regis Mohawk Reserve, which straddles the New York state border with both Ontario and Quebec. Although reports on this region contain liminal references, they generally eschew the allusions to amity and cultural affinity that are commonplace in 
other articles that feature liminal imagery. ${ }^{79}$ Instead, these articles tend to focus on the juridical fact of colocation, explaining simply that the reserve "straddles the New YorkOntario border" (CNN, 2003b) or is located "partly in Canada, partly in New York" (MSNBC, 2003a). A Los Angeles Times report uses somewhat more flair in its description, but still refrains from representing the community in terms of cultural closeness or overlap: "[The reservation is] a geographic hiccup, the only Indian reservation that straddles America's northern border. Part of the St. Regis Mohawk reservation is in America, part is in Canada, and a river and several islands fall in between" (Associated Press, 2005).

This version of liminality, one stripped of cultural content, is easily adapted to discussions of Canada as a threat to US security. Indeed, all of the reports that touch on St. Regis stress its role as a hidden entry route to the United States for threatening individuals, such as smugglers, illegal immigrants and terrorists. For instance, in the days following the release of a mistaken FBI report about five men who were reportedly smuggled into the United States, both MSNBC (2003a) and CNN (2003b) speculated that they may have entered the country from Canada via St. Regis. An Associated Press story in the Los Angeles Times claims that the reserve's position on the border makes the territory "some of the country's most popular for smuggling" (Associated Press, 2005). It also claims that in the context of the government trying to secure the country's border, St. Regis is "one door that remains wide open." A New York Times article calls the reserve "a favorite territory for smugglers" and notes that in the winter people can use

\footnotetext{
${ }^{79}$ This difference in representation is, perhaps, not unexpected, as Aboriginal peoples are often depicted in starkly different terms than the settler communities around them.
} 
snowmobiles to cross the border without passing through a checkpoint, before ultimately heading towards New York (Purdy, 2002). Such observations, particularly when offered in an article labelled, "Our Towns; Looking Over the Northern Border, and Over Their Shoulder," are made even more sinister when they are accompanied by the claim that the border, along with Canadian immigration laws, facilitates travel for terrorists looking to enter the United States.

These impressions of danger and threat are further accentuated by the coverage's tendency to link the area's liminal status to jurisdictional confusion and a lack of effective police enforcement. In one report, the local district attorney bemoans the lack of enforcement on the reserve: "If we're going to have a border, it should really mean something" (Associated Press, 2005). When an MSNBC host asks who monitors the borders on the reserve, his guest, Bernard Kerik, one of the country's most influential voices on security matters at the time, confesses confusion: "Honestly...I don't know who exactly controls those border lines. I would say it's INS in conjunction with the Canadian authorities" (MSNBC, 2003a).

The Great Lakes water system provides another setting in which the liminalitythreat dynamic is evident. One report quotes an expert from the Council on Foreign Relations who claims,

there never has been or will be an effective way of stopping people from coming across 4,000 miles of wilderness...On a hot summer day, there are more than six million boats on the Great Lakes, about four million from the U.S. and two million from Canada. Who can tell whether they are on the right side of the line? (Sullivan, 2002) 
In a similar vein, a Fox News report includes an interview with a Marine Interdiction Agent who emphasizes the colocation of the two countries on the Great Lakes: "That is Canada on that side. That's Ontario...you can hardly see [the United States] - you are looking at both countries seamlessly blending together...Not even a mile [between them]. Not even 2,000 yards" (Fox News, 2008b). An NBC news report contributes to the same trend: "Here on the Detroit River, you can hardly find a dividing line between the United States and Canada, but Americans like it that way" (NBC, 2001d). In terms of linking liminality to threat, two of the reports discuss the border situation in the context of both 9/11 and the arrest of Ahmed Ressam (Sullivan, 2002; Fox News, 2008b). The third suggests that "today, the concern is terrorists...at least fifty terrorist groups are operating in Canada." The report reinforces this contention by quoting a Canadian security expert who calls Canada "a major kind of centre internationally for terrorist activity and support" (NBC, 2001d).

A wide variety of other border communities and areas are also portrayed through this same mixture of liminality and threat. For instance, in an ABC newscast, viewers are informed that in High Gate, Vermont, Canada and the United States are "separated only by a low fence and linked by a well-worn path" (ABC, 2006). This otherwise neighbourly diminution of borders is, however, transformed with references to the 1999 arrest of Ressam, the 2006 arrest of seventeen terrorist suspects in Ontario, the "vulnerability" of the Canadian border and a State Department report that "expresses growing concern that weak immigration laws in Canada make that country a safe haven for terrorists." In Lynden, Washington, readers are told that "if not for a small stone marker with 'United 
States' on one side and 'Canada' on the other, the border between the two nations here would be impossible to discern" (Miller, 2002). However, the Washington Post article contextualizes this friendly situation by recounting details surrounding $9 / 11$, the arrest of terror suspects Ghazi Ibrahim Abu Mezer and Ahmed Ressam, and a Canadian intelligence report that estimates that fifty terrorist groups operate in Canada, including some who have allegedly set up operations "just 32 miles" from the border.

Two US exclaves only reachable by land through Canadian territory, Point Roberts, Washington and Angle Inlet, Minnesota, received news coverage as a result of their unusual geographical situation. Point Roberts is called a "geopolitical quirk (Ammons, 2002) and a "cartographic curiosity" (Egan, 2001). A Washington Post article writes about a villager whose house is in Canada and whose yard is in the United States (Pomfret, 2006b). As one television news report claims, "here at Point Roberts, most of the border between the US and Canada is nothing more than a homeowner's fence" (CNN, 2001h). However, as with most other reports on border towns, all of these stories are contextualized through references to the link between terrorism and the Canadian border. For example, a CNN report about Angle Inlet refers to the "charm of this tranquil town" and emphasizes the area's bucolic nature with its claim that "there are more deer than people who live here" (CNN, 2006a). However, the report's primary effect is to illuminate the dangers that reside in the sleepy enclave. The reporter hints at the possibility of a Canadian threat with his question to the local sheriff, "It is your professional opinion that terrorists have gone through Angle Inlet into the mainland 
United States?" Not surprisingly, the threat is confirmed by the officer's response: "Yes, it is...we have pretty accurate, pretty reliable intelligence that that has happened."

\section{Derby Line, Vermont}

The town of Derby Line, Vermont appears to have captured the particular attention of CNN and the Washington Post. Their coverage of this small town serves as an apposite example of how the news media uses liminal images of Canada to instantiate the threat of terror for Americans. The reports represent Canada as intertwined with the United States in a variety of compelling ways, including questioning the definitiveness of the border and showing how the lives of Canadians and Americans are part of a shared experience.

Described by one report as both "a historic curiosity" and "largely invisible" (Richburg, 2008), the international border at Derby Line is shown to lack a concrete and predictable quality. The news media describes it as winding through the town, often leaving visitors unsure which side of the border they are on. For example, signs for border inspection stations apparently result in "a maze-like terrain where wrong turns can result in inadvertent border-jumping" (Ferdinand, 2000). One border agents admits, "if you were to walk around town, you would probably walk into Canada and not know it" (Richburg, 2008). This confusion is evident in the words of one CNN reporter:

Right now I'm in the US. It's not exactly clear where the exact border is because there is no monument...you can look at the maple leaf flag there, that is Canada, that house. This house next to it is also in Canada. We believe this house is in the United States, so we don't think we're technically breaking the law. (CNN, 2007b) 
This sense of overlapping confusion also appears in an article that details the difficulties encountered by a volunteer civil defence group that has set up in the region:

Somewhere near this spot...runs the long and mostly invisible border between the United States and Canada. The New England Minutemen were here to guard this border. They just weren't precisely sure where it was. "That's west, so I believe the border is that way," said Jeffrey Buck, the group's leader, as he made an expansive gesture in the direction of a nearby home on Saturday. "It's not really clear to me." ...Perhaps the most vexing [problem] has been the difficulty of finding the border itself...It was in Derby Line that they had their first problem with the elusive border. On one scouting expedition, member Bob Casimiro said they became, for a moment, illegal visitors in Canada. (Farenthold, 2005)

One of the most powerful examples of this representational pattern occurs when a CNN reporter discusses the border with a local resident. When the woman, who has been a resident of Derby Line for 27 years, is asked if she knows whether they are currently in Canada or the United States, she responds, "No, you will have to see probably the maps" (CNN, 2007c).

Beyond the confusion represented by the border itself, however, is the degree to which news reports show Canadians and Americans as members of a single, integrated community. For example, one report claims, "this area...considers itself one unified community" (CNN, 2007c). This same point is conveyed by a 76-year old resident: "I have one brother - he's American. He was born on the US side. I was born on the Canadian side...It was like there was no border - people back and forth. Actually, we're like one people...like two brothers, one family" (Richburg, 2008). Another report quotes a woman with dual citizenship who lives in Canada: "We function here like one 
community" (Ferdinand, 2000). And the coverage is replete with wide-ranging examples of quotidian affairs that show the integration of people from both sides of the border:

People went to church and to school on either side of the line. Members of the same family lived on either side. Some streets, an old factory, the local library and opera house, and a few houses straddle the line...The two sides share a water system, a sewer system and snow-removal services. For years, the fire departments of both sides have helped each other without regard to a border. (Richburg, 2008)

One of the most powerful symbols of liminality in this coverage is the Derby Line library, which, as most of the reports emphasize, is split in two by the border. As one report claims, the building is the product of a gentleman's agreement, imbued with a bilateral and bilingual spirit, and "built more than a century ago so that both Americans and Canadians would have access" (CNN, 2007a). Descriptions of this nature, common within the news coverage, typically treat the building as a marker of a closely intertwined Canada-US relationship. They frame the building, and the relationship itself, as part of an idyllic era when cooperation, kinship and co-mingling were the norm:

Nowhere are the advantages of cross-pollination and the desire to sustain amity more apparent than here at the Haskell Free Library and Opera House (motto: "Good Books/Good Neighbors")...that physically straddles the border and has dual addresses and telephone numbers, and an international board of trustees. The front door leads to the Victorian homes and tree-lined streets of Derby Line, the back fire exit opens onto Rock Island, Quebec. The building has hosted three criminal trials involving smuggling of drugs, bombs and illegal immigrants with two judges - one sitting on each side of the border. (Ferdinand, 2000)

Derby Line, however, does more than stand in as a symbol of close cooperation and friendship between Canada and the United States. Considering the town is typically discussed in the context of US government efforts to improve border security against terrorist threats, it also serves as an effective vehicle to inform Americans that Canada 
has become a threat. The combination of representations of liminality with repeated reminders of Canada's links to terrorism serves to warn Americans that the close relationship they have with Canada is freighted with danger. For example, the coverage of Derby Line frequently references illegal immigration or high-profile terrorist incidents. Sometimes these references involve cases where Canada was somehow involved, such as the Ressam case: "The idea of beefing up this border goes hand in hand with terrorism concerns. Canada was the starting point for a high-profile terrorist plot in 1999 when Ahmed Ressam was caught by border guards entering Washington state" (CNN, 2007c). In other cases, however, reports on Derby Line refer to high profile terrorist cases that had no connection to Canada, such as 9/11. For example, in a 2008 Washington Post article, a local border patrol agent quips, " $9 / 11$ changed everything...This may have been Mayberry before, but it's not anymore" (Richburg, 2008).

The net effect of linking Canada with terrorism in the context of Derby Line is to demonstrate that the close relationship with Canada puts the town and, by extension, the United States at risk. For example, the report on the New England Minutemen coming to Derby Line suggests that the group is interested in watching the 'forgotten' Canadian border because "it also has problems with immigrants being smuggled across, and because it could provide a way for terrorists to infiltrate the country" (Farenthold, 2005). As part of this process, aspects of the town's unique liminal geography are transformed from symbols of unity into opportunities for terrorists. In particular, the unmonitored streets that link the two countries and serve as an emblem of the closeness of the liminal community are refigured as dangerous: 
Sept. 11 exposed the vulnerability of America's northern frontier and the ease with which anyone - a terrorist with a portable nuclear device, for example - could cross into the United States from Canada using one of the multitude of unguarded back roads or forest paths, or, in a border town such as Derby Line, simply by crossing the street. (Richburg, 2008)

When CNN's Glenn Beck asks a reporter how easy it would be for terrorists to enter the United States at Derby Line, he is told,

Glenn, for the bad guys this is certainly a more convenient place to cross into the United States...And what officials are concerned about, here, is right next to that sign is the entrance to Interstate 91 South. And officials are very concerned that terrorists or drug smugglers could go down this street, where there's no border officials, and then zoom down that highway. (CNN, 2007b)

Later in the report, as if to emphasize the threat posed by Canada, Beck asks a guest a rhetorical question: "Canada has real extremists living up in Canada, do they not?" Beck's guest, journalist Mark Steyn, obliges with a response that paints Canada in a decidedly negative light:

particularly just north of Derby Line in Montreal, which is Jihad central.... [Montreal is] a kind of soft underbelly...in terms of getting into America. If you're in Montreal, you just have to hop in the car, and you're not very far from New York and Boston. And you might not even be asked for ID on the border. (CNN, 2007b)

The coverage of these border communities emphasizes the impression that Canadians play a considerable role in the lives of Americans. The links between the Canadian and US sides of the border are consistently represented as enduring and deeplyfelt. Although the two sides of these shared communities are obviously linked by geography, the people themselves are portrayed as though they feel the real links are deeper: cultural, social and familial. Indeed, the two peoples are typically depicted as unconcerned or even resentful about the borders that officially weave around them, and 
are, ultimately, represented as living in the same community. However, these communities, despite their enduring affinities and shared resources, are primarily a journalistic vehicle through which news coverage is able to relate stories about the War on Terror. As such, in addition to serving as symbols of unity and amity, they also serve to link the United States more closely to the threat of terror. When expressed in the context of a version of Canada that hosts terrorists, the physical and cultural colocation of the communities becomes refigured as a source of anxiety for Americans. When the intertwined relationships symbolized by these communities is generalized to the larger Canada-US relationship, so too is the localized sense of threat made national.

\section{Border Images}

One of the most popularly accessible symbols of the Canada-United States relationship is 'the world's longest undefended border.' Normally understood as an affirmation of peace and friendship, this narrative is representative of the sense of liminality that typically attends the border. However, in the context provided by the War on Terror, this marker of reassurance and security was transformed into a source of insecurity and vulnerability (Andreas, 2003). In effect, the news media questioned and redefined the meaning attached to Canada's proximity. In the wake of representational patterns that depicted Canada as a dangerous space where terrorists reside, the liminality communicated by both an undefended border and Canada's immediate proximity became a source of imminent danger. This section first explores the process and implications of 
the shift in news coverage that served to transform the understanding of the undefended border; instead of a symbol of security and amity, the border was reworked into a marker of vulnerability and insecurity. It then turns its attention to an examination of how the news coverage depicted the United States as vulnerable to an imminent attack originating from Canadian soil

\section{Implications of 'Undefended'}

In its coverage of Canada's place in the War on Terror, the news media paid considerable attention to the Canada-US border. As part of this trend, much was made of the historical and cultural understanding of the border as the 'longest undefended border in the world.' However, in many cases, this commonly-held impression of the border was simultaneously jolted by a concurrent redefinition that transformed the implications of its undefended status. Instead of the border acting as a cherished reminder of an enduring peaceful relationship, it became a symbol of vulnerability and betrayal. Fundamental to this shift was the impression that proximity to Canada, along with misplaced trust, had effectively rendered the United States insecure against the machinations of terrorists.

Liminality is a key component in representations that figure the Canada-US boundary as 'the longest undefended border in the world'. The border is defined by its openness, its relaxed nature and its capacity to stand in as a marker of historical partnership and amity. All of these factors contribute to a liminal understanding of Canada that places the country on the verge of the American self-conception. This vision of liminality was also put into play when the border was redefined as a source of 
vulnerability. Indeed, the very possibility of Canada being re-scripted as a threat to US security was enabled by precisely this notion. Instead of an open border that allows friends to cross unhindered, the boundary was transformed into a porous or invisible line that is incapable of stopping terrorists. In both cases, liminality structured the discussion and powered the accompanying images, though with radically different results. A CNN report provides a succinct example of this transformation: "The United States and Canada share the world's longest unmilitarized border in all the world. Critics say it is also one of the most porous and, therefore, a threat." (CNN, 2002b) Ashleigh Banfield, a Canadian newscaster with MSNBC, gives another glimpse of the same pattern:

there is that massive border with my homeland Canada up north of us, 4,000 miles of border mostly unprotected and it is the longest undefended border between two nations in the world. Of course, Canada's been getting a bit of a rough ride lately because of the terrorists that have been able to make their way over the border from Canada and into this country. (MSNBC, 2002b)

The effectiveness of the border transformation is often enhanced by the whiplash effect that links expressions of pride or emotional attachment to the undefended border with the unexpected revelation of imminent threat. This is the effect achieved in a report covering an FBI hunt for five men suspected of crossing into the United States: "We used to boast that that was the longest unfortified border in the world. Now it's not something we're quite as happy about" (CNN, 2002c). A similar report reminds readers that the border "is often extolled with pride as the longest undefended border in the world," before ultimately warning them of the presence of terrorists in Canada and cautioning that "it is time to reassess security on the border" (Livingstone, 1999). The same trend is found in an MSNBC report: "4,000 miles of undefended border....this is something we've 
looked to with pride...that's a luxury we're not going to be able to afford in the future" (MSNBC, 2001a).

Instead of explicitly tying the border to a future threat, other news reports accomplish a similar whiplash effect by referencing recent examples of terrorism. The events of $9 / 11$, which were accompanied by widespread misreporting that several of the terrorists entered the United States from Canada, are frequently deployed in this context. It is found, for example, in the New York Times:

The United States and Canada have long boasted that they had the world's longest undefended border. But the porous nature of that 5,525-mile boundary came in for close scrutiny today, as FBI agents swept through Maine to investigate whether hijackers responsible for the terrorist attacks on Tuesday had entered this country from Canada. (Pear, 2001)

ABC provides another example from the aftermath of 9/11 (ABC, 2001d). When a guest describes the boundary as "the largest unprotected border in the world," Nightline host Ted Koppel responds by suggesting "several of these terrorists apparently entered the United States across that border...that we've always cherished between our two countries."

The transformation of the undefended border is even more powerful in those instances when the expression of threat is framed using sensational or evocative imagery. The use of military themes, detailed further in the next section, is a particularly common approach. A 60 Minutes segment, entitled "North of the Border," provides a compelling example of this process. Indeed, the documentary employs this technique throughout its entirety, using a wide variety of military images to describe Canada, including "strategic centre for international terrorists" and "jumping off point." The segment's introduction 
alone uses multiple military images in the process of transforming the border from marker of friendship to mark of vulnerability:

Canada and the United States share the longest undefended border in the world - a frontier that stretches 5,500 miles and for more than a century has reflected a peaceful and friendly alliance. But now, according to Canadian intelligence, the country has become a sanctuary, a staging ground and a fund-raising base for hundreds of terrorists from all over the world... [they have] transformed Canada into a potential launching pad for attacks against the United States. (CBS, 2002c)

The repeated use of violent military imagery in this example has a shocking effect when it follows so closely on the heels of otherwise benign descriptors, such as "a peaceful and friendly alliance." These, and the other inducements of threat discussed above, help to create the whiplash effect that reinforces the fundamental transformation of the border.

\section{Proximity and Vulnerability}

One of the most effective means of revealing US vulnerability to the Canadian threat is to play on Canada's proximity while using themes and imagery related to imminent attack. This section will examine this trend by exploring four interrelated areas: the tendency to portray Canada as a vulnerability for US security; the various ways in which Canada is represented as complicit in a military assault against the United States; the call to militarize the US border with Canada; and, the use of imagery that confirms Canada as an accomplice in plots to attack the United States.

One common discursive strategy that draws on Canada's proximity to the United States is to emphasize how Canada makes the United States vulnerable to terrorist attacks. For instance, immediately after a $\mathrm{CNN}$ reporter introduces her story with a claim 
concerning "the vulnerability of the United States' border with Canada," an expert provides background on the scope of the terrorist presence in Canada: "Canada became a major base for terrorists to come through or exploit the hospitality of Canada to get into the United States" (CNN, 1999a). A wide variety of other stories make similar claims. An $\mathrm{ABC}$ story about a series of terrorist-related arrests in Canada draws the conclusion that "those seventeen terror arrests in Canada are a chilling reminder that our northern border is also vulnerable" (ABC, 2006). A piece in USA Today suggests the Canadian border has been "long regarded as one of the nation's most vulnerable entry points" (Johnson, 2002). When a Fox News report raises a concern over Canadian border guards who are not equipped with firearms, it suggests that the situation "all adds up to a border that is viewed by many as vulnerable" (Fox News, 2006b).

News sources use a variety of more evocative terms and phrases that serve to communicate the impression of vulnerability to even greater effect. For instance, the Wall Street Journal paraphrases a report from a Canadian Senate committee that warns "Canada is fast becoming the continent's 'soft underbelly"” (Baglole, 2002). The border with Canada is also frequently referred to as a weak spot in US defences. For example, CBS asserts that "the United States considers its border with Canada a weak point in the defence against terrorism" (CBS, 1999b). CNN labels the border a "clear weak link" (CNN, 2001f) and a USA Today report defines it as "a dangerously weak link in the nation's post-9/11 effort to shore up security against terrorist attacks" (Hall, 2006b). As part of this same trend, a provocative Nightline feature entitled "The Border: Is it America's Achilles' Heel?" spends most of the broadcast answering its titular question in 
the affirmative $(\mathrm{ABC}, 2002)$. This is an opinion shared by the CBS Evening News: "Canada today represents the Achilles' heel of the United States. It is a largely undefended border" (CBS, 2003a).

The use of militarized images is part of another effective method for rendering Canada's proximity a threat to US security. More specifically, by using military metaphors to re-figure Canada, the news media is able to move the discussion away from an arid discussion of details towards a more compelling and frightening version of events. Within this tendency, the use of military images can be classified along a spectrum. At one end of the spectrum, Canada is represented in primarily passive ways, as a place that simply hosts terrorists bent on destroying the United States. As the spectrum progresses, however, Canada is increasingly defined as a larger, more violent military menace. At the more mundane end of the spectrum, US news coverage of Canada is crowded with metaphors that define the country as a base for terrorists wanting to attack the United States. For instance, CBS calls Canada "a relatively safe base for terrorists planning attacks against the United States" (CBS, 1999b). The New York Times asserts that Canada "has a reputation for being less than vigilant about screening out terrorists who have used it as a base of operations" (Crossette, 2001b). A Newsweek report references US investigators who believe "bin Laden was using Canada as a safe base for assaults on the United States" (Thomas, 2001). The Los Angeles Times refers to a Montreal apartment that "served as a base of operations for a terrorist organization that had 'spread throughout the international scene"' (Meyer, 2001b). The Wall Street Journal quotes a 
terrorism expert who labels Canada "a useful operation base" for terrorists (King and Chipello, 1999).

Further along the spectrum, the coverage describes Canada in more active terms, as a place that goes beyond simply hosting enemies of the United States and actually provides them a platform from which they can launch their attacks. For example, the New York Times suggests that "authorities have expressed fears that extremists could use Canada as a platform to make attacks inside the United States" (Austen and Johnston, 2006). The Wall Street Journal refers to Canada as both "a staging ground" (Baglole, 2001b) and as "a jumping-off point" (Baglole, 2002) for terrorists bent on attacking the United States. With respect to $9 / 11$, the Washington Post details the possibility that "as many as five participants in the deadly attack used Canada as a staging ground" (Eggen, 2001a). In a discussion concerning students at an al Qaeda training camp in Afghanistan, an $\mathrm{ABC}$ informant "made a point saying that bin Laden always took time out to meet privately with the Canadian students, because it was the closest jumping off point to America" (ABC, 2001c). Finally, Canadian terrorism expert David Harris makes this point particularly well during a lead-in to a 60 Minutes segment:

Canada has everything for the discriminating terrorist. We're a modern country. Now you've got proximity to the United States of America. And if you are in the business of destroying the western world and the United States and everything they represent, you couldn't have a better jumping off point, could you? (CBS, 2002c)

At the far end of the spectrum, the coverage uses even more evocative language, describing Canada as an actual weapon of war that is turned towards the United States. For example, NBC claims that Americans are concerned "that Canada is becoming a 
launching pad for future attacks on the United States" (NBC, 2006c). Similarly, CBS quotes Canadian intelligence sources as admitting that "Canada is used as a launching pad for terrorist activity" (CBS, 1999a). Even the US Ambassador to Canada takes part in this process of redefinition: "Our shared geography alone makes it inevitable that terrorists will consider using Canada as a potential launching pad into the USA. For us, the simple fact is we cannot defend our homeland without Canada's help" (Fox News, 2004e). NBC takes this metaphor even further, quoting a Canadian journalist who claims that "many Islamic extremist groups...seem to regard Canada as a kind of aircraft carrier for the launching of Jihad-type attacks on the United States" (NBC, 2001b). This is a sentiment echoed by a Canadian official quoted in the Los Angeles Times: "there is a concern that Canada not be used as a giant aircraft carrier for terrorists targeting Americans" (Orme, 2002).

The representation of Canada as a threat is perhaps at its most credible when it is accompanied by a call to militarize the border. This trend represents a step beyond the mere use of imagery to express American misgivings towards Canada; by calling for a militarized response, it defines Canada as an existential threat. The immediate cause of danger underlying such calls is typically the presence of terrorists in Canada. However, a more fundamental problem is often identified: Canada's reluctance or inability to take the steps necessary to protect the United States from its enemies. As such, the demand to militarize the border is often freighted with the corollary accusation that Canada is the permissive cause of US insecurity. 
Reports that are intended to simply present the facts surrounding a policy decision to militarize the border regularly do so through a process of contextualization that highlights the threat of terror in Canada. For example, a CBS report conforms to this pattern: "From the home front in the war on terrorism, concerned about potential terrorists crossing from Canada, the Justice Department wants military helicopters to patrol the 4,000 mile border and National Guard troops to help with inspections" (CBS, 2001b). This same approach is adopted by a wide variety of news outlets, including the Los Angeles Times: "More than 700 National Guard troops will begin patrolling the U.SCanadian border within the next several weeks as part of a major campaign to gird the nation against possible terrorist attacks" (Lichtblau and Gill, 2002). A more explicit definition of threat frequently emerges from the ranks of conservative television news commentators. Bill O'Reilly often tilts his comments in this direction: "We're not safe...I don't feel safe with 300 agents patrolling 4,000 miles of border...I'm looking for the army and the military to go up there and help out" (Fox News, 2001c). Tucker Carlson, though often engaging his viewers with a tongue-in-cheek style, exploits and sustains the same anxieties: "In the meantime, the United States military is drawing up contingency plans to invade, conquer and annex Canada, thereby solving the problem of border-hopping terrorists and, just as significant, providing Americans much needed room to park their SUVs" (CNN, 2002d).

Calls for the militarization of the border evoke the spectre of threat even more effectively when they are accompanied by the claim that the Canadian border is more deserving of troop deployment than even those foreign theatres where US soldiers are 
already deployed in defence of US national interests. Pat Buchanan, for example, laments the stationing of US troops in South Korea and Europe in the face of the threat emanating from Canada: "I can't understand why the armed forces of this country are all over the world defending borders when we're talking about bombs coming into this country and terrorists walking in from Canada" (CNN, 2001g). Michelle Malkin makes a similar point, though she does so with extra emphasis on Canada's passive complicity:

Canada bears a lot of responsibility for making us as vulnerable as we are to terrorism. I mean, everybody knows that Canada continues to be a welcome mat for terrorist organizations around the world...we could use armed national guardsmen on both the north and the south, but primarily in the north now to send a message that our borders do matter, and that if Canada is not going to take matters into its own hands, which it's not, then we need to do that...it's a shame that we're ready to send hundreds of thousands of troops overseas to defend other countries' borders, but we're not willing to defend our own. There is a war going on at our borders. (Fox News, 20021)

The final method of representation that draws explicitly on dangerous imagery to depict Canada's proximity as a threat to the United States focuses on the use of metaphors that convey stealthy plots. As part of this trend, the method of attack is shifted from the purely military to the treachery and shadows more commonly associated with espionage and spy novels. This approach is particularly effective at invoking notions of threat because it combines the possibility of a catastrophic attack with the element of surprise. Some of the imagery serves to implicate Canada as a central component in secret terrorist plots involving hidden enemies and global networks. For instance, the Los Angeles Times writes about a Canadian group that is "part of an international constellation of Islamic terrorists whose main bond is a common hatred for the U.S." (Farley, 1999b). The Wall Street Journal quotes a Belgian police officer who says that Algerian terrorists are able to 
"camouflage" themselves in Montreal, a city that he labels "part of a larger terrorist network" (Chipello and Bilefsky, 2002). The New York Times discusses "how a largely hidden network of militant groups uses Canada to raise money, recruit members, provide refuge and plan attacks" (DePalma, 1997). Another story explains how investigators are trying "to untangle a plot who tentacles have reached from Canada into New York, Boston, Vermont and Seattle" (Weiser and Pyes, 2000). ABC's Good Morning America also employs the imagery of tentacles when discussing the possibility that some of the 9/11 attackers slipped into the United States from Canada (ABC, 2001a). As part of his analysis, veteran television journalist Charlie Gibson admits to the complexity and severity of the situation: "Talking about the Florida investigation, the situation of the groups coming in from Canada into Bangor, Maine and into Portland, just how wideranging this investigation is. And there's so many different tentacles to it to keep track of."

As part of this process, the coverage frequently depicts Canada with imagery more suited to descriptions of a lair belonging to dangerous animals or insects. For example, the Los Angeles Times explains that some US and French officials consider Canada "a breeding ground for recruits of Osama bin Laden" (Peterson, 2001b). An NBC report characterizes the Montreal apartment of Ahmed Ressam as "a den of terrorists" (NBC, 2001b). Fox News also resorts to a similar style of representation. In one instance, a Canadian terrorism expert claims, "we know that simply Zarqawi's enterprise was a global one and that [Canada] has been well and truly infested with his agents and friends" 
(Fox News, 2006e). In another case, Fox News host John Gibson expresses the same concerns:

We worry that Canada's arms are open a little too wide, in that people who have malevolent feelings for the United States are a little too welcome in Canada, that we have to worry about Canada, you, becoming a nest of terrorists plotting to go south of the border and do us harm. (Fox News, 2005b)

Images of infiltration and betrayal are also commonly used, typically with the effect of heightening the sense that Canada is a threat. For example, a Los Angeles Times cover story begins its examination of Ahmed Ressam with the contention that he was a member of a Canadian "sleeper cell" that was activated to sneak across the border and bomb US targets (Meyer, 2001a). Fox News employs the imagery of infiltration while tracing several of the $9 / 11$ attackers to Canada: "Some of these guys evidently came down from Canada the day they hijacked the planes in Boston or the day before and it appears weren't really on anybody's watch list. They were just silent killers on their way to do their deed" (Fox News. 2001a). This same sense of infiltration is also emphasized in a story concerning the hunt for five suspects who reportedly crossed from Canada into the United States. Indeed, the impression is that much more powerful in this instance, as the report also references the traumatic events of September 11:

Canada has now become an accessory staging ground, and there is no question but that they are trying to surround the United States with ability to get in and infiltrate. The sleeper cells that are already here, that were probably here before September 11 took place, those sleeper cells need to have new instruction sets, and I think these people are being infiltrated in to bring those instructions in. (CNN, 2003a)

Finally, MSNBC provides a quotation from California Congressman Bob Dornan that exemplifies the treacherous imagery the news media often use to express Canada's 
complicity in terrorist plots against the United States: "Canada has stuck a knife in our back with their open policy to terrorists" (MSNBC, 2003c).

Most of the above patterns share a similar approach. They draw upon a preexisting and widely-recognized understanding of Canada that is based on notions of loyalty and alliance. This understanding is enabled by a sense of liminality, defined by Canada's proximity to the United States and the presence of an undefended border that projects a reassuring vision of sameness. However, with the introduction of the terrorist threat to Canada, this vision of sameness becomes cause for concern and a source of vulnerability. The undefended border becomes a threat to US security and Canada's proximity engenders fears of imminent attack. This process, by which the threat of the terrorist Other is instantiated within the American conception of the homeland, plays a role in heightening the fears that help to congeal American identity.

\section{Redefining the Border}

One of the most compelling ways in which the news coverage redefined Canada as a threat during the War on Terror was through its depiction of the Canada-US border. Like all social facts, the Canada-US border is a focal point for negotiation and struggle over meaning. However, during the War on Terror, a time of uncertainty and insecurity when social resources were being rallied to secure and strengthen a threatened American identity, the border became an increasingly important site in the contest for meaning. This struggle was not, for the most part, over the liminal nature of the border. As the 
point at which the two countries meet, the border is the ultimate marker of liminality. Indeed, in the words of US Attorney General, John Ashcroft, "it is a border that unites us rather than divides us" (DePalma, 2001b). Thus, the fact of liminality was not debated; rather, the contest was one around the implications of that liminality. Instead of treating the border as a marker of shared belonging where the US government plays an important role in safeguarding US interests, the War on Terror prompted the news media to redefine the boundary as a place of insecurity. This strategy depended on an understanding that terrorists had already infiltrated Canada. However, also integral to this process was a representational strategy that attempted to deplete the border's ability to act as a marker of US power and authority. It transformed the border into a nebulous and empty liminal space, bereft of a governmental presence and incapable of excluding terrorist intruders.

This section explores this redefinition of the Canada-US border in three related areas. First, it explores how the news coverage minimized the border's role as a marker of US government authority and power. Second, it examines how the border was figured not as a place where agents of US government restrict access to travellers, but as an access point or area that facilitates entry into the United States. Finally, it identifies how the news media 'Mexicanized' the Canadian border, effectively superimposing the fears and insecurities typically reserved for the Mexican border onto the Canadian border. ${ }^{80}$

\footnotetext{
${ }^{80}$ Andreas also uses the term "Mexicanization" (2003, 2005). His use refers to how the post-9/11 Canadian border has been increasingly politicized as a security threat in a manner similar to the way in which the Mexican border has been politicized over perceived threats related to undocumented migrants and drug smuggling.
} 


\section{$\underline{\text { Minimization }}$}

One of the most prominent representational patterns that news reports used to redefine the border acted to minimize the border's status as a symbol and outpost of US security. In this telling, the boundary lost its capacity to embody the authority and power of the state. This pattern effectively rendered Canada liminal to the United States by denying the border that separates them a meaningful role. This scripting of minimization also helped in the depiction of Canada a threat to the United States. The suggestion that the border between the two countries is little more than an imaginary line implied that it could do little to keep out the terrorists that already lurk within Canada. Even though the border's minimization took many forms, the diminishment itself was usually accompanied by this reminder of threat.

Examples of the minimization of the border are common throughout the coverage. Sometimes a report will minimize the border by suggesting the governmental presence on the boundary is little more than a formal one. This is the effect of an ABC broadcast of Nightline: "The northern border is four thousand miles long. And some areas are quite open. At one point, this marker between Washington state and Canada is all that separates the two countries. Easy access to anyone who wants to quickly enter this country" (ABC, 2002). A Los Angeles Times article that labels Canada a "haven" for terrorists and discusses the need for "filling the holes on a porous border" claims that crossing at the checkpoint at Morses Line, Vermont was "so effortless it was known as a cattle crossing" (Mehren, 2001). Even more effective, however, are those reports that strip the border entirely of its veneer of authority by reducing it to a nondescript and commonplace 
geographical feature. An NBC Today report suggests that in one area, there are no fences or sensors and "the only thing separating the United States from Canada is this ditch" (NBC, 2002a). A Fox News broadcast adopts a similar approach: "Terrorism remains the top priority along the border, where in many places like this one, only a few rocks separate the two countries" (Fox News, 2008a). The Washington Post declares, "in most places, the U.S.-Canadian border is delineated by nothing more than a ditch or a clear-cut through a forest" (Pomfret, 2006a).

Other reports deviate slightly from this trend, but achieve the same effect by stressing the lack of barriers along the border. A CNN reporter provides a simple example of this trend: "This is the border between the United States and Canada - the United States here, Canada here. As you can see there's no fence along this border" (CNN, 2003e). This ease of passage is emphasized in another CNN report that begins with a leading question: "Could terrorists find easy passage across our northern border?" In answer to this question, an expert suggests, "this attack wasn't aimed at the United States, it was aimed at Canada...they've got their own problem and their problem could easily spill over the border" (CNN, 2006f). A more full-throated expression is provided by a Canadian security expert, who claims, "the Canada-US border does not look like it is a particular obstacle to possible terrorists trying to break across into the US for dangerous purposes" (NBC, 2006a). His analysis is later corroborated by a network terrorism analyst: "Islamic extremists could use Canada as a place to locate and ultimately cross what are dozens of unmanned border locations and then disappear into the American population." An MSNBC report also conforms to the trend with its claim that "patrol 
agents face a daunting challenge, monitoring four thousand miles of international border like this one, Canada on the left, America on the right, and nothing in between" (MSNBC, 2002b). The report quotes an agent, who advises the audience, "sometimes they'll even come through these blackberries on a trail just like this one right here...[on] the border here we have no fences, have no barriers of any kind."

This lack of barriers along the border is the implicit centrepiece of the commonlyfound suggestion that terrorists can cross the border from Canada into the United States with ease. The coverage is replete with statements that minimize the border by contending that many people simply walk across without challenge of any kind. For example, a CBS report suggests, "in many spots, the border isn't even marked. People can simply walk from one country to the other, especially at night, in remote areas where agents rarely patrol" (CBS, 1999c). In a report "about borders and how easy it would be for the wrong people to bring dangerous materials into this country, specifically over our northern border with Canada," an NBC correspondent explains how an "undercover federal investigator simply walks across the border in an unguarded area, carrying a duffel bag loaded with materials which resemble the makings of a dirty bomb" (NBC, 2007). On the Record with Greta Van Susteren, which often uses inflammatory language and imagery when discussing Canada in the context of the War on Terror, draws on this theme several times. In one report, a correspondent claims, "once in Canada, for a terrorist or anyone else, getting into the US can be as easy as a walk in the woods" (Fox News, 2002d). In another episode, the announcer launches the show with similarly 
provocative language: "Is our country open to danger from the north? Getting into the US from Canada is a walk in the park, and it's ripe for a terror invasion" (Fox News, 2002d).

It is also common for reporters to minimize the border by suggesting that it does not occupy a place of importance in the minds of Americans. For instance, CNN quotes Attorney General John Ashcroft as saying, "we tend to take this northern border for granted, and we can't any longer" (CNN, 2001e) The New York Times quotes an aide to Washington representative Jack Metcalf: "The northern border is our neglected border...the area is just made to order for smugglers and terrorists" (Egan, 1997). And a USA Today report cites the president of the National Border Patrol Association, who claims the border with Canada "really is the forgotten border...we're just so vulnerable up there" (Hall, 2006b). Indeed, at its most extreme, the pattern effaces the boundary entirely, calling it "an invisible line" (Leinwand and Anwar, 2000) or a "long and mostly invisible border" (Farenthold, 2005).

This dynamic linking a dangerous version of Canada with a minimized CanadaUnited States border is on vivid display in an exchange between John Gibson and Congressman Tom Tancredo (Fox News, 2002k). Gibson first introduces the possibility of a Canadian threat with his rhetorical set-up of the interview: "So, if men with terror ties sneak into this country from Canada, who is to blame? Is it us, or is it Canada?" In the interview itself, Tancredo then confirms Canada's status as a dangerous space:

I joke - although it's not really that much of a joke, I joke about the fact that Osama bin Laden could shave off his beard, land in Canada, call himself Omar the Tentmaker, come in, and - without identification, and he could be allowed into Canada because they don't request it, if you say that you are coming in as a refugee. 
He then follows this statement up with a compelling example of how Canada is made liminal through the minimization of the border:

Well, the problem with this is that our borders are just as insecure as Canada's if -- because if you -- whoever Canada lets into their country essentially can get into ours, so that Canada's policy of border control, what little there is, is actually our own because our borders really don't even exist between the United States and Canada, for all intents and purposes.

As with other examples in this section, this interview provides a glimpse into how the news media is able to define Canada as a threat to the United States by combining representations that script Canada as both dangerous and liminal.

One of the most frequently-used adjectives to describe the boundary is porous. For example, a terrorism expert calls Canada "an extremely porous border" (Fox News, $2002 \mathrm{~m}$ ). A Time report suggests that the border "is as porous as Swiss cheese" (McGeary et al., 1999). Similar claims are routinely made by high profile individuals, such as Washington Senator Slade Gorton (NBC, 1999a) and former ambassador Richard Holbrooke (Fox News, 2001d). When used in the context of the War on Terror, this kind of imagery serves to portray Canada as a threat to the United States. For instance, a CBS broadcast from 2006 makes this connection explicit: "Critics have long worried that Canada's liberal immigration policies and a porous border make for a dangerous mix" (CBS, 2006d). A report from NBC's Nightly News adopts a similar approach: "So tonight, with those two Algerian suspects from Montreal still in American jails, there is still concern here from Canadian experts that indeed their country may, indeed, be a place that is attractive for terrorists anxious to get close to the American border, which is sometimes so porous" (NBC, 1999c). And, although he uses slightly different language, New York 
Senator Charles Schumer expresses the same concern: "The northern border is like a sieve and if you are a bad, smart person, and want to come into the United States, you know that you should go north and not south" (Baker, 2001).

A USA Today article from 2000 provides another example of how the news coverage acts to minimize the Canadian border. The selection quoted below demonstrates how the article renders Canada both liminal (by diminishing the border) and threatening (by inferring the presence of an array of threatening characters):

At night, when Immigration and Naturalization Service inspector Jeff Beil closes the border crossing here between Canada and the USA, he plops six orange traffic cones on the road. Those six cones on Highway 32 are the only defense in Walhalla against smuggling, illegal immigrants and terrorism from 10 p.m. until an agent returns at 9 a.m. the next day. (Leinwand and Anwar, 2000)

North Dakota Senator Byron Dorgan has long used the orange traffic pylon as a powerful symbol of the insignificance with which the border is viewed and treated. A month after 9/11 he claimed, "all terrorists and smugglers know that the only thing that precludes them from entering this country in many locations at the northern border is a rubber cone" (Edsall, 2001). Holding one of these cones aloft in the Senate, he emphasized what he saw as the lack of security on the Canadian border: "Do not tell us that we don't need additional resources on the northern border. This [pylon] is not a substitute for security. It's inexpensive, yes. But it's also ineffective" (Fox News, 2001e). The reporter from the Fox News broadcast from which Dorgan's quote is taken provides his viewers with additional details that place the senator's comments within the context of Canada's negative effect on US security: "Take our northern border with Canada. Three-hundred 
border patrol agents cover a 4,000-mile border. In some areas, we are told the only thing keeping the bad guys out of the country late at night are orange traffic cones."

This incident received considerable coverage in the weeks and months that followed, and a number of high-profile commentators weighed-in on the subject. Chris Matthews, for instance, claimed "a lot of these border crossings are simply orange cones put out at night....all you have to do is move the cones and drive through" (NBC, 2001e). A Los Angeles Times article quotes from a Michelle Malkin book, in which the author states, "at the northern border with Canada...every rubber orange cone and measly 'No Entry Sign' should immediately be replaced with an armed National Guardsman"' (Healy, 2003).

Each of the representational trends identified above are part of a wider pattern that diminishes the US governmental presence on the border. This diminution creates the impression of an uncontrolled no-man's land where the two countries meet. Moreover, this liminal overlapping, when combined with the absence of meaningful markers or agents of US authority, provides an ideal location for terrorists seeking entry to the United States.

\section{$\underline{\text { Point of Access }}$}

The second pattern under discussion also serves to transform the border's role. Instead of a formal setting for navigating national laws, performing security checks and confirming the identity and status of travellers, the border is presented as an access point that serves to ease transit and facilitate entry to the United States. This section explores 
how the border is redefined from a marker of governmental authority and security, and a site from which enemies can be identified and detained, to a place where security is limited and terrorists are allowed entry to the United States. Although most of this redefinition is aimed at the border, both Canada and Canadian policies are also often redefined as means of access to the United States. In this fashion, the border, Canadian policies, and the country itself are minimized or transformed to such a degree that not only are they shown incapable of stopping terrorists, they are portrayed as actually facilitating their entry into the United States. This section explores and identifies three ways in which the news coverage redefines the Canadian border as an access point for terrorists: the use of a set of metaphors that characterize the border as an open door or gateway; the emphasis on the threatening nature of the otherwise quotidian exchange of goods across the border; and, the use of historical analogies of dangerous border crossings.

The most common way of representing the Canadian border as a transit point for terrorists seeking entry to the United States is through language that equates the border or, very frequently, Canadian policies or Canada itself, to a door or portal of some kind. For instance, in an article that discusses border security, the Los Angeles Times calls the border, "one door that remains wide open" (Associated Press, 2005). Similarly, CNN asks its viewers, "might our open northern border with Canada be an open door for terrorists?" (CNN, 2006e) A variety of other words and phrases are also used to represent both Canada and the Canadian border in a similar way. In a CBS report that discusses the case of Ahmed Ressam, a reporter calls the border a "tempting gateway" (CBS, 2002a). 
Another CBS report claims, "the US believes Canada could be a gateway for terrorists who want to strike the US" (CBS, 2006b). A third broadcast reminds its viewers that "Al Qaeda used Canada as a gateway before" (CBS, 2002d). Other news outlets rely on the more neutral concept of an 'entry point'. For instance, the New York City police commissioner tells CNN viewers that "we know that Canada is clearly an easy point of entry for people that come from places like the Middle East, get into Canada and then come across our border" (CNN, 2001b). Other reports call the Canadian border "a point of entry for potential terrorists" (ABC, 2006) or refer to Canada as "an easy entry point...for Al Qaeda" (CNN, 20061). One of the media's favourite synonyms for portal appears to be 'back door'. The term conjures images of illicit entry, while also connoting neglect on the part of those charged with securing the door. As a result, reports that use this phrase often imply some act of betrayal on Canada's part. There is a multitude of sources that claim Canadian immigration policies provide terrorists with a back door into the United States (NBC, 2001c; CBS, 2001a).

Although much of the coverage uses the image of a portal to refigure Canada and the Canadian border, a variety of other images are also deployed to similar effect. Several reports use the metaphor of a path or route. Thus, Canada is "an easy route on the way to the United States for terrorists" (Pearlstein, 1999) or "an overlooked path for terrorists to enter the US" (CBS, 2006e). Several sources employ colourful language to express their message. For instance, the Canadian border is a "welcome mat for terrorists with weapons of mass destruction" (CBS, 2007). Terrorists are attracted to Canada because it is "on the front doorstep of the United States" (Fox News, 2005c). The Wall Street 
Journal discusses the possibility of terrorists using Canada as "a possible springboard for entry into the U.S." (Cloud, McMorris and Baglole, 1999). Time contends that some believe Canada's immigration policies are equivalent to "an open invitation to terrorists intent on making their way south into the U.S." (Reaves, 2001). A New York Times article entitled "Easy Illegal Entry in Northwest" covers multiple bases, labelling the border as both a "gateway" and a "smuggler's byway" and questioning whether it has become "an entry point for terrorists" (Egan, 1997).

Reports frequently maximize the impact of the threat component of their coverage by situating it within the context of the otherwise innocuous exchange of goods that occurs across the border on a routine basis. The quotidian nature of these exchanges serves to emphasize the ease and naturalness with which these goods are transported across the border and, in so doing, encourages a sense of shock and potential danger when it is revealed that the goods are themselves part of a terrorist scheme.

A Wall Street Journal article devoted to exploring how Canadian ports constitute a "weak link" in US security provides an example of this pattern (Baglole, 2003). The article details the scope of the activity at Canadian ports and the number of incoming shipping containers that end up in the United States: "Some three million containers of goods...travel in and out of Canada's three major ports each year - and $27 \%$ of the 1.5 million containers imported from abroad are eventually shipped to the U.S." The article, which specifically cites the possibility that weapons of mass destruction might be smuggled into North America in these containers, suggests that "Canadian ports could provide a back door into the continent for terrorists targeting the U.S." This same concern 
is also directed towards the cross-border trucking industry. For example, in a New York Times article that discusses the considerable number of trucks that cross the border on a daily basis, the Commissioner of the US Customs Service reminds readers of the omnipresent threat of terrorism:

We have to be sure there is no likelihood that a weapon of mass destruction has been concealed in that truck...There is at least a certain number of Al Qaeda terrorists in Canada...One of them could get a job at one of these [border] plants, and then you may have nuclear material inserted in that truck. (Brinkley, 2002)

A feature on ABC's Nightline devoted primarily to the Canadian border explores another way terrorists might be able to exploit the close commercial relationship between Canada and the United States:

You have, on average, 5,000 trucks a day rolling across a single bridge. There's more trade that comes across the Ambassador Bridge...than the United States has with China...If you want to take on the United States, you...try to weaken our soft underbelly which is our dependence of being a globally engaged society, a commercial society. (ABC, 2002)

Another report quotes the manager of the Ambassador Bridge reacting to the possibility of a terrorist attack on the bridge: "Everyone on that bridge would be fresh meat. It's stupid, but it's reality right now" (Grunwald, 2001).

The same threat is presented in a variety of other areas. For example, a Time article addresses a concern with the import of gum arabic plants for use as a food additive. The magazine notes, "these come largely from Sudan, once bin Laden's lair, via Canada, and because of the North American Free Trade Agreement may enter the U.S. uninspected" (Golden, 2001). Similarly, CNN reports on what is perhaps one of the most innocuous of dangers: trash. In several reports, the network covers Senator Carl Levin's 
concern that terrorists could attack the United States through loads of trash that Canada ships across the border for disposal. As a correspondent notes, Levin "believes terrorists could conceal weapons of mass destruction in trash shipments and successfully smuggle them into the US" (CNN, 2006c). Levin provides more details in his own words: "Trash, it's just one black glob on the x-ray. There's no way to say, 'Oh, look at that little black spot there. That's a biological weapon, or that's a chemical weapon...' You can't determine it. We don't need trash from Canada. Canada should take care of their own bloody trash. It's that simple" (CNN, 2006b).

In a related area, the news media provides extensive coverage of the debate over prescription drugs entering the United States from Canada. Within this coverage, Canada is effectively represented as a helpless middleman for nameless terrorists. For example, the Washington Post paraphrases a warning from Bernard Kerik that "allowing Americans to buy lower-cost drugs from countries such as Canada could invite terrorists to launch a biological attack under the guise of a legal purchase." The paper also quotes the former New York City police commissioner as saying, "if wholesale importing is permitted, it will make this country's medicine supply extremely vulnerable to terrorist intervention" (Connolly, 2004). Similarly, the New York Times, which covered the initial debate closely, quotes a statement from the pharmaceutical industry that expresses the same worry: "If importation were legal, Canada would become the easiest portal into the United States for the world's terrorists and counterfeiters" (Pear, 2003). In another article, the paper quotes Senator Orrin Hatch of Utah: "We are just placing our country in the hands of terrorists who could easily get hold of various prescription drug products and 
spread desolation and disease" (Pear, 2002). And finally, a third article quotes Senator Judd Gregg to similar effect: "If I were a creative terrorist, I would say to myself, 'hey, listen, all I've got to do is produce a can here that says 'Lipitor' on it, make it look like the original Lipitor bottle, which isn't too hard to do, fill it with anthrax"' (Associated Press, 2006). Even the cross-border trade in illegal drugs is implicated in the broader fear of terrorists using Canada to attack the United States:

The ability of organizations to move contraband back and forth across the border [using helicopters] is a national security issue, because these are people who figured out a mechanism to penetrate the U.S. and Canadian border...Those small helicopters can move 250 pounds of marijuana at a time. But what does a suitcase carrying a dirty bomb weigh? Maybe 80. (Pomfret, 2006a)

During the contemporary War on Terror, it is not unusual for reports to stress the historical continuity of Canada's role as a conduit for threat. For instance, when discussing the ease with which terrorists are able to cross from Canada into the United States, a number of articles also make reference to the existence of routes that were reportedly used by Soviet spies during the Cold War. As a Fox News reporter asks, "what's to stop a terrorist from using the same trails?" (Fox News, 2002d). The media also draws parallels with the threat posed by Canada during the Civil War. For example, the Los Angeles Times references Confederate raids into New England from bases in Canada (Anonymous, 2001a). Similarly, a Washington Post article that explores terrorism during the Civil War era gives a nod to a modern parallel: "Many of the plots against Washington and New York were dreamed up in Canada, a haven for Confederate agents throughout the Civil War" (Singer, 2003). These nineteenth-century plots, many of which were also discussed with reference to al Qaeda, included assassination, 
contamination of New York's water supply with deadly chemicals and the release of a biological agent in order to cause an epidemic. This pattern of intertwining threat and historical examples of ease of access even extends to Canada's role during the "rumrunning days of Prohibition" (Kasindorf, 1998).

The tendency for the news media to fixate on the border as a place where travel is facilitated rather than managed helps to generate the impression that there is a virtually open and seamless link between Canada and the United States. This depiction of liminality takes on sinister overtones in the context of the War on Terror, particularly when the news coverage has already committed to the presence of terrorists in Canada. Therefore, like the trend identified in the above section, the depiction of the Canada-US border as an access point is able to contribute to the construction of a threatening Canada and enhance the fear that helps to rigidify American identity.

\section{$\underline{\text { Mexicanization }}$}

The final strategy that manipulates the border in an effort to demonstrate the threat posed by Canada is the comparison of Canada with Mexico. The United StatesMexico border has long been a site upon which American fears and suspicions have been built. Illegal immigration across this border is regularly linked to a wide variety of issues portrayed as threatening to Americans, including drugs, prostitution, crime, unemployment, language diversity, and the rising expense of government services. The seriousness of the situation has been authoritatively confirmed by a government response that relies heavily upon militarizing the border. Within this context, news coverage 
frequently intertwined and exploited the liminal status of both countries in order to render Canada a threat to the United States. The end result was the 'Mexicanization' of the Canadian border. ${ }^{81}$

There were two broad methods by which this process unfolded, both of which made use of a pre-established and ingrained understanding of the Mexican border as an insecure and dangerous locale. In the first, the coverage juxtaposed details and statistics on the US borders with Canada and Mexico. For the most part, this approach drew on the differences in both the length of the two borders and the number of border agents that patrol them. The second method drew attention to the long-standing negative image of the Mexican border, but then explicitly compared that threatening image with an emerging picture of Canada. In this comparison, Canada was invariably judged to represent a greater danger to US security.

Although numbers vary somewhat between reports, the American border with Canada is usually reported at 4,000 miles in length, a figure that is typically contrasted with the 2,000-mile length of the United States-Mexico border. Reports often emphasize this disparity by pointing out that the Canadian border is twice as long as the Mexican border (and almost three times as long if Canada's 1,500-mile border with Alaska is included). The differing border lengths provide context for an accompanying discussion concerning the number of agents assigned to each border. These figures also vary by report and are obviously contingent on the date of the broadcast or article; however, the

\footnotetext{
${ }^{81}$ For a general discussion on the Mexicanization of the Canadian border, see Andreas (2003, 2005).
} 
most common figure for the Canadian border is 300 agents, while the most common total for the Mexican border is 9,000 agents.

This emphasis on numbers does more than simply convey purportedly factual information. As van Dijk suggests, the use of numbers by the news media has the effect of imbuing a report with a sense of truth: "Few rhetorical ploys more convincingly suggest truthfulness than these number games...[Numbers] are predominantly meant as signals of precision and hence of truthfulness" (1988: 88). In this case, therefore, the ubiquitous use of numbers helps to reinforce the 'truth' behind the broad meaning communicated by the coverage. Therefore, the message that the sense of threat normally reserved for the Mexican border must also be considered in the case of the Canadian border achieves a greater degree of salience. The otherwise innocuous use of statistics serves to heighten the danger posed by Canada.

By using a comparison that emphasizes the longer border with Canada and the smaller number of agents assigned to protect that border, the coverage implies that the boundary with Canada may be easier to cross undetected than its counterpart with Mexico. Such an impression might be particularly jarring for an audience that has been previously inundated with the charged and voluminous rhetoric associated with illegal immigration from Mexico (Nevins, 2002). Moreover, when these juxtaposed numbers are presented alongside an analysis of Canada's role as a 'safe haven' for terrorists, the primary implication is that Canada poses a greater threat than Mexico, despite the latter's previous association with any number of dangers to US national security. 
For example, in a broadcast that focuses on US borders and national security, the finding that Canada is a greater threat than Mexico is assisted by the reporter's emphasis on the disparity in numbers: "For every one Border Patrol agent on the northern border, there are nine agents down south" (Fox News, 2006c). One report exploring the state of US security one year after $9 / 11$ exuberantly suggested that the ratio was actually fifty to one (MSNBC, 2002b). A similar pattern is in evidence in a report on the NBC Nightly News: "While 7,400 agents police the border between the US and Mexico, only 300 patrol America's 4000-mile border with Canada. A warning to Congress last April that the northern border is wide open to anyone, including terrorists" (NBC, 1999b). Bill O'Reilly adopts a similar approach, though his heated rhetoric perhaps helps to make the point even more effectively:

we have a 5,500-mile border with Canada and only a 1,900-mile border with Mexico. We all know that [suspected terrorist Adnan] Shukrijumah could show up in Canada and say I'm a landed immigrant, please give me food stamps and an apartment, and then wander across the border anywhere he wanted. Why wouldn't we worry about Canada more than Mexico? (Fox News, 2004h)

Finally, when a prominent national security commentator and practitioner appearing on CNN is asked if the United States is focusing "on the wrong border," he responds by informing his host of the danger posed by Canada: "Well, certainly from a terrorist perspective, the northern border and our northern neighbour is the country we need to be worried about... when you're interested in protecting the country from external terrorist attack, Canada is much more dangerous and deserves a whole lot more focus." In response, the host then helps to cement the impression of threat by invoking a comparison with the Mexican border: "And yet, we're told, fewer than 10 percent of the 
nation's Border Patrol agents - about 1,000 of 11,500 - are stationed on that Canadian border, which is...double the US-Mexican border" (CNN, 2006h). In each of the above instances, a juxtaposition of numbers plays an important role in making the case that Canada is a threat.

The second method by which the Canadian border is effectively Mexicanized is one in which reports attempt to emphasize the seriousness of the Canadian threat by claiming it is worse than the threat posed by Mexico. Therefore, like the first pattern, this approach implicitly references the ubiquitous understanding of the Mexican threat in order to heighten concern for Canada. For example, a CBS commentary that explores several Canadian arrests with "terrorist implications" and labels the Canadian border "soft," also reminds viewers that "with all the attention that's been paid to immigrants crossing illegally into the United States from south of the border, we forget sometimes that there is another, even longer and even less well-guarded border with Canada" (CBS, 2006a). A New York Times article, under a section heading entitled "A Nation Challenged: The Northern Border," uses the recognizable spectre of the Mexican threat to introduce its audience to the possibility that Canada also poses a danger to US security:

Raise the issue of illegal immigrants sneaking across the border, and images come to mind of people wading across the Rio Grande or hiking across a scorching desert. But for United States Border patrol officials like Robert Finley, chief agent for a nearly 500-mile stretch of the United States-Canadian border here in the Great Plains, there are other situations to worry about now as he faces new mandates to secure the border against terrorists. (Verhovek, 2001)

Other reporters and media outlets, however, go much further in their use of rhetoric to make their point. Sean Hannity, for instance, resorts to the imagery of war to 
emphasize the Canadian threat in his introduction to a report that lambastes northern border security: "When you think of securing our borders, the 2,000 miles along Mexico first comes to mind. But our own Ainsley Earhardt takes us to Detroit to show us up close the battle up north" (Fox News, 2008b). At a time of intense public debate over the construction of a fence on the US-Mexico border, John Gibson devotes a section of his show to a discussion on the Khadr family from Canada, and concludes his remarks with a blatant example of Mexicanization: "Build a wall on our border with Mexico? Sure. But don't forget Canada" (Fox News, 2005e). A guest on Nancy Grace resorts to hyperbole to make his point: "We talk about our southern border, but what about our northern border? We see terrorists coming through Canada all the time" (CNN, 2007d). A quote from a national security expert appearing on CNN provides another excellent example of how the Mexican border is combined with notions of Canada's liminality to render the country a threat to the United States:

It is a very porous border....if there's terrorists in Canada, they're effectively in the United States...when you're worried about terrorism, you look north. You look at Canada. If you're worried about low-wage workers without proper documentation, you look south and you look at Mexico. We haven't seen any terrorists trying to infiltrate the United States from Mexico. Mexico is not a hotbed for Islamic extremism. Canada is. (CNN, 2006g)

The combination of the Mexicanization of the Canadian border with the suggestion that Canada is a 'hotbed' for extremists finds regular expression in the news media. For example, in response to a USA Today 'Question and Answer' section that asks readers, "What about the northern border?" the paper claims that "security experts and intelligence officials are just as concerned - if not more concerned - about terrorists 
coming across the border with Canada" (Hall, 2006a). It goes on to provide a corroborating quotation from a "homeland security expert" who claims, "if we need to secure the border against al-Qaeda infiltration, [the Mexican border] is the wrong border. There are far more al-Qaeda sympathizers in Canada than Mexico." Similarly, on a broadcast of The Situation with Tucker Carlson, the host asks an introductory rhetorical question of his audience: "With all the recent focus on the Mexican border, shouldn't we be worried about a terror threat from the north, the Canadian border?" Later in the show, he and a network terrorism analyst agree with a congressman's statement that characterized Canada as hosting "a disproportionately large number of al Qaeda members" (MSNBC, 2006b). Finally, in a discussion about Islamic extremism, a guest on Glenn Beck makes use of the same pattern: "Canada lost control of its border, just as we in Britain have lost control of our borders, and I think in America you have something of a similar situation too. You've been convulsed by a debate over your border with Mexico. I think you should look to your border with Canada" (CNN, 2006i).

The juxtaposition of the Mexican and Canadian borders serves to transfer the general fears and anxieties traditionally reserved for the Mexican boundary to the northern border. By stressing both the border's relative lack of border agents and its longer length, the coverage coveys the impression that it lacks the ability to play a meaningful security function and poses an even greater threat than its Mexican counterpart. Moreover, when accompanied by representations of Canada as an obliging host for terrorists, such depictions contribute to an impression of Canada as a dangerous space. 
Borders are crucial sites for the negotiation of national identity. They are the lines that separate the "inside" from the "outside" (Walker, 1993), delineating an arena for the specification of threat and for the definition of the self in relation to the Other. However, the border between Canada and the United States is not limited to this role. Instead, this border is often represented as a place of liminality, where Canada's presence joins or shades into that of the United States. This does not, however, exclude this border from its role in the struggle over identity. As a marker of Canada's liminality, the border is regularly scripted in such a way as to deny the existence of a meaningful barrier between the two countries. In the context of the War on Terror, it is defined and redefined in order to deplete its gravitas and capacity to provide security for Americans. The border is represented as a place of danger, a place where terrorists residing in Canada are able to secure unimpeded access to the United States. This instantiation of the terrorist threat helps to encourage the sense of threat that enables American identity to harden its parameters.

\section{Shared Identity}

A powerful vehicle for the expression of liminality emerges from news coverage that links Canada to the United States in terms of cultural similitude or shared identity. This pattern uses familiar imagery to tie Canada and the United States together in some deep and fundamental way. In effect, the two countries are represented as belonging to the same unit, although the nature of that unit varies with each individual report. This 
approach is effective at eliding the differences between the two societies and furthering the perception of a liminal Canada that belongs within a wider understanding of the American experience. Although it is perhaps counterintuitive, the use of representations that draw on impressions of shared belonging also serves to contribute to portrayals of Canada as a threat. For instance, when found alongside reports of terrorists infiltrating Canada, the perception that Canada and the United States are both part of the same society suggests that if such events can transpire in Canada, then they can also unfold in the United States. Moreover, when Canada is represented as a neighbour or brother to the United States, the revelation that Canada has neglected its borders, or otherwise facilitated the plans of terrorists bent on attacking the United States, is easily received as an act of betrayal. The emotion conveyed by such representations help to personalize and accentuate the threat posed by Canada.

This section explores three broad examples of this trend in the news media coverage. First, it explores the pattern by which news reports stress similarities between the two countries that apparently bind them together. Second, it examines the media's use of three specific metaphors that are saturated with a sense of emotional connectedness: neighbour, friend and family. Third, it identifies and analyzes the various ways in which reports either diminish or deny Canada's foreignness, effectively rendering it a part of the United States.

\section{Cultural Similitude}


It is not uncommon for television news shows to contextualize a discussion about Canada with an explicit statement regarding the cultural similarities between Canada and the United States. This tendency encourages the audience to understand Canada as part of a wider cultural grouping centred on the United States. However, when paired with revelations concerning Canada's connection to terrorism, this representational pattern serves to heighten the immediacy of the dangers faced by the United States.

For example, a commentator on The O'Reilly Factor suggests that "Canada is imbued with American culture. You can't imagine Canada without its connections to the American way of seeing things" (Fox News, 2004f). This statement, explicitly linking Canada to the United States, is presented alongside a wider discussion concerning whether or not Canada is a "friend" to the United States. The host clearly doubts the accuracy of the 'friend' label, pondering if perhaps Canada might not "evolve, like France, into an enemy." The discussion also includes the suggestion that Canada is useful to terrorists because the country allows them to "come in with a carte blanche as refugees and go to the United States." In another broadcast, O'Reilly laments the trend towards secularism in the United States because "the USA cannot defeat terrorism and any other evil without a strong traditional foundation that clearly defines right from wrong." He later fingers Canada as a product of secularism's corrosive effect and discusses with his guest, Newt Gingrich, the possibility that the United States might follow Canada's example:

Now am I wrong in making a comparison with Canada? And Canadians are all over me, but I see Canadians and Americans as the same people. Same roots, same societies, same everything. Yet that country has become, 
as you put it, radicalized. And I say if it can happen there, it can happen here. (Fox News, 2004g)

CNN provides additional examples of this dynamic in its coverage of the arrest of seventeen terrorism suspects in Ontario. On American Morning, for example, a commentator stresses the dangers that Canada poses to the United States and then subsequently emphasizes the closeness of the two countries (CNN, 2006h). He begins by suggesting, "we have had more evidence of Islamic extremism and militancy in Canada than we've had in the United States...Some [terrorist cells], like this one in Toronto, are far more dangerous than anything we've seen here domestically in the United States." In a move that then serves to heighten the threat posed by Canada, the commentator discusses how close and intermingled the two countries are:

It's the longest unmilitarized border in the world. It's also the most economically significant border in the world. More trade moves across that border than any other border in the world. But it seems to me the odds of ever getting a really strong barrier between the United States and Canada are rather slim, just given how intermingled our societies are and how interdependent our economies are.

During a broadcast of Paula Zahn Now the former Chair of the $9 / 11$ commission employs the same logic when he simultaneously stresses both the cultural similarities between Canada and the United States and the threat implied by such closeness: "This should be a tremendous wakeup call, because it's right across the border. Those people are there. Canada is a country very much like us. It could happen here if it could happen there" (CNN, 2006j).

These references to a shared identity are prominent within the news coverage of Canada, and provide a powerful statement of liminality. As detailed above, such 
representations depict Canada and the United States as linked together in a fundamental way. In the context of the War on Terror, these representations imply that the presence of terrorists in Canada is effectively equivalent to their presence in the United States.

\section{Metaphors of Belonging}

The news media's coverage of Canada during the US War on Terror is replete with metaphors that define Canada and the United States as intimately connected and sharing an emotional or familial bond. The ubiquitous use of these metaphors, and the fact that they are all anthropomorphisms, encourages an understanding of the Canada-US relationship that transcends and humanizes the more impersonal impressions often associated with international relations. This emotional link helps news outlets to frame Canada as liminal to the United States. In the face of repeated representations that script Canada as a host for terrorists, this impression of liminality helps to make it possible for Americans to understand Canada as a threat to the United States. This section explores the use of three of these structuring metaphors: neighbour, friend and family member.

One of the most commonly used metaphors, found in many of the print and television sources under review, is that of neighbours. Throughout the coverage, the word neighbour is imbued with at least two meanings. In some cases, it expresses the friendly intimacy typically associated with a good-natured and healthy relationship. For instance, three days after the events of $9 / 11, A B C$ 's Barbara Walters refers to her daughter's frequent unreported trips back and forth to Canada, and calls the country "our good neighbour" (ABC, 2001b). In a similar vein, a US News and World Report article refers 
to Canada as "our friendly neighbor to the north" (Zuckerman, 2006). A Los Angeles Times editorial describes the Canadian-American relationship in terms of "neighbourly intimacy" (Anonymous, 2001b). However, in these cases, even when the commentators appear predisposed to Canada, an appreciation for the northern neighbour is nonetheless accompanied by an acknowledgement that Canada also harbours a threat to the United States. Thus, the ABC broadcast with Barbara Walters features a reporter calling the US border with Canada "very soft" and suggesting that Canada is a "favoured" entry point for terrorists seeking access to the United States. The otherwise genial reference to Canada found in the US News and World Report article is buried within an assessment of Canada that finds the country both naïve and compromised: "For the first time, we must think about defending against infiltrators from our friendly neighbor to the north, which has only limited knowledge of recent immigrants from Muslim cities." The Los Angeles Times editorial, titled with the clever headline, "Neighborhood Watch," discusses "rumors of terrorists leaking down into the lower 48."

Other news reports put considerably less emphasis on the friendlier connotations of the term neighbour, choosing instead to focus on the simple proximity implied by the word. Not surprisingly, these reports tend to stress the dangers to the United States that flow from living next to Canada. For example, in a 2004 broadcast of Hardball, Chris Matthews asks his expert guest about this precise danger: "You mentioned Canada. Talk about the threat to us there from al Qaeda's presence. What do we know now? It's our neighbour." His guest responds with a claim that Canadian authorities are convinced that their country hosts a large infrastructure for terrorists and is being used as "a backdoor to 
plot attacks against the United States" (MSNBC, 2002a). In an article that questions if Canada has become a "terrorist haven," one of the subsections is entitled: "Canada's Border: A good neighbor with bad fences" (Strobel et al., 2000). The Los Angeles Times calls Canada and the United States "neighbors that rarely even get into a spat." However, it also confirms that Canada is increasingly viewed as "a haven for terrorists" and that the border is "treated so casually that snowboarders have been known to accidentally glide right over it" (Peterson, 2001a).

Even more damning for the image of Canada, however, are those reports that employ the concept of neighbour in a sarcastic manner, implying that Canada is not acting the way one might expect from a 'good' neighbour. These reports typically belittle the emotional component of the term and stress the danger that Canada's proximity poses to the United States. This passage, from the introduction to a Fox News story, provides an example of this pattern:

Now, if you're thinking in this age of terrorism, America's neighbour would never let someone in without checking his background, think again. In Canada, proof of identity is not required to enter the country as a refugee. Since September 11, 26,000 people have become Canadian refugees simply by showing up and asking. (Fox News, 2002c)

The report goes on to paraphrase a former immigration official from Canada as saying, "Canada's open-door immigration policy leaves [Canada] and the US, which share nearly a 4,000 mile-long border, vulnerable to new terrorist attacks." It also features a former national security official from Canada who makes a related claim: "It certainly raises big questions about how effective American defence can be if Canada presents an open sore for international terrorists." Another report from the same network follows a similar 
pattern (Fox News, 2002a). Introductory comments stress the closeness of Canada and the United States before invoking the neighbour metaphor in the threatening context of the War on Terror:

Canada is just next door to the United States...And just like the United States, Canada is a land of immigrants...But what does America's neighbour to the north do to keep terrorists from entering the country? Not nearly enough, says the former chief of strategic planning for the Canadian intelligence service.

The report then goes on to describe the ways in which Canada's immigration system amounts to a threat to US security.

Although the neighbourhood metaphor is commonly deployed to frame the Canada-US relationship, even more ubiquitous in news media coverage is the metaphor of friendship. ${ }^{82}$ Like the neighbour metaphor, the concept of friendship is used to emphasize the closeness of the two countries before ultimately exposing the relationship as dangerous to the United States. For the most part, commentators use the label 'friend' to communicate an emotional link that has joined the two countries over many years. In this sense, the word implies that the countries have transcended the strains and vagaries that typically haunt bilateral relations between states. For instance, a Wall Street Journal article describes the dyad as "two best friends" (Baglole and Valbrun, 2002). An editorial in the same publication explains that Canada "has been a good friend of the U.S. since the middle of the $19^{\text {th }}$ century" (Anonymous, 2005). However, despite the apparently

\footnotetext{
${ }^{82}$ The word 'ally' also appears frequently in the coverage, and is often used interchangeably with 'friend'. However, as this term does not serve to anthropomorphize countries as entities capable of human interaction, and can be employed as a technical term to describe a strategic relationship between international actors, it does not serve as a metaphor. As such, it is less imbued with the emotional trappings that accompany the other words under discussion and, therefore, does not come under scrutiny in this thesis.
} 
enduring and emotional nature of the connection between the two countries, the use of the friend label is typically accompanied by the disclosure that friendship with Canada is not entirely to the benefit of the United States. For example, the above report that calls Canada and the United States "two best friends" is an analysis on Canada-US relations in the context of Canada's immigration policy (Baglole and Valbrun, 2002). It suggests that US officials "say Canada's relatively liberal refugee laws and security checks make it easy for terrorists or smugglers to enter Canada and perhaps wind up in the U.S." It also points to US demands that Canada increase its military spending and improve its coastal patrols. Similarly, the Wall Street Journal editorial, entitled "Canadian Free Riders," laments Canada's decision to forgo participation in the US missile defence plan (Anonymous, 2005). The implication in both of these pieces is that, despite their friendship together, Canada is simply unwilling to assist the United States in defending North America.

Canada's friendship is found to be of mixed value in a variety of other sources as well. One example is found in a Dateline NBC broadcast entitled, "A Tale of Terror," which explores Ahmed Ressam's plot to bomb the Los Angeles airport:

In many ways, the plan would be a blueprint for the terrorist war on America in the $21^{\text {st }}$ century by hitting a high-profile target at the very heart of the US economy. What's more, Ressam would do it from a base unwittingly provided by the United States' closest friend and neighbour: Canada. (NBC, 2001b)

The comments of prominent US diplomat Richard Holbrooke, in a cable news interview broadcast several days after $9 / 11$, employ the same logic:

It is time for us to start talking to our Canadian friends - and they are our closest friends in the world, geographically and otherwise...we cannot go 
on with a system in which the cargoes that come into the United States are loosely checked in Canada and could be carrying something even more serious than the horrible thing that struck the World Trade towers and the Pentagon last week. (Fox News, 2001b)

In other cases, however, the friend label is used sarcastically (as is the neighbour metaphor explored above) to emphasize a sense of betrayal. A broadcast of CNN's Crossfire provides an example of this pattern:

The FBI is asking the public to be on the lookout for the latest invasion force allowed in by our neighbour and sometimes ally to the north, that would be Canada. Sometime around Christmas Eve, while our friends in Canada were feeding their dog sled teams or repairing their igloos or maybe it's drink beer, five suspected terrorists snuck across the border into the United States...As a civilized nation, what Canada purports to be, you would think they have some interest in keeping terrorists from moving about freely within their borders and they don't. (CNN, 2002d)

As Allan suggests, this sense of betrayal is not an unusual response from US media sources in the wake of significant policy disagreements between the two countries (2009:

xii). Pat Buchanan unleashes similar betrayal-tinged invective on the MSNBC programme Buchanan and Press (2002d) in response to indelicate comments from Canadian officials during the run-up to the US invasion of Iraq. He begins by adopting a personal perspective from which he frames the Canada-US relationship in terms of friendship:

I was one of those who was raised in grammar school to talk and be taught about the longest undefended border in the world, our relationship with Canada, our old friend. We fought with Canada on their side. We came in a little late in two world wars, and we led the world into victory in the Cold War with Canada at our side.

He then proceeds by explaining to his audience how, in the era of terrorism, the United States both defends Canada militarily and supports Canada economically, while 
Canadians respond with nothing short of disdain for the United States. He closes by switching to a family metaphor from Shakespeare's King Lear, in which Canada is condescendingly portrayed as an ungrateful child: "How sharper than a serpent's tooth it is to have a thankless child. ${ }^{, 83}$

The family metaphor, used by Pat Buchanan in the above example, makes a number of other appearances in the US news media's coverage of Canada and the War on Terror. The use of this metaphor serves to anthropomorphize the two countries, representing Canada as a sibling or child of the United States. The choice of a familial metaphor, freighted as it is with readily accessible impressions of emotional attachment, belonging and loyalty, is one of the most powerful rhetorical devices for framing the Canada-US relationship as liminal. One of the most prominent uses of the metaphor, reported by most news sources, occurred two weeks after $9 / 11$. In response to complaints that he neglected to thank Canada for its response to the terrorist attacks, President Bush defended himself by saying, "I didn't necessarily think it was important to praise a brother; after all, we're talking about family" (Chen and Reynolds, 2001). ${ }^{84}$ These kinds of references, particularly when they originate from a prominent source like the president, leave the impression that the two countries are linked by enduring emotional ties that transcend a more practical partnership born of proximity and economics. They also set the stage for later representations of betrayal, and a heightened sense of insecurity, when

\footnotetext{
${ }^{83}$ This is actually the second time in the programme that Buchanan uses the metaphor of a parent-child relationship. Earlier in the show, he claims, "We're dealing, in these Canadians, with the spoiled brats of the new world order and they deserve to be told things directly."

${ }^{84}$ Bush's comments that day were laden with liminal imagery. Other phrases included: "it was like getting a call from a brother," "we got a great partner in our neighbourhood" and "we combine together to fight" $(\mathrm{CNN}, 2001 \mathrm{c})$.
} 
the "brother" is subsequently revealed to be careless, indifferent or unsupportive in the face of an implacable enemy. For instance, the Los Angeles Times article that referenced the above statement by Bush also cited US concerns that "the porous U.S.-Canada border, along with Canada's more lax immigration policies, could facilitate terrorists' entry into the United States." In a similar vein, a Washington Post article that also covered Bush's use of the family metaphor details severe shortcomings in Canada's military capabilities and questions both the country's ability to defend itself and its capacity to contribute to the emerging War on Terror in a meaningful way (Brown, 2001).

In a segment of The Big Story with John Gibson the host discusses how Americans think of Canadians as "their brothers and sisters to the north" (Fox News, 2002i). However, the segment is mostly dedicated to exposing the Canadian government's response to $9 / 11$ as insufficient. For instance, he introduces the segment by referring to a magazine's tongue-in-cheek story about Canada: "The National Review argues that we need to threaten a full-scale invasion, or at least slap them around a bit, so they'll get serious about fighting terror." He then asks his guest, a Canadian journalist, an obviously leading question: "Is Canada a laggard in this war on terror?" The journalist obliges the host by disparaging Canada's military capacity and its lacklustre response to 9/11: "We have no security in this country. We really have no security on our border...Security is a myth in this country." In another example of this trend, a Washington Post reporter interviews a woman who laments the need for increased security measures on the border with Canada by invoking the family metaphor: "At one time, Canadians and Americans were, just like the Peace Arch says, 'children of a 
common mother.' We're no longer that. There used to be a special community living along the border, but that community is gone" (Pomfret, 2006b).

In a story devoted largely to the questionable security of the Canadian border, the host of ABC's Nightline uses an imaginative version of the family metaphor (ABC, 2002). In suggesting that the Canadian border should no longer be overshadowed by the Mexican border when it comes to security issues, he effectively renders Canada a child to the United States: "The Canadian border is a bit like a neglected sibling whose misbehaving brother [the Mexican border] gets all the family's attention." In addition to linking Canada to the United States through the use of this condescending and paternalistic metaphor, the report also confirms Canada to be a security threat. For instance, during the introduction to the story, which features a US Customs official proclaiming, "our number one focus is on stopping terrorists from entering the United States and looking for weapons of mass destruction," the host effectively labels the Canadian border "America's Achilles' heel." The rest of the segment goes on to detail a series of ways in which the border's security protocols can be circumvented.

The news media's use of anthropomorphisms to structure its representations of the Canada-US relationship injects an emotional component into the coverage. In the context of the insecurity engendered by the War on Terror, this emotion can be realized through either a greater degree of attachment and closeness or a sense of abandonment or betrayal. When these metaphors of friendship and family are deployed as part of a wider discussion on the presence of terrorists in Canada and, frequently, the ease with which 
they are able to cross into the United States, it typically conveys an increased level of threat and imminent danger.

\section{Diminished Foreignness}

Beyond declarations of cultural similarity and metaphors of emotional linkage, the coverage frequently goes so far as to represent Canada as being part of the United States. Subtle examples of this trend describe Canada in terms that represent the country as a location that is not entirely foreign to Americans. In these reports, although Canada is, at some level, acknowledged to be a different country, its foreignness is explicitly diminished. More extreme examples describe Canada as effectively part of the United States, its foreignness not simply diminished, but actually denied. By minimizing or denying Canada's foreignness, these representations render the linkages between the two countries seamless. In the context of terrorist hostility, this seamlessness encourages an understanding of Canada as part of the American self and enables the scripting of the country as an immediate source of a potentially catastrophic threat against the United States.

An example of the diminution of Canada's foreignness is apparent in a $2002 \mathrm{New}$ York Times article that explores the security situation on the Canada-US border (Simon, 2002). The report begins by suggesting that the Canadian city of Windsor is "very close to the United States without being part of it." It goes on to claim that a trip to Windsor "offers Americans the mild thrill of going to a foreign country where signs are in French as well as English." A USA Today article cites a "symbiotic" relationship between 
Canadian and American border towns, claiming "American and Canadian lives are intertwined through commerce, marriage, jobs and plain proximity" (Leinwand and Anwar, 2000). The article also quotes a Canadian who asserts, "You may cross [the border] twice a day sometimes. When you're a local, it's different. We're almost Americans."

A similar effect is created in another article from the New York Times, although in this example, the effort to minimize Canada's status as a foreign country is immediately followed up with a strong statement of the risks associated with Canada's liminal nature:

The United States-Canada border was always sort of the class trip of foreign travel - novel, but non-threatening. But the post-Sept. 11 hunt for holes in the security net identified it as a prime place from which terrorists could slip into the United States, helped by Canada's relatively lax immigration laws. (Purdy, 2002)

An even more explicit example of this pattern occurs in a Time article released a month after 9/11:

Before September $11^{\text {th }}$, the 5,525 -mile stretch that separates the northern United States from Canada wasn't considered much of a border - it was seen more as a formality designed to enhance the 'international' experience of US tourists. After the attacks, however, the border took on new meaning and new political weight. The events of September $11^{\text {th }}$ forced many Canadians to focus an untrained eye on their own very liberal immigration policies, which some argue serve as an open invitation to terrorists intent on making their way south into the U.S. (Reaves, 2001)

Although these articles show how the diminution of Canada's foreignness helps to enable the representation of Canada as a threat, a more prominent trend goes even further by suggesting that Canada might as well be part of the United States. For example, the cover story from a 2003 issue of Newsweek devotes considerable attention to Canada's apparent infiltration by terrorists, although the title of the article is "Al Qaeda in America: The 
Enemy Within" (Thomas, 2003). The implication of both the title and the article itself is that Canada is considered "in America" for the purposes of fighting terrorists. An editorial in the Los Angeles Times draws a similar conclusion (Lowenthal, 2003). It claims that as Americans deliberate the concept of homeland security, they should consider Canada part of their homeland: "Homeland - as a source of both identity and loyalty, and as a defensible perimeter against terrorism - should encompass all North America, not just the United States...for millions of Americans, homeland means Mexico and Canada because of origin and ties."

A USA Today article from 2002 quotes a man whose wife thinks of Canada as part of the United States: "My wife didn't feel comfortable traveling post-9/11 out of the country, but she doesn't consider Canada out of the country" (Clark, 2002). Another USA Today article, this one focusing on increased border security in an era of terrorism, begins with a similar contention: "When you live in Buffalo, going to Canada doesn't seem like foreign travel. It's more like crossing state lines" (El Nasser, 2005). It goes on to quote a man who suggests that crossing the border "was just like going from one county to another, except for a casual inspection.” Two weeks after 9/11, the host of The Big Story with John Gibson draws a distinction between Canada and Mexico, suggesting that the border with Canada is "much like the border between two states in the United States" (Fox News, 2001d). Such a claim is likely to induce concern among the show's viewers, especially considering the programme devotes considerable attention to exposing Canada's culpability in allowing terrorists access to the United States in what Gibson calls an "internal war." 
One of the most powerful representational patterns that script Canada as a threat to the United States is that which depends upon an understanding of Canada and the United States as sharing a common identity. Whether they come in the form of images of cultural similitude, metaphors of friendship and familial belonging or expressions of national affiliation, these representations contribute to the wider impression that Canada and the United States are intrinsically linked in a shared sense of belonging. Although the liminality conveyed by this representational pattern can act as a reassuring force in terms of confirming national identity, it can also convey a sense of threat. During the War on Terror, the media made considerable use of this particular expression of liminality in order to more effectively portray Canada as a dangerous space that poses a threat to the United States. Drawing on the threat implied by the presence of terrorists in Canada, the news media used the liminal representations of shared identity to transform this threat and instantiate it within the wider definition of the US homeland. As was the case with the other patterns discussed above, this magnification of threat contributed to the "discourse of danger" operating to strengthen American identity claims.

\section{Conclusion}

The US news media, among a variety of other social actors and institutions, is constantly engaged in the process of defining and maintaining American identity. During the War on Terror, when Americans were confronted by representations of an implacable enemy that threatened their country's security, news coverage worked to increasingly 
script the American self in opposition to that terrorist Other. By virtue of its independent existence, among a variety of other factors, Canada became one of the arenas in which this redefinition of American identity unfolded. The news media's coverage of Canada during the War on Terror was marked by a series of consistent othering patterns. In effect, by portraying Canada as a place with characteristics that enable terrorists to operate within its borders, the news media scripted a version of the American self that opposes and repudiates those objectionable characteristics.

However, in terms of the dynamics of identity, the news media did not stop at using Canada as a foil for American identity. It also drew upon the widespread understanding of Canada as liminal in order to accentuate the fear of the terrorist Other. By manipulating the impression that Canada shares American space, both physically and culturally, the news media effectively enabled the threat of terror to seep from Canada into the United States. In this sense, it used Canada as a more concrete and imminent proxy for the otherwise distant and abstract terrorist Other. This imminence provided a sense of immediacy to the threat of terrorism and prompted a more urgent and rigid scripting of American identity.

This process, by which a liminal scripting of Canada enabled a heightened appreciation for the threat of terrorism, proceeded in a number of forms. The above discussion detailed four of these forms. First, it examined how the notion of colocation, or the sense that Canada and the United States occupy a shared physical space, made it possible for audiences to imagine that terrorists who were in Canada were effectively already in the United States. Second, it explored how depictions of Canada's proximity to 
the United States and the redefinition of 'the world's longest undefended border' were used to suggest that Canada makes the United States vulnerable. Third, it detailed a number of ways in which the news media redefined the Canada-US border in such a way that it was stripped of its trappings of power and authority, and reduced to an empty noman's land; in effect, instead of a site that regulates travel, the border became an open space that facilitates transit. Fourth, the discussion examined how the news media deployed notions of shared belonging and identity in order to create the impression that the terrorist threat had already permeated the United States.

In the wake of the US response to $9 / 11$, Clarkson references the role of "panicky media" in helping to generate an "image of mortal threat from the north" (2003: 76). I argue that Canada's role as a "mortal threat" was primed by the widespread notion that the country had become a haven for terrorists and actualized by representations that intertwined Canada with the United States. By instantiating the threat of terror for Americans, a liminal version of Canada enhanced the insecurity that prompts people to seek comfort and reassurance in others like themselves. In this sense, not only did Canada's otherness provide assistance in scripting the content of American identity, its liminality provided a sense of urgency that contributed to the intensity with which that scripted identity was reinforced. 


\section{Chapter 7 Conclusion}

\section{Introduction}

In this dissertation, I examine the concept of liminality in the context of international relations, and explore the implications that US representations of Canadian liminality have for American identity. This chapter retraces the arguments made in the dissertation and the evidence upon which they are based. It also explores some of the implications that emerge from my research and how this work can be situated in the field of IR. This chapter first provides a brief summary of the main contours of my argument. It then explores the contribution I make to the literature in terms of advancing a more nuanced appreciation of liminality. Specifically, it expands on the idea that Canada acts as a spatial liminar. This extension of Norton's concept provides a new formulation that enables an understanding of how representations of shared geography can contribute to insecurity. The chapter then briefly articulates some of the specific ways in which Canada contributes to American identity. Next, I examine the contributions made by my research in terms of the discipline of IR. More specifically, I touch upon how my work augments the literature that studies both identity formation in IR theory and the theoretical understanding of Canadian-American relations. The chapter then explores some of the implications that emerge from this research for the practice of Canadian-American relations. The chapter concludes with a brief examination of four potential areas of future research that emerge from this dissertation. First, it considers the presence and 
implications of a trend within conservative news coverage to script Canada with sensationalist and inflammatory imagery and rhetoric. Second, it examines the complicity of Canadian actors in the scripting of Canada's liminal relationship with the United States. Third, it touches on the need to expand this study and explore notions of liminality from a comparative perspective that considers Mexico as well as Canada. Finally, it concludes with an initial formulation of the 'Ressam narrative' as an avenue to further explore a prominent discursive technique that US news sources used to frame Canada in the context of terrorism.

\section{Summary of the Argument}

This dissertation explores the process by which Canada becomes understood as a threat to the United States. I argue that depictions of Canadian threat are enabled as part of a broad social process that works to define American identity. To explain this process, I begin by arguing that American impressions of Canada are structured by an understanding of liminality. In effect, the American geopolitical culture figures Canada as a partner to the United States, placing it in an ambiguous position of simultaneous belonging and exclusion. This liminal position means that Canada acts as a mirror to the American self, reflecting images of both similarity and difference. During times of crisis, when American identity is being scripted in opposition to a threatening Other, I argue that Canada's difference becomes a source of anxiety. Shading increasingly into otherness, markers of difference are deployed by social actors to explain the presence 
within Canada of an element or aspect of the threat facing the United States. In short, Canadian difference is exploited in order to script the country as Other and label it as a potentially dangerous place. In an even more crucial move, however, these depictions of otherness are often intertwined with representations of liminality. In such a situation, when the presence of threat in Canada is teamed with an understanding of Canada as a virtual appendage of the United States, the result is a more immediate manifestation of threat. In other words, if Americans understand Canada to be an extension of the United States, then the presence of threat in Canada is tantamount to threats being in the United States as well. In effect, Canada acts as a local proxy of the threat facing the United States, serving to instantiate an otherwise more distant and abstract danger.

In tracing this argument, I turn to popular culture for evidence of these representational patterns. In so doing, I eschew the more common approach of analyzing the political statements and policy discourses that emerge from the corridors of formal power. This approach appreciates the importance of the broader social milieu in which all representations of threat, including those that emanate from sites of official power, must operate. To the extent that even official designations of threat are effective, they must also be able to resonate and find expression within the context of so-called 'low brow' and popular forms of expression. In the first case study, I explore how Canada is represented in Hollywood films from the Classical era of cinema. More specifically, I examine how films consistently represent Canada in terms of both alterity and liminality. I also expose how the intertwining of these representational patterns acts to script Canada as a dangerous and potentially threatening place. In the second case study, I explore 
representations of Canada as they appeared in the US news media during the War on Terror. As with the first case, I trace how patterned depictions of otherness script Canada as a place where terrorists are able to find refuge. I also demonstrate how depictions of Canadian liminality are combined and intertwined with this othered version of Canada in order to render the country a threat to US security.

I do not claim that this process unfolds as part of an intentional scheme masterminded by unscrupulous individuals. Rather, I contend that representations of all kind are produced and circulate throughout society as part of the processes that work to define identity. In this case, depictions of Canadian otherness are deployed as a small component of the broader effort to reinforce prevailing notions of American identity. Similarly, depictions of Canadian liminality that enable an understanding of Canada as a threat can be understood as part of the wider process whereby the limits and borders of American identity are secured by the ongoing specifications of threat that constitute the 'discourse of danger.'

\section{The Liminality of Canadian Space}

Norton understands liminality in terms of societal subgroups (1988: 53-94). The ambiguous sense of belonging that links these groups to the wider national identity that surrounds them means that they can become a source of insecurity for that identity. More specifically, the stubborn difference represented by such groups means that they can be 
easily scripted with a dangerous association with the self's threatening Other. Because liminars also embody the self, and their very existence is within the bounds of the nation, they imply that the threat of the Other is effectively interior to the self. Norton cites the Cold War 'Red Scares' and the push to intern Japanese Americans in the Second World War as examples of this process (1988: 55).

This dissertation builds on Norton's concept of liminality by expanding its scope from an analysis of societal subgroups within the national self to an examination of distinct states on the margin of the national self. By looking at Canada's role as an American liminar, I have added an extra layer to our understanding of the functioning of liminality. Exploring the potential for an adjacent state to play the role of liminar, instead of just considering social groups within a state, allows my dissertation to add a spatial dimension to the definition of liminality. In essence, this dissertation attempts to extend Norton's ideas by providing a reformulation wherein space itself, as opposed to the people that occupy that space, can be scripted as liminal.

Canada's capacity to act as a liminar comes only partially from the country's status as a social group akin to Norton's territorial, intellectual and structural liminars. Instead, much of Canada's liminality, and the potential for threat that comes with it, is a consequence of being defined in terms of spatial ambiguity. ${ }^{85}$ In other words, it is not just Canadians and Canadian culture that are understood to be in a position of ambiguous

\footnotetext{
${ }^{85}$ Although Norton's use of the label 'territorial liminar' clearly implies a spatial component to her thinking, it is the people who occupy that territory, not the territory itself, that play a role in shaping the self's identity. In other words, although cowboys, Bedouin and other groups certainly inhabit the border, it is those groups that play a constitutive role with respect to the nation's identity, not the territory they occupy.
} 
belonging to America; so too is Canadian territory. As chapters 4 and 6 demonstrate, the border that ostensibly marks the division between Canada and the United States is regularly re-figured as mutual space, a region where the countries' territories bleed into one another. Moreover, considering the pivotal and constitutive role that the concept of the frontier plays in terms of American identity, the consistency with which US popular media represents Canada in those same terms serves to further enhance the ambiguity that attends the reach of American jurisdiction. In effect, the scripting of Canada as frontier renders the country's border areas a broad palimpsest upon which Canadian history and identity are overwritten by American narratives of national regeneration and Manifest Destiny.

This understanding of Canadian territory as ambiguously connected to the United States is further reinforced by periodic calls for the United States to annex Canada. Whether serious or tongue-in-cheek, these calls are informed by a strain of thought that suggests the United States has a natural and inevitable claim on Canadian territory. Indeed, far from being an episodic expression of merely frivolous punditry, Stewart suggests that this idea has long infused US perceptions of Canada:

the evidence is overwhelming that an incipient imperialist ideology with respect to Canada has existed in the United States since the end of the War of 1812. Its core belief is best summarized in a phrase used by John Quincy Adams in a letter to Richard Rush back in 1818. Adams wrote of 'our natural dominion in North America.' This view, that the United States had the right to dominate the continent, informed the entire range of American thinking. (1992: 196-197)

This precise view was espoused in 1869 , shortly after Canadian Confederation, by the managing editor of the Chicago Tribune: "By the doctrine of nationalities and natural 
frontiers, that country should be ours, and some day will be" (quoted in Allan, 2009: 9). Forty years later, while Canada and the United States were in the process of negotiating a reciprocity agreement, a representative from Missouri expressed similar sentiments from the floor of the House of Representatives: "I look forward to the time when the American flag will fly over every square foot of British North America, up to the north pole. The people of Canada are of our blood and our language" (quoted in Allan, 2009: 17-18). A more recent manifestation of these views comes from a 1992 column written by former presidential candidate Pat Buchanan: "There is nothing wrong with Americans dreaming of a nation which, by the year 2000, encompasses the maritime and western provinces of Canada, the Northwest Territories all the way to the North Pole" (quoted in Goar, 1996).

Canada's status as a spatial or geographical liminar has important implications for US security. Whereas Norton's liminal actors come to represent threat in their capacity as subcultures living within the nation, the threat that emerges from depictions of Canada's liminality is one attached to Canada's geography. In other words, it is Canada's actual physical space that becomes a source of threat for Americans. Having been othered as the kind of place where foreign and dangerous individuals or groups are able to find refuge, Canada's liminal overlapping with US territory serves to imbue this threat with an exaggerated sense of immediacy. Indeed, because of Canada spatial liminality, this threat is often figured as interior rather than merely proximate.

As Buzan et al. claim, "because most political and military threats travel more easily over short distances than over long ones, insecurity is often associated with proximity" (1998: 11). In the case of the United States, however, there is an accentuated 
emphasis on the importance of proximity. Long insulated from most threats by either vast oceans or quiescent and largely inoffensive neighbours, the American geopolitical culture has fixated on the dangers associated with proximity. For instance, as Weldes points out, much of the fear induced by the so-called Cuban Missile Crisis was rooted in spatial factors. Although some of this was related to the perceived incursion into the US protectorate of the western hemisphere by the Soviet Other $(1999 \mathrm{~b}: 38,43)$, much of the incident's salience as a crisis obtained as a consequence of representations that emphasized Cuba's proximity to the United States: "Cuba is primarily represented as a physical space, one that is a too-close-for-comfort ninety miles from the United States" (Weldes, 1999a: 39). Gaddis implies a similar form of spatial reasoning in his examination of a nineteenth century trend in which US policymakers launched preemptive attacks or acts of expansion against proximate territories (2004: 16-22). In effect, Gaddis suggests that the United States was compelled to establish control over a variety of Central American countries, as well as the territories that would ultimately become the states of Florida, Texas and California, out of a fear that weakness or a power vacuum in those areas might enable foreign threats to establish a presence on the margins of US power. ${ }^{86}$ He quotes Theodore Roosevelt to this effect:

Chronic wrongdoing, or an impotence which results in a general loosening of the ties of civilized society, may...ultimately require intervention by some civilized nation, and in the Western Hemisphere... may force the

\footnotetext{
${ }^{86}$ It should be noted that this theme concerning the need to domesticate space is not based simply on proximity. As Dalby suggests, the tendency to understand the natural world as distinct from the human world has prompted an understanding of natural space as a threat, something that needs to be conquered (2009: 54; see also Patterson and Dalby, 2006). In this sense, proximate space that is deemed uncontrolled invites imperial intervention at multiple levels. The closely related fear of environmental danger has become a structuring trope for justifying the expansion of empire around the globe.
} 
United States, however reluctantly...to the exercise of an international police power. (quoted in Gaddis, 2004: 21)

The US fixation on the dangers implied by proximity has been particularly intense when it comes to Canada. Well before the United States had achieved its independence from Britain, the Catholic presence in Canada represented an imminent threat to the largely Protestant US colonies (Kaufman, 1999: 441). ${ }^{87}$ This threat was inflamed considerably with the passage of the Quebec Act in 1774, which Alexander Hamilton equated with "the permanent support of Popery" (quoted in Kaufmann, 1999). Moreover, as Clarkson and Fitzgerald note, Canada's continued connection to Britain ensured that the insecurity prompted by the country's immediate proximity to the United States did not diminish in subsequent decades:

For over a century after 1776 , the United States viewed Canada as an extension of the largely hostile British Empire and, thus, a constant threat. At first, many Americans thought that to ensure their security they needed to annex the dominion of their traditional enemy and unsuccessfully launched three invasions - 1775, 1777, and 1812 - to achieve this objective. (2009: 2; see also Stewart, 1992: 23-59)

As this quotation implies, even though the final resolution of the War of 1812 precipitated a marked decline in Canada's capacity to pose an overt and existential threat to the United States, it "did little to alter the basic American suspicion of Canada" (Stewart, 1992: 35). This suspicion was evident during the US Civil War, when British connivance enabled Confederate raids to be launched from Canada. Granatstein and Hillmer quote Senator Zachary Chandler in this context, who warned at the time that if Canada was allowed to prosper, it would become "a standing menace" (1991: 5).

\footnotetext{
${ }^{87}$ See Haglund (2010: 196-197) for a brief discussion on a related and more recent example of this.
} 
Similarly, when combined with its subordinate status within the British Empire, Canada's presence on the northern border of the United States also threatened US efforts to establish "a continental empire that stretched from ocean to ocean (Crapol, 1973: 10). The westward expansion of the Canadian Pacific Railway was seen to be particularly threatening to US interests, both in terms of the development of the US west and its implications for trade with the Pacific region (Stewart, 1992: 74-78; Granatstein and Hillmer, 1991: 22; Crapol, 1973: 136).

Although formal bilateral relations between Canada and the United States improved dramatically as the "unguarded frontier myth" (Stewart, 1992: 182) increasingly took hold in the twentieth century, American policymakers still understood Canada's proximity as a source of insecurity. More specifically, during the lead-up to the Second World War, Franklin Roosevelt foresaw the potential for US insecurity in the event of a German invasion of Canada. Therefore, in 1938, when he promised Canadians that the United States would protect their country from the encroachments of other countries, the implicit message was that US security interests dictated that the United States would secure Canadian territory regardless of the wishes of Canadians themselves. ${ }^{88}$ Understanding this implication, Prime Minister Mackenzie King asserted that Canada would take whatever steps necessary to ensure that no other power would use the country as a conduit to attack the United States. Understood together, the comments

\footnotetext{
${ }^{88}$ Roosevelt's statement was, in many ways, a northern re-articulation of the Monroe Doctrine (itself a classic example of the spatial formulations that typify geopolitical thinking).
} 
made by Roosevelt and King have been termed the Kingston Dispensation (Fortmann and Haglund, 2002).

King's response to Roosevelt's veiled warning was an important attempt to influence US geopolitical logic. His assurance that Canada would not allow other powers to strike at the United States through Canadian territory can be understood as an attempt to refigure the implications of Canadian proximity. It was an attempt to redefine Canada's presence on the US northern border from a source of insecurity to a bulwark that could reassure and lend support to the United States. In this sense, it was an attempt to put secure space between the United States and its potential enemies. As the Cold War developed, the redefinition of Canadian liminality was pushed even further. For example, with the two countries having joined together under the bilateral framework of NORAD in 1957 , their combined territories were "considered a single territory to be defended against bomber attack, with the forces of each country combined into a single command" (Nossal et al., 2011: 28). Within this framework, the sameness reflected by Canada's spatial liminality came to provide security for the United States. Proximity was increasingly being redefined in a positive and reassuring manner. This redefinition is perhaps best exemplified by Canada's emerging role as a Cold War glacis for US security (Clarkson and Fitzgerald, 2009: 9-10; Nossal et al., 2011: 27-29). Its position on the US northern border meant that the country provided extra geographic space that Soviet bombers or missiles would have to first traverse before reaching the United States. In this sense, the country represented extra time for the United States to respond to incoming Soviet threats. Indeed, as the location over which incoming bombers or missiles would 
most likely be intercepted, Canada had willingly put itself at risk in order to assuage US security concerns (Clarkson and Fitzgerald, 2009: 9). From this perspective, Canadian space was now understood as a source of additional security.

This emerging fixation on distance qua security was part of a broad conceptual framework that structured US geopolitical logic during the Cold War. As Dalby phrases it, this was a period during which "the relations of space and power came to be understood in terms of distance providing security" (1990: 38). The United States enacted a forward defence strategy that aligned it with various partners in Europe and Central Asia and across the Pacific region. Collective defence agreements, a network of forward military bases, foreign troop deployments and tripwire strategies combined in a massive effort to contain the expansion of communism. The spatial logic infusing this strategy of containment (Chilton, 1996) was part of a protracted effort to force distance between the United States and its adversaries. In the North American context, Canada's efforts in NORAD and the other bilateral institutions that came to define the continental security architecture were an attempt to refigure the country's liminal space as the embodiment of that secure distance that US policymakers were trying to interpose between their country and their enemies.

For some, the conclusion of the Cold War initially signalled a potential change in this understanding of security (Dalby, 2002). The end of the bipolar world apparently promised a neoliberal future where borders and territorial identities would no longer constrain financial flows and global economic growth (Ó Tuathail, 1999). According to this emerging vision of the future, traditional understandings of territorial threats would 
no longer dominate the attention of policymakers (Dalby, 2002: 8; Ó Tuathail, 1998) ${ }^{89}$ In the case of Canadian-American relations, however, as with a host of other security dynamics the world over, the terrorist attacks of $9 / 11$ served to reassert the primacy of territory with sudden celerity and persuasive force. Instead of a trend based on "territory losing its significance and power in everyday life" (Ó Tuathail, 1999: 139), policymakers were abruptly reminded of the immediacy of geography.

The attacks changed the North American security calculus for US policymakers. Even though none of the terrorists had entered the United States across its northern border, Canada's position changed in both media representations and in the minds of US security planners. The security implications of Canada's proximity to the United States were transformed; no longer could the country offer up its own space as a glacis to safeguard US security. Indeed, as a 2004 Fraser Institute report suggests, Canada could "no longer trade geography for American security because the value of geography has been drastically reduced" (quoted in Sokolsky, (2004/05: 44). In other words, the terrorist attacks of $9 / 11$ not only served to reassert the primacy of space in the face of neoliberal promises of globalization, they did so in such a way that they also repudiated the value that the Cold War era had placed on Canadian geography. Now, instead of providing the United States with a reassuring measure of distance from its enemies, Canada's proximity had become a source of threat.

\footnotetext{
${ }^{89}$ To be clear, a host of Realist IR scholars, left unconvinced by the increasing ferment within the field of Security Studies, held firm to the primacy of territory in their geopolitical formulations. See, for example, Layne (1997) and Huntington (1996).
} 
Clarkson and Fitzgerald emphasize the Manichean role that Canada's spatial liminality plays with respect to US security. "By virtue of its geographical contiguity," they suggest, "Canada serves either as a conduit of possible attack to the United States or as a buffer against external threats" (2009: 3). On September 11, Canada's role shifted from the latter to the former. In the weeks and months that followed the attacks, media reports feminized Canada's counterterrorism efforts and scripted the country's immigration policies as dangerously liberal. Indeed, Americans were reminded that these and other failings had transformed their genial and northern neighbour into a terrorist haven. In the context of the terrorist attacks, such depictions helped to transform the implications of Canada's spatial liminality. The otherwise reassuring understanding of Canada as an extension of America was replaced with a vision of danger. The presence of terrorists on Canadian soil made the sense of shared geography an existential threat to US security.

After $9 / 11$, US security discourse and strategy made a determined attempt to reestablish a sense of security by once again embracing distance. In this sense, reterritorializing the enemy, first in Afghanistan and then in Iraq, can be understood as part of an attempt to reprioritize space in an era when the forces of globalization had purportedly eroded its tradition meaning. The crucial importance of putting geography between the United States and its terrorist enemy became a constant theme in speeches presented by the Bush administration:

We are waging a global campaign from the mountains of Central Asia to the deserts of the Middle East, from the Horn of Africa to the Philippines...We are fighting these terrorists with our military in 
Afghanistan and Iraq and beyond so we do not have to face them in the streets of our own cities. (Bush, 2004)

Although Canada was certainly complicit in this US attempt to re-territorialize the terrorist threat in Afghanistan, the country has been unable to counteract the impression that its own territory serves to re-territorialize that same threat in North America. Indeed, even though Canada was quick to enact a wide range of cooperative security measures after 9/11 (Sokolsky, 2004/05: 47-51) ${ }^{90}$, the persistence with which US public figures continued to reinforce the myth of a Canadian connection on 9/11 suggests that such measures have failed to reassure their intended audience in the United States. In this sense then, despite Canadian efforts to improve border security, and thereby redefine Canada's spatial liminality in such a way as to reassure Americans, the sense of shared geography continues to function as a potential conduit for terrorists to strike at the United States. As Campbell suggests, the counterintuitive dynamic of this specification of threat means that the creation of insecurity among Americans actually serves to reinforce and perpetuate the state's identity (1998: 13). ${ }^{91}$

\section{American Identity}

\footnotetext{
${ }^{90}$ As Sokolsky notes, it is "evident that in the war on terrorism, Ottawa is actually placing more relative emphasis and associated spending upon homeland security and defence than the United States where overseas military services consume the lion's share of security spending" (2004/05: 51).

${ }^{91}$ To be clear, Campbell does not make this claim with respect to Canada specifically. Rather, as this dissertation has argued, this is the point he makes about representations of dangers more generally: "the constant articulation of danger though foreign policy is thus not a threat to a state's identity or existence: it is its condition of possibility" (1998: 13).
} 
This dissertation contends that Canada plays a constitutive role in the construction of American identity. In this sense, it stands in the face of a vast scholarship on Canadian-American relations that assumes most important dynamics linking the countries flow the other direction. In making the claim that Canada 'matters' to the United States, I am mindful of important limiting factors. Thus, although my observations have important implications, they remain modest.

Canada serves a dual role in terms of American identity. In times of crisis or threat, Canada's status as liminar to the United States finds the country scripted with traces of the American Other. In this sense, the country plays the part of a local instantiation of the distant threat - a domestic proxy for the enemy Other. As a consequence of Canada's virtual interiority, the immediacy of this threat can be considerable. In such circumstances, Canada becomes an unwitting accomplice in Campbell's discourse of danger. It provides a tangible instance of danger that licenses social actors in the United States to script American identity in increasingly rigid terms. In this sense, therefore, the threat resident within Canada helps to strengthen and rigidify the boundaries of what it means to be American.

Canada's second role concerns the specific contours of American identity. The American imaginary does not conceive of Canada in terms that are fundamentally different from America. It is important to stress, therefore, as I have at several points throughout this dissertation, that Canada does not serve as a kind of essential Other against which core elements of American identity are defined. In this sense, Canada does not serve in a capacity similar to the Other represented by the Cold War Soviet Union or 
revolutionary era Great Britain. Indeed, as the above section indicates, Canada's role is more modest. Because the country's liminal status enables Americans to locate traces of the Other in Canada, the country serves as a mere junior partner to the Other, a sort of 'ontological accomplice' that simply aids in the scripting of American identity.

One of the arguments that I try to advance in this dissertation is that Canada serves as a variable signifier for American identity. The country takes on whatever characteristics the American self needs in order to make itself secure against its Other. Thus, in the face of the British monarchy, Canada's status as a subordinate colony reinforces an independent and republican America. In the face of the communist threat, Canadian socialism helps to buttress American capitalism. In the face of the threat of terror, a liberal and multicultural Canada presses the need for a conservative and homogeneous America.

As the above statements clearly imply, it may be ill-advised to make sweeping and generalized statements about Canada's role in constructing specific elements of American identity. After all, Canada's role is historically contingent, almost entirely dependent on the nature of the Other being scripted by the American discourse of danger. As a consequence, I am loath to generalize about Canada's contribution in terms of specific aspects of American identity. There are trends, however, that are evident in both of the case studies explored in my research.

For example, dominant representational patterns emerge from both Hollywood films and US news coverage that overwhelmingly script Canada in terms of gender. The 
feminization of Canada as weak and passive is ubiquitous within the discourse. ${ }^{92}$ In addition to providing an implicit invitation for US intervention in Canada, such depictions help to reinforce notions of American masculinity. Although the specific ways in which masculinity is represented and understood may be historically contingent, there is little doubt that Canada provides a foil against which aggressive and militarized agency is licensed.

Notions of American mastery are also supported by a number of related themes of Canadian otherness. For example, filmic representations of Canada are saturated with themes of empty space and wilderness. Such themes are further supported by news representations that depict Canada, particularly its border region, as a vast and rugged area, nigh on impossible to secure. Such depictions have clear implications in terms of the scripting of a modern and urbanized America, itself premised on a prior conquering of the natural space around it. Moreover, like the representations of gender discussed above, they also invite a more capable US presence to render the geography more docile. Similarly, US news coverage of Canada during the War on Terror was structured by impressions of liberalism. In the face of the threat purportedly posed by a foreign Islamic fundamentalism, such depictions aided in the scripting of an America made safe by strong borders, conservative values, unquestioning and united support for the president and an aggressive, militarist response to threat.

\footnotetext{
${ }^{92}$ It should be noted that the research material for this dissertation shows Canada being feminized through a wide array of representations that scripts the country and its people as naïve, nurturing, submissive and emotional. Space limitations required me to limit my observations to the most common representations, weakness and passivity.
} 


\section{International Relations Scholarship}

\section{IR Theory}

This dissertation is an enthusiastic response to Neumann's call for increased attention to be paid to the role played by "marginal elements of human collectives" in the dynamics of identity (1996: 167). As the above section contends, the re-formulation of liminality put forward in this dissertation furthers our understanding of the processes of identity formation. It helps to better illustrate how the scripting of identities in the context of threat occurs all around us, not just in relation to the significant and threatening Other that so often monopolizes the attention of scholars (and practitioners). In this sense, a focus on liminality encourages critical scholars of international relations and security to move beyond a binary approach to understanding international identities. It may prove particularly valuable as an approach for understanding the constitutive relations between countries in other dyads where, like the Canada-United States relationship, asymmetry is a defining characteristic.

This dissertation attempts to further our understanding of otherness and threat in the international realm. It joins a growing body of work, including the impressive corpus being produced by scholars of critical geopolitics, that explores the role of popular media (Dittmer, 2010). Our understanding of the world around us is made possible through representations. Those representations that surround us on a daily basis, taken for granted as quotidian, play a crucial role in rendering our world intelligible. While not denying the pivotal importance of state actors and intellectuals of statecraft in specifying danger, this 
research makes room for an appreciation of banal depictions of threat. The latter provides a framework within which the former can find traction.

By exposing the dichotomous thinking that structures our thoughts and so often frames our encounters with difference in threatening ways, the questioning spirit that infuses poststructuralist scholarship can contribute to the critical project. Indeed, to the extent that scholarly research and teaching can contribute to the remaking of social relations, breaking down the oppositional categories of self and Other is a crucial first step. This research makes a modest contribution in this direction by showing how conceptions of liminality serve to replicate dichotomous logic in even the most innocuous of international relations. By furthering our understanding of the sites and dynamics that work to uphold the logic of otherness, this research seeks to undermine a system of thought that perpetuates exploitative and militaristic international practices (Dalby, 2010: 2).

\section{Canadian-American Relations}

Although the broader field of Canadian foreign policy has benefitted considerably from the increasing attention of critical IR scholars (Turenne Sjolander et al, 2003; Beier and Wylie, 2010), the Canadian-American relationship remains largely insulated from such efforts. My research attempts to move beyond the field's traditional preoccupation with the economic, political and military dynamics that structure the bilateral relationship. Instead, it looks to the insights of post-structural IR in order to see how the two countries relate at the level of identity. 
Although there is certainly no shortage of scholarly work exploring the CanadianAmerican relationship in terms of identity, it is mostly focused on the effects of North American integration and the implications for Canada of the enormous footprint created by US cultural industries. In this sense, the existing work confines itself to the more obvious implications for identity that play out at a cultural level. Although such work may very well have considerable merit, my own approach seeks to delve deeper by looking at the sociological impulses that enable the very understanding of difference.

As the above section on the practice of Canadian-American relations indicates, my research has implications for understanding the US response to Canada. By applying Campbell's (1998) ideas on the discourse of danger to the specific case of the US relationship with Canada, my work hints at the myriad of ongoing processes that combine to constitute the American self. An appreciation of foreign policy as constitutive of the self promises to bring nuance to the scholarship on the US relationship with Canada.

\section{The Practice of Canadian-American Relations}

My contention that the US reaction to Canada is structured by impressions of liminality also has implications for the practice of Canadian-American relations. When Canadian policies and approaches differ from their US counterparts, there is always the possibility that popular media and government sources will make those differences understandable to Americans by attributing them to some characteristic that ostensibly marks Canada as fundamentally distinct from America. As Allan point out, "waves of 
anti-Canadianism in the American media correlate with periods when major government policies differed between the two countries" (2009: 105). In other words, policy differences between the two countries can always be explained to Americans by othering Canada. For the most part, this dynamic usually manifests as representations that script Canadian differences in quaint or humorous terms. In the context of threat, however, when Americans perceive themselves to be at risk from an imminent enemy or threatening phenomenon, such representations of otherness can become more problematic for Canada. Under such circumstances, underlying impressions of liminality can be intertwined with depictions of Canadian otherness in such a way that Canada can be scripted as a threat. This intertwining effectively transforms Canada into a vehicle through which the threat in question (illegal drugs, gay marriage, illegal immigration, socialism, terrorism) can more effectively menace America. In this sense, any time American identity is threatened or challenged, impressions of liminality can transform manifestations of Canadian difference into a source of threat. As witnessed during the War on Terror, such a dynamic can have important consequences for Canadians.

In this way, my thesis refutes the notion that Canada is viewed as a threat because its policies put the United States at risk in some objective sense. Instead, I argue that Canada is depicted as a threat because the difference represented by its distinct policy responses serves to question the appropriateness and 'truth' of the American identity at a time when the United States is responding to a threat or challenge. In this sense, it is not US security that is put at risk by Canada, but American identity. The initial US reaction in the immediate wake of $9 / 11$ provides a glimpse at how constitutive social processes 
respond to Canada when American identity is threatened. The attacks initially prompted calls for a US response to Canada along two extreme trajectories, both of which were articulated through spatial tropes. One response, originally pressed hard by US Ambassador Paul Cellucci, was the notion of a continental security perimeter (Adelman, 2002: 22). Complete with a drive for more comprehensive continental integration, this approach would attempt to safeguard US security by pushing US border control standards from the Canada-United States border to the outer edges of the continent. ${ }^{93}$ The other reaction, particularly popular among conservative news sources, advocated a militarized response that would reinforce and harden the Canadian border (CBS, 2001b; Fox News, 2001c; CNN, 2001g). This response, premised on the contention that Canada could not be trusted to protect the United States, would ensure security through a fortified presence on the Canada-United States border.

These two US responses mirror those one might expect from an actor confronted by the threat posed by liminality. Understood and scripted by Americans as a liminar, Canada conjures two images: an image of sameness that acts to confirm and reassure American identity, and an image of otherness that acts as a foil against which American identity is scripted in opposition. These two images prompt corresponding reactions that range from colonization to confrontation. The first response, a call to harmonize policies and push the line of sovereign control from the interior to the exterior of the continent

\footnotetext{
${ }^{93}$ It should be noted that Canadian business interests played a crucial role in driving this "big idea" in Canadian-American relations in an effort to secure continued access to US markets and suppliers (Barry, 2007; Whitaker, 2004/05). Although many versions of this plan also include Mexico within their ambit, the idea of a US-led continental security perimeter is received with even less enthusiasm in that country than it is in Canada (Kilroy, 2007).
} 
(effectively redefining what counts as 'inside'), can be understood as an attempt to secure American identity by redefining Canada as ever closer to the American self. In this sense, the reassurance provided by Canada's sameness would serve to reinforce American identity. ${ }^{94}$ The second response, a call to militarize the border, can be understood as an attempt to secure American identity by drawing a more definitive distinction between the two countries. In effect, by scripting Canada in starker and less ambiguous terms, this response would both draw on and reinforce Canada's capacity to act as an Other. Thus, American identity would be reinforced in opposition to the increasingly profound otherness of Canada. In the end, the United States settled upon a more nuanced third alternative. This response, which was in many ways a repudiation of the more extreme notion of a security perimeter, was an "incremental" approach (Barry, 2007). Rejecting both the sameness implied by calls for a security perimeter and the otherness posited by calls for a militarized border, this incremental approach effectively maintained and reaffirmed Canada's status of ambiguous liminality.

All of this suggests that Canadian efforts to modify domestic policies in response to US pressure may not ultimately be sufficient. If US demands on Canada are an outgrowth of challenges to American identity, then Canadian threat functions at an ontological level. This argument contends that at an ontological level, the United States is not seeking just any kind of change in Canadian policies that will make it safer. Rather, it seeks policy convergence because, at an ontological level, this will provide the image of

\footnotetext{
94 The post-9/11 US decision to create Northcom, a new regional military command with an operational area of responsibility that encompasses all of North America, is perhaps evidence of an effort to impose this 'reassuring' version of liminality.
} 
sameness that the American self needs to confirm the truth and validity of its identity in the face of threat. In this sense, the insight provided by liminality suggests that the specification of Canadian threat is likely an enduring condition of the dynamics of American identity. As such, the precarious position that Canadians found themselves in after 9/11 will likely continue to resurface as long as the United States continues to script alterity in Manichean terms. Indeed, as long as this dynamic persists, Canadian policymakers can expect to face a diminished range of options while they navigate the space between US expectations of sameness and otherness.

\section{Further Research}

\section{The Conservative Perspective}

The broad dynamic outlined in this dissertation - how representations of Canadian otherness and liminality are linked together in the specification of Canadian threat - is present across the spectrum of US news media outlets. In other words, there is no substantial difference of kind when it comes to liberal and conservative representations of Canada. Indeed, both viewpoints deploy representational patterns that construct Canada in terms of otherness and liminality, and both perspectives intertwine these depictions in advancing an understanding of Canada as a threat to US security. At one level, therefore, my research highlights the similarities rather than the differences that that emerge in the coverage. This finding suggests that the dynamic itself, and the very plausibility of Canadian threat, has considerable traction in US society. In this sense, my 
argument implies that the dynamic needs to be understood as part of the broader social processes that shape American identity, and not as a narrow manifestation of a particular political or social perspective.

At another level, however, even though there are few differences of kind in the representations deployed by various news outlets, there is no denying the existence of considerable differences of degree. Indeed, as chapter 5 demonstrates, representations from conservative news outlets regularly script Canadian otherness in more rigid and inflammatory ways. Differences of degree are even more pronounced when it comes to the depictions of threat explored in chapter 6. In this area, conservative news sources regularly issue the direst of warnings, and their depictions of threat are often structured in terms of immediacy and enormity. There is a sense in which this coverage can be understood as part of what Hofstadter terms "the paranoid style in American politics" (1967: 3-40). The rhetoric of the Canadian threat, often characterized by accusations of indifference and betrayal, frequently displays the "heated exaggeration, suspiciousness, and conspiratorial fantasy" (3) that marks the paranoid style.

As Hofstadter suggests, the paranoid style is "above all, a way of seeing the world and of expressing oneself' (1967: 3). In this way, it can perhaps be viewed as an extreme version of US geopolitical culture. ${ }^{95}$ This seems plausible considering the degree to which conservative commentary is framed by jingoistic and nativist impulses that explicitly frame Canada as inferior to the United States. Hofstadter's comments on the

\footnotetext{
${ }^{95}$ Debrix suggests that Bill O'Reilly and his ilk draw from and contribute to what he calls "tabloid geopolitics" (2008: 145-150). This is a perspective mediated through lowbrow and middlebrow popular culture that exploits fears and anxieties to create common-sense 'truths' about the US position in the world and about the content of American identity.
} 
"modern right wing" movement of 1960s America are particularly apt in this context. This movement espoused a politics rooted in a sense of dispossession. Its leaders lamented a loss of traditional values and sought to reclaim them from a mythical past. From their perspective,

America has been largely taken away from them and their kind, though they are determined to repossess it and to prevent the final destructive act of subversion. The old American virtues have already been eaten away by cosmopolitans and intellectuals; the old competitive capitalism has been gradually undermined by socialist and communist schemers. (23)

Much of this approach has certainly made a resurgence in the so-called culture war currently being waged in the United States. In terms of the conservative coverage of Canada during the War on Terror, it is perhaps not surprising that this style of commentary is at its most forceful in discussions and representations that denigrate Canada for its liberal social policies. In this context, Canada is frequently othered as a degenerative society, based on accusations of socialism, liberalism and multiculturalism. As a consequence of this social degeneracy, the country's geography is scripted as a haven for terrorists. When combined with sarcastic and accusatory depictions of liminality, the effect is to render a version of Canada that threatens US security. Norton's discussion of extreme reactions to liminality describes a similar dynamic and the same propensity to understand the world in terms of rigid dichotomies:

Those who identify the liminal as wholly foreign exhibit the same symptoms: fear of conspiracy and a sense of omnipresent danger. They are unable to perform the abstraction that would enable them to recognize the liminal as simultaneously other and like. The mingling of identity and difference in the liminal challenges the integrity of the paranoid observer. Because such observers are incapable of abstraction, they can recognize only self and other. (1988: 55) 
In emphasizing the broad patterns by which Canada is represented in US news coverage, chapters 5 and 6 implicitly efface differences in the style of these representations. The above discussion, which identifies the extreme tendencies in the coverage emanating from conservative news outlets, suggests the need for further research into these differences. Such research might inquire into the origins of these different styles of representation and the impact that extreme depictions of Canadian otherness and threat have on wider US impressions of Canada. Future research in this area might explore historical trends in US conservative attitudes towards Canada and the degree to which the representations explored in this dissertation are reflected in other periods.

\section{Canadian Complicity}

One of Norton's (1988) main arguments concerning liminality is that the nation attaches liminal traits to marginalized groups in order to transform such groups into symbolic markers that serve to define the boundaries of the nation. For instance, with respect to territorial liminality, she claims "the insistent attribution of liminal traits to the inhabitants of certain regions marks the territorial limits of the nation" (57). However, Norton clarifies that the marking of such groups is not performed exclusively by the nation itself. Instead, the groups themselves also appear to play an independent role in claiming this status. For instance, further into her discussion on territorial liminars, Norton suggests "they are regarded, and regard themselves, as unconventional and egalitarian, as wanderers removed from obligation to kinsmen and neighbors" (57; 
emphasis added). Similarly, when she turns to intellectual liminars, she suggests that bohemians "are described, and describe themselves, as 'mad' and 'crazy" (71; emphasis added).

The contention that the liminar is complicit in its own ambiguous scripting is an important one. It provides a more nuanced understanding of the dynamics of identity by rejecting the notion that acts of representation are always purely one-sided affairs in which the self simply foists a description onto passive or unwilling Others. In the specific case of liminality, this insight suggests that marginal groups, in the face of an otherwise dominant and overwhelming nation, will take the counterintuitive step of turning to ambiguity as a way to define their identity. This suggestion runs counter to most poststructuralist thinking, which sees identity defined in oppositional terms.

Norton's reflections on how liminars are implicated in the scripting of their own ambiguity holds up well when transferred from her discussion on marginalized groups within larger societies to my reformulation that explores the idea at the international level. For example, statements from Canadian politicians and representations from Canadian popular culture regularly confirm a trend whereby Canadians construct their identity using many of the stereotyped othering patterns that emerge from US sources.

Thus, just as US popular representations often essentialize Canada as a northern place of howling blizzards and frigid, inhospitable climes, so too do Canadians nurture their own myths of 'northernness' (Arnold, 2010), seemingly oblivious to the fact that the 
vast majority of them live within 200 kilometres of the US border. ${ }^{96}$ As Nossal, Roussel and Paquin claim, "while Canada's 'nordicity' is often celebrated, and governments routinely claim that Canada is an Arctic nation, in fact Canadians have a distinctly southern orientation" (2011: 21).

Similarly, Canadian popular culture continues to mirror US othering patterns that overemphasize wilderness as a defining feature of Canadian living, despite statistics that show $80 \%$ of Canadians live in urban centres (Canada, 2009). An advertisement for Molson Canadian beer provides a telling, and by no means atypical, example of this tendency for Canadian sources to script Canadian identity according to this essentialized fixation on wilderness:

When you think about Canadians, you might ask yourself, 'Why are we the way we are?' Well, the answer is laying right under our feet. Literally. Fact is, it's this land that shapes us...This land is unlike any other. We have more square feet of awesomeness per person than any other nation on earth. It's why we flock towards lakes, mountains, forests, rivers and streams. We know we have the best backyard in the world, and we get out there every chance we get. Because it's not just the great outdoors we're chasing, its freedom. And this place gives it to us at every turn. (Starkman, 2010)

The ad's narrative, stirring soundtrack and stunning visuals are clearly designed to prompt viewers to conceive of themselves as belonging to a proud and admirable nation whose essence is defined by wilderness.

Not only does Canadian popular culture tend to mimic US representations depicting Canada as Other, Canadians also frequently script their country's relationship

\footnotetext{
${ }^{96}$ Canadian newspaper columnist Richard Gywn reinforces this myth: "Northernness is Canada's most nearly distinct quality... While this northernness oppressed the early Canadians physically, it also elevated them spiritually...We still today stand on guard for The True North Strong and Free" (1985: 22).
} 
with the United States with the same stress on ambiguous belonging often found in US representations. For example, in debunking the notion that Canadians are anti-American, Hillmer (2006) frames the Canada-United States relationship in terms of "convergence, similarity and interdependence" (63). He approvingly quotes Seymour Martin Lipset's contention that the two countries "resemble each other more than either resembles any other nation" (65). Buckley sees evidence of similar sentiments in Canadian news coverage of the United States. He identifies a recurring theme in the coverage, which he classifies under the label 'Our American Cousins.' He claims that this theme is based on "the notion that the Canada-US tie is analogous to a family relationship" (2003: 89). His analysis subsequently suggests that within Canadian coverage of US news items, "differences between the two countries are seen as somehow unnatural or aberrant" (89).

This dissertation contends that the notion of Canadian liminality plays an important role in the scripting of Canada as a threat to US security. In this light, the possibility that Canadian social actors are complicit in effecting this aura of liminality is intriguing. So, although this particular stream of thought falls outside the scope of this thesis, it is an area deserving of further study.

\section{Liminality in Comparative Perspective}

Part of this dissertation examines the Mexicanization of the Canadian border (Andreas, 2005). More specifically, it explores how the US news media intertwined narratives about the Canadian and Mexican borders as part of its coverage of Canada during the War on Terror. This technique effectively transferred to the Canadian border 
the sense of threat and insecurity that many Americans attach to the Mexican border. This trend hints at a broader opportunity to study Canada's status as an American liminar in a comparative perspective that includes Mexico. ${ }^{97}$

Beyond their obvious role in marking the limits of US sovereignty, the Canadian and Mexican borders both play a crucial role in defining the cultural boundaries of the United States and scripting the content and contours of American identity. Both countries mark the continental limits of Manifest Destiny and the expansion of the American ideal. Indeed, in the case of Mexico, the border represents the terminus of a US policy of military expansion that conquered and annexed half of the country. This history of violent US expansion continues to play a contentious role in defining Mexican-American relations to this day. In this sense of defining the limits of US culture and identity, both countries represent distinct instances in which American identity was confronted by proximate manifestations of alterity that ultimately came to mark the edges of formal US expansion. As such, both countries occupy distinct places in the American geopolitical culture.

The Mexico-United States border is a site of intense cross-border flows involving people, ideas, capital and goods. It is also a place that regularly captures the attention of US political leaders and arouses any number of contradictory responses in American popular imagination. However, even more than the US border with Canada, this border has also long been understood as a site of otherness and danger for Americans. The

\footnotetext{
${ }^{97}$ There is a vast body of work that examines the border area that Mexico shares with the United States. For a sampling of this material, consult the Journal of Borderlands Studies. Comparative analysis is an explicit focus of many borderlands scholars; the online bibliography of the Association of Borderlands Studies (2010) provides many relevant examples.
} 
enduring ambiguity with which the American imaginary apprehends the southern border surely marks Mexico as an American liminar. Therefore, as is the case with Canada, when Americans are grappling with questions of threat and identity, they must inevitably negotiate a response through the prism provided by Mexico's presence on their southern frontier.

A number of questions are prompted when Mexico is brought into the equation. Although Canada and Mexico surely occupy very different places in the American imaginary, they are both understood in the context of liminality. With this in mind, how do representations of Mexican liminality differ from representations of Canadian liminality? What are the implications of these differences? More specifically, how do these differences impact on the specifications of threat that emerge from US popular media? Moreover, given the previous discussion on the "paranoid style in American politics," how do such attitudes operate in the context of calls for further North American integration in terms of NAFTA and the Security and Prosperity Partnership? Perhaps most crucially, what are the implications of these different versions of liminality for the construction of American identity and the exercise of US power?

An examination along these lines promises to provide a more thorough comprehension of how liminality operates, while also expanding our understanding of the dynamics that shape American identity. One example of the potential value of a comparative approach to liminality is found in the work of Dominique Brégent-Heald. Her comparative examination of Hollywood representations of the Canadian and Mexican borders $(2004 ; 2006 \mathrm{a} ; 2006 \mathrm{~b} ; 2007)$ provides a rich analysis of the variety of 
ways in which American identities are negotiated in the context of liminality. BrégentHeald herself identifies explicitly the value of a comparative approach in challenging assumptions:

I had expected that Classical Hollywood films would depict Canada as 'God's Country' - pristine and orderly - while castigating Mexico as a shaky 'south of the border' republic. I was instead struck by the similarities within Hollywood's portrayals of the northern and southern frontiers. (2004: 6)

Her comparative approach reveals that films "vacillated between envisioning both borders as either areas of peaceful exchange or as perilous perimeters...[and] the tension between a desire for and a paranoia about America's neighboring 'Others"' (2004: 7). In this sense, Brégent-Heald's comparative approach is able to provide a comprehensive understanding of the functioning of liminality without sacrificing an analysis grounded in the specificity of the Canadian and Mexican contexts. This is an approach that might well be applied to achieve a broader understanding of the role played by popular media in framing identities and structuring the US response to threat.

\section{The Ressam Narrative}

The role of Ahmed Ressam in the construction of Canadian threat during the War on Terror is an interesting one. As recounted briefly in the introduction to chapter 5, Ressam was arrested on December 14, 1999 at the Canada-United States border crossing at Port Angeles, Washington. The trunk of his vehicle contained explosives that authorities would later determine were destined for an attack against the Los Angeles international airport. In the wake of Ressam's arrest, the case became an instant cause 
célèbre in the US news media. It was marked by such an array of remarkable features that it immediately captured the public's attention.

Ressam's route into the United States was a strange one, and garnered considerable attention in the coverage. He travelled from Montreal to Vancouver, where he stayed in a motel for several weeks while he perfected his explosive device. He eschewed the land crossing that straddles the main highway linking Vancouver and Seattle, opting instead to take a ferry to Victoria and, from there, another ferry to the United States. He ensured that his rental car was last off the ferry, on the last trip of the day. He had reservations at the Best Western in downtown Seattle (Wright and Murphy, 1999). It was a circuitous that defied intuitive explanation. It added considerably to the surreal nature of the case.

Diana Dean, the border guard who discovered something was amiss, was cast as an 'everyman' hero. Her instincts having prevented an enormous attack, she achieved the status of minor celebrity. However, at the same time that Dean was being lauded for her instincts and professional skills, there was an appreciation nonetheless that the United States had been very lucky to have caught Ressam. A Time report claimed that Ressam "was caught by luck as much as by diligence" (McGeary et al., 1999). Indeed, as Stephen Flynn later remarked, Ressam's capture was “the border-control equivalent of winning the lottery" (quoted in Andreas, 2005: 453).

As Ressam's backstory emerged, Canadian officials were presented in a less than flattering light. His murky past in Canada was quickly revealed to include multiple arrests, a series of aliases and fake passports, to say nothing of his questionable 
associates, ties to terrorist organizations and an outstanding order for his arrest and deportation. It is no surprise, therefore, that Canadian policies came under harsh criticism in the weeks and months after the arrest. However, in addition to ubiquitous claims of bureaucratic mishandling and incompetence, entire policy mechanisms were indicted. Law enforcement was found in need of upgrading, immigration policies required considerable tightening and multiculturalism needed to be re-evaluated.

With all of these factors, it is no wonder that the affair was a constant feature of news coverage for weeks. What is more interesting is the way the 'Ressam narrative' has been deployed in the years since this story originally broke. In the decade since Ressam's arrest, his narrative has been replayed over and over again, virtually anytime the US news media encounters a terrorism story with any kind of Canadian component. It provided context for unrelated arrests at a Vermont border crossing five days after Ressam's arrest in Washington. It emerged in full force immediately after the terrorist attacks of 9/11, playing no small part in the persistent rumours of the Canadian connection. It reappeared again in late 2002 when the FBI circulated an erroneous report that five suspicious men had been smuggled into the United States from Canada. The narrative made another prominent appearance with the arrests of Canada's so-called 'homegrown' terrorists in June 2006.

December 1999 was a time of increased social anxiety over the approaching millennium and the attendant worries over the uncertainties of $\mathrm{Y} 2 \mathrm{~K}$. It was a time marked by "reports and warnings about possible millennial violence" (Kifner, 1999). The Ressam narrative reminds Americans about that anxious time and the close call they 
managed to avoid. Even Ressam's ubiquitous nickname serves as a powerful reminder every time it resurfaces: 'the Millennium Bomber' simultaneously recalls both the inauspicious timing of Ressam's entry into American consciousness as well as the heinous nature of his mission. The narrative summons the sense of insecurity implied by the improbable luck at having avoided a catastrophe at LAX. It also provides the reassuring memory of the simple and unassuming heroism of a border guard following her hunch.

Mostly, however, the Ressam narrative reminds American of the laxity and incompetence of Canadian law enforcement and the dangers of Canadian immigration and multiculturalism policies. In short, the Ressam narrative serves to reiterate the everpresent nature of the danger posed by Canada. It grants instant plausibility to those stories about terrorists sneaking in from Canada, even when the stories themselves later turn out to have no basis in reality. To quote Todorov again:

when an author is mistaken or lying, his text is no less significant than when he is speaking the truth; the important thing is that the text be 'receivable' by contemporaries, or that it has been regarded as such by its producer. From this point of view, the notion of 'false' is irrelevant here. (1984: 54)

It is clear that Ressam plays a role in sustaining the image of a threatening Canada. It would be a fascinating exercise to track the Ressam narrative more closely and examine its implications in greater depth.

\section{Conclusion}


In this dissertation, I attempt to answer the question, 'How is it possible that Canada becomes understood as a threat to US security?' In order to understand the notion of Canadian threat, I turn primarily to the work of two theorists: David Campbell and Anne Norton. Campbell's redefinition of foreign policy (1998) provides crucial insight into how national identities are sustained. His examination of the relationship between US foreign policy and American identity demonstrates that a state's foreign policy plays a constitutive role in maintaining that state's identity. In other words, the ceaseless act of identifying external identities as foreign and threatening Others serves to construct and normalize the self's identity.

I also draw upon Anne Norton's understanding of the role played by the liminar in matters of identity (1988). Drawing on representations of Canada in Hollywood films and US news sources, I contend that Canada occupies a place of liminality in the American imaginary - it is scripted by Americans as both part of and separate from the American experience. In other words, Canada's ambiguity marks the country as simultaneously self and Other to the American identity. When the United States is facing an external threat, Canada's otherness prompts Americans to perceive within it traces of the threatening Other. However, because Canada also reflects an image of likeness, the threat that it represents comes to take on an omnipresent quality.

The liminal understanding of Canada as an extension of the United States suggests that if the threatening enemy is in Canada then it is effectively in the United States as well. The immediacy of this sense of threat prompts the American self to script its identity in increasingly rigid terms. In response to my research question, therefore, I 
demonstrate that Canada's capacity to threaten US security can be understood as a subsidiary consequence of the dynamics of identity whereby the American self defines itself in opposition to an Other. 


\section{References}

\section{Academic Sources}

Adelman, Howard. 2002. "Canadian Borders and Immigration Post 9/11." International Migration Review 36 (1): 15-28.

Adler, Emanuel. 1997. "Seizing the Middle Ground: Constructivism in World Politics." European Journal of International Relations 3 (3), 319-363.

Aho, James. 1994. This Thing of Darkness: A Sociology of the Enemy. Seattle: University of Washington Press.

Alberts, Sheldon. 2009a. "Envoy rebukes U.S. for linking 9/11 terrorists to Canada." National Post, April 21.

Alberts, Sheldon. 2009b. "Renewed anger as McCain claims 9/11 attackers came from Canada." National Post, April 24.

Allan, Chantal. 2009. Bomb Canada and Other Unkind Remarks in the American Media. Edmonton, AB: Athabasca University Press.

Allison, Deborah. 2008. "Title Sequences in the Western Genre: The Iconography of Action." Quarterly Review of Film and Video 25 (2): 107-115.

Anderson, Benedict. 1991. Imagined Communities. New York: Verso.

Andreas. Peter. 2003. "A Tale of Two Borders: The U.S.-Canada and U.S.-Mexico Lines After 9-11." In The Rebordering of North America: Integration and Exclusion in a New Security Context, Eds. Peter Andreas and Thomas J. Biersteker. London: Routledge.

Andreas, Peter. 2005. "The Mexicanization of the US-Canada border." International Journal 60 (2): 449-462.

Arnold, Samantha L. 2010. "Home and Away: Public Diplomacy and the American Self." In Canadian Foreign Policy in Critical Perspective, Eds. J. Marshall Beier and Lana Wylie. Don Mills, ON: Oxford University Press. 
Ashley, Richard K. and R. B. J. Walker. 1990. "Speaking the Language of Exile:

Dissident Thought in International Studies." International Studies Quarterly 34 (3): 259-268.

Association of Borderlands Studies. 2010. "ABS-CIBR Bibliography.” Available: http://www.qub.ac.uk/research-centres/CentreforInternationalBordersResearch/ ABS-CIBRBibliography/ Accessed June 1, 2010.

Audit Bureau of Circulations. 2009. “Consumer Magazines: News-Weeklies.” FAS-FAX Report, December 31.

Audit Bureau of Circulations. 2010. "US Newspaper Circulation.” FAS-FAX Report, March 31.

Balz, Dan and Bob Woodward. 2002. "America's Chaotic Road to War.” Washington Post, January 27: A01.

Barton, Richard L. 1990. Ties That Blind in Canadian/American Relations: Politics of News Discourse. Hillsdale, NJ: Lawrence Erlbaum Associates.

Barry, Donald. 2007. "Managing Canada-US Relations in the Post-9/11 Era: Do We Need a Big Idea?" In Readings in Canadian Foreign Policy: Classic Debates and New Ideas, Eds. Duane Bratt and Christopher J. Kukucha. Don Mills, ON: Oxford University Press.

Bathurst, Robert B. 1993. Intelligence and the Mirror: On Creating an Enemy. London: Sage.

Bazin, Andre. 1971a. "The Western: Or the American Film Par Excellence." trans. Hugh Grey. In What is Cinema? Vol. 2. Berkeley: University of California Press. Bazin, Andre. 1971b. "The Evolution of the Western." trans. Hugh Grey. In What is Cinema? Vol. 2. Berkeley: University of California Press.

Beaudreau, Sylvie. 2002. "The Changing Faces of Canada: Images of Canada in National Geographic." American Review of Canadian Studies 32 (4): 517-546.

Beck, Ulrich. 1997. “The Sociological Anatomy of Enemy Images: The Military and Democracy After the Cold War." trans. Susan Vogel. In Enemy Images in American History, Eds. Ragnhild Fiebig-von Hase and Ursula Lehmkuh1. Providence: Berghahn Books. 
Beier, J. Marshall. 2005. "Canada: Doubting Hephaestus." Contemporary Security Policy $26(3): 431-446$.

Beier, J. Marshall and Lana Wylie, Eds. 2010a. Canadian Foreign Policy in Critical Perspective. Don Mills, ON: Oxford University Press.

Beier, J. Marshall and Lana Wylie. 2010b. "Introduction: What's So Critical about Canadian Foreign Policy?" In Canadian Foreign Policy in Critical Perspective, Eds. J. Marshall Beier and Lana Wylie. Don Mills, ON: Oxford University Press.

Belch, Christopher. 2004. "A View from Abroad: An Analysis of Canadian Coverage in U.S. Newspapers." MA Thesis. University of Windsor, Windsor, ON.

Berland, Jody. 1999. "Weathering the North: Climate, Colonialism and the Mediated Body." In Pop Can: Popular Culture in Canada, Eds. Lynne Van Luven and Priscilla L. Walston. Scarborough, ON: Prentice-Hall Canada.

Berton, Pierre. 1975. Hollywood's Canada: The Americanization of our National Image. Toronto: McClelland and Stewart.

Black, David R. and Heather A. Smith. 1993. "Notable Exceptions? New and Arrested Directions in Canadian Foreign Policy Literature." Canadian Journal of Political Science 26 (4): 745-774.

Black, David and Claire Turenne Sjolander. 1996. "Multilateralism Re-constituted and the Discourse of Canadian Foreign Policy." Studies in Political Economy 49: 736.

Blum, William. 2000. Rogue State: A Guide to the World's Only Superpower. Monroe, ME: Common Courage Press.

Bratt, Duane and Christopher J. Kukucha, Eds. 2007. Readings in Canadian Foreign Policy: Classic Debates and New Ideas. Don Mills, ON: Oxford University Press.

Brégent-Heald, Dominique. 2004. "Reel Borders: Imaging Mexico and Canada During Classical Hollywood Period, 1929-1960.” PhD Dissertation. Duke University, Durham, NC.

Brégent-Heald, Dominique. 2006a. "Dark Limbo: Film Noir and the North American Borders." Journal of American Culture 29 (2): 125-138. 
Brégent-Heald, Dominique. 2006b. "The Tourism of Titillation in Tijuana and Niagara Falls: Cross-Border Tourism and Hollywood Films between 1896 and 1960." Journal of the Canadian Historical Association 17 (1): 179-203.

Brégent-Heald, Dominique. 2007. "Primitive Encounters: Film and Tourism in the North American West." Western Historical Quarterly 38 (1): 47-68.

Buckley, Brian. 2003. "The News and the Neighbours: The Media and Canada-US Relations." In Canada Among Nations 2003: Coping with the American Colossus, Eds. David Carment, Fen Osler Hampson and Norman Hillmer. Toronto: Oxford University Press.

Burney, Derek. 2003/2004. “Canada-US Relations: The Risk of Complacency, the Need for Engagement." Policy Options 25 (1): 46-51.

Burney, Derek. 2005. “The Perennial Challenge: Managing Canada-US Relations.” In Canada Among Nations 2005: Split Images, Eds. Dane Rowlands and Andrew Cooper. Montreal: McGill-Queen's University Press.

Bush, George W. 2002. "The President's State of the Union Address." United States White House Archives. Available: http:/georgewbush-whitehouse.archives.gov /news/releases/2002/01/20020129-11.html Accessed May 16, 2010.

Bush, George W. 2004. "President's Remarks in Greeley, Colorado.” United States White House Archives. Available: http://georgewbush-whitehouse.archives.gov/ news/releases/2004/10/20041025-4.html Accessed June 5, 2010.

Buzan, Barry, Ole Wæver and Jaap de Wilde. 1998. Security: A New Framework for Analysis. Boulder: Lynne Rienner.

Callahan, James Morton. 1937. American Foreign Policy in Canadian Relations. New York: Macmillan.

Campbell, David. 1992. Writing Security: United States Foreign Policy and the Politics of Identity. Minneapolis: University of Minnesota Press.

Campbell, David. 1993. “Cold Wars: Securing Identity, Identifying Danger.” In Rhetorical Republic: Governing Representations in American Politics, Eds. Frederick M. Dolan and Thomas L. Dumm. Amherst: University of Massachusetts Press. 
Campbell, David. 1994. "Foreign Policy and Identity: Japanese 'Other'/American 'Self'." In The Global Economy as Political Space, Eds. Stephen J. Rosow, Naeem Inayatullah and Mark Rupert. Boulder: Lynne Rienner.

Campbell, David. 1998. Writing Security: United States Foreign Policy and the Politics of Identity. $2^{\text {nd }}$ ed. Minneapolis: University of Minnesota Press.

Campbell, David. 2001. "Time is Broken: The Return of the Past in the Response to September 11." Theory and Event 5 (4).

Campbell, David. 2003. "Cultural Governance and Pictorial Resistance: Reflections on the Imaging of War." Review of International Studies 29, 57-73.

Canada. 2009. "Population urban and rural, by province and territory (Canada)." Statistics Canada. Available: http://www40.statcan.ca/101/cst01/demo62a-eng.htm Accessed May 30, 2010.

Capuozzo, Robert M. et al. 2009. "So Close Yet So Far Away: American Academics on the Similarities and Differences Between the United States and Canada Following the International Canadian Studies Institute." American Review of Canadian Studies. 39 (1): 1-15.

C.A.S.E. Collective. 2006. "Critical Approaches to Security in Europe: A Networked Manifesto." Security Dialogue 37 (4): 443-487.

Charbonneau, Bruno and Wayne S. Cox. 2008. "Global Order, US Hegemony and Military Integration: The Canadian-American Defense Relationship." International Political Sociology 2 (4): 305-321.

Chapnick, Adam. 2005. The Middle Power Project. Vancouver: UBC Press.

Chermak, Steven M. 2002. Searching for a Demon: The Media Construction of the Militia Movement. Boston: Northeastern University Press.

Cellucci, Paul. 2005. “The Relationship: A US Perspective.” International Journal 60 (2): 509-515.

Chilton, Paul A. 1996. Security Metaphors: Cold War Discourse from Containment to Common House. New York: P. Lang.

Clarkson, Stephen, Ed. 1968. An Independent Foreign Policy for Canada? Toronto: McClelland and Stewart 
Clarkson, Stephen. 2003. "The View from the Attic: Towards a Gated Continental Community?" In The Rebordering of North America: Integration and Exclusion in a New Security Context. Eds. Peter Andreas and Thomas J. Biersteker. London: Routledge.

Clarkson, Stephen and Erin Fitzgerald. 2009. "A Special Military Relationship? Canada's Role in Constructing US Military Power." Journal of Military and Strategic Studies 12 (1): 1-24.

Clement, Wallace and Glen Williams. 1989. The New Canadian political economy. Montreal: McGill-Queen's University Press.

Cohen, Stanley and Jock Young, Eds. 1981. The Manufacture of News: Social Problems, Deviance and the Mass Media. Rev. ed. London: Constable.

Cohn, Carol. 1987. "Sex and Death in the Rational World of Defense Intellectuals." Signs 12 (4): $687-718$.

Cohn, Carol. 1989. "Emasculating America's Linguistic Deterrent." In Rocking the Ship of States: Toward a Feminist Peace Politics, Eds. Adrienne Harris and Ynestra King. Boulder: Westview Press.

Cohn, Carol. 1993. "Wars, Wimps, and Women: Talking Gender and Thinking War." In Gendering War Talk, Eds. Miriam Cooke and Angela Woollacott. Princeton: Princeton University Press.

Connolly, William E. 1991. Identity/Difference: Democratic Negotiations of Political Paradox. Ithaca, NY: Cornell University Press.

Corkin, Stanley. 2000. “Cowboys and Free Markets: Post-World War II Westerns and U.S. Hegemony." Cinema Journal 39 (3): 66-91.

Cox, Robert. 1981. "Social Forces, States and World Orders: Beyond International Relations Theory." Millennium 10 (2): 126-155.

Cox, Robert. 1983. "Gramsci, Hegemony and International Relations: An Essay in Method." Millennium 12 (2): 162-175.

Coyne, Michael. 1997. The Crowded Prairie: American National Identity in the Hollywood Western. New York: St. Martin's Press. 
Crapol, Edward P. 1973. America for Americans: Economic Nationalism and Anglophobia in the Late Nineteenth Century. Westport, CT: Greenwood Press.

Crosby, Ann Denholm. 2003. "Myths of Canada's Human Security Pursuits: Tales of Tool Boxes, Toy Chests, and Tickle Trunks." In Feminist Perspectives on Canadian Foreign Policy, Eds. Claire Turenne Sjolander, Heather A. Smith and Deborah Stienstra. Toronto: Oxford University Press.

Crosby, Ann Denholm. 2010. “Canada-US Defence Relations: Weapons of Mass Control and a Praxis of Mass Resistance." In Canadian Foreign Policy in Critical Perspective, Eds. J. Marshall Beier and Lana Wylie. Don Mills, ON: Oxford University Press.

Dalby, Simon. 1990. Creating the Second Cold War: The Discourse of Politics. London: Pinter.

Dalby, Simon. 1997. "Contesting an Essential Concept: Reading the Dilemmas in Contemporary Security Discourse." In Critical Security Studies: Concepts and Cases, Eds. Keith Krause and Michael C. Williams. Minneapolis: University of Minnesota Press.

Dalby, Simon. 2002. Environmental Security. Minneapolis: University of Minnesota Press.

Dalby, Simon. 2003. "Calling 911: Geopolitics, Security and America's New War." Geopolitics 8 (3): 61-86.

Dalby, Simon. 2008. "Warrior geopolitics: Gladiator, Black Hawk Down and The Kingdom of Heaven." Political Geography 27 (4): 439-455.

Dalby, Simon. 2009. Security and Environmental Change. Cambridge, UK: Polity. Dalby, Simon. 2010. "Recontextualising violence, power and nature: The next twenty years of critical geopolitics." Political Geography (In press).

Davies, Merryl Wyn, Ashis Nandy and Ziaddin Sardar. 1993. Barbaric Others: A Manifesto on Western Racism. Boulder: Pluto Press.

Davis, David Brion, Ed. 1971. The Fear of Conspiracy: Images of Un-American Subversion from the Revolution to the Present. Ithaca: Cornell University Press. 
Dawson, Michael. 1998. The Mountie: From Dime Novel to Disney. Toronto: Between the Lines.

Debrix, François. 2001. "Cyberterror and Media-Induced Fears: The Production of Emergency Culture." Strategies 14 (1): 149-168.

Debrix, François. 2008. Tabloid Terror: War, Culture, and Geopolitics. New York: Routledge.

de Larrinaga, Miguel and Claire Turenne Sjolander. 1998. “(Re)presenting Landmines from Protector to Enemy: The Discursive Framing of a New Multilateralism." Canadian Foreign Policy 5 (3): 125-146.

Der Derian, James. 1992. Antidiplomacy: Spies, Terror, Speed, and War. Cambridge, MA: Blackwell.

Der Derian, James and Michael J. Shapiro, Eds. 1989. International/Intertextual Relations: Postmodern Readings of World Politics. Lexington, MA: Lexington Books.

Dewitt, David and John Kirton. 1983. Canada as a Principle Power. Toronto: John Wiley.

Dittmer, Jason. 2005. “Captain America's Empire: Reflections on Identity, Popular Culture, and Post-9/11 Geopolitics." Annals of the Association of American Geographers 95 (3): 626-643.

Dittmer, Jason. 2010. Popular Culture, Geopolitics, and Identity. Lanham, MD: Rowman and Littlefield.

Dittmer, Jason and Klaus Dodds. 2008. "Popular Geopolitics Past and Future: Fandom, Identities and Audience." Geopolitics 13 (3): 437-457.

Dodds, Klause. 2005. "Screening Geopolitics: James Bond and the Early Cold War films (1962-1967)." Geopolitics 10 (2): 266-289.

Dodds, Klaus. 2007. 'Steve Bell's Eye: Cartoons, Geopolitics and the Visualization of the 'War on Terror'." Security Dialogue 38 (2): 157-177.

Doty, Roxanne Lynn. 1993. "Foreign Policy as Social Construction: A Post-Positivist Analysis of U.S. Counterinsurgency Policy in the Philippines." International Studies Quarterly 37 (3): 297-320. 
Doty, Roxanne Lynn. 1996. Imperial Encounters: The Politics of Representation in North-South Relations. Minneapolis: University of Minnesota Press.

Drache, Daniel. 2004. Borders Matter: Homeland Security and the Search for North America. Halifax, NS: Fernwood.

Drinnon, Richard. 1980. Facing West: The Metaphysics of Indian-Hating and EmpireBuilding. Minneapolis: University of Minnesota Press.

Eagles, Munroe. 2006. "Canadian-American Relations in a Turbulent Era." PS: Political Science and Politics 39 (4): 821-824.

Edelman, Murray. 1988. Constructing the Political Spectacle. Chicago: University of Chicago Press.

Elshtain, Jean Bethke. 1987. Women and War. New York: Basic Books.

Elshtain, Jean Bethke. 1992. "Sovereignty, Identity, Sacrifice.” In Gendered States: (Re) Visions of International Relations Theory, Ed. V. Spike Peterson. Boulder: Lynne Rienner.

Eriksson, Johan. 1999. "Observers or Advocates? On the Political Role of Security Analysts." Cooperation and Conflict 34 (2): 311-330.

Fairclough, Norman. 1995. Media Discourse. London: Edward Arnold.

Ferguson, Lee. 2010. "Tom Brokaw's love letter to Canada." CBC News (online). Available: http://www.cbc.ca/arts/media/blogs/popculture/2010/02/tom-brokawslove-letter-to-canada.html Accessed May 20, 2010.

Flynn, Stephen E. 2003. "The False Conundrum: Continental Integration versus Homeland Security." In The Rebordering of North America: Integration and Exclusion in a New Security Context. Eds. Peter Andreas and Thomas J. Biersteker. London: Routledge.

Fortmann, Michel and David G. Haglund. 2002. "Canada and the Issue of Homeland Security: Does the 'Kingston Dispensation' Still Hold?" Canadian Military Journal 3 (1): 17-22.

Foucault, Michel. 1984. The Foucault Reader, Ed. Paul Rabinow. New York: Pantheon Books. 
Gaddis, John Lewis. 2004. Surprise, Security and the American Experience. Cambridge, MA: Cambridge University Press.

Gecelovsky, Paul. 2007. "Northern Enigma: American Images of Canada." American Review of Canadian Studies 37 (4): 517-535.

Gittings, Christopher. 1998. “Imaging Canada: The Singing Mountie and Other Commodifications of Nation." Canadian Journal of Communication (23) 4: $507-$ 522.

Gittings, Christopher. 2002. Canadian National Cinema: Ideology, Difference and Representation. London: Routledge.

Goar, Carole. 1996. "The Fight of his life." Toronto Star, March 3, F 7.

Golob, Stephanie R. 2002. "North America Beyond NAFTA? Sovereignty, Identity, and Security in Canada-U.S. Relations." Canadian-American Public Policy 52.

Gouge, Catherine. 2007. "The American Frontier: History, Rhetoric, Concept." Americana: The Journal of American Popular Culture 6 (1).

Granatstein, J.L. and Norman Hillmer. 1991. For Better or For Worse: Canada and the United States to the 1990s. Toronto: Copp Clark Pitman.

Grant. George. 1965. Lament for a Nation: The Defeat of Canadian Nationalism. Toronto: McClelland and Stewart.

Grayson, Kyle. 2010. "Clandestine Convergence: Human Security, Power, and Canadian Foreign Policy." In Canadian Foreign Policy in Critical Perspective, Eds. J. Marshall Beier and Lana Wylie. Don Mills, ON: Oxford University Press.

Grondin, David and Miguel de Larrinaga. 2009. "Security prosperity or making securitization prosper?" International Journal 64 (3): 667-685.

Gwyn, Richard. 1985. The $49^{\text {th }}$ Paradox: Canada in North America. Toronto: McClelland and Stewart.

Haglund, David G. 2003. "North American Cooperation in an Era of Homeland Security." Orbis 47 (4): 675-691.

Haglund, David G. 2010. “A Security Community - 'If You Can Keep It': Societal Security, Demography, and the North American Zone of Peace." In Canada's 
Foreign and Security Policies: Soft and Hard Strategies of a Middle Power, Eds. Nik Hynek and David Bosold. Don Mills, ON: Oxford University Press. Harding, Sandra. 1986. The Science Question in Feminism. Ithaca, NY: Cornell University Press.

Hartley, John. 1982. Understanding News. London: Meuthen.

Hartsock, Nancy. 1983. "The Barracks Community in Western Political Thought: Prolegomena to a Feminist Critique of War and Politics." In Women and Men's Wars, Ed. Judith Stiehm. New York: Permagon Press.

Hataley, T.S. (Todd). 2005. "The Canadian-United States Border: Security vs.

Economics." In Canada and the United States: A Relationship at a Crossroads?

Ed. George A. MacLean. Winnipeg, MB: Centre for Defence and Security Studies, University of Manitoba.

Harvey, Frank P. 2003/04. "Addicted to Security: Globalized Terrorism and the Inevitability of American Unilateralism." International Journal 59 (1): 27-57.

Heideking, Jürgen. 1997. "The Image of an English Enemy During the American Revolution." In Enemy Images in American History, Eds. Ragnhild Fiebig-von Hase and Ursula Lehmkuhl. Providence, RI: Berghahn Books.

Higgott, Richard A. and Kim Richard Nossal. 1997. "The International Politics of Liminality: Relocating Australia in the Asia Pacific." Australian Journal of Political Science 32 (2): 169-185.

Hillmer, Norman. 2006. “Are Canadians Anti-American?” Policy Options 27 (6): 63-65.

Holmes, John. 1970. The Better Part of Valour: Essays on Canadian Diplomacy. Toronto: McClelland and Stewart.

Hooper, Charlotte. 2001. Manly States: Masculinities, International Relations, and Gender Politics. New York: Columbia University Press.

Hofstadter, Richard. 1967. The Paranoid Style in American Politics and Other Essays. New York: Vintage Books.

Holmes, John. 1970. The Better Part of Valour: Essays on Canadian Diplomacy. Toronto: McClelland and Stewart. 
Hristoulas, Athanascos. 2003. "Trading places: Canada, Mexico, and North American Security." In The Rebordering of North America: Integration and Exclusion in a New Security Context. Eds. Peter Andreas and Thomas J. Biersteker. London: Routledge.

Huntington, Samuel P. 1996. The Clash of Civilizations and the Remaking of World Order. New York: Touchstone.

Hynek, Nik and David Bosold, Eds. 2010. Canada's Foreign and Security Policies: Soft and Hard Strategies of a Middle Power. Don Mills, ON: Oxford University Press. Jackson, Richard. 2005. "Language, Power, and Politics: Critical Discourse Analysis and the War on Terror." $49^{\text {th }}$ Parallel 15.

Jervis, Robert. 2003. "Understanding the Bush Doctrine." Political Science Quarterly $118(3): 365-388$.

Katzenstein, Peter J., Ed. 1996. The Culture of National Security: Norms and Identity in World Politics. New York: Columbia University Press.

Kaufmann, Eric. 1999. “American Exceptionalism Reconsidered: Anglo-Saxon Ethnogenesis in the 'Universal' Nation, 1776-1850." Journal of American Studies 33 (3): 437-457.

Keeble, Edna, and Heather A. Smith. 1999. (Re)Defining Traditions: Gender and Canadian Foreign Policy. Halifax, NS: Fernwood.

Kilroy, Richard J., Jr. 2007. "Perimeter Defense and Regional Security Cooperation in North America: United States, Canada, and Mexico." Homeland Security Affairs, Supplement no. 1 (online). Available: http://www.hsaj.org/pages/supplement/ issuel/pdfs/supplement.1.3.pdf Accessed: June 7, 2010.

Kirton, John. 2007. Canadian Foreign Policy in a Change World. Toronto: Nelson.

Klein, Bradley S. 1990. "How the West Was One: Representational Politics of NATO." International Studies Quarterly 34 (4): 311-325.

Klein, Bradley S. 1994. Strategic Studies and World Order. Cambridge, UK: Cambridge University Press. 
Khong, Yuen Foong. 1987. "Seduction by Analogy in Vietnam: The Malaya and Korean Analogies." In Institutions and Leadership: Prospects for the Future, Ed. Kenneth W. Thompson. Lanham, MD: University Press of America.

Knowles, Richard P. 1995. "Representing Canada: Teaching Canadian Studies in the United States." American Review of Canadian Studies 25 (1): 9-26.

Krauss, Clifford. 2003. "Canada's View on Social Issues is Opening Rifts with the U.S." New York Times, December 2: A16.

Krause, Keith and Michael C. Williams, Eds. 1997. Critical Security Studies: Concepts and Cases. Minneapolis: University of Minnesota Press.

Krugman, Paul. 2010. "Good and Boring." New York Times, January 31, A19.

Kurki, Milja and Colin Wight. 2007. "International Relations and Social Science." In International Relations Theories: Discipline and Diversity, Eds. Tim Dunne, Milja Kurki and Steve Smith. Oxford: Oxford University Press.

Lapid, Yosef. 1989. “The Third Debate: On the Prospects of International Theory in a Post-Positivist Era." International Studies Quarterly 33 (3): 235-254.

Lapid, Yosef and Friedrich Kratochwil, Eds. 1995. The Return of Culture and Identity in IR Theory. Boulder: Lynne Rienner.

Layne, Christopher. 1997. "From Preponderance to Offshore Balancing: America's Future Grand Strategy." International Security 22 (1): 86-124.

Leal, David L. 2006. Canada: The Unknown Country. PS: Political Science and Politics 39 (4): 813-814.

Lee, Erika. 2002. "Enforcing the Borders: Chinese Exclusion along the U.S. Borders with Canada and Mexico, 1882-1924." Journal of American History 89 (1): 54-86.

Lipschutz, Ronnie D. 2001. Cold War Fantasies: Film, Fiction, and Foreign Policy. Lanham, MD: Rowman and Littlefield.

Lipset, Seymour Martin. 1993. "Canadian Studies in the United States: A Summary." In Northern Exposures: Scholarship on Canada in the United States, Eds. Karen Gould, Joseph T. Jockel and William Metcalf. Washington: Association for Canadian Studies in the United States. 
Macdonald, Laura. 1995. “Unequal Partnerships: The Politics of Canada's Relations with the Third World." Studies in Political Economy 47: 111-141.

Mahant, Edelgard and Graeme S. Mount. 1999. Invisible and Inaudible in Washington: American policies Toward Canada. Vancouver: University of British Columbia Press.

Mason, Dwight N. 2003. "Canada and the Future of Continental Defense: A View from Washington." Center for Strategic and International Studies, Policy Papers on the Americas: 14 (10).

Mason, Dwight N. 2007. "Is Canada a Threat to U.S. Security?" In The New Security Equation in the Americas, Eds. Gordon Mace and Catherine Durepos. Quebec City: Centre d'études interaméricaines.

Massie, Justin. 2009. “Making sense of Canada's 'irrational' international security policy: A tale of three strategic cultures." International Journal 64 (3): 625-645.

May, Ernest. 1992. "The U.S. Government, a Legacy of the Cold War." In The End of the Cold War: Its Meanings and Implications, Ed. Michael J. Hogan. Cambridge, UK: Cambridge University Press.

Meyer, Karl E. 2003. "Macho America, Diffident Canada." World Policy Journal 20 (2): 103-106.

Miles, Donna. 2008. "Bush Praises Australia's Support in Afghanistan, Iraq." United States Department of Defense, American Forces Press Service (online). Available: http://www.defense.gov/news/newsarticle.aspx?id=49403 Accessed May 17, 2010.

Milliken, Jennifer. 1999. "The Study of Discourse in International Relations: A Critique of Research and Methods." European Journal of International Relations 5 (2): 225-254.

Milliken, Jennifer and David Sylvan. 1996. "Soft Bodies, Hard Targets, and Chic Theories: US Bombing Policy in Indochina." Millennium 25 (2): 321-359.

Molot, Maureen Appel. 1990. "Where Do We, Should We, or Can We Sit? A Review of Canadian Foreign Policy Literature." International Journal of Canadian Studies 1-2: 77-96. 
Moore, Stephen T. 2004. "Defining the 'Undefended': Canadians, Americans, and the Multiple Meanings of Border during Prohibition." American Review of Canadian Studies 34 (1): 3-32.

Morris, Peter. 1992. Embattled Shadows: A History of Canadian Cinema 1895-1939. Montreal: McGill-Queen's University Press.

Mutimer, David. 2000. The Weapons State: Proliferation and the Framing of Security. Boulder: Lynne Rienner.

Nathanson, Charles, E. 1988. "The Social Construction of the Soviet Threat: A Study in the Politics of Representation." Alternatives 13 (4): 443-483.

Neufeld, Mark. 1995a. "Hegemony and Foreign Policy Analysis: The Case of Canada as a Middle Power." Studies in Political Economy 48: 7-29.

Neufeld, Mark A. 1995b. The Restructuring of International Relations Theory. Cambridge: Cambridge University Press.

Neufeld, Mark. 1999. "Democratization in/of Canadian Foreign Policy: Critical Reflections.” Studies in Political Economy 58: 97-119.

Neufeld, Mark. 2004. "Pitfalls of Emancipation and Discourses of Security: Reflections on Canada's 'Security with a Human Face'." International Relations 18 (1): 109123.

Neufeld, Mark. 2010. “"Happy Is the Land That Needs No Hero': The Pearsonian Tradition and the Canadian Intervention in Afghanistan." In Canadian Foreign Policy in Critical Perspective, Eds. J. Marshall Beier and Lana Wylie. Don Mills, ON: Oxford University Press.

Neumann, Iver B. 1996. "Self and Other in International Relations." European Journal of International Relations 2 (2): 139-174.

Neumann, Iver B. 1999. Uses of the Other: 'The East' in European Identity Formation. Minneapolis: University of Minnesota Press.

Nevins, Joseph. 2002. Operation Gatekeeper: The Rise of the 'Illegal Alien' and the Making of the U.S.-Mexico Boundary. New York: Routledge.

Norton, Anne. 1988. Reflections on Political Identity. Baltimore: Johns Hopkins University Press. 
Nossal, Kim Richard. 2000. "Home-Grown IR: The Canadianization of International Relations." Journal of Canadian Studies 35 (1): 95-114.

Nossal, Kim Richard, Stéphane Roussel and Stéphane Paquin. 2011. International Policy and Politics in Canada. Toronto: Pearson Canada.

Ó Tuathail, Gearóid. 1998. "De-Territorialised Threats and Global Dangers: Geopolitics and Risk Society." Geopolitics 3 (1): 17-31.

Ó Tuathail, Gearóid. 1999. "Borderless Worlds? Problematising Discourses of Deterritorialisation." Geopolitics 4 (2): 139-154.

Ó Tuathail, Gearóid. 2006. "General Introduction: Thinking Critically about Geopolitics." In The Geopolitics Reader, $2^{\text {nd }}$ ed. Eds. Gearóid Ó Tuathail, Simon Dalby and Paul Routledge. New York: Routledge.

Ó Tuathail, Gearóid and Simon Dalby. Eds. 1998a. Rethinking Geopolitics. London: Routledge.

Ó Tuathail, Gearóid and Simon Dalby. 1998b. "Introduction: Rethinking Geopolitics: Towards a Critical Geopolitics.” In Rethinking Geopolitics. London: Routledge.

Ó Tuathail, Gearóid and John Agnew. 1992. "Geopolitics and Discourse: Practical Geopolitical Reasoning in US Foreign Policy." Political Geography 11 (2): 190204.

Patterson, Matthew and Simon Dalby. 2006. "Empire's ecological tyreprints." Environmental Politics 15 (1): 1-22.

Peterson, V. Spike. 1995. "The Politics of Identity and Gendered Nationalism." In Foreign Policy Analysis: Continuity and Change in its Second Generation, Eds. Laura Neack, Jeanne A. K. Hey and Patrick J. Haney. Englewood Cliffs, NJ: Prentice Hall.

Power, Marcus and Andrew Crampton. 2005. "Reel Geopolitics: Cinemato-graphing Political Space." Geopolitics 10 (2): 193-203.

Rieber, Robert W. and Robert J. Kelly. 1991. "Substance and Shadow: Images of the Enemy." In The Psychology of War and Peace: The Images of the Enemy, Ed. Robert W. Rieber. New York: Plenum Press. 
Rivenburgh, Nancy K. 1997. "Social Identification and Media Coverage of Foreign Relations." In News Media and Foreign Relations: A Multifaceted Perspective, Ed. Abbas Malek. Norwood, NJ: Ablex Publishing.

Robertson, Alexa. 2001. "Mediated Threats." In Threat Politics: New Perspectives on Security, Risk and Crisis Management, Ed. Johan Eriksson. Aldershot, UK: Ashgate.

Rumelili, Bahar. 2003. "Liminality and Perpetuation of Conflicts: Turkish - Greek Relations in the Context of Community-Building by the EU." European Journal of International Relations 9 (2): 213-248.

Said, Edward W. 1978. Orientalism. New York: Vintage Books.

Savage, Robert L. 1990. "The Stuff of Politics through Cinematic Imagery: An Eiconic Perspective." In Politics in Familiar Contexts: Projecting Politics Through Popular Media, Eds. Robert L. Savage and Dan Nimmo. Norwood, NJ: Ablex. Schmitt, Carl. 1996. The Concept of the Political, trans. George Schwab. (Based on the 1932 edition of Der Begriff des Politischen, published by Duncker \& Humbolt) Chicago: University of Chicago Press.

Shapiro, Michael J. 1988. The Politics of Representation: Writing Practices in Biography, Photography, and Policy Analysis. Madison: University of Wisconsin Press.

Shapiro, Michael J. 1989a. "Textualizing Global Politics." In International/Intertextual Relations: Postmodern Readings of World Politics, Eds. James Der Derian and Michael J. Shapiro. Lexington, MA: Lexington Books.

Shapiro, Michael J. 1989b. "Representing World Politics: The Sport/War Intertext." In International/Intertextual Relations: Postmodern Readings of World Politics, Eds. James Der Derian and Michael J. Shapiro. Lexington, MA: Lexington Books.

Shapiro, Michael J. 1997. Violent Cartographies: Mapping Cultures of War. Minneapolis: University of Minnesota Press.

Sharp, Joanne P. 1998. "Reel Geographies of the New World Order: Patriotism, masculinity, and geopolitics in post-Cold War American movies." In Rethinking Geopolitics, Eds. Gearóid Ó Tuathail and Simon Dalby. London: Routledge. 
Sharp, Joanne P. 2000. Condensing the Cold War: Reader's Digest and American Identity. Minneapolis: University of Minnesota Press.

Slotkin, Richard. 1973. Regeneration Through Violence: The Mythology of the American Frontier, 1600-1860. Middleton, Connecticut: Wesleyan University Press.

Slotkin, Richard. 1985. The Fatal Environment: The Myth of the Frontier in the Age of Industrialization, 1800-1890. New York: Atheneum.

Slotkin, Richard. 1992. Gunfighter Nation: The Myth of the Frontier in Twentieth Century America. New York: Atheneum.

Smith, Heather A. 1999. "Caution Warranted: Niche Diplomacy Assessed." Canadian Foreign Policy 6 (3): 57-72.

Smith, Heather A. 2003. "Disrupting Internationalism and Finding the Others." In Feminist Perspectives on Canadian Foreign Policy, Eds. Claire Turenne Sjolander, Heather A. Smith and Deborah Stienstra. Toronto: Oxford University Press.

Smith, Heather. 2010. “The Disciplining Nature of Canadian Foreign Policy." In Canadian Foreign Policy in Critical Perspective, Eds. J. Marshall Beier and Lana Wylie. Don Mills, ON: Oxford University Press.

Smith, Heather A. and Claire Turenne Sjolander. 2005, Eds. Gender and Canadian Foreign Policy, special issue of Canadian Foreign Policy 15 (1).

Smith, Ron. 2006. "Rose Marie: I Don't Love You." Scope 4.

Smith, Steve. 1996. "Positivism and beyond." In International theory: positivism and beyond, Eds. Steve Smith, Ken Booth and Marysia Zalewski. Cambridge, UK: Cambridge University Press.

Sokolsky, Joel J. 2004/05. "Northern Exposure?: American Homeland Security and Canada." International Journal, 60 (1): 35-52.

Starkman, Aaron. 2010. "Molson Canadian - Made from Canada." Molson Canadian Channel. Available: http://www.youtube.com/mymolsoncanadian\#p/a/u/0/ 5aQkrV3ppAw Accessed May 30, 2010.

Stewart, Gordon T. 1992. The American Response to Canada Since 1776. East Lansing, MI: Michigan State University Press. 
Struck, Doug. 2005. “Canada Fights Myth It Was 9/11 Conduit.” Washington Post, April 9: A20.

Swann, Paul. 1995. "International Conspiracy in and around The Iron Curtain." Velvet Light Trap 35: 52-60.

Taylor, Philip M. 1997. Global Communications, International Affairs and the Media Since 1945. New York: Routledge.

Thacker, Robert. 1980. "Canada's Mounted: The Evolution of a Legend." Journal of Popular Culture 14 (2): 298-312.

Thompson, John Herd and Stephen Randall. 2002. Canada and the United States: Ambivalent Allies. $3^{\text {rd }}$ ed. Athens, GA: University of Georgia Press.

Thompson, John Herd and Stephen Randall. 2008. Canada and the United States: Ambivalent Allies. $4^{\text {th }}$ ed. Athens, GA: University of Georgia Press.

Tilley, Charles. 1985. "War Making and State Making as Organized Crime." In Bringing the State Back In, Eds. Peter B. Evans, Dietrich Rueschemeyer and Theda Skocpol. Cambridge, UK: Cambridge University Press.

Todorov, Tzvetan. 1984. The Conquest of America: The Question of the Other, trans. Richard Howard. New York: Harper and Row.

Tomlin, Brian W., Norman Hillmer and Fen Osler Hampson. 2008. Canada's International Policies: Agendas, Alternatives, and Politics. Don Mills, ON: Oxford University Press.

Turenne Sjolander, Claire. 2010. "The Obama Charm? Canada and Afghanistan Under a New American Administration." American Review of Canadian Studies 40 (2): 292-304.

Turenne Sjolander, Claire and Wayne S. Cox, Eds. 1994. Beyond Positivism: Critical Reflections on International Relations. Boulder: Lynne Rienner.

Turenne Sjolander, Claire and Kathryn Trevenen. 2010. "Constructing Canadian Foreign Policy: Myths of Good International Citizens, Protectors, and the War in Afghanistan." In Canadian Foreign Policy in Critical Perspective, Eds. J. Marshall Beier and Lana Wylie. Don Mills, ON: Oxford University Press. 
Turenne Sjolander, Claire, Heather A. Smith and Deborah Stienstra, Eds. 2003. Feminist Perspectives on Canadian Foreign Policy. Don Mills, ON: Oxford University Press.

Turner, Frederick. 1966 [1894]. The Significance of the Frontier in American History. New York: Readex Microprint.

Turner, Victor. 1969. The Ritual Process: Structure and Anti-Structure. Chicago: Aldine. van Dijk, Teun A. 1988. News as Discourse. Hillsdale, NJ: Lawrence Erlbaum Associates.

Walker, R. B. J. 1993. Inside/Outside: International Relations as Political Theory. Cambridge, UK: Cambridge University Press.

Walt, Stephen. 1987. The Origins of Alliances. Ithaca, NY: Cornell University Press. Walt, Stephen. 1991. "The Renaissance of Security Studies." International Studies Quarterly 35 (2): 211-239.

Waltz, Kenneth. 1979. Theory of International Politics. New York: Random House.

Weber. Cynthia. 1995. Simulating Sovereignty: Intervention, the State and Symbolic Exchange. Cambridge: Cambridge University Press.

Weber, Cynthia. 1998. "Performative States." Millennium 27 (1): 77-95.

Weber, Cynthia. 1999. Faking It: U.S. Hegemony in a 'Post-Phallic' Era. Minneapolis: University of Minnesota Press.

Weber, Cynthia. 2006. Imagining America at War: Morality, Politics, and Film. New York: Routledge.

Weber, Max. 1946. From Max Weber: Essays in Sociology, trans., Eds. H. H. Gerth and C. Wright Mills. New York: Oxford University Press.

Weldes, Jutta. 1999a. Constructing National Interests: The United States and the Cuban Missile Crisis. Minneapolis: University of Minnesota Press.

Weldes, Jutta. 1999b. "The Cultural Production of Crises: U.S. Identity and Missiles in Cuba." In Cultures of Insecurity: States, Communities, and the Production of Danger. Minneapolis: University of Minnesota Press.

Weldes, Jutta, Ed. 2003a. To Seek Out New Worlds: Exploring Links between Science Fiction and World Politics. New York: Palgrave Macmillan. 
Weldes, Jutta. 2003b. "Popular Culture, Science Fiction, and World Politics: Exploring Intertextual Relations." In To Seek Out New Worlds: Exploring Links between Science Fiction and World Politics, Ed. Jutta Weldes. New York: Palgrave Macmillan.

Weldes, Jutta, Mark Laffey, Hugh Gusterson and Raymond Duvall, Eds. 1999a. Cultures of Insecurity: States, Communities, and the Production of Danger. Minneapolis: University of Minnesota Press.

Weldes, Jutta, Mark Laffey, Hugh Gusterson and Raymond Duvall. 1999b. "Introduction: Constructing Insecurity." In Cultures of Insecurity: States, Communities, and the Production of Danger. Minneapolis: University of Minnesota Press.

Wendt, Alexander. 1992. "Anarchy is What States Make of It: The Social Construction of Power Politics." International Organization 46 (2), 491-425.

Wendt, Alexander. 1999. Social Theory of International Politics. Cambridge, UK: Cambridge University Press.

Whitaker, Reg. 2004/05. "Securing the 'Ontario-Vermont border: Myths and realities in post-9/11 Canadian-American security relations." International Journal 60 (1): 53-70.

Whitworth, Sandra. 1994. Feminism and International Relations. London: Macmillan. Whitworth, Sandra. 2003. "Militarized Masculinities and the Politics of Peacekeeping: The Canadian Case." In Feminist Perspectives on Canadian Foreign Policy, Eds. Claire Turenne Sjolander, Heather A. Smith and Deborah Stienstra. Toronto: Oxford University Press.

Williams, Glen. 1988. “On Determining Canada's Location Within the International Political Economy." Studies in Political Economy 25: 107-140.

Winks, Robin W. 1971. The Myth of the American Frontier: Its Relevance to America, Canada and Australia. Leicester: Leicester University Press.

Winks, Robin W. 1993. "Imagining Canada." In Northern Exposures: Scholarship on Canada in the United States, Eds. Karen Gould, Joseph T. Jockel and William Metcalf. Washington: Association for Canadian Studies in the United States. 
Wolfers, Arnold. 1962. "National Security as an Ambiguous Symbol." In Discord and Collaboration. Baltimore: Johns Hopkins Press.

Young, Iris Marion. 2003. "The Logic of Masculinist Protection: Reflections on the Current Security State." Signs 29 (1): 1-25. 


\section{Filmic Sources}

Blue Canadian Rockies. George Archainbaud. United States: Columbia Pictures, 1952.

Canadian Bacon. Michael Moore. United States: Dog Eat Dogs Films, 1995.

Canadian Pacific. Edward L. Marin. United States: Twentieth Century Fox, 1949.

Canadian Mounties versus Atomic Invaders. Franklin Adreon. United States: Republic Pictures, 1953.

Crashing Thru'. Elmer Clifton. United States: Criterion Pictures, 1939.

Danger Ahead. Ralph Staub. United States: Criterion Pictures, 1940.

Dangers of the Canadian Mounted. Fred Brannon and Yakima Canutt. United States:

Republic Pictures, 1948.

Fighting Mad. Sam Newfield. United States: Criterion Pictures, 1939.

God's Country and the Man. Robert N. Bradbury . United States: Monogram Pictures, 1937.

Gunfighters of the Northwest. Spencer Gordon Bennet and Charles S. Gould. United States: Columbia Pictures, 1954.

I Confess. Alfred Hitchcock. United States: Warner Brothers, 1953.

Island in the Sky. William A. Wellman. United States: Warner Brothers, 1953.

Johnny Belinda. Jean Negulesco. United States: Warner Brothers, 1948.

King of the Mounties. William Witney. United States: Republic Pictures, 1942.

King of the Royal Mounted. William Witney. United States: Republic Pictures, 1940.

Klondike Fury. William K. Howard. United States: Monogram Pictures, 1942.

Murder on the Yukon. Louis Gasnier. United States: Criterion Pictures, 1939.

Mysterious Pilot. Spencer Gordon Bennet. United States: Columbia Pictures, 1937.

Niagara. Henry Hathaway. United States: Twentieth Century Fox, 1953.

Niagara Falls. Gordon Douglas. United States: Hal Roach Studios, 1941.

Nikki, Wild Dog of the North. Dan Haldane and Jack Couffe. United States: Walt Disney

Productions, 1960.

North of the Border. B. Reeves Eason. United States: Screen Guild Productions, 1948. 
North of the Great Divide. William Witney. United States: Republic Pictures, 1950.

North of the Rockies. Lambert Hillyer. United States: Columbia Pictures, 1942.

North West Mounted Police. Cecil B. DeMille. United States: Paramount Pictures, 1940.

Northern Pursuit. Raoul Walsh. United States: Warner Brothers, 1943.

Northwest Trail. Derwin Abrahams. United States: Action Pictures, 1942.

Northwest Stampede. Albert S. Rogell. United States: Eagle-Lion Films, 1948.

O'Malley of the Mounted. David Howard. United States: Twentieth Century Fox, 1936.

Perils of the Royal Mounted. James W. Horne. United States: Columbia Pictures, 1942.

Perils of the Wilderness. Spencer Gordon Bennet. United States: Columbia Pictures, 1956.

Phantom Patrol. Charles Hutchinson. United States: Ambassador Pictures, 1936.

Pony Soldier. Joseph M. Newman. United States: Twentieth Century Fox, 1952.

Quebec. George Templeton. United States: Paramount Pictures, 1951.

Red Blood of Courage. John English. United States: Ambassador Pictures, 1935.

Renfrew of the Royal Mounted. Al Herman. United States: Criterion Pictures, 1937.

Reunion. Norman Taurog. United States: Twentieth Century Fox, 1936.

Royal Mounted Rides Again. Ray Taylor and Lewis D. Collins. United States: Universal

Pictures, 1945.

River of No Return. Otto Preminger. United States: Twentieth Century Fox, 1954.

Rose-Marie. W. S. Van Dyke. United States: Metro-Goldwyn-Mayer, 1936.

Saskatchewan. Raoul Walsh. United States: Universal International Pictures, 1954.

Sky Bandits. Ralph Staub. United States: Criterion Pictures, 1940.

Snow Dog. Frank McDonald. United States: Monogram Pictures, 1950.

South Park: Bigger, Longer \& Uncut. Trey Parker. United States: Paramount, 1999.

Susannah of the Mounties. William A. Seiter. United States: Twentieth Century Fox, 1939.

The $49^{\text {th }}$ Parallel. Michael Powell. United Kingdom: Ortus Films, 1941.

The Canadians. Burt Kennedy. United States: Twentieth Century Fox, 1961.

The Cariboo Trail. Edward L. Marin. United States: Twentieth Century Fox, 1950.

The Country Doctor. Henry King. United States: Twentieth Century Fox, 1936. 
The Far Country. Anthony Mann. United States: Universal International Pictures, 1954.

The Fighting Trooper. Ray Taylor. United States: Ambassador Pictures, 1934.

The Iron Curtain. William A. Wellman. United States: Twentieth Century Fox, 1948.

The Scarlet Claw. Roy William Neill. United States: Universal Pictures, 1944.

The Silent Enemy. H. P. Carver. United States: Burden-Chandler Productions, 1930.

The Trail Beyond. Robert N. Bradbury. United States: Lone Star Productions, 1934.

The Viking. George Melford. United States: Newfoundland-Labrador Film Company, 1931.

Trail of the Mounties. Howard Bretherton. United States: Screen Guild Productions, 1948.

Trail of the Royal Mounted. Stuart Paton. United States: Guaranteed Pictures, 1935; (originally released as The Mystery Trooper. Stuart Paton. United States: Harry Webb Productions, 1931).

Wag the Dog. Barry Levinson. United States: New Line, 1997.

Where the North Begins. Howard Bretherton. United States: Screen Guild Productions, 1947.

Yukon Flight. Ralph Staub. United States: Criterion Pictures, 1940.

Yukon Gold. Frank McDonald. United States: Monogram Pictures, 1952. 


\section{News Sources}

ABC. 1999. World News Tonight Sunday, December 19.

ABC. 2001a. Good Morning America, September 13.

ABC. 2001b. Special Report: America Under Attack, September 14.

ABC. 2001c. Nightline, September 14.

ABC. 2001d. Nightline, September 19.

ABC. 2002. Nightline, May 9.

ABC. 2003. Good Morning America, January 1.

ABC. 2006. Good Morning America, June 6.

Ammons, David. 2002. "Isolated Washington Enclave Near Breaking Point" Los Angeles Times, June 9, California, 6.

Anonymous. 2001a. "A Border in Sharper Focus." Los Angeles Times, September 26, California, 12.

Anonymous. 2001b. "Neighborhood Watch." Los Angeles Times, December 7, California, 14.

Anonymous. 2005. "Canadian Free Riders." Wall Street Journal, February 28, A16. Associated Press. 2005. "Security Efforts Falling Through Cross-Border Cracks." Los Angeles Times, November 20, A35.

Associated Press. 2006. "Senate Backs Allowing Drugs From Canada." New York Times, July 12 , A18.

Austen, Ian and David Johnston. 2006. "17 Held In Plot To Bomb Sites Across Ontario." New York Times, June 4, Sec. 1, p. 1.

Baglole, Joel. 2001a. "Canada Hastens to Bolster Borders, Security --- Legislation on Fast Track to Reassure the U.S." Wall Street Journal, October 12, A13.

Baglole, Joel. 2001b. "Ottawa's Plan for G-20 Security Is Out of Sight." Wall Street Journal, November 6, A20.

Baglole, Joel. 2001c. "Canada Cracks the Whip on Terror; Some Don't Like the Sound of It." Wall Street Journal, December 18, A13. 
Baglole, Joel. 2002. "Washington Is Urging Canada To Increase Military Spending." Wall Street Journal, October 17, A16.

Baglole, Joel. 2003. "Canada Tightens Security at Its Seaports --- One of Country's 'Weak Links' Is Seen as Entry Point for Terrorists Targeting." Wall Street Journal, April 21, B4.

Baglole, Joel and Marjorie Valbrun. 2002. "Terrorists or Refugees? --- U.S. Scrutiny of Foreign-Born Canadians Riles Ottawa.” Wall Street Journal, December 18, A14.

Baker, A1. 2001. "A Nation Challenged: Notebooks; More Eyes Toward Canada." New York Times, October 10, B14.

Brill, Steven. 2002. "This Dog Won't Hunt.” Newsweek, June 3, 26.

Brinkley, Joel. 2002. "A Nation Challenged: Border Security; Canada Wants Some Trucks Exempt From Border Inspection.” New York Times, February 1, A13.

Brown, DeNeen L. 2000. "Chinese Man Puts Canada In Quandary; Suspect Says He Faces Execution if Deported." Washington Post, December 1, A28.

Brown, DeNeen L. 2001. "Canada Fears Military Isn't Up to the Fight; Budget Cuts May Impede Help for U.S." Washington Post, September 30, A30.

Brown, DeNeen, L. 2002. “U.S., Canada Reach Agreement to Let Troops Cross Border; Continental Terrorism Concerns Cited." Washington Post, December 10, A19.

Brown, DeNeen, L. 2003. "Canadians' Culture of Tolerance Is Tested by Cases Against Arabs." Washington Post, December 17, A34.

Brown, DeNeen L. and Ceci Connolly. 2001. "Suspects Entered Easily From Canada; Authorities Scrutinize Border Posts in Maine." Washington Post, September 14, A17.

Burns, John F. 1999. “Arrest at U.S. Border Reverberates in France.” New York Times, December 22, A1.

CBS. 1999a. CBS Evening News, December 19.

CBS. 1999b. The Early Show, December 20.

CBS. 1999c. CBS Evening News, December 20.

CBS. 1999d. CBS Morning News, December 22.

CBS. 2001a. CBS Evening News, September 24. 
CBS. 2001b. CBS Evening News, December 2.

CBS. 2002a. CBS Evening News, January 2.

CBS. 2002b. CBS Evening News, April 2.

CBS. 2002c. 60 Minutes, April 28.

CBS. 2002d. CBS Evening News, December 30.

CBS. 2003a. CBS Evening News, January 1.

CBS. 2003b. CBS Evening News, September 11.

CBS. 2006a. The Osgood File, April 13.

CBS. 2006b. CBS Evening News, June 3.

CBS. 2006c. CBS Evening News, June 4.

CBS. 2006d. The Early Show, June 5.

CBS. 2006e. CBS Evening News, June 5.

CBS. 2007. CBS Evening News, September 26.

Chen, Edwin and Maura Reynolds. 2001. "After The Attack." Los Angeles Times, September 25, A1.

Cherney, Elena and Chris Chipello. 2006. "Canada's Social Stance is Tested by Arrests." Wall Street Journal, June 13, A6.

Chipello, Christopher J. and Joel Baglole. 2002. "Official Says al Qaeda Group Left Canada Recently." Wall Street Journal, May 24, A11.

Chipello, Christopher J. and Dan Bilefsky. 2002. "A Global Journal Report: Is Canada a Launching Pad for Terror?” Wall Street Journal, July 10, A10.

Chipello, Christopher J., Mark Heinzl and Joel Baglole. 2001. "Canada Denies Any Links to Sept. 11 Attacks in U.S. - Nation Works to Dispel Notion It Is Lax on Immigrants." Wall Street Journal, November 16, A10.

Clark, Jayne. 2002. “Americans are answering Canada's call.” USA Today, December $20,12 \mathrm{D}$.

Cloud, David S., Frances A. McMorris and Joel A. Baglole. 1999. "U.S. Arrests Algerian, Sees Ressam Link.” Wall Street Journal, December 31, A3.

CNN. 1999a. CNN Saturday, December 18.

CNN. 1999b. The World Today, December 22. 
CNN. 2001a. Inside Politics, May 30.

CNN. 2001b. Live Event/Special, September 12.

CNN. 2001c. Live Event/Special, September 24.

CNN. 2001d. Wolf Blitzer Reports, September 24.

CNN. 2001e. Live At Daybreak, September 27.

CNN. 2001f. Live This Morning, October 12.

CNN. 2001g. The Point With Greta Van Susteren, October 30.

CNN. 2001h. Live Today, November 26.

CNN. 2001i. Live Today, December 12.

CNN. 2002a. Larry King Live, January 21.

CNN. 2002b. Lou Dobbs Moneyline, June 12.

CNN. 2002c. NewsNight with Aaron Brown, December 30.

CNN. 2002d. Crossfire, December 30.

CNN. 2003a. American Morning With Paula Zahn, January 1.

CNN. 2003b. Daybreak, January 3.

CNN. 2003c. Crossfire, January 8.

CNN. 2003d. Late Edition With Wolf Blitzer, March 9.

CNN. 2003e. Lou Dobbs Tonight, July 4.

CNN. 2004a. Newsnight with Aaron Brown, October 11.

CNN. 2004b. Lou Dobbs Tonight, November 23.

CNN. 2004c. Live Saturday, November 27.

CNN. 2005. Lou Dobbs Tonight, March 29.

CNN. 2006a. Anderson Cooper 360 Degrees, May 2.

CNN. 2006b. Anderson Cooper 360 Degrees, May 9.

CNN. 2006c. Live Saturday, May 13.

CNN. 2006d. Late Edition With Wolf Blitzer, June 4.

CNN. 2006e. The Situation Room, June 5.

CNN. 2006f. Live Today, June 6.

CNN. 2006g. Anderson Cooper 360 Degrees, June 6.

CNN. 2006h. American Morning, June 6. 
CNN. 2006i. Glenn Beck, June 7.

CNN. 2006j. Paula Zahn Now, June 7.

CNN. 2006k. The Situation Room, June 7.

CNN. 20061. Paula Zahn Now, July 11.

CNN. 2007a. Newsroom, June 5.

CNN. 2007b. Live Event/Special, July 3.

CNN. 2007c. Anderson Cooper 360 Degrees, July 3.

CNN. 2007d. Nancy Grace, November 13.

Connolly, Ceci. 2004. "Drug-Importation Foes Speak Out; Industry Backers Have Strong Voice At Public Sessions.” Washington Post, April 15, A03.

Crossette, Barbara. 2001a. "After The Attacks: The Northern Neighbor; U.S. Seeks Canada's Reassurance on Security." New York Times, September 14, A21.

Crossette, Barbara. 2001b. "A Nation Challenged: Canada; Chretien Under Pressure From Right and Left Over What to Give Washington." New York Times, September 23, 1B-7.

Crossette, Barbara. 2001c. "A Nation Challenged: Neighbor; Support for U.S. Security Plans Is Quietly Voiced Across Canada." New York Times, October 1, B3.

DePalma, Anthony. 1997. "Saudi Case Casting a Light on How Militants Infiltrate and Exploit Canada." New York Times, May 4, Sec. 1, p. 8.

DePalma, Anthony. 2001a. "A Nation Challenged: Security Concerns; Canada Altering Its System Of Vigilance Against Terror." New York Times, December 3, B4.

DePalma, Anthony. 2001b. "A Nation Challenged: The Northern Frontier; Canada and U.S. Sign Accord To Tighten Security on Border." New York Times, December 4, B7.

Dobbs, Michael. 2001. "In France, Judge Fights Terrorism And Critics." The Washington Post, November 23, A34.

Edsall, Thomas, B. 2001. "Attacks Alter Politics, Shift Focus of Immigration Debate." The Washington Post, October 15, A05.

Egan, Timothy. 1997. "Easy Illegal U.S. Entry in Northwest." New York Times, August 7, B8. 
Egan, Timothy. 2001. “A Nation Challenged: Inconveniences; A U.S. Town Reached Via Canada Is Suddenly Boxed In at the Border." New York Times, November 11, 1B, 7.

Eggen, Dan. 2001a. “FBI Launches Massive Manhunt; Hijackers Trained As Pilots in U.S." Washington Post, September 13, A01.

Eggen, Dan. 2001b. "U.S. Plans Stronger Border Security; Guard Troops Would Help Monitor Entry Ports From Canada." Washington Post, December 2, A14.

El Nasser, Haya. 2005. "Canada, Mexico soon will seem farther away." USA Today, April 6, 5A.

Farenthold, David A. 2005. "On Patrol in Vt., Minutemen Are the Outsiders; Along the Border, Group Targets Illegal Immigrants." Washington Post, October 31, A02.

Farley, Maggie. 1999a. “Canada's Lapses Kept Algerian Suspect Free.” Los Angeles Times, December 23, A1.

Farley, Maggie. 1999b. "Terror Again Touches Exile Community." Los Angeles Times, December 24, A6.

Ferdinand, Pamela. 2000. "Northern Border Has an Extra Edge; Security Tighter on Friendly Vermont-Canada Frontier." Washington Post, January 24, A03.

Fox News. 2001a. Live Event, September 14.

Fox News. 2001b. Special Report With Brit Hume, September 19.

Fox News. 2001c. The O'Reilly Factor, September 21.

Fox News. 2001d. Live Event, September 27.

Fox News. 2001e. Special Report With Brit Hume, October 25.

Fox News. 2002a. The Big Story With John Gibson, June 4.

Fox News. 2002b. Special Report With Brit Hume, June 4.

Fox News. 2002c. On The Record With Greta Van Susteren, June 4.

Fox News. 2002d. On The Record With Greta Van Susteren, June 5.

Fox News. 2002e. The O'Reilly Factor, June 11.

Fox News. 2002f. The O'Reilly Factor, June 20.

Fox News. 2002g. The O'Reilly Factor, June 26.

Fox News. 2002h. On The Record With Greta Van Susteren, September 5. 
Fox News. 2002i. The Big Story With John Gibson, November 14.

Fox News. 2002j. The Big Story With John Gibson, December 17.

Fox News. 2002k. The Big Story With John Gibson, December 30.

Fox News. 20021. Hannity and Colmes, December 30.

Fox News. 2002m. The O'Reilly Factor, December 30.

Fox News. 2003a. Special Report With Brit Hume, September 10.

Fox News. 2003b. On The Record With Greta Van Susteren, September 16.

Fox News. 2004a. The O'Reilly Factor, February 20.

Fox News. 2004b. The O'Reilly Factor, April 12.

Fox News. 2004c. The O'Reilly Factor, May 26.

Fox News. 2004d. The Big Story With John Gibson, May 26.

Fox News. 2004e. The O'Reilly Factor, November 16.

Fox News. 2004f. The O'Reilly Factor, November 30.

Fox News. 2004g. The O'Reilly Factor, December 6.

Fox News. 2004h. The O'Reilly Factor, December 28.

Fox News. 2005a. The O'Reilly Factor, March 24.

Fox News. 2005b. The Big Story With John Gibson, May 4.

Fox News. 2005c. The O'Reilly Factor, July 6.

Fox News. 2005d. The Big Story With John Gibson, August 12.

Fox News. 2005e. The Big Story With John Gibson, December 21.

Fox News. 2006a. The Big Story With John Gibson, January 23.

Fox News. 2006b. Special Report With Brit Hume, April 13.

Fox News. 2006c. The Big Story With John Gibson, May 29.

Fox News. 2006d. The O'Reilly Factor, June 5.

Fox News. 2006e. The Big Story With John Gibson, June 8.

Fox News. 2008a. Special Report With Brit Hume, April 3.

Fox News. 2008b. Hannity's America, August 17.

Golden, Frederick. 2001. "What's Next?" Time, November 5, 44+. 
Grimaldi, James V., Steve Fainaru and Gilbert M. Gaul. 2001. "Losing Track of Illegal Immigrants; Once in U.S., Most Foreigners Escape Notice of INS." The Washington Post, October 7, A01.

Grunwald, Michael. 2001. "Economic Crossroads on the Line; Security Fears Have U.S. and Canada Rethinking Life at $49^{\text {th }}$ Parallel." Washington Post, December 26, A01.

Hall, Mimi. 2006a. "Guard troops to have a limited role." USA Today, May 16, 4A.

Hall, Mimi. 2006b. "Focus shifts north amid terror fears." USA Today, December 18, 4A.

Healy, Gene. 2003. "Commentary." Los Angeles Times, February 5, California, 15.

Johnson, Kevin. 2002. "700 troops to help patrol northern border." USA Today, February $27,3 \mathrm{~A}$.

Kasindorf, Martin. 1998. "Northern exposure Drugs, terrorists, smugglers provoke calls for tighter net." USA Today, July 21, 1 A.

Keen, Judy. 2006. "Up North, the worry on border is economic; Tighter security could hurt tourism, add daily hassles." USA Today, June 5, 3A.

Kifner, John. 1999. “Terrorists Said to Hide In Canada's Melting Pot." New York Times, December 24, A1, A8.

King, Neil and Christopher J. Chipello. 1999. “Worry Rises Over Possibility of Terrorism - Authorities Track 2 Cases, Fearing Year-End Plots Targeted at the U.S." Wall Street Journal, December 27, A3.

Krauss, Clifford. 2002. "A Nation Challenged: Ottawa; Canada Alters Security Policies to Ease Concerns of U.S." New York Times, February 18, A8.

Krauss, Clifford. 2003a. "Threats And Responses: Ottawa's Tactics; In Antiterror Effort, Canada's Authorities Use Surveillance More Than Arrests." New York Times, March 13, A16.

Krauss, Clifford. 2003b. "A Nation At War: The Canadian Border." New York Times, March 23, B13.

Leinwand, Donna and Yasmin Anwar. 2000. "America's guard is down on porous frontier." USA Today, March 15, 21 A. 
Lichtblau, Eric and Sean Gill. 2002. "700 National Guard Troops, Minus Guns, Will Bolster Security at Canadian Border." Los Angeles Times, February 27, A9.

Livingstone, Neil C. 1999. "Border Security Isn't Enough to Stop Terrorists." Wall Street Journal, December 23, A18.

Lowenthal, Abraham F. 2003. "Borders; Security for All of North America." Los Angeles Times, August 31, M2.

Luttwak, Edward N. 1999. “Commentary.” Los Angeles Times, December 23, B11.

McGeary, Johanna, Massimo Calabresi, Viveca Novak, Mark Thompson, Thomas Sancton, Susan Kuchinskas and Yusufzai Rahimullah. 1999. "New Year's Evil?" Time, December 31, 204.

Mehren, Elizabeth. 2001. "Response To Terror; Security; Dispatch From Morses Line, Vt.; Filling in the Holes on a Porous Border" Los Angeles Times, December 16, A1.

Meyer, Josh. 2001a. "Sunday Report; Border Arrest Stirs Fear of Terrorist Cells In U.S." Los Angeles Times, March 11, A1.

Meyer, Josh. 2001b. “Most Of Terrorism Expert's Testimony Is Barred." Los Angeles Times, April 3, B3.

Meyer, Josh and Ellen Barry. 2006. "Plot on N.Y. Tunnels Alleged." Los Angeles Times, July 8 , A1.

Miller, Bill. 2002. "Plugging a Very Porous Northern Border." Washington Post, April 8, A03.

Morgan, Anna. 2006. "Northern Ire; Canadian Politics Are All About America." Washington Post, January 8, B02.

MSNBC. 1999. The News With Brian Williams, December 21.

MSNBC. 2001a. The News With Brian Williams, September 18.

MSNBC. 2001b. Hardball, September 24.

MSNBC. 2002a. Hardball, January 11.

MSNBC. 2002b. Ashleigh Banfield: On Location, August 12.

MSNBC. 2002c. Buchanan and Press, October 31.

MSNBC. 2002d. Buchanan and Press, November 22. 
MSNBC. 2002e. Buchanan and Press, December 9.

MSNBC. 2002f. Buchanan and Press, December 30.

MSNBC. 2002g. Nachman, December 30.

MSNBC. 2003a. The Abrams Report, January 2.

MSNBC. 2003b. Countdown: Iraq, May 26.

MSNBC. 2003c. Scarborough Country, September 11.

MSNBC. 2006a. The Abrams Report, June 5.

MSNBC. 2006b. The Situation With Tucker Carlson, June 5.

MSNBC. 2006c. Scarborough Country, July 10.

MSNBC. 2007. Tucker, November 14.

NBC. 1999a. NBC Nightly News, December 18.

NBC. 1999b. NBC Nightly News, December 21.

NBC. 1999c. NBC Nightly News, December 21.

NBC. 2001a. Special Report: Attack on America, September 13.

NBC. 2001b. Dateline NBC, October 1.

NBC. 2001c. Today Show, October 4.

NBC. 2001d. NBC Nightly News, October 6.

NBC. 2001e. Today Show, October 12.

NBC. 2002a. Today Show, March 25.

NBC. 2002b. NBC Nightly News, December 30.

NBC. 2006a. NBC Nightly News, May 17.

NBC. 2006b. NBC Nightly News, June 4.

NBC. 2006c. NBC Nightly News, June 6.

NBC. 2007. NBC Nightly News, September 26.

O'Grady, Mary Anastasia. 2001. "The Americas: Canada Needs to Toughen up on Terrorists." Wall Street Journal, September 14, A11.

Orme, William. 2002. "Response To Terror; In Canada, a Sea Change Follows Wave of Terrorism." Los Angeles Times, January 28, A1.

Pear, Robert. 2001. "After The Attacks: The Northern Border; Tightened Inspections Mean Delays From Maine to West." New York Times, September 14, A21. 
Pear, Robert. 2002. "Plan to Import Drugs From Canada Passes In Senate, but Bush Declines to Carry It Out." New York Times, July 18, A14.

Pear, Robert. 2003. "Senate Votes Again to Allow Importing of Drugs From Canada." New York Times, June 21, A13.

Pearlstein, Steven. 1999. “Canadians Examine Lapses in Security; Suspected Terrorist Benefits From Bungling by Police, Immigration Agents." Washington Post, December 22, A08.

Pearlstein, Steven. 2000. “Algerian Charged in Bombing Plot Aids FBI Probe. Washington Post, January 21, A21.

Peterson, Jonathan. 2001a. "Response to Terror; Border Security; U.S.-Canada Border to Be Scrutinized." Los Angeles Times, October 3, A10.

Peterson, Jonathan. 2001b. "Response To Terror; Security; U.S., Canada Agree to Tighten Border." Los Angeles Times, December 4, A1.

Pianin, Eric and DeNeen L. Brown. 2001. "U.S., Canada Agree to Tighten Border." The Washington Post, December 13, A17.

Pomfret, John. 2006a. "At the Other Border, No Talk of Walls; U.S., Canada Collaborate to Enforce Law." Washington Post, July 2, A01.

Pomfret, John. 2006b. "The Border's Right Here, but the Debate Is Many Miles Away." Washington Post, July 20, A02.

Purdy, Mathew. 2002. "Our Towns; Looking Over the Northern Border, and Over Their Shoulder." New York Times, November 24, Sec. 1, p. 33.

Pyes, Craig, John Kifner, Sam Howe Verhovek and John F. Burns. 1999. “Arrest at Border Reverberates in France." New York Times, December 22, A1.

Pyes, Craig, Josh Meyer and William C. Rempel. 2001. "Response To Terror; Sunday Report; Bosnia Seen as Hospitable Base and Sanctuary for Terrorists." Los Angeles Times, October 7, A1.

Reaves, Jessica. 2001. "Should we keep them out?” Time, October 11.

Richburg, Keith B. 2008. "A Way of Life Changes at the Border." Washington Post, August 24, A03. 
Roane, Kit, R. 2000. "North of the border, terror's 'Club Med'." U.S. News and World Report, August 7, 46.

Schneider, Howard. 1997. "Canada Imports Troubles With Refugees; Ottawa Tries to Balance Possible Threats With Maintaining Liberties." Washington Post, August 9, A13.

Singer, Jane. 2003. "The Fiend in Gray." The Washington Post, June 1, W18.

Simon, Bernard. 2002. "A Border Giveth and Taketh Away." New York Times, April 11, W1.

Smith, James, F. 2001. "After The Attack; Foreign Relations; Canadians Debate Laws on Refugees." Los Angeles Times, September 20, A13.

Strobel, Warren P., Chitra Ragavan, Warren Cohen and Kevin Whitelaw. 2000. "Terror tries to come home." U.S. News and World Report, January 3, 12.

Struck, Doug. 2006a. "Arrests Shake Image of Harmony; Muslims in Canada Brace for a Backlash After Foiled Bomb Plot." Washington Post, June 5, A10.

Struck, Doug. 2006b. "School Ties Link Alleged Plotters; Arrested Canadians Had Bonded at Clubs and on Soccer Fields." Washington Post, June 11, A16.

Struck, Doug. 2006c. "Canadian Border Force To Be Armed; Policy to Be Implemented Gradually Over a Decade." Washington Post, September 2, A17.

Sullivan, John. 2002. "A Nation Challenged: The Border; U.S. and Canada Unite to Secure Open Portal." New York Times, March 11, A12.

Thomas, Evan. 2001. "The Road to September 11." Newsweek, October 1, 38.

Thomas, Evan. 2003. "Al Qaeda in America: The Enemy Within.” Newsweek, June 23, 40.

Turner, Craig and Robin Wright. 1997. "Hezbollah Support Network In Canada Alleged." Los Angeles Times, March 29, A6.

Verhovek, Sam Howe. 2001. “A Nation Challenged: The Northern Border; Vast U.S.Canada Border Suddenly Poses a Problem to Patrol Agents." New York Times, October 4, B1.

Weiser, Benjamin and Craig Pyes. 2000. "U.S., in Pursuit of Bomb Plot, Indicts Man Held in Canada." New York Times, January 19, A1. 
Willing, Richard and Kevin Johnson. 2001. "U.S. targets cells tied to bin Laden." USA Today, September 13, $1 \mathrm{~A}$.

Wright, Robin and Kim Murphy. 1999. "Bin Laden Tie Seen In Border Arrest." Los Angeles Times, December 19, A25.

Zuckerman, Mortimer B. 2006. "Doing What's Necessary." U.S. News and World Report, June 19, 60 . 